
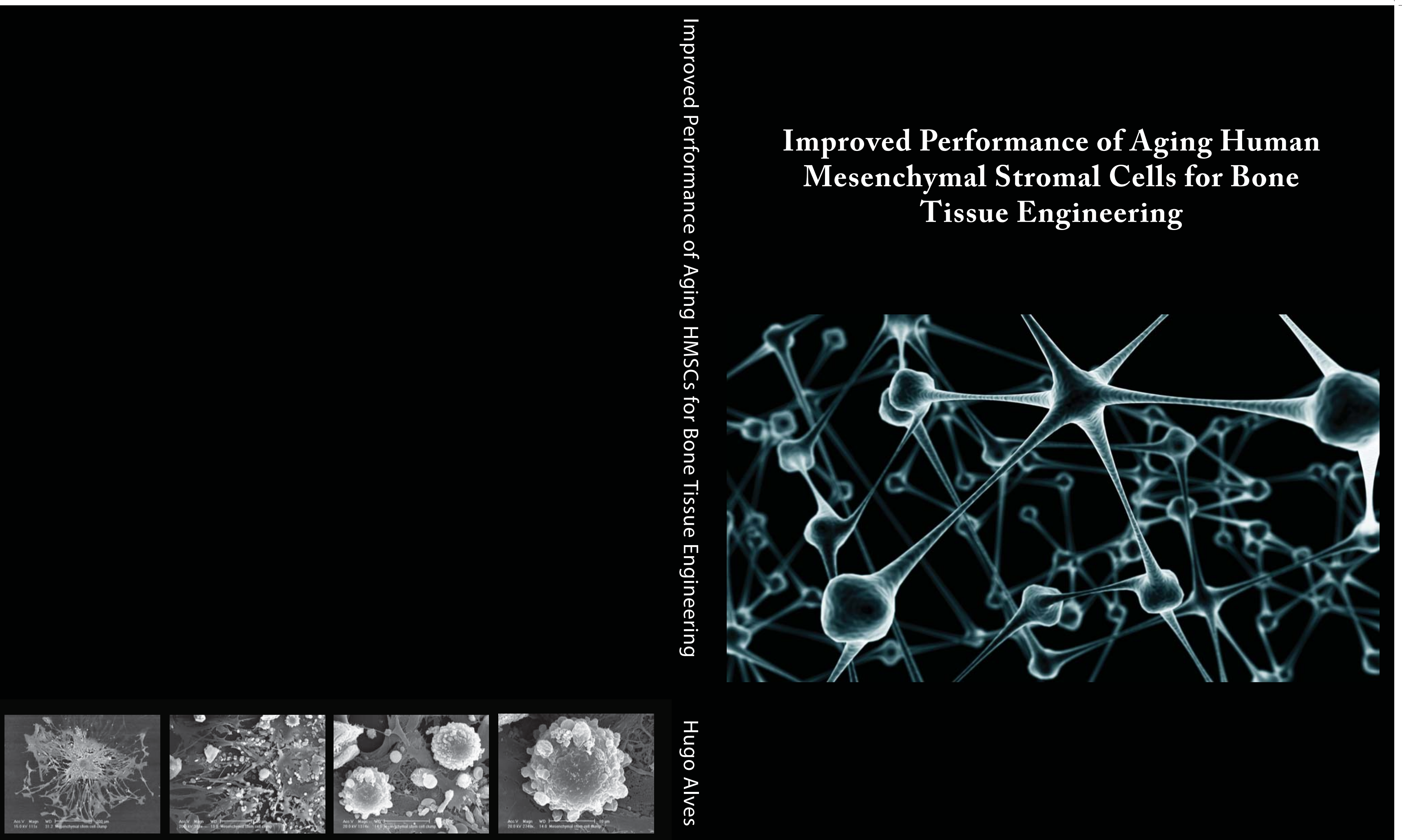

$I$
I
$\mathbb{0}$
0
$\frac{D}{\delta}$
$\Phi$ 


\section{Improved Performance of Aging Human Mesenchymal Stromal Cells for Bone Tissue Engineering}




\section{Members of the Committee:}

Chairman: Prof. Dr. G. van der Steenhoven

Promotor: Prof. Dr. C.A. van Blitterswijk (Universiteit Twente)

Assistant Promotor: Dr. J. de Boer (Universiteit Twente)

Members: Prof. Dr. G. de Haan (Universiteit Groningen)

Dr. K. Dechering (Merck Research laboratories)

Prof. Dr. D. B. F. Saris (Universiteit Twente)

Prof. Dr. L. Terstappen (Universiteit Twente)

Dr. J. Rouwkema (Universiteit Twente)

Improved Performance of Aging Human Mesenchymal Stromal Cells for Bone Tissue Engineering

\section{Hugo André da Cunha Ribeiro Alves}

PhD thesis, University of Twente, The Netherlands

The research described in this thesis was financially supported by the Dutch Technology Foundation (STW) / Dutch Program for Tissue Engineering (DPTE) (TGT. 6745).

The publication of this thesis was sponsored by:
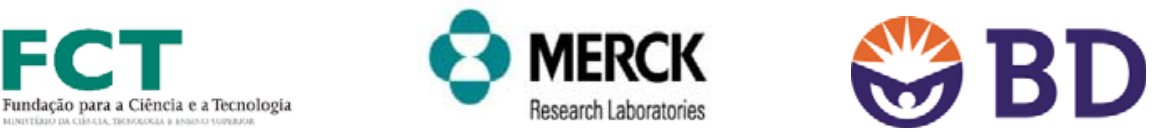

Copyright (c) Hugo Alves, Enschede, The Netherlands, 2011. Neither this book nor its parts may be reproduced without written permission of the author.

ISBN: 978-90-365-3218-1

Printed by: Wöhrmann Print Service, Zutphen, The Netherlands 


\title{
IMPROVED PERFORMANCE OF AGING HUMAN MESENCHYMAL STROMAL CELLS FOR BONE TISSUE ENGINEERING
} DISSERTATION

\author{
to obtain \\ the doctor's degree at the University Twente, \\ on the authority of the rector magnificus, \\ Prof. Dr. H. Brinksma, \\ on account of the decision of the graduation committee, \\ to be publicly defended \\ on Wednesday, July $6^{\text {th }} 2011$, at $16: 45$
}

by

Hugo André da Cunha Ribeiro Alves

Born on November $1^{\text {st }} 1980$

in Fafe, Portugal 
Promotor: Prof. Dr. Clemens A. van Blitterswijk Assistant Promotor: Dr. Jan de Boer 


\section{List of Publications}

\section{This thesis is based on the following publications:}

Alves H, Munoz-Najar U, de Wit J, Renard AJ, Hoeijmakers JH, Sedivy JM, van Blitterswijk CA, de Boer J. (2010) A link between the accumulation of DNA damage and loss of multipotency of human mesenchymal stromal cells. J Cell Mol Med 14: 2729-2738.

Alves H, Doorn J., van Blitterswijk CA, de Boer J. Factors influencing the biological properties of mesenchymal stromal cell quality: implications for cell therapy. Submitted.

Alves H, Mentink A, van Blitterswijk CA, de Boer J. Effect of antioxidant supplementation on the total yield, oxidative stress levels and multipotency of bone marrow-derived human mesenchymal stromal cells. Submitted.

Alves H, Dechering K, van Blitterswijk CA, de Boer J. Hight-throughput assay for the identification of compounds regulating osteogenic differentiation of human mesenchymal stromal cells. Submitted.

Mentink A, Hulsman M, Licht R, Dechering K, Alves H, Dhert W, van Someren E, Reinders M, van Blitterswijk CA, de Boer J. A mesenchymal stem cell signature for therapeutic efficacy of bone tissue engineering. In preparation.

Alves H, Ginkel J, Hulsman M, Reinders M, van Blitterswijk CA, de Boer J. A mesenchymal stem cell signature for donor age. Submitted. 


\section{Selected Abstracts (oral presentation):}

Alves H, van Blitterswijk CA, de Boer J. Improved performance of aging human mesenchymal stem cells - senescence and loss of multipotency of expanded hMSCs. Dutch symposium on Tissue Engineering (DPTE), The Netherlands 2007.

Alves H, Munoz-Najar U, de Wit J, Hoeijmakers JH, Sedivy JM, van Blitterswijk CA, de Boer J. Accumulation of dna damage is associated with loss of pluripotency upon culture expansion of human mesenchymal stem cells. 16th Conference of the Dutch Society for Biomaterials and Tissue Engineering (NBTE), The Netherlands 2007.

Alves H, Munoz-Najar U, de Wit J, Hoeijmakers JH, Sedivy JM, van Blitterswijk CA, de Boer J. Accumulation of dna damage is associated with loss of pluripotency upon culture expansion of human mesenchymal stem cells. 17th Annual meeting of the Dutch society for calcium and bone metabolism (NVCB), The Netherlands 2007.

Alves H, Munoz-Najar U, de Wit J, Hoeijmakers JH, Sedivy JM, van Blitterswijk $\mathrm{CA}$, de Boer J. Accumulation of dna damage is associated with loss of pluripotency upon culture expansion of human mesenchymal stem cells. 8th World Biomaterials Congress (WBC), The Netherlands 2008.

Alves H, Munoz-Najar U, de Wit J, Hoeijmakers JH, Sedivy JM, van Blitterswijk $\mathrm{CA}$, de Boer J. Accumulation of dna damage is associated with loss of pluripotency upon culture expansion of human mesenchymal stem cells. 6th International Society for Stem Cell Research (ISSCR) , U.S.A. 2008.

Alves H, van Blitterswijk CA, de Boer J. Improved performance of aging human mesenchymal stem cells - high throughput screening in bone tissue engineering. Dutch symposium on Tissue Engineering (DPTE), The Netherlands 2008.

\section{Awards:}

Travel grant for the International Society for Stem Cell Research (ISSCR), USA, 2008 .

First prize for the best scientific project XI JOCEM, PT, 2011. 


\section{Table of Contents}

\section{Chapter 1}

General introduction

\section{Chapter 2}

Factores influencing the biological properties of mesenchymal stromal cell quality: Implications for cell therapy

\section{Chapter 3}

A link between the accumulation of DNA damage and loss of multipotency of human mesenchymal stromal cells

\section{Chapter 4}

Effect of antioxidant supplementation on the total yield, oxidative stress levels and multipotency of bone marrow-derived human mesenchymal stromal cells

\section{Chapter 5}

High-throughput assay for the identification of compounds regulating osteogenic differentiation of human mesenchymal stromal cells

\section{Chapter 6}

A mesenchymal stem cell gene signature for therapeutic efficacy of bone tissue engineering

\section{Chapter 7}

A mesenchymal stromal cell gene signature for donor age

\section{Chapter 8}

Overview, discussion and general conclusions

Summary

Samenvatting 


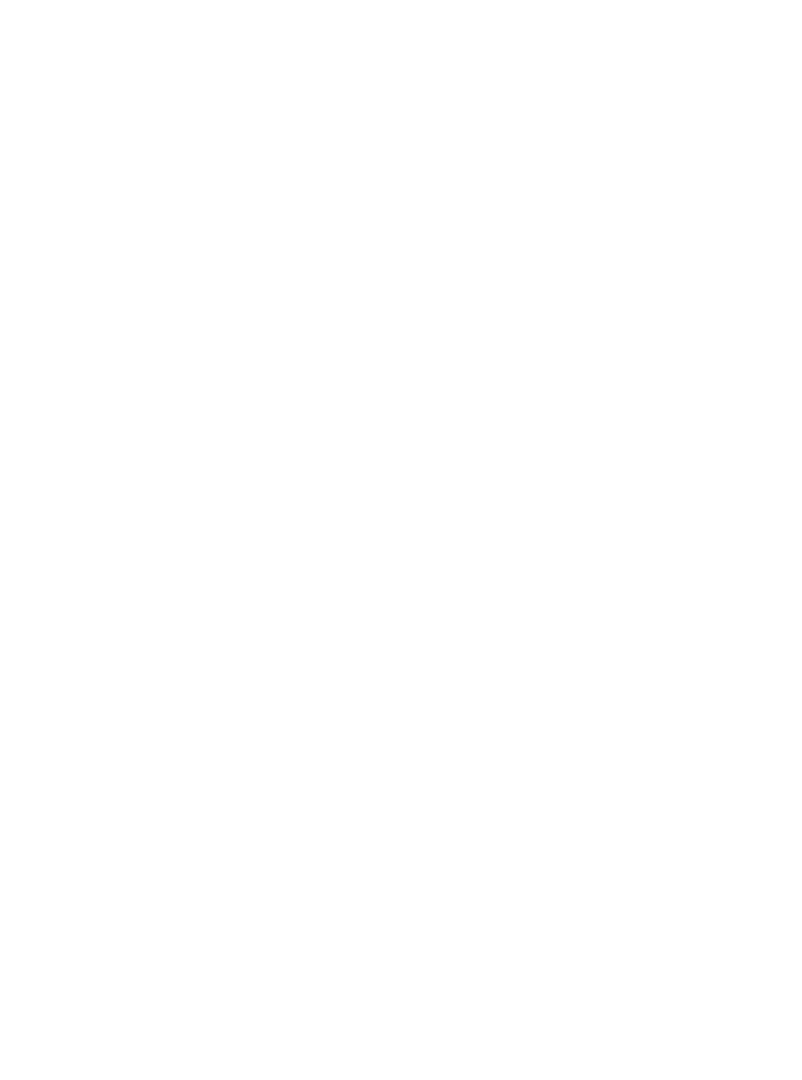




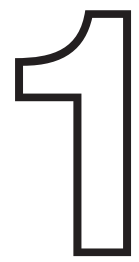




\section{Chapter 1}

\section{General Introduction}

\section{Tissue engineering and Regenerative medicine}

Human lifespan has been continuously increasing over the last decades, mainly due to the constant advances in the medical research, the improvements in the health care system, and the improvement of general life conditions. According to a US Census Bureau the population of 65 years and older is expected to more than double in the course of the next 25 years. This increase in the aging population is concomitant with an increase in bone fractures and a growing crisis in organ transplantation, but also in elderly diseases like Parkinson and Alzheimer, which have driven a search for new and alternative therapies. Cell therapy is expected not only to increase current available therapies in bone fracture healing and cartilage repair, but also to allow the treatment of a broad range of clinical pathologies (Table 1) that currently have few accepted treatments or no cure, like the cases of neurological, cardiovascular diseases or even diabetes. The list of diseases and injuries cited as potential targets of stem cell therapy reveals, in large measure, why stem cells offer hope for revolutionary advances in medicine (Table 1). These are part of the reasons why the field of tissue engineering and regenerative medicine gained increasing awareness in the last decades.

\begin{tabular}{ll}
\hline Condifion & Number of patients \\
\hline Cardiovascular disease & 58 million \\
Autoimmune diseoses & 30 million \\
Diabetes & 16 million \\
Osteoporosis & 10 million \\
Cancers & 8.2 million \\
Alzheimer's disease & 5.5 million \\
Parkinson's disease & 5.5 million \\
Burns (severe) & 0.3 million \\
Spinal-cord injuries & 0.25 million \\
Birth defects & 0.15 million/year \\
\hline
\end{tabular}

tional Academy Press 2001. Stem Cells and the Future of Regenerative Medicine.
Table 1. Potential US patient populations for stem cell-based therapies. The conditions listed occur in many forms and thus not every person with these diseases could potentially benefit from stem cell-based therapies. Nonetheless, the widespread incidence of these conditions suggests that stem cell research could help millions of persons worldwide. (c) Na- 
Tissue engineering can be defined as "the use of a synthetic or natural biodegradable material, which has been seeded with living cells when necessary, to regenerate the form and/or function of a damaged or diseased tissue or organ in a human patient" [1]. However, it precludes the usage of cell-only therapies and therefore, the term regenerative medicine is somehow more global. Both terms are however, interchangeably used since the boundaries between both are not well defined. Current regenerative medicine applications are as broad as total bone marrow reconstitution, for example, in leukemia patients, to skin substitutes (ex: INTEGRA, Apligraf, Epicel). Other current clinical trials or clinical applications include cartilage repair (Carticel); corneal cell sheets; encapsulated pancreatic islets, and three-dimensional applications like bone regeneration, bladder augmentation and blood vessel repair.

\section{Musculoskeletal disorders, current strategies and limitations}

The observed increase in life expectancy is, however, coupled with increased susceptibility for diseases, and those of the skeletal system are among the most frequent ones. The frequency of diseases related to elderly has been increasing to a point that led the World Health Authority to decree that 2000-2010 would be the Bone and Joint Decade, which was supported by the United Nations. The following statements present the rationale for their measure.

"Joint diseases account for half of all chronic conditions in people over 65; back pain is the second leading cause of sick leave; and osteoporotic fractures have doubled in the last decade, so that $40 \%$ of all women over 50 will eventually suffer from one. It is estimated that $25 \%$ of health expenditure in developing countries will be spent on trauma-related care by the end of the decade (2010)" [2].

In the United States alone, musculoskeletal conditions cost society an estimated $\$ 269.3$ billion every year. One out of every seven Americans reports a musculoskeletal impairment, and 28.6 million Americans incur a musculoskeletal injury every year [3]. Bone is the second most implanted material in the body, being blood transfusions the first. Bone grafts are estimated to be used in over 600,000 procedures annually just in the United States (U.S.). There are estimated 170,000 fractures in U.S. per year, which fail to heal and are diagnosed as "non-union" bone fractures and, therefore, require bone graft for total healing. The market for bone grafts is increasing every year and in 2000 was estimated to be around 517 million dollars (allograft bone tissue proceedings, synthetic graft substitutes and autograft bone tissue procedures). Only allograft procedures fraction was estimated to be around 257 million dollars in 2000. Synthetic bone grafts substitutes 
are estimated to be used in $11 \%$ of bone graft procedures each year (adapted from [4]).

However, bone applications are not restricted to fractures, for example, in 1999 there were an estimated 350,000 spinal fusion procedures performed that required bone grafts to secure the areas of the spine affected [5]. Current bone applications include the treatment of "non-union" bone fractures, spinal fusions, hip arthroplasty, oral-maxillofacial surgery, treatment of bone tumors/trauma surgery, and joint replacements. Most of these surgeries often demand the usage of grafting materials. Currently, there are several bone grafts and bone grafts substitutes that can be used, however, all of them have advantages and pitfalls. Among them, natural bone grafts (autologous bone) are still considered the golden standard for bone repair since they meet many requirements for bone formation like absence of immunogenic response and good osteogenicity, osteoconductivity and osteoinductivity [6-11]. Despite providing the osteoconductive matrix, growth factors and osteogenic cells, which are the necessary elements for a proper bone repair, are associated with: increased donor site morbidity inflicted in the patient; potential of infection at the bone harvest site; and potential risk of injuring the surrounding structures near the harvest site $[6,8,9,12,13]$. Even more worrying is the fact that, patients often need revision surgeries, making autologous bone sparse, not to mention patients whose bones are of poor quality, or patients that exhibit limitation on the amount of transplantable autologous bone, like children.

Allogeneic bone, from cadaveric material, is an alternative, however, the risk of immune rejection and disease transmission [14] are increased even though current techniques like lyophilization and low temperature freezing do minimize such risks $[15,16]$, at the expense of a higher resorption rate and slower formation of new bone [8]. Despite all the problems associated with their use, autografts and allografts represent respectively $50 \%$ and $30 \%$ of all the bone grafts used in the clinic. As an alternative, several bone substitutes (Synthetic materials / Biomaterials) have been developed in the past decades providing clinicians a replacement for bone. These materials include, for example, metal implants like titanium and its alloys, frequently used in trauma patients or in total hip replacements. These materials are frequently used for load bearing applications due to their strength, however, their strength is also their weakness, and since they are much stronger than bone, they often cause osteolysis around the implant $[17,18]$. This leads to the need of more complicated revision surgeries, therefore, inflicting more pain to the patients and increasing health expenditure. Furthermore, with each revision, the lifespan of the implants is often decreased. Therefore, several techniques have been developed in order to improve currently used implants. One example is to provide the grafts with better microporosity, which in turn leads to an increase in 
the surface area, providing an optimized surface for matrix deposition, which can result in an increased osteoconductivity and therefore, a better bridging between the implant and the natural bone $[19,20]$.

The use of non-degradable materials is not optimal, and over the last decades, a lot of research was invested in the development of novel biodegradable materials, such as ceramics. Among them, the calcium phosphate-based are particularly interesting because they resemble natural bone both in terms of mineral composition and micro-structure, but also because they have a high affinity for proteins [21] and are shown to have osteoinductive properties [22-24]. These materials in contrast to the metal grafts do not present the same strength, therefore, are more used in non-load bearing applications. Alternatively to ceramics, polymers are also frequently used due to their capacity of being processed into several tridimensional custom-designed shapes, making them very interesting materials for clinical applications [25-27]. Furthermore, they not only allow the incorporation of growth factors, but also, depending of the design, a control release of the incorporated proteins or compounds [28, 29]. Despite their flexibility in terms of structures that can be made, they often have several drawbacks, which include, inferior mechanical properties, increased risk of toxicity, induction of an inflammatory response and are susceptible to wear and fast degradability.

Demineralized bone matrix $(D B M)$ is a bone graft substitutes that is prepared by acid extraction of allograft bone, resulting in loss of most of the mineralized component, but retention of collagen and non-collagenous proteins, including growth factors. Their efficacy as a bone-graft substitute may be related to the total amount of bone morphogenetic proteins (BMP) present and their ratios since BMPs are known to induce bone formation [30-33]. Although less immunogenic than allografts, due to the fact that the demineralization process destroys the antigenic material present in bone, their biggest problem relies on the fact that, the amount of BMPs present is variable depending on the donor of the allograft material and the method used, but also can be influenced by the carrier material used to deliver the DBM.

Currently, several of these materials are being used in the clinic, for example, the case of hydroxyapatite-coated systems or the case of the non-cemented hip prostheses with calcium phosphate coatings used in total hip arthroplasty or the case of DBM in small bone defects or bone augmentations. These are only some examples among many other materials and clinical applications. Although the results from the applications of these materials are very promising, there is still a significant failure rate after some years, due to bone loss around the implants or due to the fact that these materials are not entirely replaced/filled by bone. 
Therefore, revision surgeries are often needed and unfortunately the failure rates in these revisions surgeries are even higher. A new tendency of the field is, therefore, to combine the usage of cells and materials in the hope that they will help to regenerate the damaged bone tissue faster. Although initial results are still suboptimal, a significant effect of the in vitro expanded cells on bone formation has been shown [34-36]. A significantly more callus formation and clinical union was shown in the cell-loaded scaffolds than on the defects that were treated with scaffolds alone. Therefore, the usage of cells in bone tissue engineering is promising, although, there are currently contradictory opinions about the benefits versus the problems associated with the addition of cell into the clinical set-up.

In the particular situation of bone tissue engineering, an example of a cellbased approach (Figure 1) would be the collection of "adult multipotent stromal cells", generally by bone marrow aspiration (although they can be obtained from several other sources - see section Mesenchymal Stem/Stromal cells) and further selection of the multipotent, plastic adherent cells (1). These cells are then expanded in a 2D tissue culture flask in order to obtain a sufficient amount of cells for the desired purpose (2). Cells are then combined with a biodegradable scaffold material, where growth factors or other biological stimulus can be introduced to help in the future regenerative process (3). After a period of pre-differentiation in vitro, the combination of scaffold and cells would be then implanted back into the patient in order to repair the defect or degeneration (5).

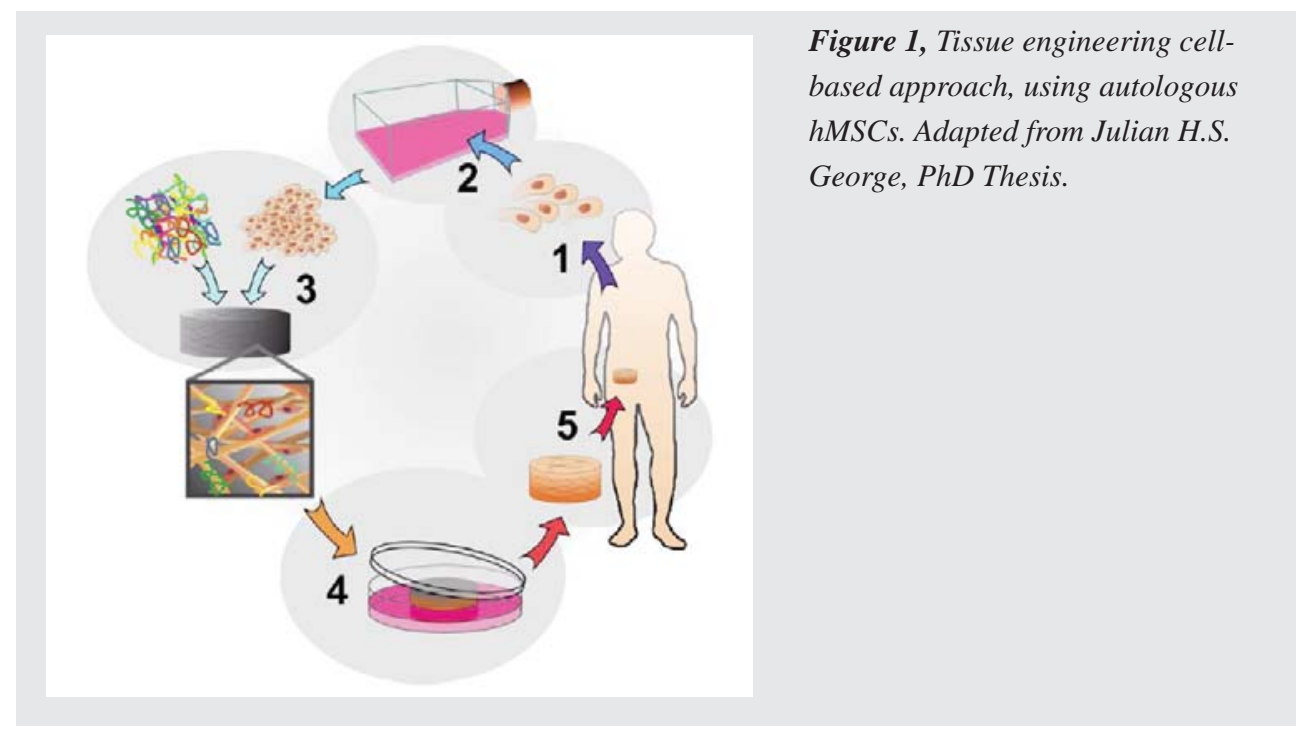




\section{Bone tissue engineering}

Bone is one of the research areas that is currently more used in the clinic, since bone grafts have been used by orthopedic surgeons for nearly a century. It's a multidisciplinary area that involves the combination of different disciplines including biology (cell culture), material science (development of novel biomaterials) and medicine (application of the constructs and clinical trials). In the past, material science and biology were very independent fields of research and bone tissue engineering relied mostly in the evolution of materials. In the last decades, however, with the advances in stem cells research, the possibility that the combination of cells and materials could accelerate both bone formation and regeneration after trauma, led to strength the link between the two fields. Therefore, in the last decades, there was a substantial improvement in the knowledge available between the interaction of cells and materials, which in turn led to the production of the so-called "smarter" or instructive materials. These materials not only work as a carrier or fillers, but are also made to accelerate or induce a response from the host and are optimized to promote cell survival within the constructs.

Bone is a highly vascular mineralized connective tissue, consisting of cells and an intercellular or extracellular matrix (ECM), in which the majority of its cells are embedded. It is a natural composite material, composed of organic materials $(30 \%$ dry weight in mature bone), which are mainly collagen fibers (Figure 2B), inorganic salts rich in calcium and phosphate (60\% in weight) and water (10\% in weight). The fibers present in the ECM are mainly constituted of collagen type I (90\%) and other non-collagenous proteins like osteonectin, osteopontin, bone sialoprotein, osteocalcin, decorin and biglycan [37]. Macroscopically, living bone is white and it has either a dense texture (compact or cortical bone), or it is composed by large cavities resembling a honeycomb, where the bone element is reduced to a network of bars and plates (trabeculae) (Figure 2A). The compact bone is mainly in the cortices of mature bone, providing increased strength, while the rest of the bone is trabecullar (also known as cancellous or spongy bone), housing the bone marrow (long bones) or filled with air (pneumatized) in many internal cavities of some bones in the skull. Examples are the mastoid process of the temporal bone, and the sinuses of the maxilla and ethmoid [38]. 

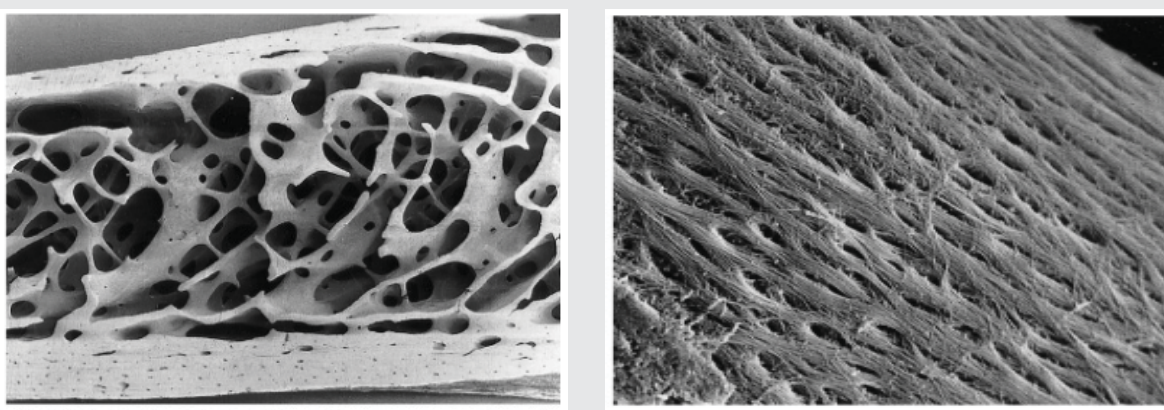

Figure $2 \mathrm{~A}$, Vertical section $2 \mathrm{~cm}$ below the anterosuperior border of the iliac crest (to the right of the field view as oriented; female, 42 years). The cancellous bone consists of intersecting curved plates and struts. Osteonal (Haversian) canals can just be seen in the two cortices at this magnification. B, Scanning electron micrographs of collagen fibers on the surface of human trabecular bone. Note branching fibers (female, 2 months, sixth rib). (C) Elsevier Ltd 2005. Standring: Gray's Anatomy 39th edition.

It is the combination of the cortical (outer shell of long bones) and the trabecullar structures (hollow medulary canal) that allows the combination of strength and light weight that bones possess. Although, bones are exquisitely adapted to resist stress with suitable resilience, to support the body and to provide leverage for movement, they also play many other important roles in the body. Bones provide the attachment sites for the muscles and tendons necessary for locomotion, protect the vital organs of the cranial and thoracic cavities, are the most abundant site of hematopoiesis in the adult, form a reservoir of metabolic calcium (99\% of body calcium is in the bony skeleton) and phosphate, allow sound transduction, balance the $\mathrm{pH}$ in the blood and are a temporary storage of heavy metals $[39,40]$. Bone is not a static but rather dynamic tissue facing continuous self remodeling. It is formed during embryonic life rapidly during childhood (formation exceeds resorption). At around 20 years of age, growth reaches its peak, after which the skeleton enters a prolonged period when bone remains stable (during approximately 40 years). During this period, there is an approximate $10 \%$ of adult skeleton turnover, where resorption and remodeling (de novo formation) of bone occurs at a similar rate, therefore, resulting in no net effect in bone mass. However, with age this balance degenerates causing loss of bone mass, stiffness and strength, increasing the fracture risk and can originate in extreme cases debilitating consequences like osteoporosis. In women, this balance is lost at menopause and in men, usually later in life. Skeletal mass is regulated through a balance between the activity of cells that resorb bone (osteoclasts) and those that form bone (osteoblasts). Clinical disorders frequently happen when bone resorption exceeds bone formation, 
being an example osteoporosis. Bone remodeling (Figure 4) is an essential process for the maintenance of our skeleton, since it enables adaptation of the bone mass and architecture to changes in external loads [41, 42], and prevents accumulation of damage by promoting a frequent turnover to repair micro-damages created during normal daily loading [43, 44]. In most bones, four different cell types can be present: osteoclasts, which are multinucleated bone resorbing cells derived from the hematopoietic lineage; osteoblasts, the bone-forming cells which are derived from the mesenchymal lineage; osteocytes, which are osteoblasts entrapped in their own calcified matrix; and bone lining cells, that are originated from osteoblasts, whose function is to regulate the transport of calcium from and into the bones. They are also hormone-responsive, and when triggered, they produce proteins that lead to osteoclast activation.

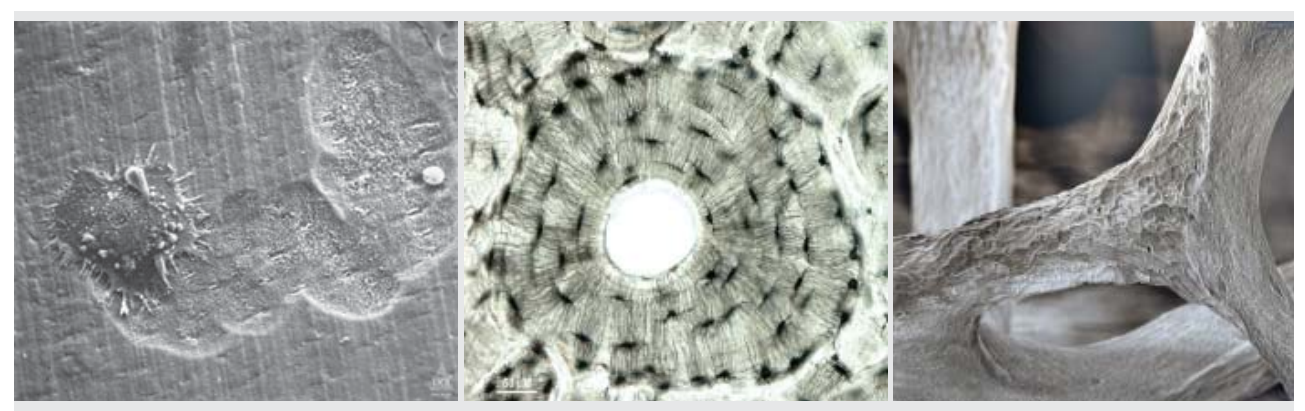

Figure 3A, Scanning electron micrograph showing osteoclast resorbing bone. (C) Alan Boyde B, Osteocytes (Human Bone) (c) Tim Arnett C, Osteoporotic Bone, Architecture in the 3rd lumbar vertebra of a 71 year old woman. Note trabecular bone element eroded by osteoclasts. (c) Tim Arnett

Not all the bones in the skeleton are formed the same way. Bone formation can occur by either intramembranous ossification or endochondral bone formation, and while on the first case, it happens by direct differentiation and condensation of osteoblasts, the latter is produced in a way where the same progenitors are differentiated first into a cartilaginous template that is later replaced by bone. Therefore, in some stages of embryonic development and when an injury or fracture occurs in the adult body, chondrocytes can also be present during the endochondral bone formation process. 


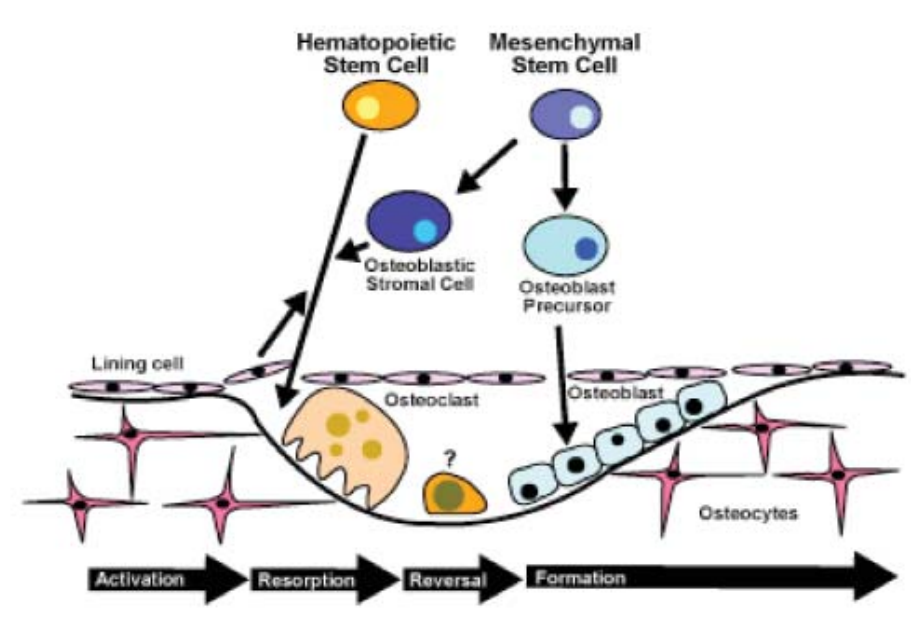

Figure 4, Schematic figure of the bone remodeling process. (c) Living medical textbook - Osteoporosis.

Bone resorption occurs in two phases: first, the demineralization of inorganic bone that is then followed by degradation of organic bone matrix [45]. Demineralization is accomplished by the creation of an acidic microenvironment beneath the surface of osteoclasts. When the organic bone matrix is exposed by demineralization, degradation occurs through the action of cathepsin $\mathrm{K}$, a collagenolytic lysosomal protease expressed by osteoclasts. Following bone resorption by the osteoclasts, there is a reversal of the process, where osteoblasts will start to mineralize the osteoid (organic matrix non-mineralized) and give rise to osteogenic proteins like alkaline phosphatase and osteocalcin that raise local concentration of calcium and phosphate, which will later, mineralize and originate new bone. During this process, osteoblasts are incorporated in their matrix, originating the osteocytes, which have a pivotal role in bone maintenance, since their death leads to the resorption of the matrix by osteoclast activity. These are the most frequent cell type present in mature bone.

Osteogenesis or bone formation is a well-coordinated, highly complex process involving numerous growth factors and signaling molecules in a regulated manner, mediated by osteoblasts. Osteoblasts differentiate from mesenchymal stromal cells (MSCs) in a highly regulated sequence of events mediated by several growth factors and cytokines [46-49]. Among these factors and cytokines, bone morphogenetic proteins (BMPs) seem to be the most potent inducers of osteoblast differentiation $[50,51]$. There are, however, several key osteogenic pathways, which directly or indirectly regulate osteogenic differentiation. Some examples of 
these pathways are: Glucocorticoid signaling, TGF- $\beta$ and BMP, Wnt and G-protein coupled receptor signaling. A detailed overview of the response of human MSC to osteogenic signals and its impact on bone tissue engineering was recently reviewed by Siddappa et al. [52]

Understanding the molecular regulation of bone will have important clinical implications for bone regeneration and treatment of bone disorders. Nowadays, a strong emphasis has been placed in the search for novel osteogenic molecules and possible new pathways leading to bone formation. With the technological advancements, this task has become easier and more accessible not only for small pharmaceutical companies but also for research institutes. While the range of compounds to screen still differ enormously between both, the easy implementation of medium to high-throughput screens, allowed the basic scientist, to use it for applications that were not cost effective or immediately appealing to a pharmaceutical company, opening the possibility for the screen of new molecules to target a specific application or pathway.

\section{Mesenchymal Stem/Stromal cells}

In vitro cell culture has been performed since the beginning of the $20^{\text {th }}$ century and was greatly enhanced by the improvement of the nutrients present in cell culture media and by the discovery, purification and availability of a large number of growth factors, which allowed not only the reduction of the amount of serum needed but helped maintain the culture of these cells under an undifferentiated state. Among all the cells that can be cultured in vitro, "stem cells" have been one of the last ones to be routinely cultured due to their complex biological requirements. The term stem cell has been generally reserved for cells with the ability of self-renewal over extended periods of time and to possess multi-lineage differentiation potential, i.e., the ability to give rise to a variety of daughter cells the so-called "transient amplifying pool" that can commit to a certain pathway and become terminally differentiated (Figure 5). 


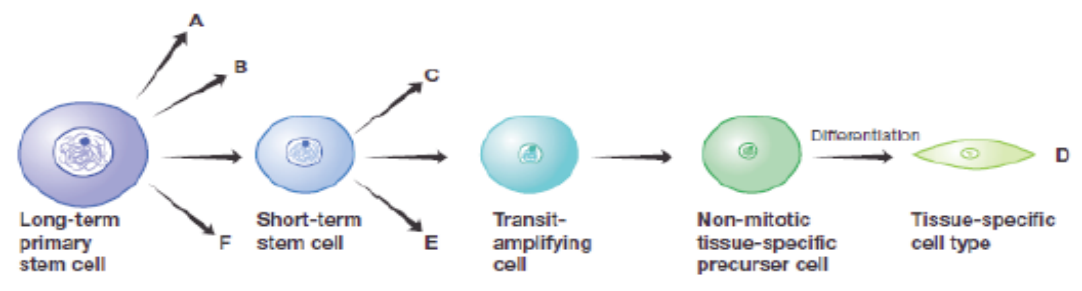

Figure 5, Scheme illustrating restriction in developmental potential of stem cells and their progeny. (C) Elsevier 2007. Principles of Regenerative Biology.

It was proposed that stem cells could divide both symmetrically (generation of daughter cells with the same fate) and asymmetrically (generation of a progenitor daughter cell and a daughter stem cell) as depicted in figure 6. However, this subject has been the focus of avid discussions since asymmetric divisions would not allow stem cells to increase in number, as it can be seen by the increase of the stem cell pools during early embryonic development [53], when they are regenerated after injury [54], or after cytokine treatment [55]. Furthermore, it has been described that HSC do not undergo asymmetrical division [56].

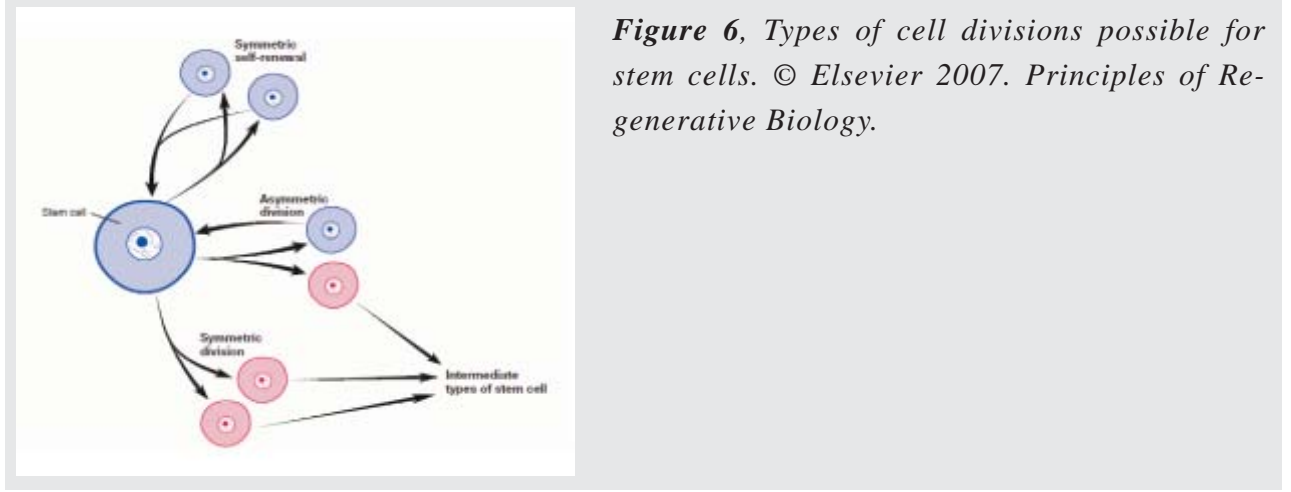

In contrast, there are examples of asymmetric division as is the case in the Drosophila germline stem cell, which divides and produces one daughter cell that is kept in the niche retaining, therefore, stem cell identity, and one daughter cell that is placed away from the niche and, therefore, starts to differentiate [57-59]. Therefore, it can be that different stem cells divide differently or that stem cells can facultatively use one or other type of division. This facultative selection was hypothesized to be a key adaptation that is crucial for adult regenerative capacity [60]. 
There are different types of stem cells, which vary in terms of their location in the body and the type of cells they can produce. Basically, they can be divided in two different groups: embryonic stem cells (ESCs), that are pluripotent, being therefore, able to generate any cell of the organism they reside in and adult "stem cells", which are multipotent cells, being the most studied cells among them, the hematopoietic stem cells (HSC) and the "mesenchymal stem/ stromal cells" (MSC).

While embryonic stem cells clearly deserve their name, since they can be kept in culture for long periods of time keeping their differentiation potential upon stimulation, the same might not hold true for "mesenchymal stem/stromal cells". Although, with the improvement of culturing conditions the time they can be expanded significantly increased, they still cannot, in normal culture conditions, renew themselves indefinitely and produce cell progeny that mature into more specialized, organ-specific cells after long term in vitro expansion. Therefore, some claim that, "mesenchymal stem cells" is not the best term to define this cell population, and would rather call them multipotent mesenchymal stromal cells or frequently use a much more ambiguous term MSC.

However, one has to keep in mind that asymmetrical cell divisions, by promoting the creation of a transient amplifying pool, have the virtue of limiting the total number of division cycles in which stem cells have to engage during the life of an organism. Therefore, unlimited self-renewal capacity might not be essential for stem cells in vivo, and in practice, the distinction between stem and transient amplifying cell may be difficult to make.

To date, there is no definite marker to characterize stem cells and knowledge regarding the anatomical location and distribution of MSCs in vivo. The demonstration of their existence has relied in assays such as the colony forming unitfibroblast (CFU-F), which essentially identifies, adherent, fibroblastic-like cells that are able to proliferate and form colonies [61]. The innovative work by Friedenstein et al., was one of the earliest experimental evidence of the existence of MSC, where it was reported that bone marrow derived cells were capable of osteogenic differentiation, which have made this assay a standard proof of MSC potency. Initially it was thought that MSC could only be found in certain organs and would only differentiate towards the phenotypes present in the originating tissue. With increased research, it become clear that adult stem cells can be obtain from a variety of tissues (Figure 7A) like: human bone marrow [62], blood [63], fat [64], liver [65], brain [66], muscle [67], pancreas [68], umbilical cord blood [69], among others and present a much broader differentiation potential (Figure 7B). How- 
ever, to date, their differentiation capacity is still less than embryonic stem cells. MSC have also the capacity to undergo terminal differentiation towards several mesenchymal phenotypes both in vitro and in vivo, which includes bone [70, 71], cartilage [72], muscle [73, 74], adipose tissue [75, 76], tendon $[77,78]$ and hematopoietic-supporting stroma [76].

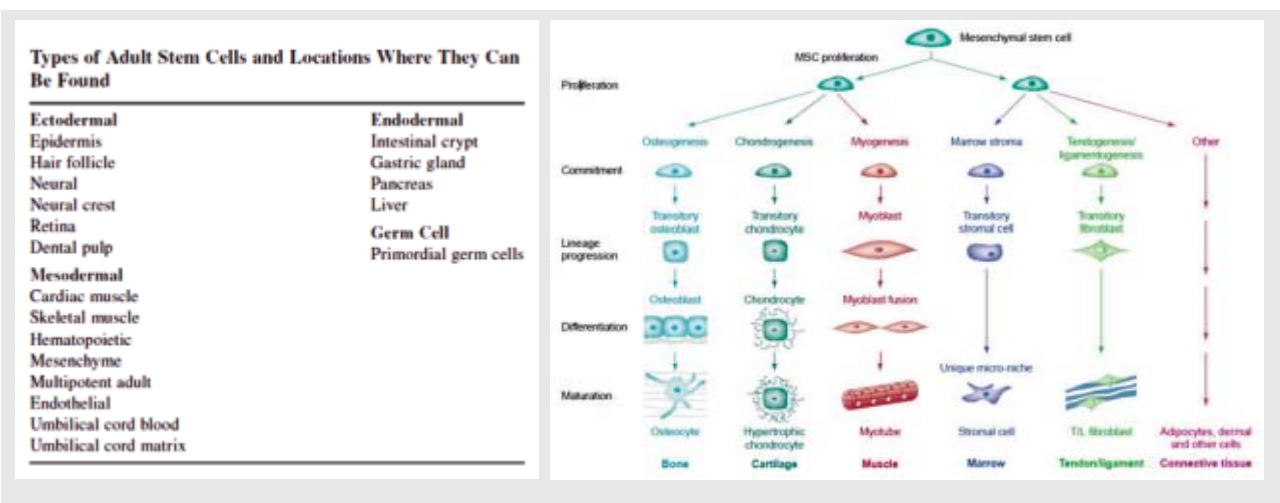

Figure 7A, Types of Adult Stem/stromal cells and locations where they can be found. () Elsevier 2007. Principles of Regenerative Biology. B, The process of commitment and differentiation of MSCs. Multipotent cells that can be designated MSCs proliferate and, in response to cues from the cellular environment, enter lineages that undergo differentiation and subsequent maturation into the mature cells types. This scheme is simplified and does not represent all the transitions of a single lineage or potential interrelationships of cells moving towards other lineages (plasticity). Recent literature also has demonstrated that the differentiation potential of MSCs is vaster than it was expected and so, not only restricted to the mesenchymal lineage. (Adapted from Caplan and Bruder [79]).

Interestingly, there are reports about stem cells that have embarked on a differentiation pathway and undergone marked morphological changes, and still can revert to a simpler state reminiscent of stem cells [80]. This process of regression into a more precursor state is called dedifferentiation.

\section{Stem cells and Regeneration}

Stem cells are thought to be in the base of tissue regeneration by giving rise to progenitor cells that can therefore, differentiate and replace damaged cells. Although repair and regeneration are universal phenomena in the biological world, the capacity for regeneration varies considerably among species. While some invertebrates like planaria or some species of earthworms, can regenerate two genetically identical individuals when cut in half, amphibians like newts can regen- 
erate whole limbs, retinas, eye lenses, spinal cords, and tails, as well as upper and lower jaws (Figure 8A). It seems that mammals had to pay the price of evolution by loosing great part of the regenerative potential, especially, when compared to lower life forms. While both invertebrates and amphibians are able to replace lost or damaged organs and tissues with new ones that are identical in structure and function to the original, mammals can only achieve partial regeneration (Figure 8 B). Even if a function of an organ may be recovered, in some situations, after the tissue has been damaged, structure, however, will never be restored.
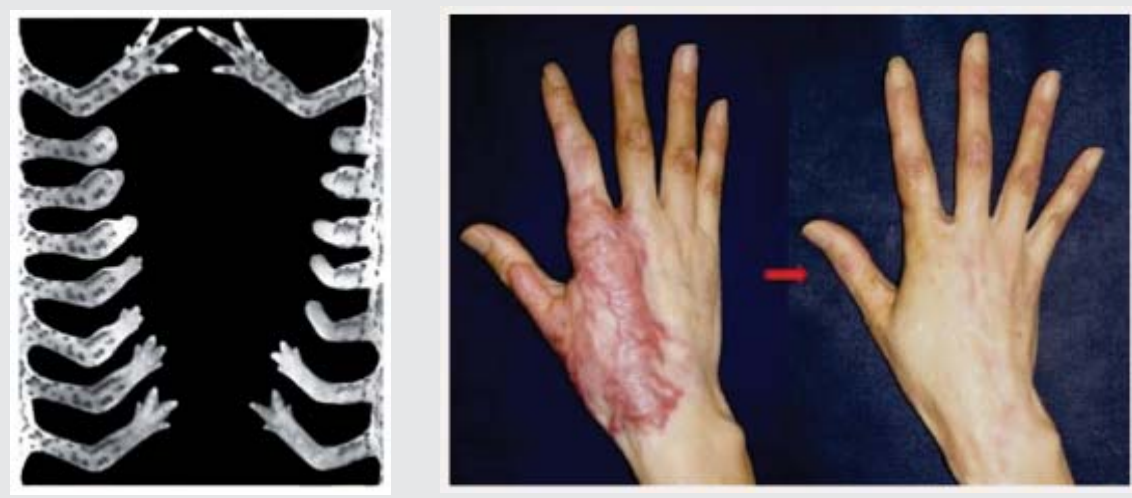

Figure 8 A, Successive stages in the regeneration of newt arms amputated at upper (right) and lower (left) arm levels. Starting below the normal arms at the top, the intervals of regeneration are 7, 21, 25, 28, 32, 42, and 70 days after amputation. (Reprinted from Goss R.J. 1969). Principles of regeneration., New York: Academic Press). B, Burn scar resurfacing using autologous skin grafts. Autologous skin grafts were harvested from the inguinal region and transplanted after removal of scars. Right image was taken after healing of the implanted tissue. (C) Springer 2010 (in press). Color Atlas of Burn Reconstructive Surgery.

Although humans do not have by far, the same regenerative capacity as some species, to a certain extent, some tissues are still rejuvenated frequently like the skin and hematopoietic cells within the bone marrow Figure 9).

The phenomenon of complete regeneration presented by lower life forms has always been a mystery. According to recent investigations, this remarkable phenomenon is hypothesized to be due either to the possession of abundance of stem cells pools or due to the capacity of these organisms to convert specialized cells into a more generalized form, which could perhaps redifferentiate into another cellular phenotype upon necessity. This ability of transdifferentiation from one phenotype into another phenotype is called cellular plasticity and is subject of high controversy within the field. A detailed review about some of the evidence for stem cell plasticity has been written by Poulsom et al. [81]. 
These regenerative processes presented in figure 9 are presumed to be associated with the presence of specific stem cells within those tissues, otherwise, the replacement of billions of dead cells by new cells every day, throughout life, could not be made and tissue homeostasis would, therefore, not be maintained. Since very few stem cells exist in each tissue, their fate seems to be controlled by their niche. Knowing how to differentiate them and how to keep them with age will be essential for the evolution of human species and will allow a more proficient use of stem cells for the treatment of degenerative diseases.
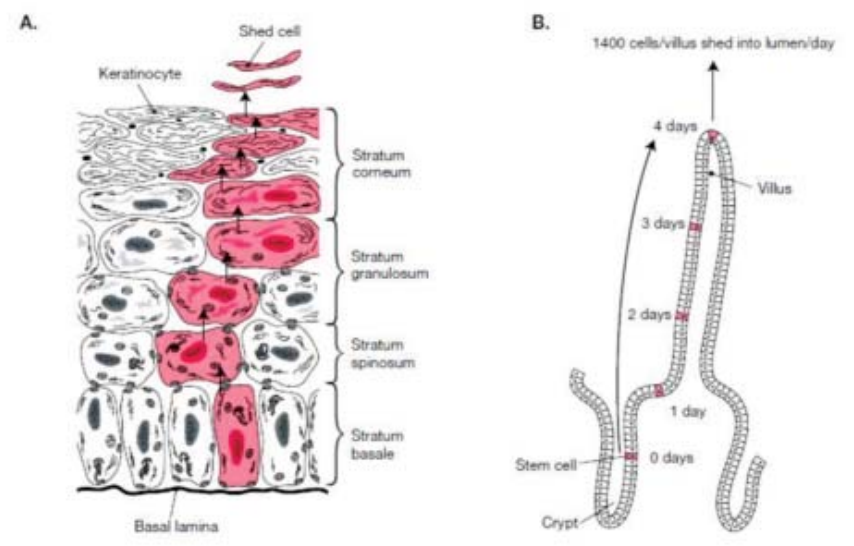

c.

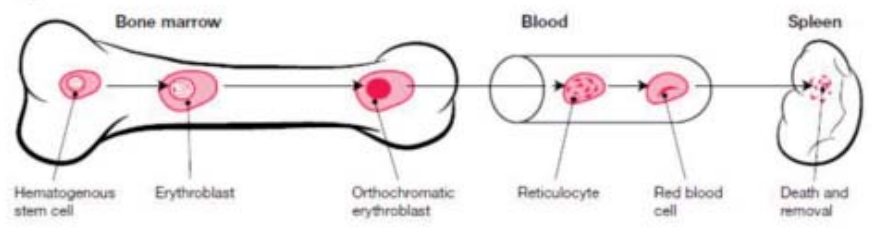

Figure 9, Three types of physiological regeneration in mammals. (A) The turnover cycle of an epidermal cell. (B) The shedding cycle of an epithelial cell on a villus in the small intestine. (C) The replacement cycle of a red blood cell. (C) Elsevier 2007. Principles of Regenerative Biology. 


\section{Stem cells niche}

For most stem cells, the niche where they reside in is poorly defined, but it seems to be a complex microenvironment composed of extracellular matrix, differentiated cells, stem cells, progenitor cells, and factors secreted by the cells present in the specific tissue. The stem cell niche that is more described is the bone marrow. In fact, it is convincingly described, that there is not only one, but that distinct niches exist within the bone marrow, supporting hematopoietic stem cell survival and growth [82]. During the lifetime of an organism, the niche has the function of providing the necessary factors and adhesive properties to maintain the viability of HSC, and, therefore, facilitating an appropriate balanced output of mature progeny [82]. These particular niches have been determined to be formed by stromal precursor cells and osteoblasts [83]. The function of the stroma, and stromal cells is to provide not only support for maturating precursors of blood cells, but also, to serve as a repository of cell-derived cues and signals responsible to drive the commitment, differentiation and maturation of hematopoietic cells [84-86]. The marrow stroma is composed primarily by endothelial cells, fibroblasts, macrophages, reticular cells, adipocytes, osteoprogenitors, HSCs and their progeny $[87,88]$, being within this dynamic and cellular microenvironment where MSC are thought to exist. It is not sure, however, if MSCs and HSCs share a unique stem cell niche or whether they reside in their own specific one since, despite their physical proximity, the external signals required to maintain their developmental program are likely to be different. In vivo, MSC are present in several tissues, suggesting that the MSC niche is not restricted to the bone marrow but ubiquitous. This concept of a niche, where stem cells reside and are protected, might also be important in the understanding of which soluble factors, which extracellular matrices and which forces or gradients are present in the niche, how a stem cell is triggered to differentiate and especially how can a stem cell remain pluripotent and not exhaust during the full lifespan of the organism they reside in. Currently, it is known that a combination of different triggers (soluble factors/ matrices/forces) play a role in the decision between maintenance of pluripotency and enrolment of the differentiation process. (figure 10A). What is important to know is that all the research that is done in vitro, and especially in $2 \mathrm{D}$ systems, although highly valuable, need a further validation either in more complex in vitro $3 \mathrm{D}$ models or/and ultimately in vivo, in animal models, mainly because cells in their in vivo niche face a complete different environment. 

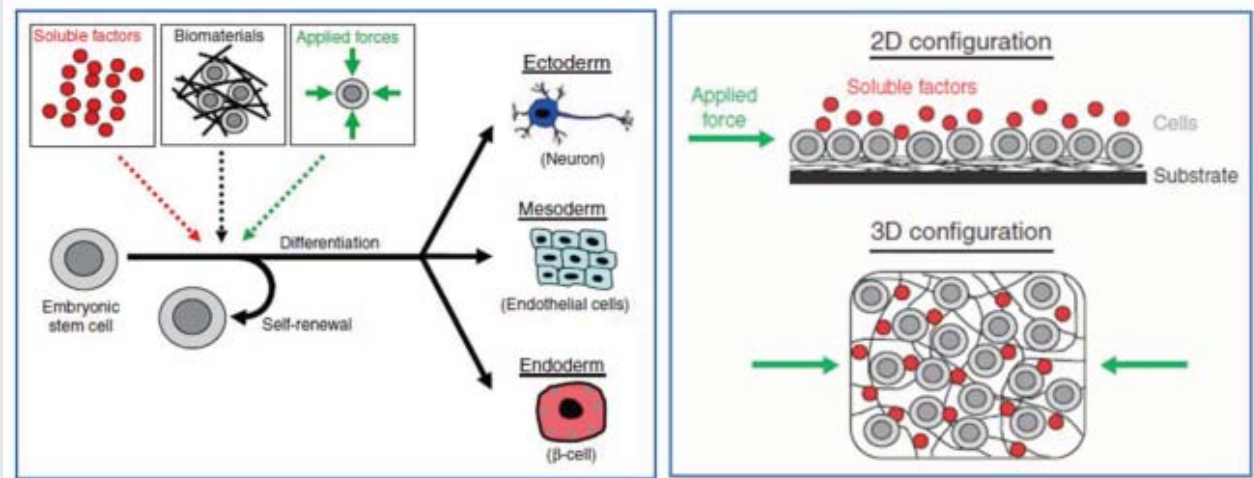

Figure $10 \mathrm{~A}$, Cues in the microenvironment that affect stem cell fate. This schematic indicates the effect of chemical and physical cues on embryonic stem cell fate (as an example), including self-renewal processes and differentiation toward all three germ lineages. $\boldsymbol{B}$, The different configurations and environmental cues during cell culture. In two dimensions, cells (gray circles) may be (a) adhered to a surface via a protein substrate (black strands), (b) exposed to soluble factors (red circles) in the medium, and (c) subjected to applied forces (green arrows) via surface distention or fluid motion. In three dimensions, cells may be (a) seeded onto or embedded within a scaffold with matrix molecules, (b) exposed to soluble factors in the medium, and (c) subjected to applied forces via scaffold deformation, fluid motion, or fluid pressurizations. (C) Elsevier 2008. Principles of Regenerative Medicine.

\section{Embryonic Stem cells (ESC) versus Adult Mesenchymal stromal cells (MSC) for regenerative purposes}

Although currently ESC present a bigger differentiation potential and better self-renewal capacity than MSC, there are still several aspects that limit their usage for regenerative purposes: (1) ESC when implanted often remain undifferentiated originating teratomas in the recipients; (2) the need to be grown in the presence of feeder layers or alternately on matrigel under specific growth factor supplementation, which usually will originate a small percentage of differentiated cells in the population. Although a novel method was described where new hESC lines were derived and established in completely feeder-layer-free and serum free conditions [89], several studies have shown that, hESC cultured on mouse feeder cells and with serum replacement culture medium were contaminated by the xeno-carbohydrate $\mathrm{N}$-glycolylneuraminic acid (Neu5Gc), which is an immunogenic, nonhuman, sialic acid that can be potentially taken-up by hESC, making them potentially unfit for human therapy [90]); (3) ESC are not immuno-privileged and therefore immune-rejection may be expected; and arguably the greatest hurdle, 
(4) human ESC derived from the inner cell mass of a blastocyst results in the destruction of a spare pre-implantation embryo from in vitro fertilization techniques (Figure 11), which therefore raises huge ethical, legal and social concerns about their usage.

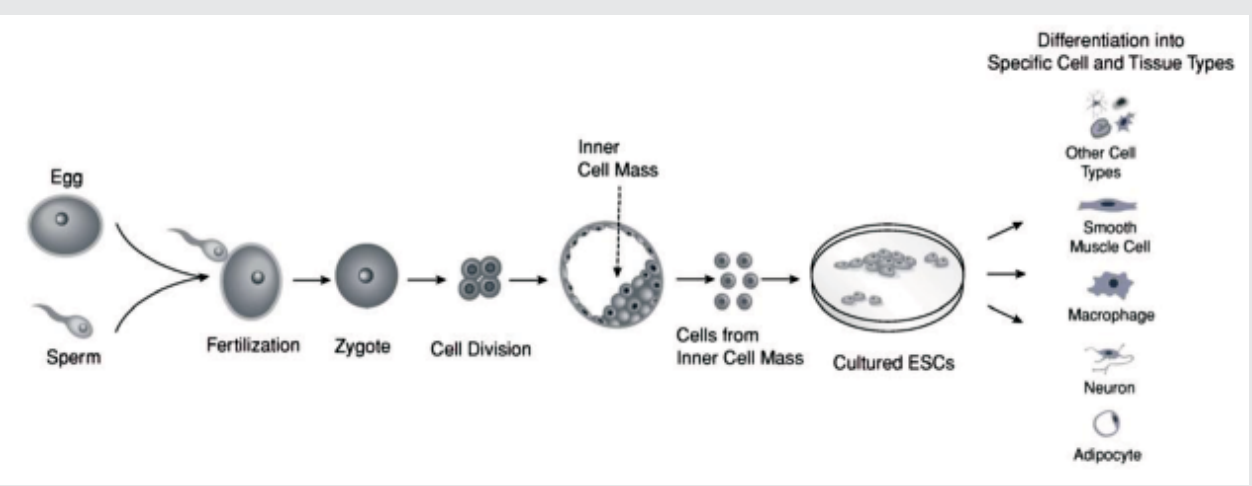

Figure 11, This figure schematically depicts the process of isolation and differentiation of ESCs. Adapted from (c) National Academy Press 2001. Stem Cells and the Future of Regenerative Medicine.

Opposed to ESC, MSC do not present ethical dilemmas since they can be obtain from a several sources and don't preclude the usage of an embryo. They can be easily expanded in vitro to obtain relevant amounts for clinical applications, they secrete immune-modulatory compounds, making immune-rejection less likely to happen, and in normal culture conditions, do not induce tumor formation upon implantation. Another significant benefit is the fact that, they can be easily isolated from the same patient prior to treatment and, therefore, avoid problems with immune-rejection and the effects of long-term immunosuppressive treatment. However, there are also several limitations with their usage. They present less differentiation capacity than ESC, and after in vitro expansion, they lose significantly their differentiation potential, which might compromise their usage for clinical applications, especially when long-term expansion is needed.

In recent years, most of the attention is focused in the use of iPS cells. These cells, not only present all the advantages of ESC, like infinite self-renewal potential and the ability to form any cell from the body, but since they are derived from somatic cells, they offer the possibility of the creation of patient-specific and disease-specific pluripotent stem cells. This allows the creation of banks of disease-specific stem cells, which in term will be a revolutionary tool, for example, in the field of toxicology. In this line of thinking, one can envision the creation, for example, of myocytes where new drugs can be tested for a specific disease. 
Although, they present advantages of both systems and despite most of its drawbacks were already addressed, they still induce, frequently, cancer formation in their recipients, which is unacceptable for clinical applications. For all the previous stated reasons, MSC are much more likely to be used in clinical applications than ESC or iPS, at least, in the near future. In fact, they are already being used in some cell-based therapies, but are expected ultimately to be applied in many more applications.

\section{Application of stem cells research}

The possibilities offered by stem cell applications created an unprecedented enthusiasm in the history of biomedical research with tremendous repercussions at a global scale. Mostly, due to three main breakthroughs: the successful cloning of the sheep "Dolly" by Ian Wilmut, Keith Campbell and co-workers in 1997 [91]; the establishment of human embryonic stem cell (ESC) lines by James Thomson and co-workers in 1998 [92]; and more recently the discovery of how to induce pluripotent stem cells (iPS) from adult somatic cells by the laboratory of Shinya Yamanaka [93]. These discoveries were a big step forward into the possibility of rejuvenation or even replacement of defective organs and tissues of the human body. While, hopes are high that many age-relative degenerative diseases will be cured by stem cell therapy, there are still some serious hurdles that need to be addressed.

\section{References:}

1. Lanza RP, Langer RS, Vacanti J (2007) Principles of tissue engineering. Amsterdam ; Boston: Elsevier / Academic Press. xxvii, 1307 p. p.

2. The Need for Bone Substitutes, http://www.btec.cmu.edu/tutorial/need/need.htm.

3. Cambron J, King T (2006) The bone and joint decade: 2000 to 2010. J Manipulative Physiol Ther 29: 91-92.

4. Weiss LE (2002) Web watch. Tissue Eng 8: 167.

5. Lee CK, Langrana NA (2004) A review of spinal fusion for degenerative disc disease: need for alternative treatment approach of disc arthroplasty? Spine J 4: 173S-176S.

6. Brown KL, Cruess RL (1982) Bone and cartilage transplantation in orthopaedic surgery. A review. J Bone Joint Surg Am 64: 270-279.

7. Yaszemski MJ, Payne RG, Hayes WC, Langer R, Mikos AG (1996) Evolution of bone transplantation: molecular, cellular and tissue strategies to engineer human bone. Biomaterials 17: 175-185.

8. Lane JM, Tomin E, Bostrom MP (1999) Biosynthetic bone grafting. Clin Orthop Relat 
Res: S107-117.

9. Damien CJ, Parsons JR (1991) Bone graft and bone graft substitutes: a review of current technology and applications. J Appl Biomater 2: 187-208.

10. Urist MR (1965) Bone: formation by autoinduction. Science 150: 893-899.

11. Cornell CN, Lane JM (1998) Current understanding of osteoconduction in bone regeneration. Clin Orthop Relat Res: S267-273.

12. Cowley SP, Anderson LD (1983) Hernias through donor sites for iliac-bone grafts. $J$ Bone Joint Surg Am 65: 1023-1025.

13. Younger EM, Chapman MW (1989) Morbidity at bone graft donor sites. J Orthop Trauma 3: 192-195.

14. Strong DM, Friedlaender GE, Tomford WW, Springfield DS, Shives TC, et al. (1996) Immunologic responses in human recipients of osseous and osteochondral allografts. Clin Orthop Relat Res: 107-114.

15. Kakiuchi M, Ono K (1996) Preparation of bank bone using defatting, freeze-drying and sterilisation with ethylene oxide gas. Part 2. Clinical evaluation of its efficacy and safety. Int Orthop 20: 147-152.

16. Kakiuchi M, Ono K, Nishimura A, Shiokawa H (1996) Preparation of bank bone using defatting, freeze-drying and sterilisation with ethylene oxide gas. Part 1. Experimental evaluation of its efficacy and safety. Int Orthop 20: 142-146.

17. Spector M (1992) Biomaterial failure. Orthop Clin North Am 23: 211-217.

18. Tengvall P, Lundstrom I (1992) Physico-chemical considerations of titanium as a biomaterial. Clin Mater 9: 115-134.

19. Li J, Habibovic P, Yuan H, van den Doel M, Wilson CE, et al. (2007) Biological performance in goats of a porous titanium alloy-biphasic calcium phosphate composite. Biomaterials 28: 4209-4218.

20. Li JP, Habibovic P, van den Doel M, Wilson CE, de Wijn JR, et al. (2007) Bone ingrowth in porous titanium implants produced by 3D fiber deposition. Biomaterials 28: 2810-2820.

21. Kwon B, Jenis LG (2005) Carrier materials for spinal fusion. Spine J 5: 224S-230S.

22. Ripamonti U (1996) Osteoinduction in porous hydroxyapatite implanted in heterotopic sites of different animal models. Biomaterials 17: 31-35.

23. Yuan H, van Blitterswijk CA, de Groot K, de Bruijn JD (2006) A comparison of bone formation in biphasic calcium phosphate (BCP) and hydroxyapatite (HA) implanted in muscle and bone of dogs at different time periods. J Biomed Mater Res A 78: 139-147.

24. Yuan H, Yang Z, Li Y, Zhang X, De Bruijn JD, et al. (1998) Osteoinduction by calcium phosphate biomaterials. J Mater Sci Mater Med 9: 723-726.

25. Moroni L, Curti M, Welti M, Korom S, Weder W, et al. (2007) Anatomical 3D fiberdeposited scaffolds for tissue engineering: designing a neotrachea. Tissue Eng 13: 2483-2493.

26. Lin CY, Kikuchi N, Hollister SJ (2004) A novel method for biomaterial scaffold inter- 
nal architecture design to match bone elastic properties with desired porosity. J Biomech 37: 623-636.

27. Hutmacher DW (2001) Scaffold design and fabrication technologies for engineering tissues-state of the art and future perspectives. J Biomater Sci Polym Ed 12: 107-124.

28. Healy KE, Rezania A, Stile RA (1999) Designing biomaterials to direct biological responses. Ann N Y Acad Sci 875: 24-35.

29. Sohier J, Hamann D, Koenders M, Cucchiarini M, Madry H, et al. (2007) Tailored release of TGF-beta1 from porous scaffolds for cartilage tissue engineering. Int J Pharm 332: 80-89.

30. Urist MR, Strates BS (1971) Bone morphogenetic protein. J Dent Res 50: 1392-1406.

31. Kirker-Head CA (2000) Potential applications and delivery strategies for bone morphogenetic proteins. Adv Drug Deliv Rev 43: 65-92.

32. Johnson EE, Urist MR, Finerman GA (1988) Repair of segmental defects of the tibia with cancellous bone grafts augmented with human bone morphogenetic protein. A preliminary report. Clin Orthop Relat Res: 249-257.

33. Johnson EE, Urist MR (2000) Human bone morphogenetic protein allografting for reconstruction of femoral nonunion. Clin Orthop Relat Res: 61-74.

34. Kon E, Muraglia A, Corsi A, Bianco P, Marcacci M, et al. (2000) Autologous bone marrow stromal cells loaded onto porous hydroxyapatite ceramic accelerate bone repair in critical-size defects of sheep long bones. J Biomed Mater Res 49: 328-337.

35. Petite H, Viateau V, Bensaid W, Meunier A, de Pollak C, et al. (2000) Tissue-engineered bone regeneration. Nat Biotechnol 18: 959-963.

36. Bruder SP, Kraus KH, Goldberg VM, Kadiyala S (1998) The effect of implants loaded with autologous mesenchymal stem cells on the healing of canine segmental bone defects. $J$ Bone Joint Surg Am 80: 985-996.

37. Derkx P, Nigg AL, Bosman FT, Birkenhager-Frenkel DH, Houtsmuller AB, et al. (1998) Immunolocalization and quantification of noncollagenous bone matrix proteins in methylmethacrylate-embedded adult human bone in combination with histomorphometry. Bone 22: $367-373$.

38. Standring S, Gray H (2008) Gray's anatomy : the anatomical basis of clinical practice. Edinburgh: Churchill Livingstone/Elsevier. xxiv, 1551 p. p.

39. Bilezikian JP, Raisz LG, Martin TJ (2008) Principles of bone biology. San Diego, Calif.: Academic Press. 2 v.

40. Fawcett DW, Bloom W, Raviola E (1994) A textbook of histology. New York: Chapman \& Hall. $x x, 964$ p. p.

41. Frost HM (1987) Bone "mass" and the "mechanostat": a proposal. Anat Rec 219: 1-9.

42. Frost HM (1987) The mechanostat: a proposed pathogenic mechanism of osteoporoses and the bone mass effects of mechanical and nonmechanical agents. Bone Miner 2: 73-85.

43. Burr DB (1993) Remodeling and the repair of fatigue damage. Calcif Tissue Int 53 
Suppl 1: S75-80; discussion S80-71.

44. Mori S, Burr DB (1993) Increased intracortical remodeling following fatigue damage. Bone 14: 103-109.

45. Teitelbaum SL (2007) Osteoclasts: what do they do and how do they do it? Am J Pathol 170: 427-435.

46. Ducy P, Schinke T, Karsenty G (2000) The osteoblast: a sophisticated fibroblast under central surveillance. Science 289: 1501-1504.

47. Karsenty G (1999) The genetic transformation of bone biology. Genes Dev 13: 30373051.

48. Wagner EF, Karsenty G (2001) Genetic control of skeletal development. Curr Opin Genet Dev 11: 527-532.

49. Yamaguchi A, Komori $T$, Suda $T$ (2000) Regulation of osteoblast differentiation mediated by bone morphogenetic proteins, hedgehogs, and Cbfa1. Endocr Rev 21: 393-411.

50. Reddi AH (1997) Bone morphogenetic proteins: an unconventional approach to isolation of first mammalian morphogens. Cytokine Growth Factor Rev 8: 11-20.

51. Wang EA, Rosen V, D’Alessandro JS, Bauduy M, Cordes P, et al. (1990) Recombinant human bone morphogenetic protein induces bone formation. Proc Natl Acad Sci U S A 87: 2220-2224.

52. Siddappa R, Fernandes H, Liu J, van Blitterswijk C, de Boer J (2007) The response of human mesenchymal stem cells to osteogenic signals and its impact on bone tissue engineering. Curr Stem Cell Res Ther 2: 209-220.

53. Kimble JE, White JG (1981) On the control of germ cell development in Caenorhabditis elegans. Dev Biol 81: 208-219.

54. Stocum DL (2004) Amphibian regeneration and stem cells. Curr Top Microbiol Immunol 280: 1-70.

55. Bodine DM, Seidel NE, Orlic D (1996) Bone marrow collected 14 days after in vivo administration of granulocyte colony-stimulating factor and stem cell factor to mice has 10fold more repopulating ability than untreated bone marrow. Blood 88: 89-97.

56. Kiel MJ, He S, Ashkenazi R, Gentry SN, Teta M, et al. (2007) Haematopoietic stem cells do not asymmetrically segregate chromosomes or retain BrdU. Nature 449: 238-242.

57. Yamashita YM, Fuller MT, Jones DL (2005) Signaling in stem cell niches: lessons from the Drosophila germline. J Cell Sci 118: 665-672.

58. Xie T, Spradling AC (2000) A niche maintaining germ line stem cells in the Drosophila ovary. Science 290: 328-330.

59. Spradling A, Drummond-Barbosa D, Kai T (2001) Stem cells find their niche. Nature 414: 98-104.

60. Morrison SJ, Kimble J (2006) Asymmetric and symmetric stem-cell divisions in development and cancer. Nature 441: 1068-1074. 
61. Friedenstein AJ, Chailakhjan RK, Lalykina KS (1970) The development of fibroblast colonies in monolayer cultures of guinea-pig bone marrow and spleen cells. Cell Tissue Kinet 3: 393-403.

62. Edwards RG (2004) Stem cells today: B1. Bone marrow stem cells. Reprod Biomed Online 9: 541-583.

63. Ogawa M (1993) Differentiation and proliferation of hematopoietic stem cells. Blood 81: 2844-2853.

64. Zuk PA, Zhu M, Ashjian P, De Ugarte DA, Huang JI, et al. (2002) Human adipose tissue is a source of multipotent stem cells. Mol Biol Cell 13: 4279-4295.

65. Tosh D, Strain A (2005) Liver stem cells-prospects for clinical use. J Hepatol 42 Suppl: S75-84.

66. Steindler DA, Pincus DW (2002) Stem cells and neuropoiesis in the adult human brain. Lancet 359: 1047-1054.

67. Alessandri G, Pagano S, Bez A, Benetti A, Pozzi S, et al. (2004) Isolation and culture of human muscle-derived stem cells able to differentiate into myogenic and neurogenic cell lineages. Lancet 364: 1872-1883.

68. Zulewski H, Abraham EJ, Gerlach MJ, Daniel PB, Moritz W, et al. (2001) Multipotential nestin-positive stem cells isolated from adult pancreatic islets differentiate ex vivo into pancreatic endocrine, exocrine, and hepatic phenotypes. Diabetes 50: 521-533.

69. Erices A, Conget P, Minguell JJ (2000) Mesenchymal progenitor cells in human umbilical cord blood. Br J Haematol 109: 235-242.

70. Bruder SP, Jaiswal N, Haynesworth SE (1997) Growth kinetics, self-renewal, and the osteogenic potential of purified human mesenchymal stem cells during extensive subcultivation and following cryopreservation. J Cell Biochem 64: 278-294.

71. Bruder SP, Kurth AA, Shea M, Hayes WC, Jaiswal N, et al. (1998) Bone regeneration by implantation of purified, culture-expanded human mesenchymal stem cells. J Orthop Res 16: $155-162$.

72. Kadiyala S, Young RG, Thiede MA, Bruder SP (1997) Culture expanded canine mesenchymal stem cells possess osteochondrogenic potential in vivo and in vitro. Cell Transplant 6: $125-134$.

73. Ferrari G, Cusella-De Angelis G, Coletta M, Paolucci E, Stornaiuolo A, et al. (1998) Muscle regeneration by bone marrow-derived myogenic progenitors. Science 279: 1528-1530.

74. Galmiche MC, Koteliansky VE, Briere J, Herve P, Charbord P (1993) Stromal cells from human long-term marrow cultures are mesenchymal cells that differentiate following a vascular smooth muscle differentiation pathway. Blood 82: 66-76.

75. Dennis JE, Merriam A, Awadallah A, Yoo JU, Johnstone B, et al. (1999) A quadripotential mesenchymal progenitor cell isolated from the marrow of an adult mouse. J Bone Miner Res 14: 700-709.

76. Prockop DJ (1997) Marrow stromal cells as stem cells for nonhematopoietic tissues. 
Science 276: 71-74.

77. Young RG, Butler DL, Weber W, Caplan AI, Gordon SL, et al. (1998) Use of mesenchymal stem cells in a collagen matrix for Achilles tendon repair. J Orthop Res 16: 406-413.

78. Awad HA, Butler DL, Boivin GP, Smith FN, Malaviya P, et al. (1999) Autologous mesenchymal stem cell-mediated repair of tendon. Tissue Eng 5: 267-277.

79. Caplan AI, Bruder SP (2001) Mesenchymal stem cells: building blocks for molecular medicine in the $21^{\text {st }}$ century. Trends Mol Med 7: 259-264.

80. Kai T, Spradling A (2004) Differentiating germ cells can revert into functional stem cells in Drosophila melanogaster ovaries. Nature 428: 564-569.

81. Poulsom R, Alison MR, Forbes SJ, Wright NA (2002) Adult stem cell plasticity. J Pathol 197: 441-456.

82. Janowska-Wieczorek A, Majka M, Ratajczak J, Ratajczak MZ (2001) Autocrine/paracrine mechanisms in human hematopoiesis. Stem Cells 19: 99-107.

83. Calvi LM, Adams GB, Weibrecht KW, Weber JM, Olson DP, et al. (2003) Osteoblastic cells regulate the haematopoietic stem cell niche. Nature 425: 841-846.

84. Koller MR, Manchel I, Palsson BO (1997) Importance of parenchymal:stromal cell ratio for the ex vivo reconstitution of human hematopoiesis. Stem Cells 15: 305-313.

85. Tavassoli M, Takahashi K (1982) Morphological studies on long-term culture of marrow cells: characterization of the adherent stromal cells and their interactions in maintaining the proliferation of hemopoietic stem cells. Am J Anat 164: 91-111.

86. Strobel ES, Gay RE, Greenberg PL (1986) Characterization of the in vitro stromal microenvironment of human bone marrow. Int J Cell Cloning 4: 341-356.

87. Wang QR, Wolf NS (1990) Dissecting the hematopoietic microenvironment. VIII. Clonal isolation and identification of cell types in murine CFU-F colonies by limiting dilution. Exp Hematol 18: 355-359.

88. Castro-Malaspina H, Ebell W, Wang S (1984) Human bone marrow fibroblast colonyforming units (CFU-F). Prog Clin Biol Res 154: 209-236.

89. Klimanskaya I, Chung Y, Meisner L, Johnson J, West MD, et al. (2005) Human embryonic stem cells derived without feeder cells. Lancet 365: 1636-1641.

90. Martin MJ, Muotri A, Gage F, Varki A (2005) Human embryonic stem cells express an immunogenic nonhuman sialic acid. Nat Med 11: 228-232.

91. Wilmut I, Schnieke AE, McWhir J, Kind AJ, Campbell KH (1997) Viable offspring derived from fetal and adult mammalian cells. Nature 385: 810-813.

92. Thomson JA, Itskovitz-Eldor J, Shapiro SS, Waknitz MA, Swiergiel JJ, et al. (1998) Embryonic stem cell lines derived from human blastocysts. Science 282: 1145-1147.

93. Takahashi K, Yamanaka $S$ (2006) Induction of pluripotent stem cells from mouse embryonic and adult fibroblast cultures by defined factors. Cell 126: 663-676. 


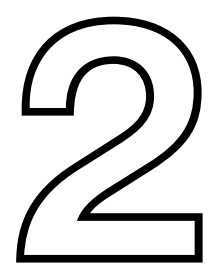




\title{
Chapter 2
}

\section{Factors Influencing the Biological Properties of Mesenchymal Stromal Cell Quality: Implications for Cell Therapy}

\author{
Hugo Alves, Joyce Doorn, Clemens van Blitterswijk, Jan de Boer \\ Department of Tissue Regeneration, MIRA Institute for Biomedical Technology and \\ Technical Medicine, University of Twente, Enschede, The Netherlands.
}

\begin{abstract}
Multipotent mesenchymal stem or stromal cells (MSCs) are considered for various cell-based clinical applications because they are relatively easy to isolate and proliferate, they display multilineage differentiation potential and exhibit favorable trophic and immune-modulatory behavior. However, their relatively low abundance makes in vitro expansion a necessary step prior to clinical usage, which influences their biological properties. In addition, large donor variability is observed as well. In this manuscript, we review current research efforts to elucidate the variables that influence stem cell quality.
\end{abstract}




\section{hMSCs as the golden standard for therapeutic purposes}

Many human diseases are caused by a loss or malfunctioning of tissue homeostasis and many therapeutic strategies aim to restore or replace the cellular defects. In the areas of cell therapy and tissue engineering, cells or cell-based tissue engineered grafts are administrated into the recipient for therapeutic purposes. These therapies have been available for several decades, however, with the current boom of stem cell research, they have regained public awareness by the promises of enhanced tissue repair and the possibilities of treatment of large defects and degenerative diseases.

Autologous transplants are still the most frequently performed treatments, even though allogeneic stem cell therapy is increasing in popularity. Unrelated bone marrow, umbilical-cord blood or mesenchymal stromal cells are utilized as main source for allogeneic transplants $[1,2,3]$, while, allogeneic pancreatic islets $[4,5]$, dopaminergic neurons from fetal tissue [6,7] and human embryonic stem cells (hESC) are currently under investigation and subject of clinical trials as potential future therapies $[8,9]$.

Adult mesenchymal stromal cells (MSCs) currently represent one of the best described cell sources for therapeutic applications. Terms like colony forming unit fibroblast (CFU-F), mesenchymal stem cells, marrow stromal cells or multipotent stromal cells have been used interchangeably to describe these cells of mesodermal origin with multilineage potential [10]. Despite current debate whether or not mesenchymal stem cells is a proper term for these cells, the name rapidly gained a global usage. However, the International Society for Cellular Therapy (ISCT) stated that "multipotent mesenchymal stromal cell" is the recommended designation [11]. This society also emitted a statement describing the minimal criteria to define MSCs: (1) they must be plastic adherent in standard culture conditions on tissue culture flasks; (2) they should express and lack specific surface antigens; 95\% of the MSC population must express CD105, CD73 and CD90, and they must lack expression (less than 2\%) of CD45, CD34, CD14 (or CD11b), CD79 $\alpha$ (or CD19) and HLA class II; (3) the cells should present multipotency (ability to differentiate into osteoblasts, adipocytes and chondrocytes) under standard in vitro differentiation conditions [12].

Human MSCs can be easily isolated from several sources $[13,14,15,16,17,18,19,20]$ and can be differentiated into a full range of functional skeletal tissue cells [21,22]. They present immunomodulatory and trophic actions [23,24] and are clinically applied $[25,26,27,28]$, which makes them good candidates for cell-based therapies. Since they do not express HLA class II, they do not elicit an immune response and, as such, are suitable for allogeneic transplantation, even between mismatched in- 
dividuals [29]. Potential applications include repair of cardiovascular and central nervous system damage, pancreatic, renal, hepatic and solid organ transplantation, as well as, applications in the gastrointestinal tract and both orthopaedic and haematopoietic applications (reviewed by Brooke G. et al.) [26]. Despite their therapeutic potential, there are several aspects that need to be addressed before MSCs can be safely used. One of them is the fact that the yield of prospective isolation is very low, estimated to be between $0.01-0.001 \%$ of total mononuclear cells isolated from the bone marrow [30], or as low as 1 in 3.4x104 [31]. This low frequency makes expansion a necessary step towards clinical applications.

\section{hMSCs donor variation}

One of the problems with the use of hMSCs for therapeutic applications is the big variation in terms of differential potential and biological characteristics of the hMSCs from different donors. Already in 1980, it was observed that the number of CFU-F obtained from a bone marrow aspirate varies between different donors [32]. In addition, it was shown that both growth rate as well as basal ALP levels and ALP levels after induction with osteogenic compounds, vary largely between hMSCs from different donors [33,34]. In our group, we observed that hMSCs from different donors not only differ in ALP expression, but also in their ability to mineralize and to differentiate into the adipogenic lineage [35]. In addition, Kuznetsov et al. demonstrated that besides the variation in performance of hMSCs from different donors, there is also a wide spread difference in growth rate and osteogenic potential between colonies obtained from a single donor [36]. These differences in osteogenic potential, in turn, result in a large variation of bone formation upon implantation, between different donors, as well as, individual colonies $[35,36]$. As of yet, however, the performance of a patient's hMSC population cannot be predicted.

\section{HMSC subpopulations, different isolation procedures and problems associ- ated with hMSC purification.}

MSC cultures comprise a heterogenic population of cells with respect to their differentiation potential and expression of surface markers. Clonal analysis reveals that mono-, bi- and multipotent cells exist and detection of cell surface markers shows subpopulations of cells positive for ALP, STRO-1 and CD146, for example. It seems logical to assume that part of the inter-donor variability can be explained by the relative abundance of subpopulations of MSCs and over time, several methods were developed to isolate pure fractions of MSCs. Seeding different amounts of mononuclear cells per surface area, the enrichment of the MSC population by ficoll/percoll gradients and the utilization of certain cell surface markers (like STRO-1, CD146, etc.) are the most used methods of isolation. Several markers 
were described as being present in MSCs [37], however, currently, there is not a single marker that is unique for MSCs which cannot be found in other cell types. Usually, in this type of procedure, a population expressing one or a certain set or markers, is isolated from the rest of the population of cells, but so far, there is no evidence supporting a better performance of sorted/enriched MSCs versus MSCs isolated by plastic adherence. Although it is thought that CD73, CD105, CD90 and CD44 are highly specific for MSCs and allow to discriminate MSCs from other tissue resident cells, more recently, several studies showed that these markers were ubiquitously expressed on stromal cells from several locations, as well as on skin fibroblasts $[8,38,39]$, which suggests that at best, these markers inform an investigator that the cells assessed are non-haematopoietic and stromal in origin [40]. Another problem is that some of these markers are not stable in culture. Some are lost after passaging, while others are gained even though the cells remain multipotent, indicating that these markers unlikely reflect MSC multipotency. Most likely, many markers expressed by MSCs in vivo are induced by the bone marrow microenvironment or reflect some of the in vivo functions of MSCs that are lost upon plastic adherence and exposure to culture media. Furthermore, a big disadvantage of this selection technique is the extensive time required for the sorting of the particular subpopulation, but also the fact that up to now, it is unknown whether the cells excluded in the sorting process may play an important role in cell therapy.

A few studies have compared the performance of differentially isolated hMSCs. In a study examining the difference between ficoll- and percoll-isolated hMSCs, ficoll-isolated hMSCs showed higher CFU-F efficiency, but no differences were found in terms of expansion capacity or the differentiation potential [41]. When comparing the ficoll- and BMAC-isolation methods, no differences in CFU-F efficiency or differentiation were found between the groups. However, MSCs isolated by the BMAC method demonstrated more bone formation, although this was not significant [42]. Another study compared MSCs isolated from different sources of the same donor and no differences were found between MSCs obtained from trabecular bone and iliac crest aspiration [43,44]. Thus, there is no convincing evidence so far that supports a better performance of sorted/enriched cells versus cells isolated by ficoll gradient or adherence to tissue culture surfaces. Furthermore, there is currently no parameter used to characterize MSCs that can be applied to consistently predict their therapeutic potential, although, some suggestive correlations were already established in certain clinical applications, like the case of renal allograft function after 1 year $[45,46]$.

A common thought is the fact that hMSCs, irrespective of the source or type of isolation used, represent a heterogeneous cell population, even though they become more homogeneous during expansion by natural selection of the cells 
with better proliferative potential. However, MSCs from different donors present an even higher variability in terms of several in vitro characteristics but also in response to stimuli [35].

\section{Consequences of culture expansion on MSC quality}

Generally, hMSCs need to be expanded in vitro before they can be used for clinical applications. However, since in vitro expansion usually results in a loss of differentiation potential and changes in morphology and gene expression (as seen in, for instance, chondrocytes - Fig. 1), concerns exist about how far these cells can be expanded prior to clinical usage without compromising their therapeutic potential.

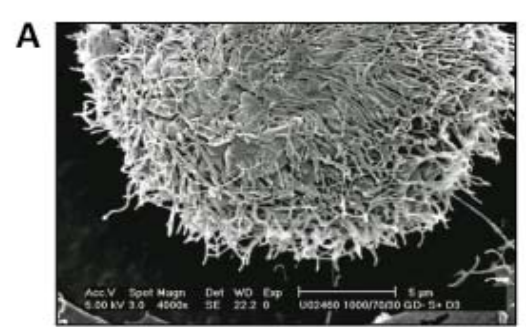

$\underline{3 D}$

Round morphology

Collagen type 2

Glycosaminoglycans

Low integrin

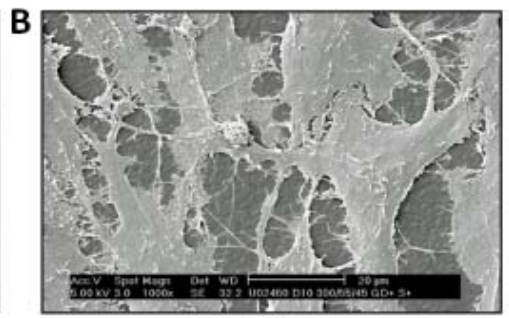

$\underline{\underline{2 D}}$

Spread morphology

Collagen type 1

High integrin

Adapted from T. Woodfield $e t$ al. Biomaterials 2006;27:1043-1053

Figure 1. Morphology of human chondrocytes changes according to substrate composition. Scanning electron microscopy (SEM) micrographs showing cell morphology of expanded human chondrocytes in either low affinity substrates (low PEG content (PEGT/ PBT) films) (A) or substrates promoting high cellular adhesion (high PEG content (PEGT/PBT) films) (B). This study demonstrated that substrates actively impact cellular morphology, gene expression, as well as chondrocyte re-differentiation capacity.

One of the main problems associated with the expansion phase is the loss of multipotency. Already in 2000, Banfi et al. showed that bone marrow stromal cells lose their multipotentiality upon expansion. They also showed that MSC expansion compromises bone formation, since bone formation by nucleated cells freshly isolated from the bone marrow was much more efficient [47]. We observed that MSCs loose the capacity to differentiate into the osteogenic and adipogenic lineage after passage 4/5 [35]. After extensive in vitro expansion, MSCs, like other 
human somatic cells, undergo a phenomenon termed replicative senescence. This state is characterized by a general growth arrest and was initially discovered by Hayflick and Moorhead, who showed that human diploid cells divide a finite number of times in culture [48] and is, therefore, also referred to as the Hayflick limit. Although arrested in their cell cycle, cells are still able to survive for a long period of time without apparent signs of cell death and they become irresponsive to mitogenic stimuli. During this process, the morphology of the cells changes and their proliferation and differentiation potential decreases [35]. They accumulate lipofuscin granules and an increased amount of actin stress fibers. Furthermore, the mean telomere size decreases, the cells start to present $\beta$-galactosidase activity and markers that are associated with senescence and the cells accumulate DNA damage [49,50,51,52] (Fig. 2).

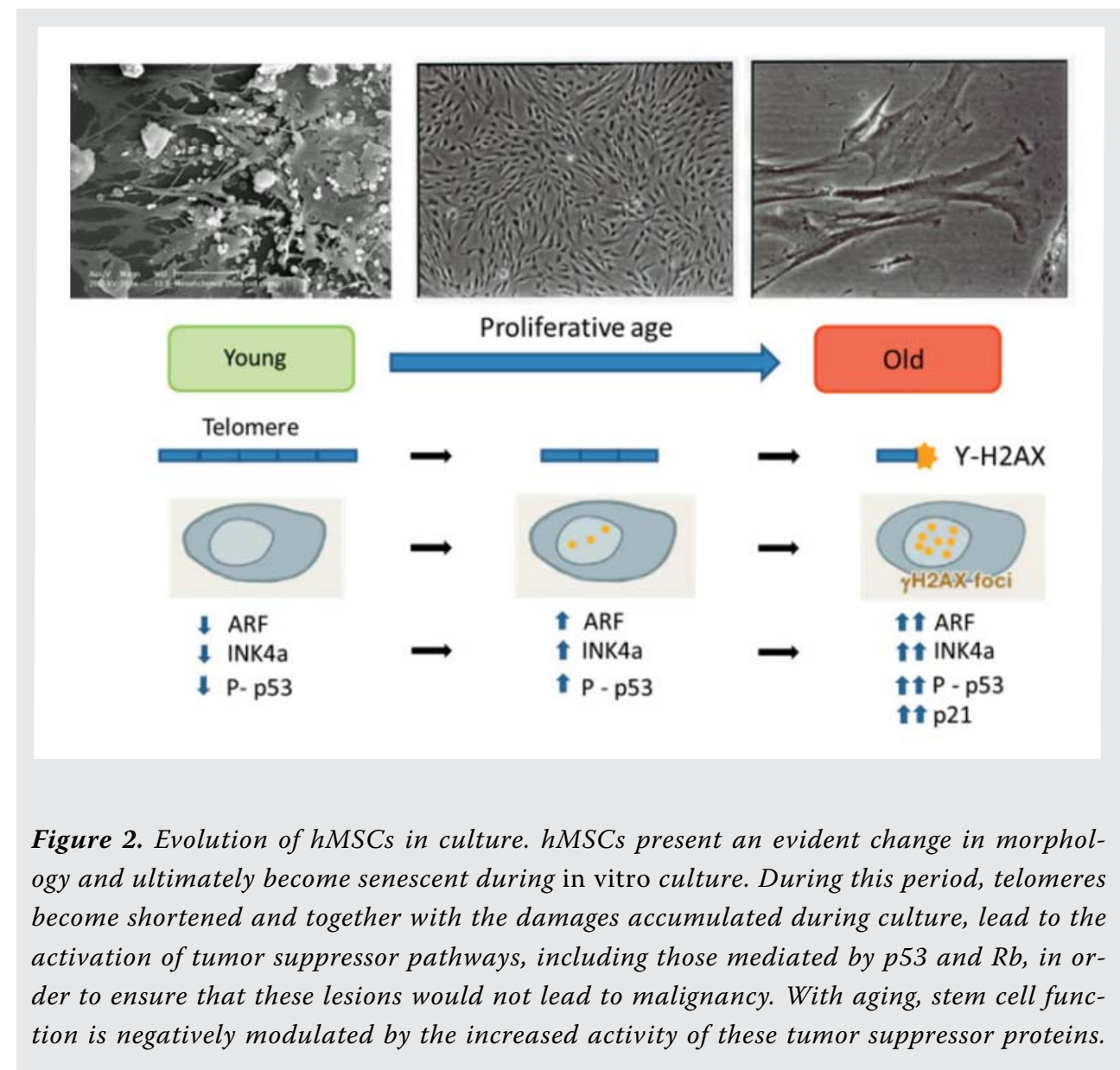


Because human MSCs lack telomerase activity [53,54] and hTERT expression [55], in vitro expansion results in telomere shortening [55,56,57], which was speculated to be the main driving force behind loss of multipotency and senescence. Indeed, several manuscripts describe that forced expression of telomerase in hMSCs not only rescues replicative senescence but also the loss of multipotency $[55,58,59,60,61]$. While many cell types (mammary epithelial cells, osteoblasts, neural progenitor cells, among others) have been reported to be immortalized by the expression of hTERT $[62,63,64,65,66,67]$, others such as HDK, HMEC, HPrEC and even lung fibroblasts, like the WI38 line, cannot be immortalized by the expression of hTERT alone $[68,69,70]$. Often, stress imposed by inadequate culture conditions induces senescence due to accumulation of p16 (INK4A), and it was shown that the introduction of Bmi-1 could inhibit p16 (INK4a) expression and extended the life span of many human cell types which was not possible by telomerase expression alone $[71,72,73]$. It is known that cellular senescence can be induced by factors such as oncogene overexpression, oxidative stress, DNA damage and improper cell-cell contacts [74]. We recently delineated a link between accumulation of DNA damage and loss of multipotency in expanding hMSCs [75]. Although telomerase dysfunction might be the principal trigger to induce cellular senescence, loss of multipotency happens earlier in culture, in a phase when hMSC are still actively dividing and, therefore, other reasons could be involved in loss of multipotency. We showed that loss of multipotency coincided with the accumulation of DNA damage and the consequent activation of the DNA damage response pathways [75]. Furthermore, induction of mild DNA damage, accelerated the loss of multipotency, without significantly affecting proliferation. It suggests that early accumulation of DNA damage leads to loss of multipotency and that DNA damage increases during the expansion phase, ultimately leading to replicative senescence by telomere dysfunction. Part, if not all, of the senescent program is triggered by DNA damage accumulated during the expansion phase.

Although there are several mechanisms/pathways to circumvent DNA damage accumulation, it seems the damage accumulated during protracted culture is more than what cells are able to repair. An example of the consequences of the accumulation of DNA damage, in this case by malfunction of the DNA repair machinery is the hereditary syndrome trichothiodystrofy (TTD). Mice presenting this mutation present symptoms of premature aging. (Fig. 3). 


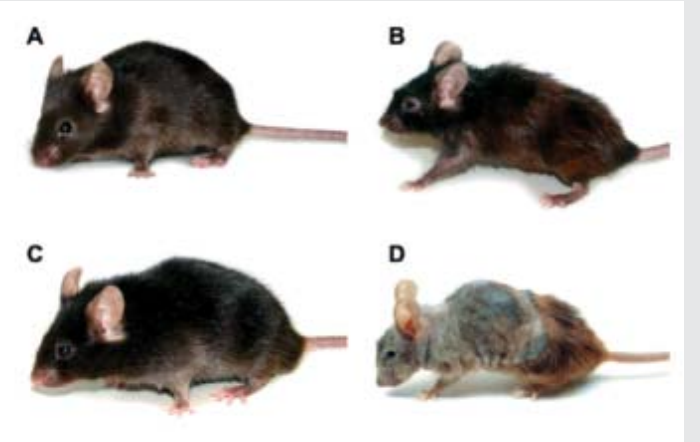

J de Boer et al. Science 2002;296:1276-1279

Figure 3. Trichothiodystrofy (TTD) mice versus wild type (Wt). Mice shown are Wt $(\boldsymbol{A}$ and $\boldsymbol{C}$ ) and TTD (B and $\boldsymbol{D})$ at age 3 months ( $\boldsymbol{A}$ and $\boldsymbol{B})$ and 15 to 16 months (C and $\boldsymbol{D})$. These mice develop normally but present premature aging phenotypes (progeroid symptoms) at the age of 3 to 4 months and symptoms become increasingly severe. The only difference to the Wt is only a single point mutation on one gene related to DNA damage repair. As with these mice, increased accumulation of DNA damage on stem cells while in culture, lead not only to loss of multipotency, but to senescence phenotypes.

Since expansion is a necessary step towards clinical applications, there is a need to investigate the genomic stability of hMSCs after protracted culture and to assure that no malignant transformation occurs.

\section{Genomic stability of hMSCs in culture}

When MSCs isolated from 10 healthy donors were propagated until senescence, array-CGH and cytogenetic analyses showed that MSCs did not present chromosomal abnormalities or telomerase activity and hTERT transcripts were not expressed [53]. In another study where the cell cycle properties of human and rhesus bone marrow and adipose-derived MSCs were evaluated [76], it was concluded that, unlike rhesus MSCs, human cells did not develop polyploidy throughout the prolonged culture and there were no chromosomal rearrangements detected in any samples from human MSCs at any passage. Spontaneous malignant transformation of adipose-derived hMSCs was reported after in vitro expansion [77] and more recently spontaneous malignant transformation of bone marrow derived MSCs was also described [78]. The authors showed that $46 \%$ of hMSCs in culture become transformed MSCs. The cells that have escaped senescence, showed increased proliferation, an altered morphology and phenotype and were extremely tumorigenic upon implantation in nude mice [78]. However, unpublished data from multiple labs (personal communication), including our own from a bank of 
over 200 donors, never demonstrated neither malignant transformation of bone marrow-derived hMSCs after in vitro expansion under normal culture condition, nor tumorigenesis in vivo. It was then difficult to explain the contradicting results from different laboratories but it raised some questions about possible cross-contaminations that could have occurred while culturing, even though one of the studies was performed in two independent laboratories [79]. Recent data shed some light on this controversy, and by performing comprehensive DNA fingerprinting of the cells and the corresponding transformed mesenchymal stem cells (TMC) the authors of the referred papers revealed that none of the TMC in the two laboratories had short tandem repeats similar to the original hMSC population [80]. Furthermore, the DNA fingerprint of the TMC obtained in both laboratories, were compared to reference commercially available cell lines, and revealed that the observed transformation phenotypes were actually a cross-contamination of the original hMSCs with osteosarcoma, fibrosarcoma or with human glioma cell lines. Previously, it was already shown that the fibrosarcoma cell line (HT1080) can remain undetected in MSC cultures for months [81], and the same was true for this study. Although the elucidation of these mistakes brings some relief to the possible utilization of hMSCs for clinical applications, it does stress the necessity to take regular characterizations of the normal cells into account, especially when MSCs are culture-expanded for therapeutic purposes.

\section{Effect of donor age on stem cell quality}

A number of studies have been performed trying to correlate the age of the donor with MSC differentiation potential, total yield of cells possible to be obtained and even lifespan of their hMSCs. Although few reports claimed a negative trend between donor age and hMSC performance, and although it is unquestionable that with age of the individuals, there is a clear loss of tissue function and repair, generally, no clear correlation is shown. It has to be noted, however, that the interpretation of data with respect to replicative lifespan is plagued by large inter-individual variation resulting in relatively low correlations. Fetal MSCs were claimed to show greater osteogenic differentiation capacity than adult MSCs both in vitro and in vivo [82]. Moreover, it was shown that this increase in differentiation capacity from fetal cells is not only restricted to osteogenesis, but also that these cells readily undergo myogenic differentiation while adult MSCs do not [83]. Furthermore, in comparison to adult MSCs, fetal MSCs grew faster, yielded more population doublings, had longer telomeres that were maintained longer due to high levels of telomerase activity, senesced later and expressed pluripotency stem cell markers Oct-4, Nanog, Rex-1, SSEA-3, SSEA-4, Tra-1-60 and Tra-1-81 [82]. The increased differentiation capacity of these fetal cells is speculated to arise from the fact that fetal MSCs represent a more immature population of stem cells, 
as compared to adult MSCs [82]. When adult MSCs of individual donors are isolated under standard conditions, large differences are observed in their biological properties. Though it thus has been shown that hMSCs from young donors $(<18$ years) give more bone in vivo than hMSCs from adults [36], no general consensus exists about the correlation between the bone forming capacity of hMSCs and the age of the donor when only adult donors ( $>18$ years) are taken into account.

Nishida et al. [84] also have shown that the highest levels of ALP-positive colony-forming-units-fibroblastic (CFU-F) were observed in the young group, particularly in the individuals under 10 years of age, after which the CFU-F yield sharply decreases reaching lower numbers by the age of 20. These high levels of CFU-F seem to coincide with the phase of skeletal growth and maturation, however, like in the previous mentioned articles, they show that osteogenic features like ALP activity and capability of formation of calcified nodules were maintained even in the older donors [84]. Although hMSCs from pre-puberty or fetal donors were reported by some authors to be more multipotent, there is no clear difference in the differential potential of cells originated from adult donors. Two studies show that the number of MSCs with osteogenic potential [ALP+ colony-forming-unitfibroblasts (CFU-Fs/ALP+)] declines with increasing age $[84,85]$. In another publication, a decrease in maximal lifespan and accelerated senescence of bone marrow stromal cells was observed with increasing age [52]. However, no differences in senescence-associated $\beta$-galactosidase positive cells and mean telomere length in early passage cells obtained from young and old donors were detected in this study and irrespective of the age of the donor, similar amounts of mineralization in vitro and normal lamellar bone in vivo were formed. Some other studies present contradictory results. In a study of 99 patients undergoing corrective surgery, the colony forming efficiency of hMSCs isolated from the patients did not show a correlation to age, disease or gender [86]. On the other hand, a significant reduction in colony size with increasing age was found which indicates a change in cell proliferative potential with age [86]. The same phenomenon was found in another study with 59 patients by the same authors [87]. In contrast with these findings, a study by Stenderup et al. on 51 individuals, showed that both the colony-forming efficiency, the average CFU-F size and the cell density per colony were the same between young and old patients [88]. Furthermore, the amount of ALP+ CFU-Fs and ALP+ cells did not differ between groups and no differences were found in bone formation between hMSCs from young or old donors [89].

In order to further elucidate these rather contradictory results, three large studies were conducted. Two have shown a negative correlation between donor age and proliferative capacity $[90,91,92,93]$. However, a closer inspection of the data of these studies shows that in the first study no correlation existed when, 
for yet unknown reasons, data from cadaveric material was removed and in the second study, the relation only existed when cell lines derived from (pre-) diabetic patients were included in the study.

Cultures of human cells have been reported to present a negative correlation between proliferative lifespan and the age of the donor from whom the culture was established $[90,92,94,95,96,97,98]$. This model was also supported by the reported decline in colony-forming capacity of older cells $[99,100]$ and by the decrease in proliferative potential of cells derived by several disease states such as diabetes $[92,101]$, Werner's Syndrome [90,102,103,104,105], Hutchinson-Gilford syndrome [103] and Down's Syndrome [103,106]. This phenomenon has contributed to the general notion that the proliferative lifespan of cells in culture reflects the physiological age as well as pathological states of the donor from which cells were isolated. However, the problem with these studies was the fact that hMSCs were not isolated from healthy individuals and that in others there were not enough donors in the studies to make it representative of the full population.

To conclude this discussion, Vincent Christofalo and co-workers re-evaluated the relationship between replicative potential and donor age by determining the replicative lifespan of 124 skin fibroblast cell lines established from healthy donors of different ages from the Baltimore Longitudinal Study of Aging [107]. He did not find a significant change in proliferation potential with donor age, nor did he find significant differences between fetal and postnatal derived cultures in terms of lifespan, even though the first presented higher initial growth rates and $[3 \mathrm{H}]$ thymidine incorporation. In addition, a comparison of cell lines established from individuals sampled sequentially at different ages failed to reveal any significant trends. In our own lab, we investigated 61 healthy donors widely varying in age, and found no correlation between the age of the donor and rate of proliferation, ALP level, in vitro mineralization or ectopic bone formation in nude mice [manuscript in preparation] (Chapter 6).

These results clearly demonstrate that there is no significant donor age-dependent change in proliferative lifespan when cell lines are established from healthy individuals and a uniform biopsy site is used. Furthermore, with respect to clinical applications, this data shows that for cell-based therapies the age of the donor does not seem to be of relevance, since MSCs from older donors have a similar differentiation potential and lifespan.

More important than the age of the donor for the outcome of clinical applications seems to be the extent that hMSCs need to be expanded in vitro prior to clinical usage and the culture conditions that cells face while in culture. 


\section{Sources of damage while culturing}

In order to replace damaged tissue and to maintain a proper physiological function, it would be logical to assume that stem cells have a lifespan equal to the organism they reside in, meaning they would have to undertake long replicative histories [108]. Even though in vitro this can never be achieved, the ex vivo environment and signals might be inducing the accumulation of DNA damage from intracellular and extracellular sources such as reactive oxygen species [109]. Ex vivo, stem cells face a completely different environment, i.e. different types and concentrations of growth factors and nutrients, different extracellular matrix, different oxygen tensions and different mechanical properties and adhesion surfaces. Cellular senescence of hMSCs could be induced by a variety of stimuli that can be both intrinsic (telomere uncapping) or extrinsic to the cells (oxidative stress, DNA damage, improper cell-cell contacts) [74] (Fig. 4). All these factors might play a role in the observed limited expansion capacity.

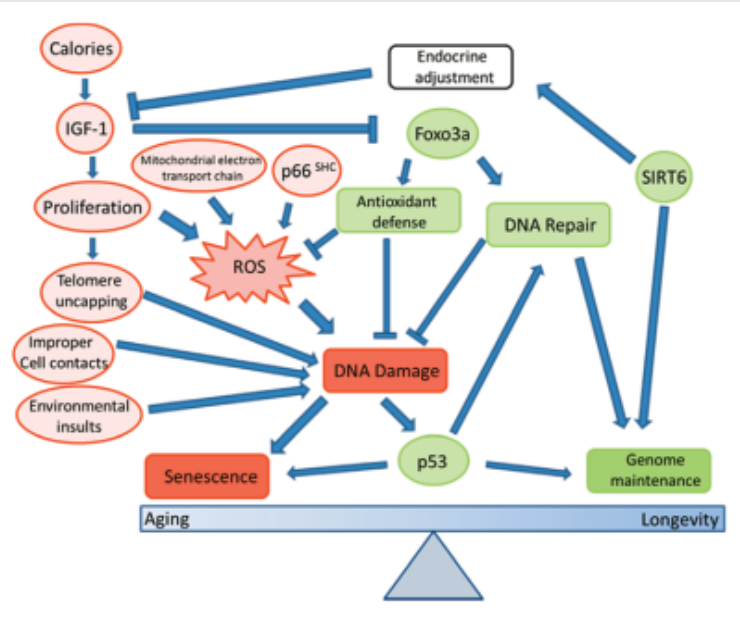

Figure 4. hMSC regulation. Regulation between aging and longevity is a delicate balance between expression of tumor suppressor genes (consequence of both intrinsic and extrinsic signals) and the contra-balance of the expression of genes whose function is to protect against DNA damage (antioxidants, DNA repair and genome maintenance related genes). During culture, when this balance gets affected, the homeostasis can easily change. All these signals act in a coordinate fashion to ensure longevity, however, when the accumulation of DNA damage becomes critical, cells enter a senescence program, ultimately, leading to aging and cellular death. The mechanisms that protect against cancer are balanced against those that ensure longevity. A striking example being the cellular gatekeeper 553 that is antagonistically pleiotropic, presenting both beneficial (by suppress aging in young age by regulating senescence and therefore, avoiding cancer) and deleterious effects to organismal aging (by promoting aging in late life). 
There are several factors that clearly affect the expansion capacity and the quality of hMSCs, of which the choice of serum, the culture conditions, and the oxygen levels are the most important ones.

\section{Choice of serum or serum-free medium?}

Fetal bovine serum (FBS) and fetal calf serum (FCS) are most commonly used, but there is no consistent usage of a unique source of serum. Due to the thousands of proteins that the serum contains and the batch-to-batch variation it is not clear which serum is best for MSC expansion [110]. Groups working with hMSCs typically compare and select the batch of serum that induces best proliferation and differentiation both in vitro and in vivo. Then usually, a large volume of serum is purchased in order to perform experiments with the same batch of serum to avoid constant checks on serum quality. However, for clinical application the usage of xenogeneic serum-free medium would be desirable. These media, though promising in a conceptual way, still present controversial results amongst the literature and this could reflect the different serum-free medium compositions being tested. Platelet lysate was investigated as a possible substitute for FBS and FGF-2 and although stromal vascular fraction cells (SVF) freshly isolated from human adipose tissue could be cultured in this medium, they were arrested shortly after the first passage, showing the limited use of this medium alternative for clinical applications [111]. However, platelet lysate was described as an alternative for the growth of several cell lines including Sp2/0 (myeloma cells), 39.5 (hybridoma cells), Hel299 (fibroblast cells), HepG2 (hepatocytic cells) and Vero (African green monkey transformed kidney epithelial cells) [112]. While some reports claim that serumfree medium leads to inhibition of wound healing activities of corneal stromal fibroblasts in vitro [113], and that it significantly reduces proliferation [114], others show that the proliferation and differentiation potential is maintained $[115,116,117,118,119]$ and some even claim enhanced proliferation in serum-free medium [120,121]. Despite these initial achievements, quite some research is still required to provide alternative serum replacements and to show their efficacy also in vivo, since most of the comparative studies were only performed in vitro.

\section{Oxygen levels}

Culturing in vitro can represent a foreign and hostile environment for cells, not only in terms of nutrient changes, but also in the type of signals cells are facing. With every medium change the cells need to adapt, and any change in culture conditions may favor cells carrying a genetic modification, since any modification that confers a growth advantage will result in a rapid displacement of the slower growing population. 
The fact that cells are cultured in a hyperoxia environment is also often used to claim enhanced oxidative damage and to explain the decrease in differentiation potential and lifespan. Human cells cultured under hypoxic conditions indeed seem to present an extended lifespan and delayed replicative senescence as compared to cells grown in normoxic conditions. The reactive oxygen species (ROS) levels of the cells in the different conditions do not exhibit significant differences. Hypoxia-cultured cells were even reported to have a slightly higher oxidative status and lower levels of antioxidant enzymes like SOD (superoxide dismutase) as compared to normoxia-cultured cells [122]. Although mouse cells are much more sensitive to oxygen levels than human cells, virtually all stem cells proliferate better under lower oxygen levels than the traditional $21 \%$ oxygen environments. It was even speculated that these low oxygen levels might reflect the normal relatively low oxygen niche of the marrow. One of the problems associated with growing cells in hypoxia is the fact that the low oxygen concentration promotes certain differentiation pathways over others. Muscle stem cells and MSCs for example, tend to undergo myogenesis rather than adipogenesis in oxygen levels below $21 \%$ [123]. This type of observation is of crucial importance since it suggests that there are oxygen-reponsive mechanisms that can promote differentiation of one lineage in favor of others. Similarly, temporary exposure of MSCs to hypoxia leads to persistent down-regulation of several osteogenic markers while increasing the expression of angiogenic factors [124]. There is also one report on attenuation of the differentiation capacity of hMSCs after being cultured in reduced oxygen tension [125]. Unfortunately, the practical issues in controlling oxygen levels in cultures within the laboratories or clinical setups are hampering the usage of more physiologic conditions, since the current technologies do not allow the exquisite control over oxygen in vitro that is accomplished in vivo. The available incubators do not prevent reperfusion of room air into the incubators and the oxygen levels are not the same as physiological levels. Furthermore, the oxygen levels are difficult to maintain precisely. In addition, medium changes under low oxygen levels are extremely labor extensive and require special equipment [126].

\section{Improving stem cell quality}

As mentioned above, the prospective isolation of hMSCs is very low and the obtained population of cells is not only heterogeneous but loses its differentiation potential after expansion, making it less effective for cell therapies. It has been a long quest for the search of a continuous and a more homogenous source of hM$\mathrm{SCs}$ with retained differentiation potential. In order to achieve that, researchers started to derive human cell lines from MSCs. Many cell biologists tried to immortalize cells from several tissues by using among others viral oncogenes like the Simian virus 40 (SV40) T antigen [127], Epstein Barr virus (EBV) [128], Adenovi- 
rus E1A and E1B [129], and human Papilomavirus (HPV) E6 and E7 [130].

Although initial experiments were successful to overcome senescence, the introduction of these oncogenes was of limited use since it was either not efficient or perturbed the differentiation programs of the transformed cells $[131,132,133,134]$. Since telomere shortening is known to be one of the mechanisms driving cellular senescence [135], the next attempts were to clone the catalytic unit of the human telomerase gene (hTERT) under a constitutive promoter [136,137]. The clones obtained could be kept in culture for long periods of time and the differentiation capacity was maintained or even enhanced with extensive in vitro expansion $[55,58,61]$. When these works were submitted, many of the reported cell lines had proceeded for 20 PD beyond their normal senescence point and not only continued to grow vigorously but also showed a normal karyotype and maintained a youthful morphology. Similar results were obtained with three different primary cell types (retinal epithelial cells, foreskin fibroblasts, and vascular endothelial cells) attesting to the universal role of telomere shortening in the senescence of human cells $[136,137,138]$. Later on, it was shown that it was not that easy to immortalize all cell types. Kiyono et al. demonstrated that in keratinocytes and mammary epithelial cells for example, immortalization does not only require the expression of hTERT but also the inactivation of the Rb/p16INK4 tumor-suppressor pathway [68]. The same was demonstrated for human mammary fibroblasts and endothelial cells [139]. Even some cell lines previously described as being immortal after the introduction of hTERT, were reported to enter normal senescence due to stress imposed by inadequate culture conditions. On many of these cell types, proliferation was blocked via the expression of the tumor supressors pRB and p16, and therefore it has been show that when hTERT was combined with BMI-1 (a protein inhibiting p16), immortalization could be induced in hMSCs and other cell types where hTERT expression alone was not enough $[71,72,73]$. These results, however, showed that by genetic manipulation, the lifespan of primary cells could be extended and that multipotency could be maintained, at least in some of the clones.

Another important breakthrough was achieved in 1996 and 1997 when Campbell et al. showed, for the first time, that a live mammalian offspring (sheep) could be produced after nuclear transfer from an established cell line [140,141]. Dolly was cloned by taking nuclei from adult mammary gland cells, inducing them into a quiescence state by serum starvation and then fusing them into sheep eggs whose own nuclei had been removed.

Then, another major discovery was done in late 2006 when Takahashi et al. managed to derive pluripotent cells, termed induced pluripotent stem cells (iPS), 
from differentiated somatic cells by introducing defined factors [142]. That paper was the beginning of the discoveries behind the creation of iPS. In the initial approach factors were screened that could induce the desired pluripotent state after which it was discovered how many were really necessary for that purpose. Now, it is pretty much established that with only four factors iPS can be derived from many somatic cells [143]. Since these cells have a similar behavior as embryonic stem cells, they raised the idea that patient-specific pluripotent cells could be produced to treat several diseases. Currently, new discoveries suggest that endogenous expression levels of critical genes required for reprogramming tissue-specific somatic cells could replace the corresponding exogenous gene expression via viral transduction and that the use of a combined chemical and genetic approach to induce iPS can be a way of reducing the need for viral vectors [144,145]. Despite the promising outcome of these landmark results, two concerns remain. First, the change in gene expression that occurs by the random integration of new genes in the genome (insertional mutagenesis), by the use of viral vectors and second the acquisition of tumorigenic potential by these cell lines. In an attempt to overcome these problems, three recent publications demonstrate the possibility of induction of iPS without viral integration. In the first approach, adenoviruses were used to transport the four genes into skin and liver cells of mice [146]. Since the adenovirus does not combine its own genes with the targeted host, the danger of creating tumors is eliminated, although this method was not yet tested in human cells. The second approach demonstrated the possibility to reprogram cells by using plasmids instead of viral vectors, although the efficiency was much lower [147]. The third approach consisted of the delivery of the four reprogramming proteins (Oct4, Sox2, Klf4, and C-Myc) by fusing them with a cell-penetrating peptide [148]. One of the main negative aspects of reprogramming remains the low efficiency of the method; only $0.1 \%$ of the cells are thought to be reprogrammed. Despite these limitations, these cell lines can be used as a continuous source of cells to study mechanisms or signaling pathways in vitro and once all these problems are overcome, these cell lines offer great clinical potential. However, caution must be taken and thorough evaluation of these cell lines is required before they can be used in clinical applications to circumvent complications. Even if clinical applications are still far away, the described studies were very novel with the idea that somatic cells can be reprogrammed to a pluripotent state thus making them potential candidates for specific applications where autologous cells can be employed, thus reducing the chance of rejection. 


\section{The concept of rejuvenated MSCs}

A rather unexplored concept is that of "rejuvenated mesenchymal stem cells" (rSC), produced by interfering with the environment or signaling of the cells. In contrast to iPS, rejuvenated mesenchymal stromal cells will not represent a risk of tumorigenesis and may provide potent autologous cells for regenerative therapy. Proof of principle for this concept is the work by Conboy et al., where aged progenitor cells were rejuvenated by exposing them to a young systemic environment [149]. Their results suggest that there are systemic factors that can modulate the molecular signaling pathways critical in the activation of tissue-specific progenitor cells. While in young animals regeneration is successfully promoted, in older animals the systemic environment either fails to promote or actively inhibits successful tissue regeneration. Their work also demonstrated that the decline of tissue regenerative potential with age can be reversed through modulation of systemic factors. This suggests that tissue-specific stem and progenitor cells retain much of their intrinsic proliferative potential even when old, but those age-related changes in the systemic environment and niche in which progenitor cells reside preclude full activation of these cells for productive tissue regeneration.

While it is a fact that expanded hMSCs lose their multipotency after expansion, there are ways to manipulate them and to possibly overcome this problem, by either adding systemic factors or via genetic manipulation to produce cells with higher potential for therapeutic applications. Since DNA damage has been shown to be linked to the loss of multipotency of hMSCs after protracted culture [75], screening for compounds that can reduce or alleviate this DNA damage accumulation would be highly beneficial. Screening for compounds by using hMSCs instead of cell lines can not only contribute to new pharmaceutical development but also to a faster transition from bench to bedside.

Further work is then needed to elucidate the systemic environment cells face, hoping to ultimately reach a protocol, where hMSCs can be expanded in vitro, without the detrimental consequences that are currently associated with it. These discoveries will not only be important to provide cells with higher differentiation potential to be used in the clinic, but may allow the opportunity to identify novel genes relevant for the maintenance of the differentiation potential.

\section{Financial contributions}

The authors gratefully acknowledge the support of the TeRM Smart Mix Program of the Netherlands Ministry of Economic Affairs and the Netherlands Ministry of Education, Culture and Science and The Netherlands Technology Foundation (STW grant TGT.6745). 


\section{References:}

1. Gluckman E, Broxmeyer HA, Auerbach AD, Friedman HS, Douglas GW, et al. (1989) Hematopoietic reconstitution in a patient with Fanconi's anemia by means of umbilical-cord blood from an HLA-identical sibling. $N$ Engl J Med 321: 1174-1178.

2. Fanning LR, Hegerfeldt Y, Tary-Lehmann M, Lesniewski M, Maciejewski J, et al. (2008) Allogeneic transplantation of multiple umbilical cord blood units in adults: role of pretransplant-mixed lymphocyte reaction to predict host-vs-graft rejection. Leukemia 22: 1786-1790.

3. Le Blanc K, Ringden O (2006) Mesenchymal stem cells: properties and role in clinical bone marrow transplantation. Curr Opin Immunol 18: 586-591.

4. Otonkoski T, Gao R, Lundin K (2005) Stem cells in the treatment of diabetes. Ann Med 37: 513-520.

5. Sumi S (2010) Regenerative medicine for insulin deficiency: creation of pancreatic islets and bioartificial pancreas. J Hepatobiliary Pancreat Sci.

6. Mendez I, Vinuela A, Astradsson A, Mukhida K, Hallett P, et al. (2008) Dopamine neurons implanted into people with Parkinson's disease survive without pathology for 14 years. Nat Med 14: 507-509.

7. Astradsson A, Cooper O, Vinuela A, Isacson O (2008) Recent advances in cell-based therapy for Parkinson disease. Neurosurg Focus 24: E6.

8. Wagner W, Wein F, Seckinger A, Frankhauser M, Wirkner U, et al. (2005) Comparative characteristics of mesenchymal stem cells from human bone marrow, adipose tissue, and umbilical cord blood. Exp Hematol 33: 1402-1416.

9. Mayor S (2010) First patient enters trial to test safety of stem cells in spinal injury. $B M J$ 341: c5724.

10. Bianco P, Robey PG, Simmons PJ (2008) Mesenchymal stem cells: revisiting history, concepts, and assays. Cell Stem Cell 2: 313-319.

11. Horwitz EM, Le Blanc K, Dominici M, Mueller I, Slaper-Cortenbach I, et al. (2005) Clarification of the nomenclature for MSC: The International Society for Cellular Therapy position statement. Cytotherapy 7: 393-395.

12. Dominici M, Le Blanc K, Mueller I, Slaper-Cortenbach I, Marini F, et al. (2006) Minimal criteria for defining multipotent mesenchymal stromal cells. The International Society for Cellular Therapy position statement. Cytotherapy 8: 315-317.

13. Zvaifler NJ, Marinova-Mutafchieva L, Adams G, Edwards CJ, Moss J, et al. (2000) Mesenchymal precursor cells in the blood of normal individuals. Arthritis Res 2: 477-488.

14. Tuli R, Tuli S, Nandi S, Wang ML, Alexander PG, et al. (2003) Characterization of multipotential mesenchymal progenitor cells derived from human trabecular bone. Stem Cells 21: 681-693. 
15. De Bari C, Dell'Accio F, Tylzanowski P, Luyten FP (2001) Multipotent mesenchymal stem cells from adult human synovial membrane. Arthritis Rheum 44: 1928-1942.

16. Bosch P, Musgrave DS, Lee JY, Cummins J, Shuler T, et al. (2000) Osteoprogenitor cells within skeletal muscle. J Orthop Res 18: 933-944.

17. Boquest AC, Shahdadfar A, Fronsdal K, Sigurjonsson O, Tunheim SH, et al. (2005) Isolation and transcription profiling of purified uncultured human stromal stem cells: alteration of gene expression after in vitro cell culture. Mol Biol Cell 16: 1131-1141.

18. Young HE, Steele TA, Bray RA, Hudson J, Floyd JA, et al. (2001) Human reserve pluripotent mesenchymal stem cells are present in the connective tissues of skeletal muscle and dermis derived from fetal, adult, and geriatric donors. Anat Rec 264: 51-62.

19. De Bari C, Dell'Accio F, Luyten FP (2001) Human periosteum-derived cells maintain phenotypic stability and chondrogenic potential throughout expansion regardless of donor age. Arthritis Rheum 44: 85-95.

20. Campagnoli C, Roberts IA, Kumar S, Bennett PR, Bellantuono I, et al. (2001) Identification of mesenchymal stem/progenitor cells in human first-trimester fetal blood, liver, and bone marrow. Blood 98: 2396-2402.

21. Prockop DJ (1997) Marrow stromal cells as stem cells for nonhematopoietic tissues. Science 276: 71-74.

22. Pittenger MF, Mackay AM, Beck SC, Jaiswal RK, Douglas R, et al. (1999) Multilineage potential of adult human mesenchymal stem cells. Science 284: 143-147.

23. Ringden O, Uzunel M, Rasmusson I, Remberger M, Sundberg B, et al. (2006) Mesenchymal stem cells for treatment of therapy-resistant graft-versus-host disease. Transplantation 81: 1390-1397.

24. Caplan AI (2009) Why are MSCs therapeutic? New data: new insight. J Pathol 217: 318-324.

25. Meijer GJ, de Bruijn JD, Koole R, van Blitterswijk CA (2007) Cell-based bone tissue engineering. PLoS Med 4: e9.

26. Brooke G, Cook M, Blair C, Han R, Heazlewood C, et al. (2007) Therapeutic applications of mesenchymal stromal cells. Semin Cell Dev Biol 18: 846-858.

27. Kumar S, Chanda D, Ponnazhagan S (2008) Therapeutic potential of genetically modified mesenchymal stem cells. Gene Ther 15: 711-715.

28. Mayhall EA, Paffett-Lugassy N, Zon LI (2004) The clinical potential of stem cells. Curr Opin Cell Biol 16: 713-720.

29. Horwitz EM, Prockop DJ, Fitzpatrick LA, Koo WW, Gordon PL, et al. (1999) Transplantability and therapeutic effects of bone marrow-derived mesenchymal cells in children with osteogenesis imperfecta. Nat Med 5: 309-313. 
30. Friedenstein AJ, Latzinik NW, Grosheva AG, Gorskaya UF (1982) Marrow microenvironment transfer by heterotopic transplantation of freshly isolated and cultured cells in porous sponges. Exp Hematol 10: 217-227.

31. Wexler SA, Donaldson C, Denning-Kendall P, Rice C, Bradley B, et al. (2003) Adult bone marrow is a rich source of human mesenchymal 'stem' cells but umbilical cord and mobilized adult blood are not. Br J Haematol 121: 368-374.

32. Castro-Malaspina H, Gay R, Resnick G, Kapoor N, Meyers P, et al. (1980) Characterization of human bone marrow fibroblast colony-forming cells (CFU-F) and their progeny. Blood 56: 289-301.

33. Donald G. Phinney, Gene Kopen, William Righter, Stephen Webster, Nicola Tremain, et al. (1999) Donor variation in the growth properties and osteogenic potential of human marrow stromal cells. Journal of Cellular Biochemistry 75: 424-436.

34. Jaiswal N, Haynesworth, S.E., Caplan, A.I., Bruder, S.P. (1997) Osteogenic differentiation of purified, culture-expanded human mesenchymal stem cells in vitro. Journal of Cellular Biochemistry 64: 295-312.

35. Siddappa R, Licht R, van Blitterswijk C, de Boer J (2007) Donor variation and loss of multipotency during in vitro expansion of human mesenchymal stem cells for bone tissue engineering. J Orthop Res 25: 1029-1041.

36. Kuznetsov SA, Krebsbach PH, Satomura K, Kerr J, Riminucci M, et al. (1997) Singlecolony derived strains of human marrow stromal fibroblasts form bone after transplantation in vivo. J Bone Miner Res 12: 1335-1347.

37. da Silva Meirelles L, Caplan AI, Nardi NB (2008) In search of the in vivo identity of mesenchymal stem cells. Stem Cells 26: 2287-2299.

38. Ishii M, Koike C, Igarashi A, Yamanaka K, Pan H, et al. (2005) Molecular markers distinguish bone marrow mesenchymal stem cells from fibroblasts. Biochem Biophys Res Commun 332: 297-303.

39. Jones EA, English A, Henshaw K, Kinsey SE, Markham AF, et al. (2004) Enumeration and phenotypic characterization of synovial fluid multipotential mesenchymal progenitor cells in inflammatory and degenerative arthritis. Arthritis Rheum 50: 817-827.

40. Jones E, McGonagle D (2008) Human bone marrow mesenchymal stem cells in vivo. Rheumatology (Oxford) 47: 126-131.

41. Chang Y. HPH, Chao C.C. (2009) The efficiency of Percoll and Ficoll density gradient media in the isolation of marrow derived human mesenchymal stem cells with osteogenic potential. Chang Gung Med J 32: 264-275.

42. Sauerbier S, Stricker A, Kuschnierz J, Bühler F, Oshima T, et al. (2009) In Vivo Comparison of Hard Tissue Regeneration with Human Mesenchymal Stem Cells Processed with Either the FICOLL Method or the BMAC Method. Tissue Engineering Part C: Methods 0. 
43. Sanchez-Guijo F, Blanco J, Cruz G, Muntion S, Gomez M, et al. (2009) Multiparametric comparison of mesenchymal stromal cells obtained from trabecular bone by using a novel isolation method with those obtained by iliac crest aspiration from the same subjects. Cell and Tissue Research 336: 501-507.

44. Lodie TA, Blickarz CE, Devarakonda TJ, He C, Dash AB, et al. (2002) Systematic analysis of reportedly distinct populations of multipotent bone marrow-derived stem cells reveals a lack of distinction. Tissue Engineering 8: 739-751.

45. Koppelstaetter C, Schratzberger G, Perco P, Hofer J, Mark W, et al. (2008) Markers of cellular senescence in zero hour biopsies predict outcome in renal transplantation. Aging Cell 7: 491-497.

46. McGlynn LM, Stevenson K, Lamb K, Zino S, Brown M, et al. (2009) Cellular senescence in pretransplant renal biopsies predicts postoperative organ function. Aging Cell 8: 45-51.

47. Banfi A, Muraglia A, Dozin B, Mastrogiacomo M, Cancedda R, et al. (2000) Proliferation kinetics and differentiation potential of ex vivo expanded human bone marrow stromal cells: Implications for their use in cell therapy. Experimental Hematology 28: 707-715.

48. Hayflick L, Moorhead PS (1961) The serial cultivation of human diploid cell strains. Exp Cell Res 25: 585-621.

49. Izadpanah R, Trygg C, Patel B, Kriedt C, Dufour J, et al. (2006) Biologic properties of mesenchymal stem cells derived from bone marrow and adipose tissue. J Cell Biochem 99: 1285-1297.

50. Bonab MM, Alimoghaddam K, Talebian F, Ghaffari SH, Ghavamzadeh A, et al. (2006) Aging of mesenchymal stem cell in vitro. BMC Cell Biol 7: 14

51. Dimri GP, Lee X, Basile G, Acosta M, Scott G, et al. (1995) A biomarker that identifies senescent human cells in culture and in aging skin in vivo. Proc Natl Acad Sci U S A 92: 9363-9367.

52. Stenderup K, Justesen J, Clausen C, Kassem M (2003) Aging is associated with decreased maximal life span and accelerated senescence of bone marrow stromal cells. Bone 33: 919-926.

53. Bernardo ME, Zaffaroni N, Novara F, Cometa AM, Avanzini MA, et al. (2007) Human bone marrow derived mesenchymal stem cells do not undergo transformation after longterm in vitro culture and do not exhibit telomere maintenance mechanisms. Cancer Res 67: 9142-9149.

54. Zimmermann S, Voss M, Kaiser S, Kapp U, Waller CF, et al. (2003) Lack of telomerase activity in human mesenchymal stem cells. Leukemia 17: 1146-1149.

55. Simonsen JL, Rosada C, Serakinci N, Justesen J, Stenderup K, et al. (2002) Telomerase expression extends the proliferative life-span and maintains the osteogenic potential of hu- 
man bone marrow stromal cells. Nat Biotechnol 20: 592-596.

56. Baxter MA, Wynn RF, Jowitt SN, Wraith JE, Fairbairn LJ, et al. (2004) Study of telomere length reveals rapid aging of human marrow stromal cells following in vitro expansion. Stem Cells 22: 675-682.

57. Banfi A, Bianchi G, Notaro R, Luzzatto L, Cancedda R, et al. (2002) Replicative aging and gene expression in long-term cultures of human bone marrow stromal cells. Tissue Eng 8: 901-910.

58. Shi S, Gronthos S, Chen S, Reddi A, Counter CM, et al. (2002) Bone formation by human postnatal bone marrow stromal stem cells is enhanced by telomerase expression. Nat Biotechnol 20: 587-591.

59. Jun ES, Lee TH, Cho HH, Suh SY, Jung JS (2004) Expression of telomerase extends longevity and enhances differentiation in human adipose tissue-derived stromal cells. Cell Physiol Biochem 14: 261-268.

60. Tsai CC, Chen CL, Liu HC, Lee YT, Wang HW, et al. (2010) Overexpression of hTERT increases stem-like properties and decreases spontaneous differentiation in human mesenchymal stem cell lines. J Biomed Sci 17: 64.

61. Abdallah BM, Haack-Sorensen M, Burns JS, Elsnab B, Jakob F, et al. (2005) Maintenance of differentiation potential of human bone marrow mesenchymal stem cells immortalized by human telomerase reverse transcriptase gene despite [corrected] extensive proliferation. Biochem Biophys Res Commun 326: 527-538.

62. Shamanin VA, Androphy EJ (2004) Immortalization of human mammary epithelial cells is associated with inactivation of the p14ARF-p53 pathway. Mol Cell Biol 24: 2144-2152.

63. Xiaoxue Y, Zhongqiang C, Zhaoqing G, Gengting D, Qingjun M, et al. (2004) Immortalization of human osteoblasts by transferring human telomerase reverse transcriptase gene. Biochem Biophys Res Commun 315: 643-651.

64. Bai Y, Hu Q, Li X, Wang Y, Lin C, et al. (2004) Telomerase immortalization of human neural progenitor cells. Neuroreport 15: 245-249.

65. Matsumura T, Takesue M, Westerman KA, Okitsu T, Sakaguchi M, et al. (2004) Establishment of an immortalized human-liver endothelial cell line with SV40T and hTERT. Transplantation 77: 1357-1365.

66. Ramirez RD, Sheridan S, Girard L, Sato M, Kim Y, et al. (2004) Immortalization of human bronchial epithelial cells in the absence of viral oncoproteins. Cancer Res 64: 9027-9034.

67. Piao CQ, Liu L, Zhao YL, Balajee AS, Suzuki M, et al. (2005) Immortalization of human small airway epithelial cells by ectopic expression of telomerase. Carcinogenesis 26: 725-731.

68. Kiyono T, Foster SA, Koop JI, McDougall JK, Galloway DA, et al. (1998) Both Rb/ p16INK4a inactivation and telomerase activity are required to immortalize human epithelial cells. Nature 396: 84-88. 
69. Jarrard DF, Sarkar S, Shi Y, Yeager TR, Magrane G, et al. (1999) p16/pRb pathway alterations are required for bypassing senescence in human prostate epithelial cells. Cancer Res 59: 2957-2964.

70. Itahana K, Zou Y, Itahana Y, Martinez JL, Beausejour C, et al. (2003) Control of the replicative life span of human fibroblasts by p16 and the polycomb protein Bmi-1. Mol Cell Biol 23: 389-401.

71. Haga K, Ohno S, Yugawa T, Narisawa-Saito M, Fujita M, et al. (2007) Efficient immortalization of primary human cells by p16INK4a-specific short hairpin RNA or Bmi-1, combined with introduction of hTERT. Cancer Sci 98: 147-154.

72. Foster SA, Galloway DA (1996) Human papillomavirus type 16 E7 alleviates a proliferation block in early passage human mammary epithelial cells. Oncogene 12: 1773-1779.

73. Foster SA, Wong DJ, Barrett MT, Galloway DA (1998) Inactivation of p16 in human mammary epithelial cells by CpG island methylation. Mol Cell Biol 18: 1793-1801.

74. Ben-Porath I, Weinberg RA (2005) The signals and pathways activating cellular senescence. Int J Biochem Cell Biol 37: 961-976.

75. Alves H, Munoz-Najar U, de Wit J, Renard AJ, Hoeijmakers JH, et al. (2010) A link between the accumulation of DNA damage and loss of multipotency of human mesenchymal stromal cells. J Cell Mol Med 14:2729-2738.

76. Izadpanah R, Kaushal D, Kriedt C, Tsien F, Patel B, et al. (2008) Long-term in vitro expansion alters the biology of adult mesenchymal stem cells. Cancer Res 68: 4229-4238.

77. Rubio D, Garcia-Castro J, Martin MC, de la Fuente R, Cigudosa JC, et al. (2005) Spontaneous human adult stem cell transformation. Cancer Res 65: 3035-3039.

78. Rosland GV, Svendsen A, Torsvik A, Sobala E, McCormack E, et al. (2009) Long-term cultures of bone marrow-derived human mesenchymal stem cells frequently undergo spontaneous malignant transformation. Cancer Res 69: 5331-5339.

79. Rosland GV, Svendsen A, Torsvik A, Sobala E, McCormack E, et al. (2009) Long-term cultures of bone marrow-derived human mesenchymal stem cells frequently undergo spontaneous malignant transformation. Cancer Res 69: 5331-5339.

80. Torsvik A, Rosland GV, Svendsen A, Molven A, Immervoll H, et al. (2010) Spontaneous malignant transformation of human mesenchymal stem cells reflects cross-contamination: putting the research field on track - letter. Cancer Res 70: 6393-6396.

81. Garcia S, Bernad A, Martin MC, Cigudosa JC, Garcia-Castro J, et al. (2010) Pitfalls in spontaneous in vitro transformation of human mesenchymal stem cells. Exp Cell Res 316: 1648-1650.

82. Guillot PV, Gotherstrom C, Chan J, Kurata H, Fisk NM (2007) Human first-trimester fetal MSC express pluripotency markers and grow faster and have longer telomeres than adult MSC. Stem Cells 25: 646-654. 
83. Chan J, O’Donoghue K, Gavina M, Torrente Y, Kennea N, et al. (2006) Galectin-1 induces skeletal muscle differentiation in human fetal mesenchymal stem cells and increases muscle regeneration. Stem Cells 24: 1879-1891.

84. Nishida S, Endo N, Yamagiwa H, Tanizawa T, Takahashi HE (1999) Number of osteoprogenitor cells in human bone marrow markedly decreases after skeletal maturation. J Bone Miner Metab 17: 171-177.

85. D'Ippolito G, Schiller PC, Ricordi C, Roos BA, Howard GA (1999) Age-related osteogenic potential of mesenchymal stromal stem cells from human vertebral bone marrow. $J$ Bone Miner Res 14: 1115-1122.

86. Oreffo RO, Bord S, Triffitt JT (1998) Skeletal progenitor cells and ageing human populations. Clin Sci (Lond) 94: 549-555.

87. Oreffo RO, Bennett A, Carr AJ, Triffitt JT (1998) Patients with primary osteoarthritis show no change with ageing in the number of osteogenic precursors. Scand J Rheumatol 27: 415-424.

88. Stenderup K, Justesen J, Eriksen EF, Rattan SI, Kassem M (2001) Number and proliferative capacity of osteogenic stem cells are maintained during aging and in patients with osteoporosis. J Bone Miner Res 16: 1120-1129.

89. Stenderup K, Rosada C, Justesen J, Al-Soubky T, Dagnaes-Hansen F, et al. (2004) Aged human bone marrow stromal cells maintaining bone forming capacity in vivo evaluated using an improved method of visualization. Biogerontology 5: 107-118.

90. Martin GM, Sprague CA, Epstein CJ (1970) Replicative life-span of cultivated human cells. Effects of donor's age, tissue, and genotype. Lab Invest 23: 86-92.

91. Martin GM, Ogburn, C. E., Sprague, C. A. (1981) Effects of age on cell division capacity. In: Danon D. S, N. W., Marios, M., editor. Aging: A Challenge to Science and Society. Oxford: Oxford University Press. pp. 124-135.

92. Goldstein S, Moerman EJ, Soeldner JS, Gleason RE, Barnett DM (1978) Chronologic and physiologic age affect replicative life-span of fibroblasts from diabetic, prediabetic, and normal donors. Science 199: 781-782.

93. Goldstein S, Moerman EJ, Soeldner JS, Gleason RE, Barnett DM (1979) Diabetes mellitus and genetic prediabetes. Decreased replicative capacity of cultured skin fibroblasts. $J$ Clin Invest 63: 358-370.

94. Bierman EL (1978) The effect of donor age on the in vitro life span of cultured human arterial smooth-muscle cells. In Vitro 14: 951-955.

95. Allsopp RC, Vaziri H, Patterson C, Goldstein S, Younglai EV, et al. (1992) Telomere length predicts replicative capacity of human fibroblasts. Proc Natl Acad Sci U S A 89: 1011410118. 
96. Hayflick L (1965) The limited in vitro lifetime of human diploid cell strains. Exp Cell Res 37: 614-636.

97. Schneider EL, Mitsui Y (1976) The relationship between in vitro cellular aging and in vivo human age. Proc Natl Acad Sci U S A 73: 3584-3588.

98. Le Guilly Y, Simon M, Lenoir P, Bourel M (1973) Long-term culture of human adult liver cells: morphological changes related to in vitro senescence and effect of donor's age on growth potential. Gerontologia 19: 303-313.

99. Schneider EL (1979) Cell replication and aging: in vitro and in vivo studies. Fed Proc 38: 1857-1861.

100. Smith JR, Pereira-Smith OM, Schneider EL (1978) Colony size distributions as a measure of in vivo and in vitro aging. Proc Natl Acad Sci U S A 75: 1353-1356.

101. Goldstein S, Littlefield JW, Soeldner JS (1969) Diabetes mellitus and aging: diminished planting efficiency of cultured human fibroblasts. Proc Natl Acad Sci U S A 64: 155-160.

102. Oshima J, Campisi J, Tannock TC, Martin GM (1995) Regulation of c-fos expression in senescing Werner syndrome fibroblasts differs from that observed in senescing fibroblasts from normal donors. J Cell Physiol 162: 277-283.

103. Goldstein S, Harley CB (1979) In vitro studies of age-associated diseases. Fed Proc 38: 1862-1867.

104. Martin GM (1978) Genetic syndromes in man with potential relevance to the pathobiology of aging. Birth Defects Orig Artic Ser 14: 5-39.

105. Danes BS (1971) Progeria: a cell culture study on aging. J Clin Invest 50: 2000-2003.

106. Schneider EL, Epstein CJ (1972) Replication rate and lifespan of cultured fibroblasts in Down's syndrome. Proc Soc Exp Biol Med 141: 1092-1094.

107. Cristofalo VJ, Allen RG, Pignolo RJ, Martin BG, Beck JC (1998) Relationship between donor age and the replicative lifespan of human cells in culture: a reevaluation. Proc Natl Acad Sci U S A 95: 10614-10619.

108. Van Zant G, Liang Y (2003) The role of stem cells in aging. Exp Hematol 31: 659-672.

109. Hasty P, Campisi J, Hoeijmakers J, van Steeg H, Vijg J (2003) Aging and genome maintenance: lessons from the mouse? Science 299: 1355-1359.

110. Satija NK, Gurudutta GU, Sharma S, Afrin F, Gupta P, et al. (2007) Mesenchymal stem cells: molecular targets for tissue engineering. Stem Cells Dev 16: 7-23.

111. Muller AM, Davenport M, Verrier S, Droeser R, Alini M, et al. (2009) Platelet lysate as a serum substitute for 2D static and 3D perfusion culture of stromal vascular fraction cells from human adipose tissue. Tissue Eng Part A 15: 869-875. 
112. Johansson L, Klinth J, Holmqvist O, Ohlson S (2003) Platelet lysate: a replacement for fetal bovine serum in animal cell culture? Cytotechnology 42: 67-74.

113. Watson SL, Marcal H, Sarris M, Di Girolamo N, Coroneo MT, et al. (2010) The effect of mesenchymal stem cell conditioned media on corneal stromal fibroblast wound healing activities. Br J Ophthalmol 94: 1067-1073.

114. Parker AM, Shang H, Khurgel M, Katz AJ (2007) Low serum and serum-free culture of multipotential human adipose stem cells. Cytotherapy 9: 637-646.

115. Agata H, Watanabe N, Ishii $Y$, Kubo N, Ohshima S, et al. (2009) Feasibility and efficacy of bone tissue engineering using human bone marrow stromal cells cultivated in serumfree conditions. Biochem Biophys Res Commun 382: 353-358.

116. Lindroos B, Boucher S, Chase L, Kuokkanen H, Huhtala H, et al. (2009) Serum-free, xeno-free culture media maintain the proliferation rate and multipotentiality of adipose stem cells in vitro. Cytotherapy 11: 958-972.

117. Pytlik R, Stehlik D, Soukup T, Kalbacova M, Rypacek F, et al. (2009) The cultivation of human multipotent mesenchymal stromal cells in clinical grade medium for bone tissue engineering. Biomaterials 30: 3415-3427.

118. Schallmoser K, Rohde E, Bartmann C, Obenauf AC, Reinisch A, et al. (2009) Platelet-derived growth factors for GMP-compliant propagation of mesenchymal stromal cells. Biomed Mater Eng 19: 271-276.

119. Felka T, Schafer R, De Zwart P, Aicher WK (2010) Animal serum-free expansion and differentiation of human mesenchymal stromal cells. Cytotherapy 12: 143-153.

120. Montzka K, Fuhrmann T, Woltje M, Brook GA (2010) Expansion of human bone marrow-derived mesenchymal stromal cells: serum-reduced medium is better than conventional medium. Cytotherapy 12: 587-592.

121. Vogel JP, Szalay K, Geiger F, Kramer M, Richter W, et al. (2006) Platelet-rich plasma improves expansion of human mesenchymal stem cells and retains differentiation capacity and in vivo bone formation in calcium phosphate ceramics. Platelets 17: 462-469.

122. Poulios E, Trougakos IP, Chondrogianni N, Gonos ES (2007) Exposure of human diploid fibroblasts to hypoxia extends proliferative life span. Ann N Y Acad Sci 1119: 9-19.

123. Csete M, Walikonis J, Slawny N, Wei Y, Korsnes S, et al. (2001) Oxygen-mediated regulation of skeletal muscle satellite cell proliferation and adipogenesis in culture. $J$ Cell Physiol 189: 189-196.

124. Potier E, Ferreira E, Andriamanalijaona R, Pujol JP, Oudina K, et al. (2007) Hypoxia affects mesenchymal stromal cell osteogenic differentiation and angiogenic factor expression. Bone 40: 1078-1087. 
125. Fehrer C, Brunauer R, Laschober G, Unterluggauer H, Reitinger S, et al. (2007) Reduced oxygen tension attenuates differentiation capacity of human mesenchymal stem cells and prolongs their lifespan. Aging Cell 6: 745-757.

126. Tokuda Y, Crane S, Yamaguchi Y, Zhou L, Falanga V (2000) The levels and kinetics of oxygen tension detectable at the surface of human dermal fibroblast cultures. J Cell Physiol 182: 414-420.

127. Mayne LV, Priestley A, James MR, Burke JF (1986) Efficient immortalization and morphological transformation of human fibroblasts by transfection with SV40 DNA linked to a dominant marker. Exp Cell Res 162: 530-538.

128. Sugden B, Mark W (1977) Clonal transformation of adult human leukocytes by Epstein-Barr virus. J Virol 23: 503-508.

129. Quinlan MP (1994) Enhanced proliferation, growth factor induction and immortalization by adenovirus E1A $12 \mathrm{~S}$ in the absence of E1B. Oncogene 9: 2639-2647.

130. Woodworth CD, Doniger J, DiPaolo JA (1989) Immortalization of human foreskin keratinocytes by various human papillomavirus DNAs corresponds to their association with cervical carcinoma. J Virol 63: 159-164.

131. Endo T (1992) SV40 large $T$ inhibits myogenic differentiation partially through inducing c-jun. J Biochem 112: 321-329.

132. Hsieh JJ, Nofziger DE, Weinmaster G, Hayward SD (1997) Epstein-Barr virus immortalization: Notch2 interacts with CBF1 and blocks differentiation. J Virol 71: 1938-1945.

133. Kannabiran C, Morris GF, Mathews MB (1999) Dual action of the adenovirus E1A 243R oncoprotein on the human proliferating cell nuclear antigen promoter: repression of transcriptional activation by p53. Oncogene 18: 7825-7833.

134. Macera-Bloch L, Houghton J, Lenahan M, Jha KK, Ozer HL (2002) Termination of lifespan of SV40-transformed human fibroblasts in crisis is due to apoptosis. J Cell Physiol 190: 332-344.

135. Sedivy JM (1998) Can ends justify the means?: telomeres and the mechanisms of replicative senescence and immortalization in mammalian cells. Proc Natl Acad Sci U S A 95: 9078-9081.

136. Bodnar AG, Ouellette M, Frolkis M, Holt SE, Chiu CP, et al. (1998) Extension of lifespan by introduction of telomerase into normal human cells. Science 279: 349-352.

137. Vaziri H, Benchimol S (1998) Reconstitution of telomerase activity in normal human cells leads to elongation of telomeres and extended replicative life span. Curr Biol 8: 279-282.

138. Shen G, Cong XQ, Du ZW, Wu CF, Liu XY, et al. (2002) [Immortalization of endothelial cells differentiated from mouse embryonic stem cells]. Shi Yan Sheng Wu Xue Bao 35: 218-228. 
139. O'Hare MJ, Bond J, Clarke C, Takeuchi Y, Atherton AJ, et al. (2001) Conditional immortalization of freshly isolated human mammary fibroblasts and endothelial cells. Proc Natl Acad Sci U S A 98: 646-651.

140. Campbell KH, McWhir J, Ritchie WA, Wilmut I (1996) Sheep cloned by nuclear transfer from a cultured cell line. Nature 380: 64-66.

141. Wilmut I, Schnieke AE, McWhir J, Kind AJ, Campbell KH (1997) Viable offspring derived from fetal and adult mammalian cells. Nature 385: 810-813.

142. Takahashi K, Yamanaka S (2006) Induction of pluripotent stem cells from mouse embryonic and adult fibroblast cultures by defined factors. Cell 126: 663-676.

143. Aoi T, Yae K, Nakagawa M, Ichisaka T, Okita K, et al. (2008) Generation of pluripotent stem cells from adult mouse liver and stomach cells. Science 321: 699-702.

144. Shi Y, Desponts C, Do JT, Hahm HS, Scholer HR, et al. (2008) Induction of pluripotent stem cells from mouse embryonic fibroblasts by Oct4 and Klf4 with small-molecule compounds. Cell Stem Cell 3: 568-574.

145. Shi Y, Do JT, Desponts C, Hahm HS, Scholer HR, et al. (2008) A combined chemical and genetic approach for the generation of induced pluripotent stem cells. Cell Stem Cell 2: 525-528.

146. Stadtfeld M, Nagaya M, Utikal J, Weir G, Hochedlinger K (2008) Induced pluripotent stem cells generated without viral integration. Science 322: 945-949.

147. Okita K, Nakagawa M, Hyenjong H, Ichisaka T, Yamanaka S (2008) Generation of mouse induced pluripotent stem cells without viral vectors. Science 322: 949-953.

148. Kim D, Kim CH, Moon JI, Chung YG, Chang MY, et al. (2009) Generation of human induced pluripotent stem cells by direct delivery of reprogramming proteins. Cell Stem Cell 4: 472-476.

149. Conboy IM, Conboy MJ, Wagers AJ, Girma ER, Weissman IL, et al. (2005) Rejuvenation of aged progenitor cells by exposure to a young systemic environment. Nature 433: 760-764. 


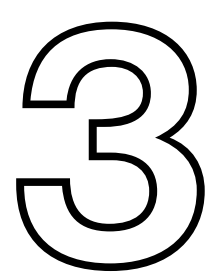




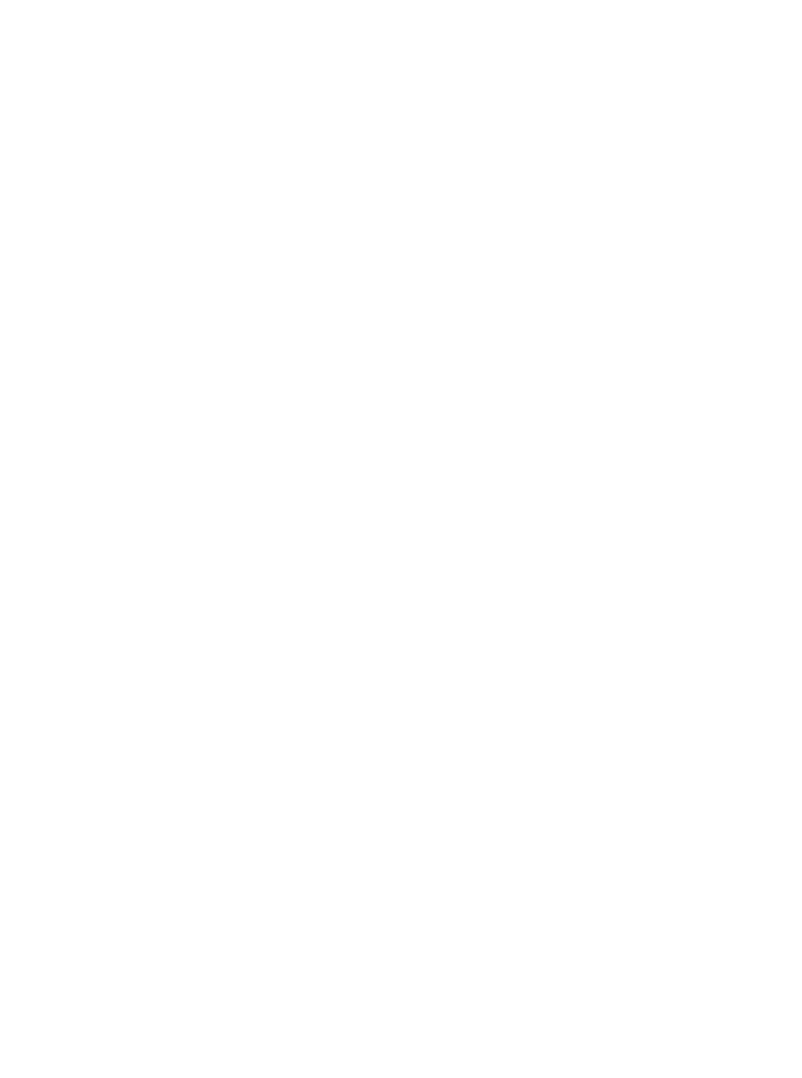




\title{
Chapter 3
}

\section{A Link Between the Accumulation of DNA Damage and Loss of Multipotency of Human Mesenchymal Stromal Cells}

Hugo Alves a, Ursula Munoz-Najar ${ }^{\text {b }}$, Jan de Wit c, Auke J. S. Renard d, Jan H. J. Hoeijmakers ${ }^{c}$, John M. Sedivy ${ }^{b}$, Clemens van Blitterswijk ${ }^{\text {, }}$, Jan de Boer ${ }^{a}$

a Department of Tissue Regeneration, MIRA Institute for Biomedical Technology and Technical Medicine, University of Twente, Enschede, The Netherlands. ${ }^{b}$ Department of Molecular Biology, Cell Biology and Biochemistry, Brown University, Providence, RI, USA. ${ }^{\mathrm{c}}$ Department of Cell Biology and Genetics, MGC Center for Biomedical Genetics, Erasmus Medical Center, Rotterdam, The Netherlands. ${ }^{d}$ Department of Orthopaedic Surgery, Medisch Spectrum Twente Hospital, Enschede, The Netherlands

\begin{abstract}
Human mesenchymal stromal cells (hMSCs) represent an attractive cell source for clinical applications. Besides being multi-potent, recent clinical trials suggest that they secrete both trophic and immunomodulatory factors, allowing allogenic MSCs to be used in a wider variety of clinical situations. The yield of prospective isolation is however very low, making expansion a required step toward clinical applications. Unfortunately, this leads to a significant decrease in their stemness. To identify the mechanism behind loss of multi-potency, hMSCs were expanded until replicative senescence and the concomitant molecular changes were characterized at regular intervals. We observed that, with time of culture, loss of multipotency was associated with both the accumulation of DNA damage and the respective activation of the DNA damage response pathway, suggesting a correlation between both phenomena. Indeed, exposing hMSCs toDNA damage agents led to a significant decrease in the differentiation potential. We also showed that hMSCs are susceptible to accumulate DNA damage upon in vitro expansion, and that although hMSCs maintained an effective nucleotide excision repair activity, there was a progressive accumulation of DNA damage. We propose a model in which DNA damage accumulation contributes to the loss of differentiation potential of hMSCs, which might not only compromise their potential for clinical applications but also contribute to the characteristics of tissue ageing.
\end{abstract}

Adapted from Alves H, et al. J. Cell. Mol. Med. Vol 14, No 12, 2010 pp. 2729-2738 


\section{Introduction}

Human mesenchymal stromal cells (hMSCs) represent an attractive cell source for clinical applications. They can be isolated from different sources and are able to differentiate into several lineages such as the osteogenic, adipogenic, chondrogenic, myogenic and neurogenic lineages [1-5]. hMSCs are generally isolated from easily accessible tissues in a reproducible way and have a high expansion potential, which makes them good candidates for the repair and regeneration of a large variety of tissues. Currently, hMSCs from bone marrow are the most common source of cells for therapeutic applications. They are used in clinical trials mainly due to proven efficacy in pre-clinical studies [6-9]. Potential applications are repair of cardiovascular and central nervous system damage, for pancreatic, renal, hepatic and solid organ transplantation, for the use in the gastrointestinal tract, and for both orthopaedic and haematopoietic applications (reviewed by Brooke et al.) [10]. Recently, new insights based on clinical experimentation also suggest that MSCs secrete large quantities of bioactive factors with both trophic and immunomodulatory activity, thus preventing autoimmunity allowing allogenic MSCs to be used in a wide variety of clinical situations [11]. Because the yield of prospective hMSC isolation is very low, expansion is a necessary step for clinical application. Thus, successful clinical applications of hMSCs will rely on the ability to extensively expand them while maintaining their multi-potency. Unfortunately, in vitro expansion of hMSCs is associated with a gradual decrease and loss of differentiation capacity of hMSCs, which currently represent one of the major bottlenecks in cell-based clinical applications. Although normally stem cells cultured in low oxygen proliferate faster than in traditional $20 \%$ oxygen environments, there are several problems associated with growing cells in a hypoxic environment. Low oxygen levels tend to favour certain differentiation pathways in detriment of others [12] and there are even reports about attenuation of differentiation after cultivation of hMSCs in low oxygen [13, 14]. Furthermore, from a clinical/commercial point of view, the cultivation of hMSCs in low oxygen would require much more specialized equipment and would be more labour intensive. Although it has been shown that hMSCs can be expanded in vitro for several population doublings (PD), they ultimately stop dividing, a phenomenon known as replicative senescence or the Hayflick limit after the discovery by Leonard Hayflick that human diploid cell strains in culture divide about 50 times before entering a senescence phase [15]. The cellular senescence program is characterized by clear morphological alterations culminating in growth arrest. This phenomenon can be triggered by multiple mechanisms including telomere shortening and uncapping, DNA damage accumulation, proto-oncogene activation, epigenetic changes, stress and other inducers like cytokines [16, 17]. Senescence was already 
implicated in the loss of regenerative potential in ageing tissues [16, 18] and although establishing a direct causal relationship between cellular senescence and ageing might be complex, there is circumstantial evidence linking both processes. For clinical applications, another important concern is the fact that hMSCs lose their differentiation capacity (referred to as functional senescence in this article) very soon during in vitro expansion as previously described [19]. Despite several reports about the mechanisms that can drive cellular senescence with ageing, little is known about mechanisms that drive the loss of multi-potency in the early expansion phase of tissue cultured hMSCs.

Some mutations in DNA repair pathways are associated with a decrease in lifespan, an increase in the incidence of cancer and genomic instability and symptoms of premature ageing. Examples are the Ku80, TTD ${ }^{\mathrm{XpdR722W}}$, Brca 1 and Trp53 mutant mice [20, 21]. Three independent research teams recently published on the link between age-related accumulation of DNA damage and decline of stemcell function [22-24]. The conclusion was that with age, adult haematopoietic stem cell function declines and that DNA damage and epigenetic modification may limit the regenerative potential of those cells. They agree that ageing may result in an accumulation of DNA mutations since stem cells are not protected from age-induced damage. However, several issues remained unclear which lead us to investigate whether DNA damage plays a role in early loss of multi-potency observed during in vitro expansion of hMSC, the susceptibility of adult mesenchymal stromal cells to accumulate DNA damage, how effective DNA-repair activities are in these cells, and to what extent this balance might contribute to the characteristics of tissue ageing.

\section{Materials and methods}

\section{Isolation and culture of hMSCs}

Bone marrow aspirates were obtained from donors with written informed consent and hMSCs were isolated and proliferated as previously described [25]. Briefly, aspirates were resuspended using $20 \mathrm{G}$ needles, plated at a density of $5 \times 10^{5}$ cells $/ \mathrm{cm}^{2}$ and cultured in hMSC proliferation medium (PM) containing $\alpha$-minimal essential medium ( $\alpha$-MEM, Life Technologies), $10 \%$ fetal bovine serum (FBS, Cambrex), $0.2 \mathrm{mM}$ ascorbic acid (Asap, Life Technologies), $2 \mathrm{mM}$ L-glutamine (Life Technologies), $100 \mathrm{U} / \mathrm{mL}$ penicillin (Life Technologies), $100 \mathrm{mg} / \mathrm{mL}$ streptomycin (Life Technologies) and $1 \mathrm{ng} / \mathrm{mL}$ basic fibroblast growth factor (bFGF, Instruchemie). Cells were grown at $37^{\circ} \mathrm{C}$ in a humid atmosphere with $5 \% \mathrm{CO}_{2}$. Me- 
dium was refreshed twice a week and cells were used for further subculturing or cryopreservation when reaching $80-90 \%$ confluency. hMSC basic medium/control medium (BM) was composed of hMSC PM without bFGF, hMSC osteogenic medium $(\mathrm{OM})$ was composed of hMSC basic medium supplemented with $10^{-8} \mathrm{M}$ dexamethasone (dex, Sigma) and hMSC mineralization medium (MM) was composed of basic medium supplemented with $10^{-8} \mathrm{M}$ dex and $0.01 \mathrm{M} \beta$-glycerophosphate (Sigma). After plating of the bone marrow aspirate, hMSCs were expanded in PM and the cells obtained from the first trypsinization were considered as PD (population doubling) 0. Relative population doublings (RPD) refers to the number of population doublings that cells had undergone, relative to PD 0. Donors information is represented in Table S4 (supplementary data).

\section{Senescence Associated- $\boldsymbol{\beta}$-Galactosidase expression}

hMSCs at different RPD were seeded at 15,000 cells $/ \mathrm{cm}^{2}$ in 6 -well plates and proliferated in PM until 70-80\% confluence was reached. Then, cells were washed twice with PBS, fixed with $4 \%$ paraformaldehyde for $10 \mathrm{~min}$., washed again three times with PBS and stained overnight with a SA- $\beta$-gal Kit (Sigma) according to the manufacturer's instructions. Cells were then counterstained with Mayer's hematoxylin for $5 \mathrm{~min}$. All chemicals were obtained from Sigma. Images were taken at a $100 \times$ magnification.

\section{Immunophenotyping of hMSCs}

To characterize the population of hMSCs during expansion, cell-surface marker expression was assessed. Low passage (RPD 6) and high passage (RPD 20) cells were harvested by trypsin and incubated for $30 \mathrm{~min}$. in block buffer [PBS with $5 \%$ BSA (Sigma) and $0.05 \% \mathrm{NaN}_{2}$ ], then incubated with primary antibodies (CD45, HLA-DR, CD19, CD90/Thy1, Endoglin/CD105, Integrin $\alpha \mathrm{M} / \mathrm{CD} 11 \mathrm{~b}$ from R\&D Systems, CD34 and CD73 from Abcam) diluted in wash buffer (PBS with $1 \%$ BSA and $0.05 \% \mathrm{NaN}_{2}$ ) for $1 \mathrm{hr}$ or with isotype control antibodies. Cells were then washed three times with wash buffer and incubated with secondary antibody (Anti-mouse IgM or Anti-mouse IgG, conjugated with Phycoerythrin from R\&D systems) for $30 \mathrm{~min}$. Samples were then washed three times and ressuspended in $250 \mu \mathrm{l}$ of wash buffer with $10 \mu \mathrm{l}$ of Viaprobe (Pharmingen) for live/dead cell staining. Only live cells were used for further analysis. The percentage of cells expressing each marker and the respective overlays of the histograms (RPD6 vs RPD20) were assessed on FACSCalibur (Becton Dickinson Immunocytometry Systems). 


\section{Acidic Phosphatase and Alamar blue}

Acidic phosphatase (ACP) and Alamar blue assays were performed to measure the proliferative and metabolic status of the cells during the experiment, respectively. The Alamar blue solution was diluted 1:10 in culture medium, and cells were incubated for $4 \mathrm{hrs}$. The Alamar blue solution from each well was then transferred into 96-well plates, and fluorescence was measured using a Perkin Elmer Luminescence Spectrometer LS50B. Results were recorded by FL winlab 12. For the acidic phosphatase (ACP) determination, cells were lysed with a $0.2 \%$ Triton $\mathrm{X}-100$ solution in $100 \mathrm{mM}$ potassium phosphate buffer $\mathrm{pH} 7.8$ and then incubated with $5 \mathrm{mM} 4$-nitrophenyl phosphate disodium salt dissolved in $0.1 \mathrm{M}$ sodium acetate, $0.1 \%$ Triton-X, pH 5.5. After $1.5 \mathrm{hrs}$ at $37^{\circ} \mathrm{C}$, the reaction was stopped by adding $0.5 \mathrm{~N}$ sodium hydroxide and allowed to equilibrate for $10 \mathrm{~min}$. The absorbance was then measured at $405 \mathrm{~nm}$.

\section{Alkaline Phosphatase (ALP) induction}

For the biochemical ALP assay, hMSCs were seeded at 5000 cells $/ \mathrm{cm}^{2}$ and allowed to adhere for 10 to $15 \mathrm{hrs}$ in BM and then cells were grown in OM for 6 days. Each experiment was performed at least in triplicate with a negative control (cells grown in BM) and a positive control (cells grown in OM). To avoid donor variation, all the experiments were performed with cells from at least 3 independent donors. Results shown are usually from one donor, unless stated otherwise and are representative for all the donors tested. Briefly, cells were washed twice with PBS (Life technologies) and lysed using a $0.2 \%$ Triton X-100 solution in $100 \mathrm{mM}$ PBS pH 7.8, supplemented with a protease inhibitor cocktail (Roche Applied Science). The lysate was incubated in the dark at $25^{\circ} \mathrm{C}$ with CDP-Star substrate (Roche) and allowed to react for $30 \mathrm{~min}$. Luminescence was measured using a VICTOR ${ }^{3}$ luminometer (Perkin Elmer) at $25^{\circ} \mathrm{C}$. The total ALP luminescence was normalized for cell number using acidic phosphatase (ACP) as readout. The data was then analyzed using Student's t-test at $\mathrm{p}<0.05$.

\section{Mineralization and Adipogenesis}

Both assays were performed as described previously [19]. Experiments were performed at least in triplicate using BM as negative control. In the mineralization experiment, the calcium content was measured at $620 \mathrm{~nm}$ (Bio-tek instruments) after 28 days in MM and expressed as percentage reduction in calcium deposition compared to RPD 6 (passage 1) which was set to $100 \%$. 


\section{Immunofluorescence}

Cells were grown on glass coverslips for at least $48 \mathrm{hr}$ prior to immunostaining to minimize stress as a consequence of passaging. Cells were washed twice with PBS and fixed for $20 \mathrm{~min}$. with freshly prepared $4 \%$ paraformaldehyde in PBS. After permeabilization for 20 min. with PBST (PBS with $0.2 \%$ Triton X-100), cells were blocked for $1 \mathrm{hr}$. The 53BP1 antibody (Novus) was diluted 1:500 in blocking buffer and incubated overnight at $4^{\circ} \mathrm{C}$. Samples were then washed with TBST, incubated with Alexa-488 secondary antibody and visualized by confocal laser scanning microscopy.

\section{ImmunoFISH}

The telomere dysfunction-induced (TIF) assay was performed as described previously [26]. Briefly, after immunofluorescent staining with 53BP1, cells were crosslinked with $4 \%$ paraformaldehyde in PBS for $20 \mathrm{~min}$. Then, cells were dehydrated using a series of $70 \%, 90 \%$, and $100 \%$ ethanol and air dried. Nuclear DNA was denatured for $5 \mathrm{~min}$. at $80^{\circ} \mathrm{C}$ in hybridization buffer containing $0.5 \mu \mathrm{g} /$ $\mathrm{ml}\left(\mathrm{C}_{3} \mathrm{TA}_{2}\right)_{3}$-Cy3-labeled peptide nucleic acid (PNA) telomeric probe (Applied Biosystems), 70\% formamide, $12 \mathrm{mM}$ Tris- $\mathrm{HCl}$ ( $\mathrm{pH}$ 8), $5 \mathrm{mM} \mathrm{KCl}, 1 \mathrm{mM} \mathrm{MgCl}$, $0.001 \%$ Triton X-100, and $2.5 \mathrm{mg} / \mathrm{ml}$ acetylated BSA. After denaturation, incubation was continued for $2 \mathrm{hrs}$ at room temperature in a humidified chamber. Cells were washed twice for $15 \mathrm{~min}$. with $70 \%$ formamide $/ 2 \times \mathrm{SSC}(0.3 \mathrm{M} \mathrm{NaCl}, 30 \mathrm{mM}$ $\mathrm{Na}$-citrate [pH 7]), followed by a $10 \mathrm{~min}$. wash with $2 \times \mathrm{SSC}$ and a $10 \mathrm{~min}$. wash with TBST. To reinforce the 53BP1 signal, cells were incubated for $1 \mathrm{hr}$ with an Alexa-488 conjugated anti-secondary antibody before mounting in a media containing DAPI.

\section{Oxidative Stress determination (8-OxoG and CM-H2DCFDA)}

For the determination of oxidative stress load, two different methods were employed. The first method was based on the detection of 8-Oxoguanine (as part of the oxidized nucleotide 8-oxyguanosine) in fixed permeabilized cells using flow cytometry. Briefly, hMSCs from different RPD were fixed and permeabilized and then a FITC-labeled protein conjugate specific for the 8-oxyguanine moity was added for $1 \mathrm{hr}$, according to manufacturer's instructions (Argutus Medical OxyDNA test - BD Biosciences). The presence of the oxidised DNA was then measured by FACS in at least 10,000 cells. The second method consisted in the direct detection of reactive oxygen metabolites as described previously [27]. Shortly, adherent cells were harvested with trypsin and combined with cells floating in the medium. Cells were then washed and treated with $10 \mu \mathrm{M}$ (5-(and-6)-chloromethyl2'7'-dichlorodihydrofluorescein diacetate acetyl ester) $\mathrm{CM}-\mathrm{H}_{2}$ DCFDA (Molecular 
Probes) for $30 \mathrm{~min}$. at $37^{\circ} \mathrm{C}$. Ten thousand cells were then analysed on a BD FACScan.

\section{Western blot}

For western blot analysis, enzymatically dispersed cells were pelleted and lysed using a solution of $0.2 \%$ Triton X-100 in potassium phosphate buffer $\mathrm{pH} 7.8$ containing a protease inhibitor cocktail (Roche Applied Science). Protein concentration was quantified spectrophotometrically using a BCA Protein Assay Kit (Pierce). Separated proteins were transferred electrophoretically to polyvinylidene difluoride membranes (Immobilon-P Millipore). Blots were incubated overnight at $4{ }^{\circ} \mathrm{C}$ with primary antibodies: p16 (c-20, Santa Cruz biotechnology); p21 (DCS60, Cell Signaling Technology); $\beta$-Actin, clone Ac-74 (Sigma) and the antibodies from the DNA Damage Antibody Sampler Kit (Cell Signaling Technology). Next the membranes were incubated with peroxidase-conjugated secondary antibody, either Anti-Rabbit IgG or Anti-Mouse IgG, for $1 \mathrm{hr}$ at room temperature. Antigen-antibody complexes were visualized by SuperSignal West Dura Extended Duration Substrate (Thermo scientific).

\section{Unscheduled DNA synthesis (UDS)}

For testing the nucleotide excision repair capacity, hMSCs were seeded onto coverslips and grown in medium without thymidine and switched to medium without FBS $24 \mathrm{hrs}$ prior to the start of the experiment. Cells were then washed with PBS, irradiated with $16 \mathrm{~J} / \mathrm{m}^{2} \mathrm{UV}-\mathrm{C}$ (Philips TUV lamp) and subsequently incubated for $2.5 \mathrm{hrs}$ in culture medium containing $10 \mu \mathrm{Ci} / \mathrm{mL}{ }^{3} \mathrm{H}$-thymidine. For analysis, cells were fixed in Bouin fixative and subjected to autoradiography as previously described [28]. Repair capacity was quantified by counting autoradiographic grains above the nuclei of $\geq 25$ cells. UDS levels are expressed as the mean of grains per fixed area plus standard error for each PD.

\section{Exposure to a DNA damage inducer}

To assess the effects of oxidative stress on ALP expression, early passage cells (RPD 10) were plated at 2000 cells $/ \mathrm{cm}^{2}$ and treated with hydrogen peroxide $\left(\mathrm{H}_{2} \mathrm{O}_{2}\right.$, Sigma) or Paraquat (Sigma) and grown either in BM or OM for 6 days. After this period, ALP expression was assessed using the biochemical method described above. In order to evaluate the DNA damage load, cells were expanded in PM and treated with either hydrogen peroxide or paraquat. The percentage of DNA damage positive cells and the average foci per cell were determined by immunofluorescence staining of 53BP1. 


\section{Results}

\section{Replicative senescence upon in vitro expansion of hMSCs}

In order to investigate the differentiation capacity with respect to expansion, hMSCs from 2 donors were expanded until cessation of growth. As expected, hMSCs presented a continuous decrease in proliferation rate with increased time in culture (Fig. 1A). After an initial difference, both donors exhibited a similar level of $\mathrm{PD} /$ day until around 60 days in culture. At this point, the cells from donor 36 stopped proliferating while the cells from donor 24 displayed a temporary recovery followed by a permanent growth arrest. Although late passage cells did not proliferate, they were able to be maintained viable in culture for at least 3 more months before the experiment was ended. No spontaneous immortalization of hMSCs was ever observed and no clonal expansion was observed during this period of in vitro expansion.

An evident change in cell morphology was observed with increasing time of culture (Fig. S1A). In RPD 0, cells presented a fibroblastic-like appearance that progressed towards a more spread morphology characterized by enlarged and flattened cytoplasm, increased granularity and heterogeneous cell shape. hMSCs from low RPD grew homogeneously while in higher RPD they grew in cluster with neighboring cells, leaving large interspaces between the clusters (Fig. S1A, RPD25). Late passage cells also displayed an increased expression of senescenceassociated $\beta$-galactosidase (SA- $\beta$-gal), a common marker for senescent cells (Fig. 1B).

hMSCs after minimally or extensively expansion were phenotypically similar, presenting the same percentage of marker expression (Fig. S2). hMSCs were negative for CD11b, CD19, CD34 and CD45 and positive for CD73, CD90 and CD105. HLA-DR was present in $6 \%$ of the cells independent of the passage.

\section{Gradual loss of the differentiation capacity of hMSCs after in vitro expansion}

To determine the differentiation capacity of hMSC during in vitro culture, we performed both in vitro osteogenic and adipogenic assays at different RPD. We observed a decrease in the levels of ALP of cells grown in basic medium (BM) mainly from RPD 13 to the following PDs. We also observed a decrease in the dexamethasone-induced ALP levels (an early marker for bone formation) with increasing RPD (Fig. 1C). At RPD 13 (passage 3) both the basal, as well as, the induced levels of ALP were already very low and the cells were no longer responsive to dexamethasone. A decline in calcium deposition (a late marker for in vitro osteogenesis) was also observed with culturing (Fig. S1B). This decrease was most pronounced (approximately $70 \%$ reduction in calcium deposition) between RPD 17 and RPD 20. After RPD 20 the cells lost their ability to mineralize in vitro. In addition, we also tested the ability of the expanded hMSC to differentiate into the 
adipogenic lineage. We observed loss of adipogenic potential during expansion (Fig. S1C). At RPD 20, a small subset of hMSC was still able to differentiate into the adipogenic lineage, but it was proportionally considerably less than in hMSC from early PDs.

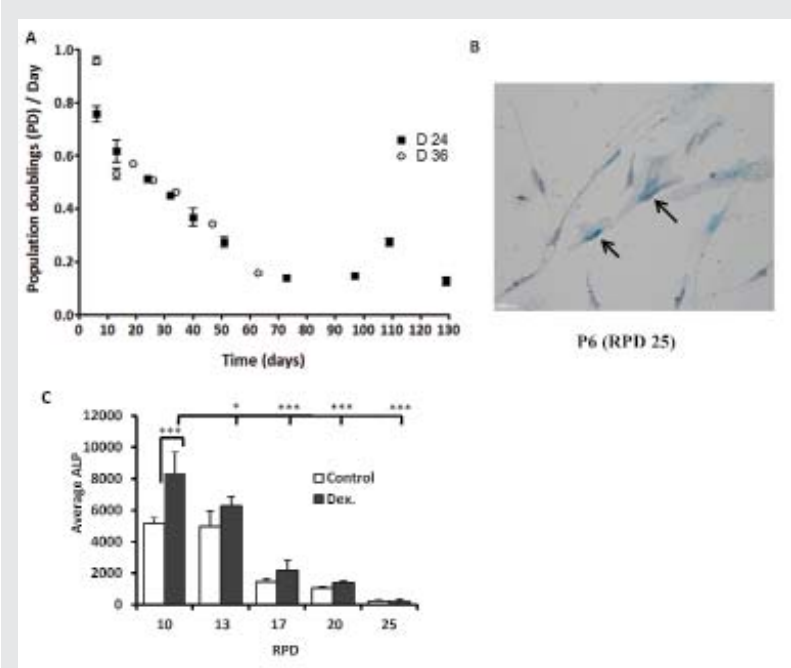

Fig. 1 Long-term in vitro expansion of hMSCs leads to loss of multi-potency. (A) Growth profiles of hMSCs in vitro depicted by the number of population doublings per day plotted against culture period. (B) Phase-contrast photo of hMSCs at RPD 25. At RPD 25, most of the cells express $S A-\beta$ Galactosidase (black arrows). With increasing time of culture not only more cells were positive for SA- $\beta$-Galactosidase but also the staining was more in-

tense (data not shown). (C) Effect of expansion in the expression of ALP, both in control and dexamethasonetreated cells. ALP expression was analysed by CDP-STAR base luminescence assay and corrected for the cell number. Error bars represent standard deviation. Statistical analysis was performed using one-way ANOVA and Tukey post-test with a significance level of 0.05 . ${ }^{*}$ represents $P<0.01$ and ${ }^{* * *} P<0.001$.

\section{DNA damage accumulation and DNA damage pathway activation during in vitro expansion}

To evaluate the relation between DNA damage and in vitro expansion, immunofluorescence staining of p53 binding protein 1 (53BP1) and telomere dysfunctioninduced foci (TIF) assays were performed at several RPD [29-32]. We observed that with increasing $P D$ there was a significant increase in the number of nuclei containing 53BP1 foci, a marker of DNA damage (Fig. 2A). Interestingly, we also observed an increase in telomere-associated DNA damage, demonstrated by the co-localization of 53BP1 staining with a telomeric probe (Fig. 2B). In cells after 27 RPD or more (passage 8), the telomeric signal could no longer be detected. To determine the changes in oxidative levels that hMSCs face during expansion we quantified the presence of 8-oxoguanine (Fig. 2C) and the presence of reactive oxygen metabolites (Fig. 2D). Both assays demonstrated that during expansion hMSCs are exposed to increased oxidative stress levels. These data demonstrate that in vitro cultured hMSCs accumulate DNA damage upon expansion. 


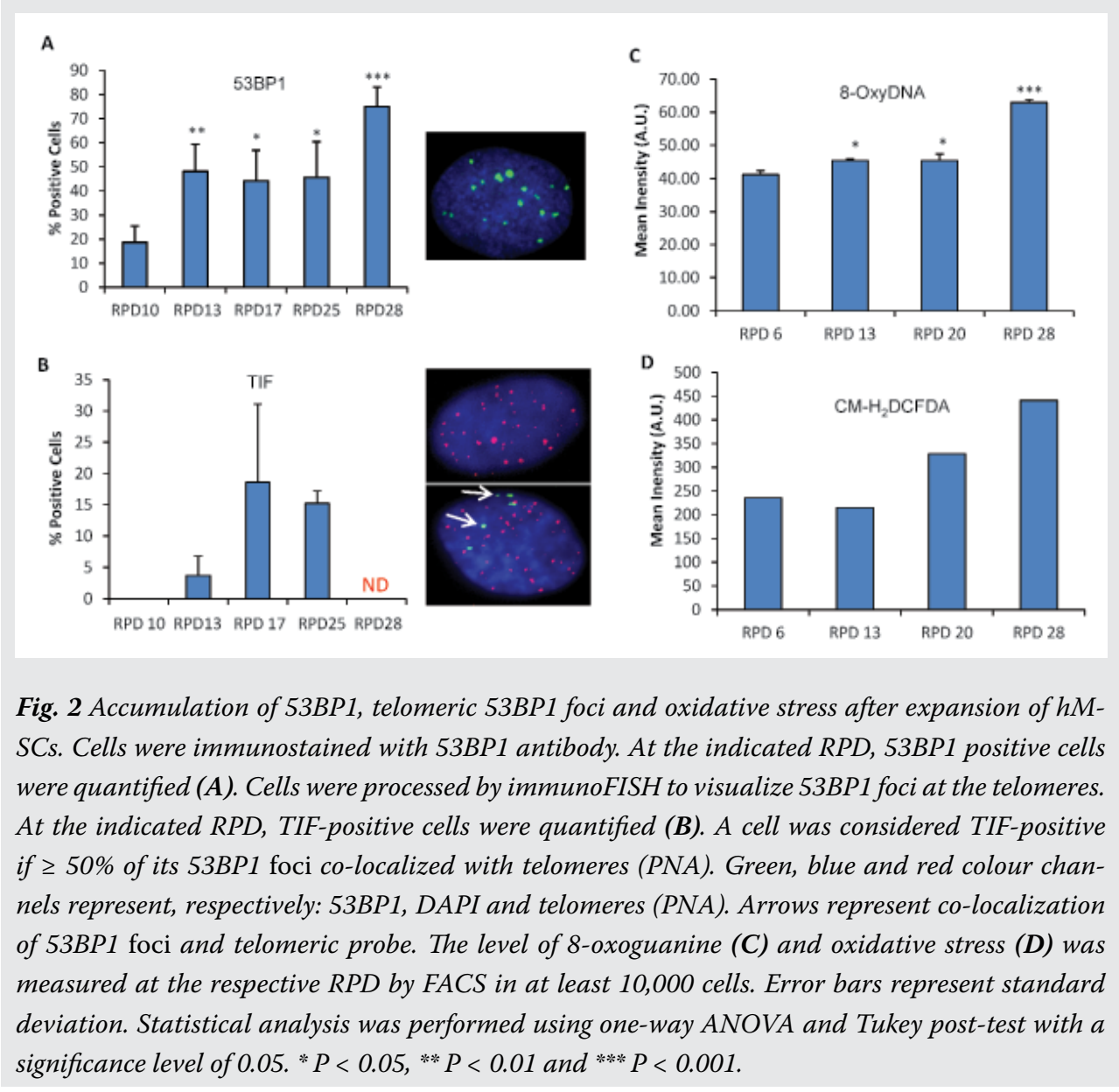

Next, we performed western blot analysis on hMSCs at different RPDs and analyzed the abundance of proteins involved in the DNA damage response pathway, such as phospho-p53 (Ser15), p16 (c-20) and p21 Waf1/Cip1 (Fig. 3A). In accordance with the previous results, we observed an activation of the DNA damage response pathway with time of culture. There was a particularly strong increase from RPD 10 to RPD 17. We hypothesized that DNA damage accumulation is due to impaired DNA repair mechanisms in late passage cells. We analyzed the capacity of nucleotide excision repair (NER) because it is involved in the repair of many types of DNA damage including the ones induced by reactive oxygen species associated with premature ageing phenotypes. To this end, hMSC from different RPD were seeded onto coverslips and irradiated with UV after which we measured the incorporation of ${ }^{3} \mathrm{H}$-thymidine. With increased $\mathrm{PD}$, there was no significant change in the nucleotide excision repair (NER) capacity (Fig. 3B). 

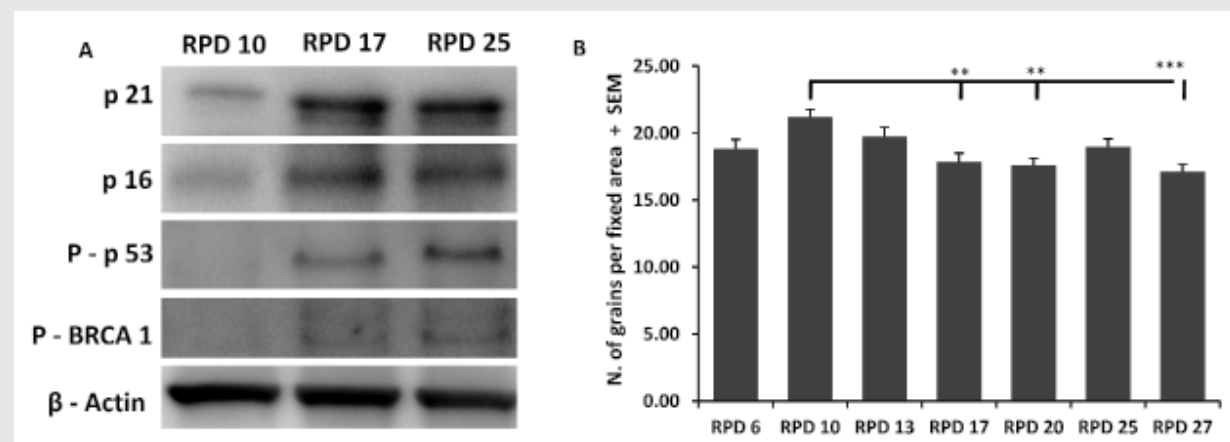

Fig. 3 Activation of the DNA damage signalling pathway and efficiency of NER. Samples from different RPD were analysed by Western blotting for $p 16$ and $p 21$ protein expression and $p 53$ and BRCA1 protein phosphorilation (A). $\beta$-actin served as loading control. NER efficiency was determined at several RPD after in vitro expansion using the unscheduled DNA synthesis assays (B). Error bars represent standard deviation. Statistical analysis was performed using one-way ANOVA and Tukey post-test with a significance level of $0.05 .{ }^{* *} P<0.01$ and ${ }^{* * * *} P<0.001$.

\section{DNA damage induction is associated with loss of multipotency}

The data described above show a correlation between DNA damage accumulation and loss of hMSC multipotency but whether this is a causal relation is not known. To mimic the increased DNA damage load in culture expanded hMSCs, we induced DNA damage using hydrogen peroxide $\left(\mathrm{H}_{2} \mathrm{O}_{2}\right)$ and paraquat (PQ). Hydrogen peroxide has been the most commonly used source of oxidative stress and known to induce features similar to replicative senescence like: morphology changes, senescence-associated galactosidade activity, cell cycle regulation [3336]. Being paraquat another extensively used compound to induce superoxide production causing extensive mitochondrial damage [37-39].

First, we established a dose-response curve of hydrogen peroxide on proliferation of hMSCs. Up to $50 \mu \mathrm{M} \mathrm{H}_{2} \mathrm{O}_{2}$, the differences observed were not statistically significant (Fig. 4A). For paraquat, a concentration of $5 \mu \mathrm{M}$ and $10 \mu \mathrm{M}$ was used based on our previous experiments (data not shown). Based on this, we choose 2 concentrations of $\mathrm{H}_{2} \mathrm{O}_{2}(30$ and $50 \mu \mathrm{M})$ and 2 of paraquat $(5$ and $10 \mu \mathrm{M})$ to treat hMSCs, where after 6 days, both DNA damage accumulation and ALP induction was assessed and compared to the control situation. Under these conditions, DNA damage accumulation occurred evidenced by the increase in $53 \mathrm{BP} 1$ positive cells $\left[33.33 \pm 4.9 \%\right.$ in the control situation to $52.83 \pm 6 \%$ in $30 \mu \mathrm{M} \mathrm{H}_{2} \mathrm{O}_{2}$ treated hMSCs and $51.8 \pm 4.7$ in $5 \mu \mathrm{M}$ paraquat treated cells, (Fig. 4B)] and the number of 53BP1 foci per cell which increased from $0.50 \pm 0.05$ to $1.68 \pm 0.19\left(\mathrm{H}_{2} \mathrm{O}_{2}, 30 \mu \mathrm{M}\right)$ or 0.77 \pm 0.06 in (Paraquat, $5 \mu \mathrm{M}$ ) in treated cells (Fig. $4 \mathrm{C}$ ). When a stronger concentra- 
tion of DNA damage inducer was used, both the percentage of damaged cells (53BP1 positive, Fig. 4B) and average foci per cell (Fig. 4C), increased even further. When a DNA-damage inducer was used, an increase in the $\beta$-galactosidase activity was also observed (Fig. S3). Exposure of hMSCs for 6 days to DNA damage inducers did not have an effect on ALP activity in basic medium (except for cells treated with $50 \mu \mathrm{M} \mathrm{H}_{2} \mathrm{O}_{2}$ ), but it did significantly inhibit dexamethasone-induced ALP expression in all the conditions tested (Fig. 4D). Mineralization was also significantly repressed by the usage of any of the inducers (Fig. 4E).

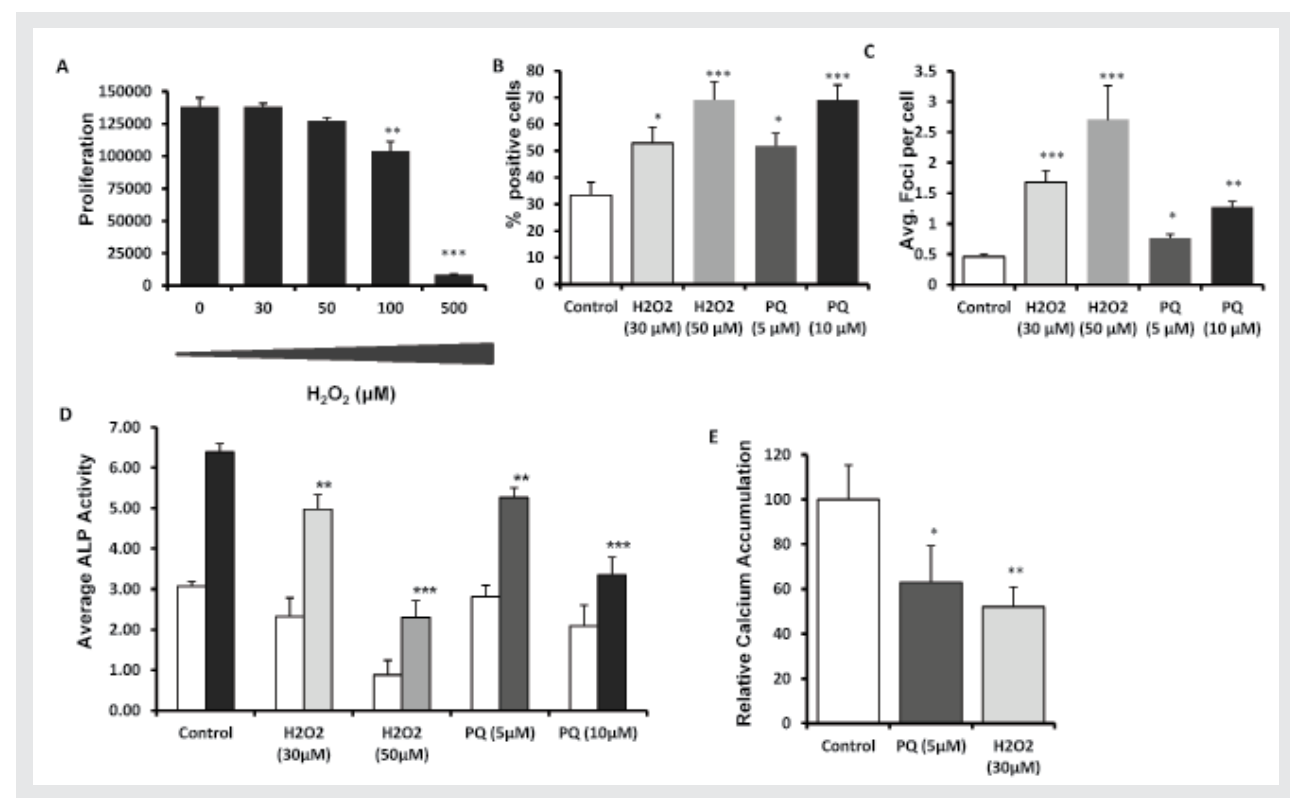

Fig. 4 Effects of the exposure of DNA damage inducers on the differentiation potential of hMSCs. Effect of variant concentrations of hydrogen peroxide $\left(\mathrm{H}_{2} \mathrm{O}_{2}\right)$ on the proliferation of hMSCs after 6 days of exposure (A). Effect of continuous exposure (6 days) of $\mathrm{H}_{2} \mathrm{O}_{2}$ and paraquat on the differentiation potential (ALP levels and mineralization) of hMSCs (D, E) and on the DNA damage load $(B, C)$. DNA damage load was assessed by quantifying the percentage of 53BP1 positive cells $(\boldsymbol{B})$ and 53BP1 foci per cell $(\boldsymbol{C})$. Data are expressed as total ALP normalized for cell number repeated in at least three different donors. Error bars represent standard deviation. Statistical analysis was performed using one-way ANOVA and Tukey post-test with a significance level of 0.05. ${ }^{*} P<0.05,{ }^{* *} P<0.01$ and ${ }^{* * *} P<0.001$. 


\section{Discussion}

Human mesenchymal stromal cells are multipotent cells, which are able to differentiate into several lineages [1-5]. They can be isolated from bone marrow and other tissues and appear not to require tissue matching between MSC donor and recipient [40]. Therefore, they are promising candidates for cell based therapies for a number of regenerative conditions [10]. However, the attractiveness of this cell source for regenerative medicine depends largely on the possibility to expand, differentiate and induce the desired effect in vivo after the expansion period. It is therefore crucial to analyze the effect of long-term in vitro expansion.

There is one report claiming spontaneous immortalization of adipose-derived MSCs [41], although we never observed it in cells from at least 6 donors which we followed up for 3 months after cell cycle arrest. Our observation is supported by a number of other studies [19, 42-43]. For example, the consequences of longterm in vitro expansion have also been evaluated in MSCs derived from bone marrow and adipose tissue of both humans and rhesus macaques [44]. The authors observed that, unlike rhesus MSCs, human MSCs did not develop polyploidy throughout the prolonged culture and no chromosomal rearrangements were detected in any of the human MSC samples analyzed at any passage. The only observation we made that may resemble spontaneous transformation was a transient and partial recovery in cell morphology and proliferation in cells from one donor. However, after a few cell divisions, the cells permanently arrested.

Although immortalization was not observed, in vitro expansion did negatively affect the hMSCs from an early time point of culture, seen by the decrease in both the proliferation rate and differentiation potential. The decrease in proliferation rate seems constant until senescence hits in after about 20 population doublings but starts right from the beginning of the expansion period. There are various stresses that can induce replicative senescence i.e. oxidative stress, oncogene overexpression and telomere shortening. The response to oncogene overexpression is thought to be a tumor-suppressive mechanism, by which cells prevent the uncontrolled proliferation due to oncogene activation. E.g. normal cells senesce in response to the activation of certain oncogenes, such as RAS or of its downstream effectors [45-46]. Oncogene mediated senescence is most likely to occur late during the expansion phase, because mutagenic events have to occur. However, we observed an instant decline in proliferative capacity in cultured hMSCs, which makes the oncogene theory not likely, although we cannot exclude it.

The decline in proliferation and differentiation can also be caused by telomere shortening. During cell expansion, a gradual shortening of the average length of telomeres is observed eventually leading to telomere uncapping. Once unprotected, dysfunctional telomeres activate a DNA damage response resulting in per- 
manent cell cycle arrest. We formerly reported that there is a direct association between the age of primates and the levels of telomere-dysfunction found in their skin fibroblasts, providing a clear association between telomere dysfunction and senescence in vivo [47]. In this respect is important to note that telomere length varies among the MSC population and therefore, initiation of the senescence program is expected to start at different numbers of population doublings for different subclones in a MSC culture. However, we never observed clonal expansion in culture. Although telomere length was not measured, we could not detect the telomeres at RPD27, which suggested to us that telomere shortening contributes to the last stages of senescence and to terminal cell cycle arrest.

In this manuscript we also describe that with increasing time of culture, there is an increase in the DNA damage load, even though the capacity of the nucleotide excision repair pathways remains unchanged. Recently, in a complementary study, the initial step of base excision repair in uncultured and cultured adipose-tissue derived mesenchymal stem cells (AT-MSCs) was compared [48]. By analyzing the base removal activities (8-oxoG, uracil, 5-ohU, and $\varepsilon$ A lesions) and expression levels of relevant DNA glycosylases, the authors concluded that the DNA glycosylase activities tested were stable throughout culturing, suggesting that high DNA repair activity (base excision repair) is maintained, although a slight decrease in 8-oxoG removal activity was observed at senescence. The gene expression analyses on the DNA glycosylases showed no substantial changes in mRNA expression. There are, however, reports where genes related to DNA repair were repressed after in vitro culturing, although, most refer to experiments performed in nonhuman cells, so possible species variation must be taken into consideration [4951]. These results suggest that the DNA damage load which the hMSCs are facing in culture is higher than what is possible to be repaired, leading to a constant DNA damage accumulation, activation of the DNA damage signaling pathway and ultimately to loss of differentiation capacity and cellular senescence. Previous reports demonstrated that DNA damage accumulation due to deficiencies in DNA damage repair not only induces premature ageing phenotypes [52] but also limit the function of hematopoietic stem cells with age [23-24]. A recent publication also suggest that the senescence growth arrest in hMSCs after in vitro expansion may result from activation of stress signaling pathways and consequent onset of stress responses, due in part to (reactive oxygen species) ROS production during prolonged in vitro culture [53]. The authors by introducing Wip1 (wild-type p53 inducible phosphatase-1), a stress signaling modulator, manage to extend the life span of hMSCs and to overcome oncogenic stress mediated growth arrest.

In addition to the decline in proliferation, we observed a decrease in the differentiation potential. In contrast to two previous reports which claim mainte- 
nance or increased propensity for osteogenic differentiation of hMSCs after in vitro expansion $[2,54]$, our data show that osteogenesis is more affected by the in vitro culture period than adipogenesis. These results are confirmed by several other reports $[19,42-43,55]$. For instance, it was shown that after 20 population doublings, hMSCs were unable to mineralize and presented a negligible ALP induction by dexamethasone. Moreover, the amount of bone formed by hMSCs after implantation in nude mice displayed a dependence on the in vitro age of the cells [42]. Interestingly, the loss of differentiation capacity observed during in vitro expansion of hMSCs precedes terminal senescence and coincides with the activation of the DNA damage signaling pathways. We hypothesize that with expansion, there is an increase in DNA damage content, and therefore activation of the DNA damage signaling pathways, which results in a decrease in differentiation potential. In accordance, we used hydrogen peroxide and paraquat to increase the level of DNA damage in hMSCs at a concentration that did not affect significantly the proliferation. These concentrations proved still to be enough to increase DNA damage levels and affect the differentiation capacity. These results, in combination with the knowledge that, with age, adult haematopoietic stem cell function declines and that DNA damage and epigenetic modification limits the regenerative potential of those cells, seem to further substantiate the possible link between DNA damage accumulation and loss of stemness [22-24].

The significant drop in quality of culture expanded hMSCs poses some concerns considering the possibility to use these cells for clinical applications. We conclude that hMSCs are susceptible to accumulate DNA damage upon in vitro expansion and that this DNA damage accumulation correlates directly with the observed loss of multipotency after hMSC in vitro expansion. Although they maintained an effective nucleotide excision repair activity, there was still a progressive DNA damage accumulation which might be one of the mechanisms underlying age-related loss of tissue function.

These results suggest that hMSCs should be minimally expanded and leave a window of possibility for the use and screen of molecules that might circumvent or reduce the in vitro DNA damage accumulation, leading to a possible extension of the differentiation capacity and making them even more suitable for clinical applications.

\section{Acknowledgments}

We thank Dr. L. Creemers, Dr. W. Dhert (University Medical Center Utrecht) for kindly providing us with bone marrow aspirates. We also thank Ruud Licht and Anouk Leusink for technical support and The Netherlands Technology Foundation (STW grant TGT.6745) for financial support. 


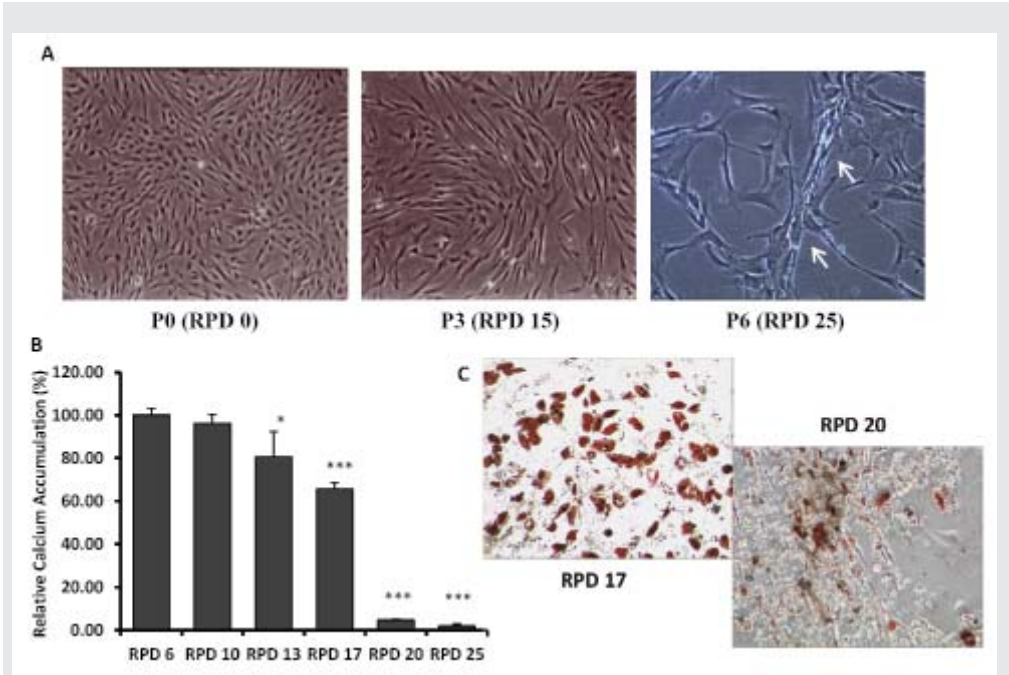

Figure S1. hMSCS morphology and differentiation is affected by in vitro $e x-$ pansion

Phase-contrast photos of hMSCs at different $R P D, x 40 \mathrm{mag}$ nification. An evident change in cell size and morphology can be observed with increased time of culture. (B) Change in the mineralization potential after in vitro expansion. Relative calcium accumulation by hMSCs in MM after 28 days, expressed as percentage reduction in calcium deposition ability over passages compared to RPD 6. No detectable calcium was measured in hMSCs cultured in BM (data not shown). (C) Phase-contrast images of hMSC in adipogenic medium at different RPD. Adipocytes are stained with Oil red $O$ and visualized at $x 40$ magnification. Error bars represent standard deviation. Statistical analysis was performed using one-way ANOVA and Tukey posttest with a significance level of 0.05 . "represents $p<0.01$ to 0.05 and ${ }^{* * *} p<0.001$.
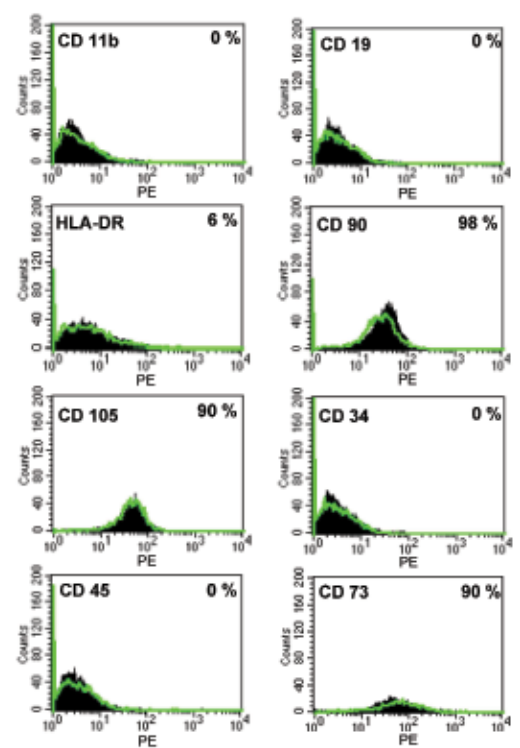

Figure S2. Immunophenotype of hMSCs (RPD 6 vs RPD 20). Representative overlay of flow cytometry histograms of hMSCs from human bone marrow are presented. Black histogram, RPD 6 and green line, histogram of RPD 20. 


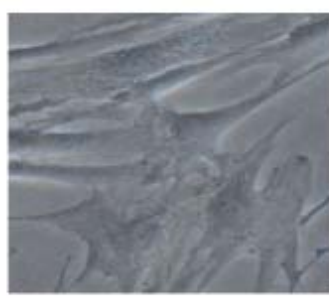

Control

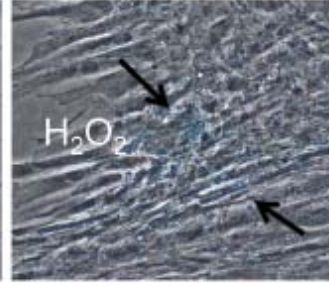

$\mathrm{H} 2 \mathrm{O} 2(30 \mu \mathrm{M})$

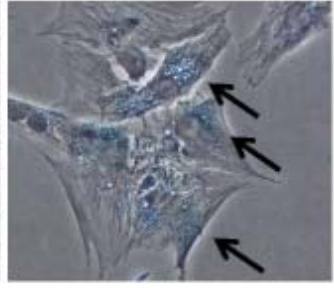

$\mathrm{H} 2 \mathrm{O} 2(50 \mu \mathrm{M})$

Figure S3. Senescence-Associated $\beta$-galactosidase expression ater DNA damage induction. RPD 6 cells were exposed to 0,30 or $50 \mu M$ of $\mathrm{H}_{2} \mathrm{O}_{2}$ for 6 days after which cells were stained for SA- $\beta$-galactosidase.

\begin{tabular}{|l|c|c|c|c|c|c|c|}
\hline $\begin{array}{l}\text { Donor } \\
\text { number: }\end{array}$ & 24 & 26 & 29 & 36 & 41 & 42 & 46 \\
\hline Gender: & Fernale & Male & Male & Fernale & Fernale & Fernale & Fernale \\
\hline Year birth: & 1945 & 1955 & 1939 & 1967 & 1967 & 1978 & 1944 \\
\hline $\begin{array}{l}\text { Aspiration } \\
\text { site: }\end{array}$ & Acetabulum & Acetabulum & Acetabulum & lliac Crest & Acetabulum & lliac Crest & Acetabulum \\
\hline
\end{tabular}

Table S4. Information relative to the hMSCs donors used on this manuscript.

\section{References:}

1. Haynesworth SE, Goshima J, Goldberg VM, Caplan AI (1992) Characterization of cells with osteogenic potential from human marrow. Bone 13: 81-88.

2. Bruder SP, Jaiswal N, Haynesworth SE (1997) Growth kinetics, self-renewal, and the osteogenic potential of purified human mesenchymal stem cells during extensive subcultivation and following cryopreservation. J Cell Biochem 64: 278-294.

3. Pittenger MF, Martin BJ (2004) Mesenchymal stem cells and their potential as cardiac therapeutics. Circ Res 95: 9-20.

4. Xu W, Zhang X, Qian H, Zhu W, Sun X, et al. (2004) Mesenchymal stem cells from adult human bone marrow differentiate into a cardiomyocyte phenotype in vitro. Exp Biol Med (Maywood) 229: 623-631.

5. Sanchez-Ramos J, Song S, Cardozo-Pelaez F, Hazzi C, Stedeford T, et al. (2000) Adult bone marrow stromal cells differentiate into neural cells in vitro. Exp Neurol 164: 247-256.

6. Meijer GJ, de Bruijn JD, Koole R, van Blitterswijk CA (2007) Cell-based bone tissue engineering. PLoS Med 4: e9.

7. Quarto R, Mastrogiacomo M, Cancedda R, Kutepov SM, Mukhachev V, et al. (2001) 
Repair of large bone defects with the use of autologous bone marrow stromal cells. $N$ Engl $J$ Med 344: 385-386.

8. Cancedda R, Mastrogiacomo M, Bianchi G, Derubeis A, Muraglia A, et al. (2003) Bone marrow stromal cells and their use in regenerating bone. Novartis Found Symp 249: 133-143; discussion 143-137, 170-134, 239-141.

9. Schimming R, Schmelzeisen R (2004) Tissue-engineered bone for maxillary sinus augmentation. J Oral Maxillofac Surg 62: 724-729.

10. Brooke G, Cook M, Blair C, Han R, Heazlewood C, et al. (2007) Therapeutic applications of mesenchymal stromal cells. Semin Cell Dev Biol 18: 846-858.

11. Caplan AI (2009) Why are MSCs therapeutic? New data: new insight. J Pathol 217: 318-324.

12. Csete M, Walikonis J, Slawny N, Wei Y, Korsnes S, et al. (2001) Oxygen-mediated regulation of skeletal muscle satellite cell proliferation and adipogenesis in culture. J Cell Physiol 189: 189-196.

13. Fehrer C, Brunauer R, Laschober G, Unterluggauer H, Reitinger S, et al. (2007) Reduced oxygen tension attenuates differentiation capacity of human mesenchymal stem cells and prolongs their lifespan. Aging Cell 6: 745-757.

14. Potier E, Ferreira E, Andriamanalijaona R, Pujol JP, Oudina K, et al. (2007) Hypoxia affects mesenchymal stromal cell osteogenic differentiation and angiogenic factor expression. Bone 40: 1078-1087.

15. Hayflick L, Moorhead PS (1961) The serial cultivation of human diploid cell strains. Exp Cell Res 25: 585-621.

16. Campisi J, d'Adda di Fagagna F (2007) Cellular senescence: when bad things happen to good cells. Nat Rev Mol Cell Biol 8: 729-740.

17. Sharpless NE, DePinho RA (2007) How stem cells age and why this makes us grow old. Nat Rev Mol Cell Biol 8: 703-713.

18. Cichowski K, Hahn WC (2008) Unexpected pieces to the senescence puzzle. Cell 133: 958-961.

19. Siddappa R, Licht R, van Blitterswijk C, de Boer J (2007) Donor variation and loss of multipotency during in vitro expansion of human mesenchymal stem cells for bone tissue engineering. J Orthop Res 25: 1029-1041.

20. Hasty P, Vijg J (2004) Accelerating aging by mouse reverse genetics: a rational approach to understanding longevity. Aging Cell 3: 55-65.

21. de Boer J, Hoeijmakers JH (2000) Nucleotide excision repair and human syndromes. Carcinogenesis 21: 453-460.

22. Chambers SM, Shaw CA, Gatza C, Fisk CJ, Donehower LA, et al. (2007) Aging hematopoietic stem cells decline in function and exhibit epigenetic dysregulation. PLoS Biol 5: e201.

23. Nijnik A, Woodbine L, Marchetti C, Dawson S, Lambe T, et al. (2007) DNA repair is limiting for haematopoietic stem cells during ageing. Nature 447: 686-690.

24. Rossi DJ, Bryder D, Seita J, Nussenzweig A, Hoeijmakers J, et al. (2007) Deficiencies in DNA damage repair limit the function of haematopoietic stem cells with age. Nature 447: 725-729. 
25. Both SK, van der Muijsenberg AJ, van Blitterswijk CA, de Boer J, de Bruijn JD (2007) A rapid and efficient method for expansion of human mesenchymal stem cells. Tissue Eng 13: 3-9.

26. Herbig U, Jobling WA, Chen BP, Chen DJ, Sedivy JM (2004) Telomere shortening triggers senescence of human cells through a pathway involving ATM, p53, and p21(CIP1), but not p16(INK4a). Mol Cell 14: 501-513.

27. Ebert R, Ulmer M, Zeck S, Meissner-Weigl J, Schneider D, et al. (2006) Selenium supplementation restores the antioxidative capacity and prevents cell damage in bone marrow stromal cells in vitro. Stem Cells 24: 1226-1235.

28. Vermeulen W, Scott RJ, Rodgers S, Muller HJ, Cole J, et al. (1994) Clinical heterogeneity within xeroderma pigmentosum associated with mutations in the DNA repair and transcription gene ERCC3. Am J Hum Genet 54: 191-200.

29. Schultz LB, Chehab NH, Malikzay A, Halazonetis TD (2000) p53 binding protein 1 (53BP1) is an early participant in the cellular response to DNA double-strand breaks. J Cell Biol 151: 1381-1390.

30. Rappold I, Iwabuchi K, Date T, Chen J (2001) Tumor suppressor p53 binding protein 1 (53BP1) is involved in DNA damage-signaling pathways. J Cell Biol 153: 613-620.

31. Anderson L, Henderson C, Adachi Y (2001) Phosphorylation and rapid relocalization of 53BP1 to nuclear foci upon DNA damage. Mol Cell Biol 21: 1719-1729.

32. Xia Z, Morales JC, Dunphy WG, Carpenter PB (2001) Negative cell cycle regulation and DNA damage-inducible phosphorylation of the BRCT protein 53BP1. J Biol Chem 276: 2708-2718.

33. Chen QM, Bartholomew JC, Campisi J, Acosta M, Reagan JD, et al. (1998) Molecular analysis of $\mathrm{H}_{2} \mathrm{O}_{2}$-induced senescent-like growth arrest in normal human fibroblasts: p53 and Rb control G1 arrest but not cell replication. Biochem J 332: 43-50.

34. Chen Q, Ames BN (1994) Senescence-like growth arrest induced by hydrogen peroxide in human diploid fibroblast F65 cells. Proc Natl Acad Sci U S A 91: 4130-4134.

35. Dimri GP, Lee X, Basile G, Acosta M, Scott G, et al. (1995) A biomarker that identifies senescent human cells in culture and in aging skin in vivo. Proc Natl Acad Sci U S A 92: 9363-9367.

36. Frippiat C, Dewelle J, Remacle J, Toussaint O (2002) Signal transduction in $\mathrm{H}_{2} \mathrm{O}_{2}$ induced senescence-like phenotype in human diploid fibroblasts. Free Radic Biol Med 33: 1334-1346.

37. Krall J, Bagley AC, Mullenbach GT, Hallewell RA, Lynch RE (1988) Superoxide mediates the toxicity of paraquat for cultured mammalian cells. J Biol Chem 263: 1910-1914.

38. Jung T, Hohn A, Catalgol B, Grune T (2009) Age-related differences in oxidative protein-damage in young and senescent fibroblasts. Arch Biochem Biophys 483: 127-135.

39. McCarthy S, Somayajulu M, Sikorska M, Borowy-Borowski H, Pandey S (2004) Paraquat induces oxidative stress and neuronal cell death; neuroprotection by water-soluble Coenzyme Q10. Toxicol Appl Pharmacol 201: 21-31.

40. Ringden O, Uzunel M, Rasmusson I, Remberger M, Sundberg B, et al. (2006) Mesenchymal stem cells for treatment of therapy-resistant graft-versus-host disease. Transplantation 81: 1390-1397. 
41. Rubio D, Garcia-Castro J, Martin MC, de la Fuente R, Cigudosa JC, et al. (2005) Spontaneous human adult stem cell transformation. Cancer Res 65: 3035-3039.

42. Stenderup K, Justesen J, Clausen C, Kassem M (2003) Aging is associated with decreased maximal life span and accelerated senescence of bone marrow stromal cells. Bone 33: 919-926.

43. Bonab MM, Alimoghaddam K, Talebian F, Ghaffari SH, Ghavamzadeh A, et al. (2006) Aging of mesenchymal stem cell in vitro. BMC Cell Biol 7: 14.

44. Izadpanah R, Kaushal D, Kriedt C, Tsien F, Patel B, et al. (2008) Long-term in vitro expansion alters the biology of adult mesenchymal stem cells. Cancer Res 68: 4229-4238.

45. Serrano M, Lin AW, McCurrach ME, Beach D, Lowe SW (1997) Oncogenic ras provokes premature cell senescence associated with accumulation of p53 and p16INK4a. Cell 88: 593-602.

46. Zhu J, Woods D, McMahon M, Bishop JM (1998) Senescence of human fibroblasts induced by oncogenic Raf. Genes Dev 12: 2997-3007.

47. Herbig U, Ferreira M, Condel L, Carey D, Sedivy JM (2006) Cellular senescence in aging primates. Science 311: 1257.

48. Hildrestrand GA, Duggal S, Bjoras M, Luna L, Brinchmann JE (2009) Modulation of DNA glycosylase activities in mesenchymal stem cells. Exp Cell Res 315: 2558-2567.

49. Kenyon J, Gerson SL (2007) The role of DNA damage repair in aging of adult stem cells. Nucleic Acids Res 35: 7557-7565.

50. Wagner W, Bork S, Horn P, Krunic D, Walenda T, et al. (2009) Aging and replicative senescence have related effects on human stem and progenitor cells. PLoS ONE 4: e5846.

51. Galderisi U, Helmbold H, Squillaro T, Alessio N, Komm N, et al. (2009) In vitro senescence of rat mesenchymal stem cells is accompanied by downregulation of stemness-related and DNA damage repair genes. Stem Cells Dev 18: 1033-1042.

52. de Boer J, Andressoo JO, de Wit J, Huijmans J, Beems RB, et al. (2002) Premature aging in mice deficient in DNA repair and transcription. Science 296: 1276-1279.

53. Lee JS, Lee MO, Moon BH, Shim SH, Fornace AJ, Jr., et al. (2009) Senescent growth arrest in mesenchymal stem cells is bypassed by Wip1-mediated downregulation of intrinsic stress signaling pathways. Stem Cells 27: 1963-1975.

54. Wagner W, Horn P, Castoldi M, Diehlmann A, Bork S, et al. (2008) Replicative senescence of mesenchymal stem cells: a continuous and organized process. PLOS ONE 3: e2213.

55. Izadpanah R, Trygg C, Patel B, Kriedt C, Dufour J, et al. (2006) Biologic properties of mesenchymal stem cells derived from bone marrow and adipose tissue. J Cell Biochem 99: 1285-1297. 


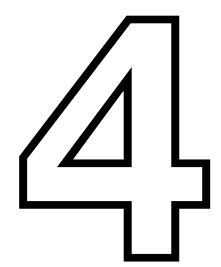




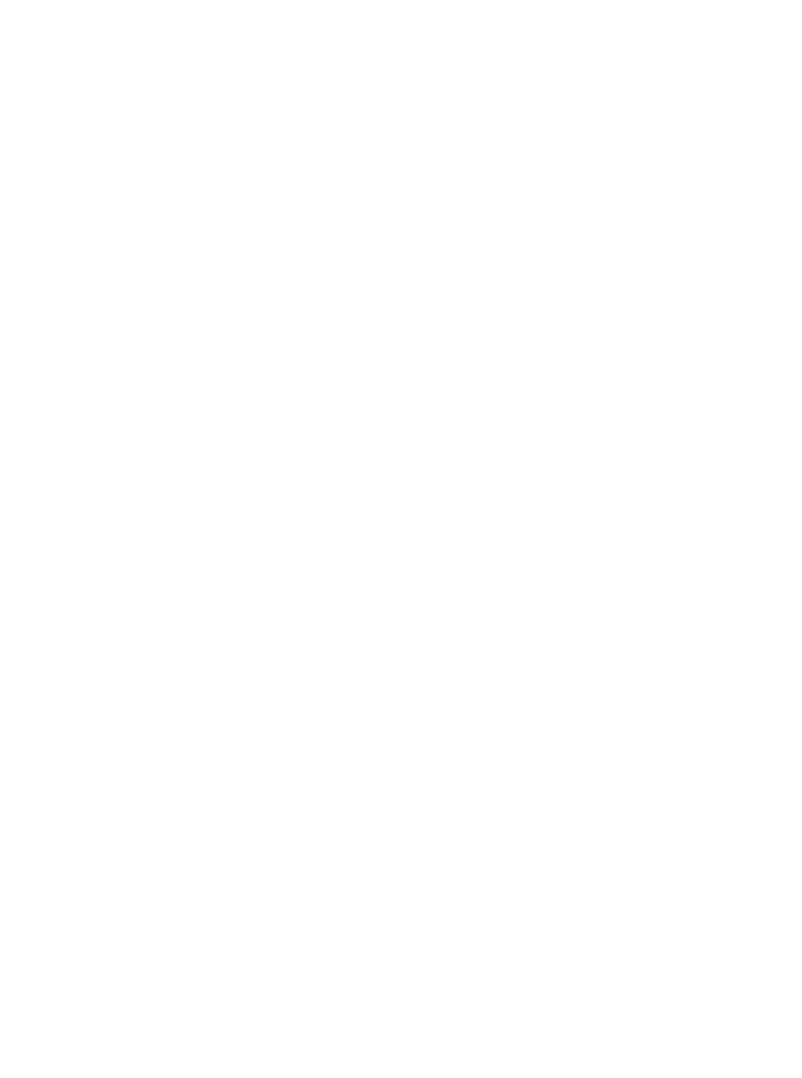




\title{
Chapter 4
}

\section{Effect of Antioxidant Supplementation on the Total Yield, Oxi- dative Stress Levels and Multipotency of bone marrow-derived Human Mesenchymal Stromal Cells}

\author{
Hugo Alves, Anouk Mentink, Clemens van Blitterswijk, Jan de Boer \\ Department of Tissue Regeneration, MIRA Institute for Biomedical Technology and \\ Technical Medicine, University of Twente, Enschede, The Netherlands.
}

\begin{abstract}
Bone marrow-derived multipotent stromal cells (MSCs) are the most frequently investigated cell type for potential regenerative strategies because they are relatively easy to isolate and are able to differentiate into several mesenchymal lineages. Unfortunately, during ex vivo culture, MSCs present gradual loss of differentiation potential and reduced clinical efficacy. Reactive oxygen species (ROS) are associated with oxidative damage and accumulate during MSC expansion. Because ROS are believed to be involved in the loss of multipotency, we hypothesized that compounds with antioxidant activity have the capacity to scavenge ROS, prevent cellular damage and rescue culture-induced loss of multipotency. In this manuscript, we show that antioxidant supplementation can partially rescue the loss of ALP expression induced by oxidizing agents and increases the yield of hMSCs, when supplemented to a fresh bone marrow biopsy. Concomitantly, oxidative DNA damage and ROS levels in hMSCs were reduced by anti-oxidants. We conclude that anti-oxidant supplementation during MSC expansion reduces the DNA damage load and increases the MSC yield.
\end{abstract}

Adapted from Alves $\mathrm{H}$, et al. Submitted for publication. 


\section{Introduction}

The possibility to apply mesenchymal stromal cells (MSC) for bone regeneration has gained considerable interest in the last decades due to their easy isolation, efficient in vitro proliferation capacity and broad differentiation potential [1]. Pre-clinical proof of concept has been obtained in animal models [2], but clinical application has been hampered by large donor variability and the loss of MSC multipotency upon expansion in vitro. For instance, it has been demonstrated that the amount of ectopic bone formation in immune-deficient mouse models correlated to the extent the cells were expanded in vitro prior to implantation [3]. These observations are in line with our own observations showing that ALP expression, mineralization and adipogenesis of culture expanded hMSCs decreases sharply between passage 3 and $4[4,5]$. Moreover, we observed that during in vitro culture of hMSCs, the level of DNA damage increases and the DNA damage signaling pathway is activated around passage 3-4 [4]. Based on this, we hypothesize that loss of multipotency is the consequence of the accumulation of cellular damage which cells face during culture. Potential sources of cellular damage are the so-called reactive oxygen species (ROS) such as hydroxyl radicals, superoxide anions and $\mathrm{H}_{2} \mathrm{O}_{2}$. ROS can inflict a multitude of damages to cells resulting in protein misfolding, altered protein conformation or even fragmentation $[6,7,8]$ and lipid peroxidation [9]. Damage to nuclear DNA includes DNA fragmentation, oxidation of bases such as 8-oxo-7,8-dihydroguanine (8-oxo-G), strand breakage [10] and DNA-protein cross-links. Oxidative stress frequently results from an imbalance in redox signaling, for instance due to the production of high levels of oxidants during normal cellular metabolism (e.g. mitochondrial electron transport or NADPH oxidases) or from environmental stimuli (e.g. cytokines) [11]. Oxidative stress is implicated in the etiology of various degenerative diseases and the process of aging $[11,12]$. Many mutations that prolong life provide a global increase in stress resistance. For instance, some strains of Drosophila with extended life span do not only display increased oxidative stress resistance but also enhanced antioxidant activity [13,14]. A correlation has been suggested between the metabolic rate of an organism, its production of ROS and life span [15], and later evidence indicates that longevity correlates best to ROS production [16].

ROS have been associated to the pathogenesis of bone loss-related diseases. For example, aged osteoporotic women present a marked decrease in plasma antioxidants [17]. A biochemical link between increased oxidative stress and reduced bone density was also established in a study of 48 women and 53 men [18]. Furthermore, osteoporosis has been noted in two mouse models of premature aging in which a role for oxidative damage has been suggested [19,20]. Finally, we observed that osteogenic differentiation was inhibited when hMSCs were exposed to 
oxidative damage inducing agents [4].

With the documented link between oxidative damage and loss of functionality during ageing and MSC expansion, several studies have addressed the potential use of reagents with antioxidant properties to suppress the effect. For instance, in hematopoietic stem cells defective in the cell cycle checkpoint activator ataxia telangiectasia mutated, the self-renewal capacity can be enhanced by supplementation of anti-oxidative substances such as $\mathrm{N}$-acetyl-cysteine to the culture medium [21]. Recently, it was demonstrated that during normal cell culturing, MSC present low antioxidant levels and, therefore, display high oxidative stress. Supplementation of the anti-oxidant selenium increased the antioxidant capacity of the cells and reduced cell damage [22]. However, it remains unclear whether antioxidant supplementation is able to restore or prevent the loss of multipotency and proliferation observed during in vitro expansion and whether it could extend the period in which these cells would remain functionally viable for clinical applications. We, therefore, investigated the role of antioxidants during in vitro expansion and differentiation of human mesenchymal stromal cells. We used a model system to mimic oxidative damage generated during hMSC in vitro expansion, to further elucidate the effect of oxidative damage in the loss of differentiation potential, as well as, the role of antioxidants to prevent or reduce damage accrual. Selected antioxidants were tested for their capability to prevent/restore the loss of multipotency that hMSCs face during normal in vitro culturing.

\section{Materials and Methods}

\section{Isolation and culture of hMSCs}

Bone marrow aspirates were obtained from donors with written informed consent. In short, aspirates were resuspended using $20 \mathrm{G}$ needles, plated at a density of $5 \times 10^{5}$ cells $/ \mathrm{cm}^{2}$ and cultured in hMSC proliferation medium (PM) containing $\alpha$-minimal essential medium ( $\alpha$-MEM, Life Technologies), $10 \%$ fetal bovine serum (FBS, Cambrex), $0.2 \mathrm{mM}$ ascorbic acid (Asap, Life Technologies), $2 \mathrm{mM} \mathrm{L-}$ glutamine (Life Technologies), $100 \mathrm{U} / \mathrm{mL}$ penicillin (Life Technologies), $100 \mathrm{mg} /$ $\mathrm{mL}$ streptomycin (Life Technologies) and $1 \mathrm{ng} / \mathrm{mL}$ basic fibroblast growth factor (bFGF, Instruchemie). Cells were grown at $37^{\circ} \mathrm{C}$ in a humid atmosphere with $5 \%$ $\mathrm{CO}_{2}$. Medium was refreshed twice a week and cells were used for further subculturing or cryopreservation when reaching 80-90\% confluence. After expansion, cells were characterized for surface marker expression, and presented the typical MSC expression profile [> 90\% positive for CD73, CD90 and CD 105; < 2\% positive for CD11b, CD19, CD34, CD45, and low expression of HLA-DR (around 
6\%)] as described previously [4]. hMSC basic medium/control medium (BM) was composed of hMSC PM without bFGF. hMSC osteogenic medium (OM) was composed of hMSC basic medium supplemented with $10^{-8} \mathrm{M}$ dexamethasone (dex, Sigma) and hMSC mineralization medium (MM) was composed of basic medium supplemented with $10^{-8} \mathrm{M}$ dex and $0.01 \mathrm{M} \beta$-glycerophosphate (Sigma).

\section{Proliferation}

To assess the effect of antioxidant supplementation on hMSC proliferation, cells were seeded at 1000 cells $/ \mathrm{cm}^{2}$ in proliferation medium until they reached 80-90\% confluence and were then counted using either a Coulter Counter or using the Alamar blue assay. Briefly, the Alamar blue solution was diluted 1:10 in culture medium, and cells were incubated for 4 hrs. The Alamar blue solution from each well was then transferred into 96-well plates, and fluorescence was measured using a Perkin Elmer Victor ${ }^{3}$ plate reader.

\section{Alkaline Phosphatase (ALP) activity}

For the biochemical ALP assay, hMSCs were seeded at 1000 cells $/ \mathrm{cm}^{2}$ and allowed to adhere for 10-15 hrs in BM and then cells were grown in OM for 6 days. Each experiment was performed at least in triplicate with a negative control (cells grown in BM) and a positive control (cells grown in OM). Briefly, cells were washed twice with PBS (Life technologies) and lysed using a $0.2 \%$ Triton X-100 solution in $100 \mathrm{mM}$ PBS pH 7.8, supplemented with a protease inhibitor cocktail (Roche Applied Science). The lysate was incubated in the dark at $25^{\circ} \mathrm{C}$ with CDP-Star substrate (Roche) and allowed to react for $30 \mathrm{~min}$. Luminescence was measured using a VICTOR ${ }^{3}$ luminometer (Perkin Elmer) at $25^{\circ} \mathrm{C}$. The total ALP luminescence was normalized for cell number using Alamar blue as readout. The data was then analyzed using Student's t-test at $\mathrm{p}<0.05$.

\section{Immunofluorescence staining of 53BP1 foci}

Cells were grown on glass coverslips for at least $48 \mathrm{hrs}$ prior to immunostaining to minimize stress as a consequence of passaging. Cells were washed twice with PBS and fixed for $20 \mathrm{~min}$. with freshly prepared $4 \%$ paraformaldehyde in PBS. After permeabilization for 20 min. with PBST-0.2\% (PBS with $0.2 \%$ Triton X-100), cells were blocked in 3\% BSA in PBST-0.1\% for $1 \mathrm{hr}$. The 53BP1 antibody (Novus) was diluted in blocking buffer and incubated overnight at $4^{\circ} \mathrm{C}$. Samples were then washed with Tris-buffered saline with Tween-20 (TBST), incubated with Al- 
exa-488 secondary antibody and visualized by confocal laser scanning microscopy.

\section{Oxidative Stress determination (8-oxoG and CM- $\mathrm{H}_{2}$ DCFDA)}

For the determination of oxidative stress load, two different methods were employed. The first method is based on the detection of 8-oxoguanine adducts in fixed permeabilized cells using flow cytometry. After fixation and permeabilization of hMSCs, a FITC-labeled protein conjugate specifically binding to the 8-oxyguanine moiety was added for $1 \mathrm{hr}$, according to manufacturer's instructions (Argutus Medical OxyDNA test - BD Biosciences). The presence of the oxidized DNA was then measured by FACS in at least 10,000 cells. The second method consisted in the direct detection of intracellular reactive oxygen metabolites as described previously [23]. CM- $\mathrm{H}_{2}$ DCFDA is a cell-permeant indicator for ROS that is non-fluorescent until removal of the acetate groups by intracellular esterases and oxidation occurs within the cell [24]. Shortly, adherent cells were harvested with trypsin and combined with cells floating in the medium. Cells were then washed and treated with $10 \mu \mathrm{M}$ 5,-6-chloromethyl-2',7'-dichlorodihydrofluorescein diacetate acetyl ester (CM- $\mathrm{H}_{2} \mathrm{DCFDA}$, Molecular Probes) for $30 \mathrm{~min}$. at $37^{\circ} \mathrm{C}$. Ten thousand cells were then analyzed on a BD FACScan.

\section{Alkaline Phospahatase (ALP) expression}

The effect of oxidative damage inducers and antioxidants on ALP expression (as a readout for osteogenic differentiation potential) was also measured by flow cytometry. In short, cells were seeded at 5000 cells $/ \mathrm{cm}^{2}$ in basic medium (BM), allowed to attach for 10-15 hrs and then cultured for 4 days. Each experiment consisted of a negative control (cells grown in BM), a positive control (cells grown in $\mathrm{OM}$ ), and one or more experimental conditions. After 4 days of treatment, cells were trypsinized and incubated for $30 \mathrm{~min}$. in phosphate-buffered saline solution (PBS) containing 5\% bovine serum albumin (BSA), after which cells were further incubated in PBS-1\% BSA containing primary antibody (anti-ALP B4-78; Developmental Studies Hybridoma Bank, University of Iowa, Iowa City, IA) for $1 \mathrm{hr}$. Cells were then washed and incubated with secondary antibody (goat anti-mouse IgG conjugated with phycoerythrin $[\mathrm{PE}]$ ) for $30 \mathrm{~min}$. After incubation, cells were washed three times and resuspended in PBS-1\% BSA. Viaprobe (BD Biosciences) was added for live/dead staining and allowed to incubate for $10 \mathrm{~min}$. Cells were then analyzed using a FACScalibur (BD Biosciences) and ALP levels were determined on live cells only. 


\section{Mineralization and adipogenesis.}

Both assays were performed as described previously [5]. Experiments were performed at least in triplicate using $\mathrm{BM}$ as negative control. In the mineralization experiment, the calcium content was measured at $620 \mathrm{~nm}$ (Bio-tek instruments) after 28 days in MM and expressed as $\mathrm{mg} / \mathrm{dL}$ for each condition.

\section{Results}

Selection of the optimal antioxidant and oxidative stress inducer concentrations

In order to investigate the effect of antioxidant supplementation on hMSCs (3 donors), the optimal concentration of each inducer or antioxidant/scavenger was established by assessing their effects on proliferation (dose-response curve, see Fig. S1 and S2). The highest concentration which did not elicit a profound effect on proliferation (arbitrary set at a reduction in cell number by $25 \%$ after 6 days of culture compared to control) was used for further experiments. With the selected concentration of each inducer or antioxidant/scavenger, we tested their effects on both the proliferation (extra donor) and on differentiation of hMSCs (Fig. 1). Supplementation of the anti-oxidant D-mannitol $(5 \mathrm{mM})$ had a mild but significantly positive effect on hMSCs proliferation in basic medium (BM), but no effect in osteogenic medium (OM) (Fig. 1A). The anti-oxidant Trolox $(50 \mu \mathrm{M})$ did not influence proliferation significantly in both BM and OM. The effect of antioxidant supplementation on dex-induced alkaline phosphatase (ALP) activity was evaluated by exposing hMSCs in BM and OM to the concentrations indicated above for 6 days after which we did not observe a significant effect showing that these concentrations of anti-oxidants do not effect hMSC proliferation or differentiation (Fig. 1B). Similarly, we assessed a concentration in which a panel of oxidative damage inducers had minimal effects on proliferation (see SFig 2 and Fig. 1C). However, all the compounds significantly reduced dex-induced ALP activity (Fig. 1D). The effect was most profound when tert-butyl hydroperoxide ( $t$-BHP) was used, with a decrease from $1.44 \pm 0.06$ (arbitrary units) in the control, to $0.37 \pm$ 0.08 in t-BHP-treated cells. Even in basic medium, t-BHP treatment resulted in a statistically significant decrease in ALP activity. 


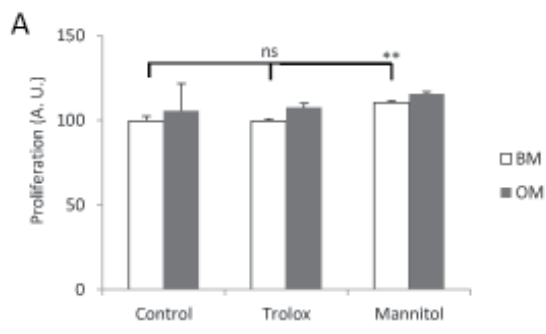

B
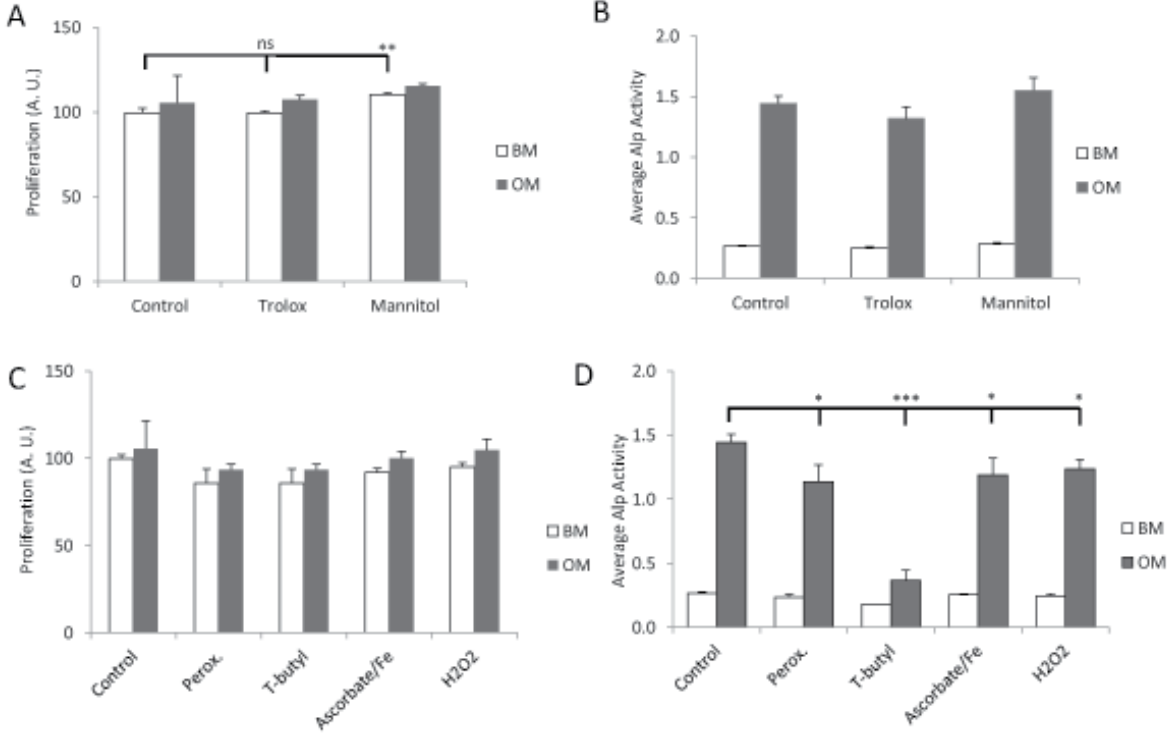

Fig. 1 Effect of oxidative damage inducers and scavengers on proliferation and differentiation of hMSCs. hMSC were culture in the presence of antioxidants (Trolox $50 \mu M$ or D-Mannitol $5 \mathrm{mM})(\boldsymbol{A}, \boldsymbol{B})$ or oxidative damage inducers (Peroxynitrite $30 \mu M$; Tert-butyl hydroperoxide $50 \mu M$, Ascorbate/Fe ${ }^{2+} 250 \mu M$ and $\left.\mathrm{H}_{2} \mathrm{O}_{2} 30 \mu M\right)(\boldsymbol{C}, \boldsymbol{D})$. Proliferation $(\boldsymbol{A}, \boldsymbol{C})$ and $A L P$ expression $(\boldsymbol{B}, \boldsymbol{D})$ was measured after 6 days of culture. For ALP, data is expressed as total alkaline phosphatase activity normalized for cell number, and for proliferation as fluorescence intensity (Alamar blue). Error bars represent standard deviation. Statistical analysis were performed using Student's T-test with a significance of $<0.05$. Asterisks represent $* p<0.05, * * 00.01$, **** $p<0.001$. Ns - non significant.

\section{Anti-oxidants can rescue ROS damage induced loss of differentiation}

Next, we tested whether the negative effect of the oxidative damage inducers on dex-induced ALP expression could be rescued by co-supplementation of ROS scavengers. The addition of $\mathrm{t}-\mathrm{BHP}$ to the medium resulted in a reduction in ALP activity from $1.44 \pm 0.06$ to $0.37 \pm 0.08$, which was partially rescued by the addition of the anti-oxidants Trolox and D-mannitol to $0.71 \pm 0.13$ and $0.86 \pm 0.10$ respectively (Fig. 2A). When peroxynitrite was used to induce oxidative damage, it resulted in the reduction in ALP levels from $1.44 \pm 0.06$ in the control to 1.14 \pm 0.13 . Co-supplementation of D-mannitol rescued the effect of peroxynitrite to $1.42 \pm 0.10$. The effect of Trolox co-supplementation $(1.34 \pm 0.19)$ was not significant (Fig. 2A). We conclude that both D-mannitol and Trolox are able to rescue oxidative damage induced loss of differentiation potential. Several other oxidative damage inducers (AAPH, $\mathrm{H}_{2} \mathrm{O}_{2}$, the pair ascorbate $/ \mathrm{Fe}^{2+}$, and paraquat) and antioxidants (Taxifolin and manganese (III) tetrakis (4-benzoic acid) porphyrin chloride 
(MnTBAP)) were tested as well, but for the sake of simplicity only two models of oxidative stress induction [tert-butyl hydroperoxide (Fig. 2A) and peroxynitrite (Fig. 2B)] were included in the manuscript.
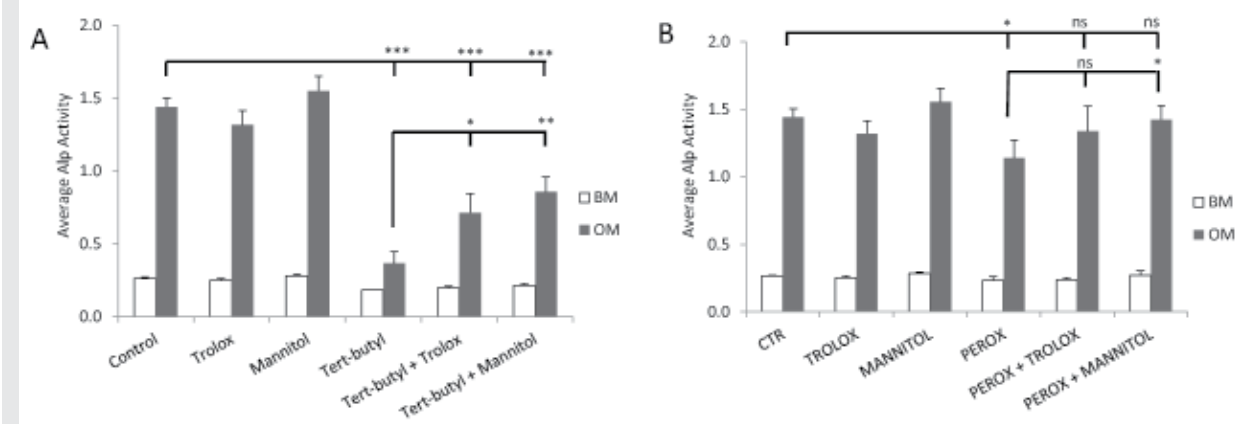

Fig. 2. Antioxidant supplementation prevents ROS induced loss of differentiation. ALP expression was measured after 6 days of culture and the antioxidant effect (Trolox $50 \mu M$ and D-Mannitol $5 \mathrm{mM}$ ) was measured in 2 model systems of oxidative stress induction: Tertbutyl hydroperoxide (50 $\mu$ M) (A) or peroxynitrite (30 $\mu M)$ (B). Data is expressed as total alkaline phosphatase activity (arbitrary units) normalized for cell numbers. Error bars represent standard deviation. Statistical analysis were performed using Student's t-test with a significance of $<0.05$. Asterisks represent $* p<0.05, * 0<0.01, * * * 0<0.001$. Ns - Non significant.

\section{Selenium reduces oxidative damage load}

Because DNA damage accumulation was previously suggested as a possible cause for loss of multipotency after extended in vitro culture, we determined whether antioxidant supplementation (D-mannitol and Trolox) could reduce the accumulation of DNA damage that hMSCs (donor 118) face during in vitro culture (Fig. 3). Sodium selenite ( $\mathrm{NaSel}$ ) was used as a positive control because it was previously described to restore antioxidant capacity and prevent cell damage in hMSCs [22].

DNA damage is presented as the percentage of 53BP1 positive cells or average foci per cell. When t-BHP is added to hMSCs, the percentage of 53BP1 positive cells increased significantly from $54.08 \pm 2.00$ in the control (Fig. $3 \mathrm{~A}$ ) to $89.37 \pm$ 1.32 in t-BHP treated cells (Fig 3C). Even more profound, the average number of 53BP1 foci per cell increased from $0.81 \pm 0.19$ in the control (Fig. 3B) to $4.58 \pm$ 0.43 in the cells treated with t-BHP (Fig. 3C). Addition of sodium selenite (NaSel) to hMSCs treated with $\mathrm{t}$-BHP resulted in a significantly decrease in 53BP-positive nuclei from $89.37 \pm 1.32$ to $72.44 \pm 2.94$ in $\mathrm{t}-\mathrm{BHP}$ and $\mathrm{tBHP}+\mathrm{NaSel}$, respectively. 
Similarly, NaSel treatment significantly reduced the number of foci per cell from $4.58 \pm 0.43$ in the $\mathrm{t}-\mathrm{BHP}$ treated hMSCs to $3.30 \pm 0.18$ when $\mathrm{t}-\mathrm{BHP}$ and NaSel were added. D-mannitol and Trolox treatment resulted in a reduction in the average number of 53BP1 foci but this was not statistically significant.

When hMSCs were grown under normal culture conditions, the addition of $\mathrm{NaSel}$ resulted in the reduction of 53BP1 positive cells from $54.08 \pm 2.00$ to 40.67 \pm 1.82 , with and without $\mathrm{NaSel}$ respectively. Addition of D-mannitol and Trolox did not result in a significant change in the percentage of 53BP1 positive hMSCs under normal culture conditions (Fig 3A), and in the case of Trolox, we even observed a mild increase in the average number of foci per cell but not the percentage of 53BP positive cells.
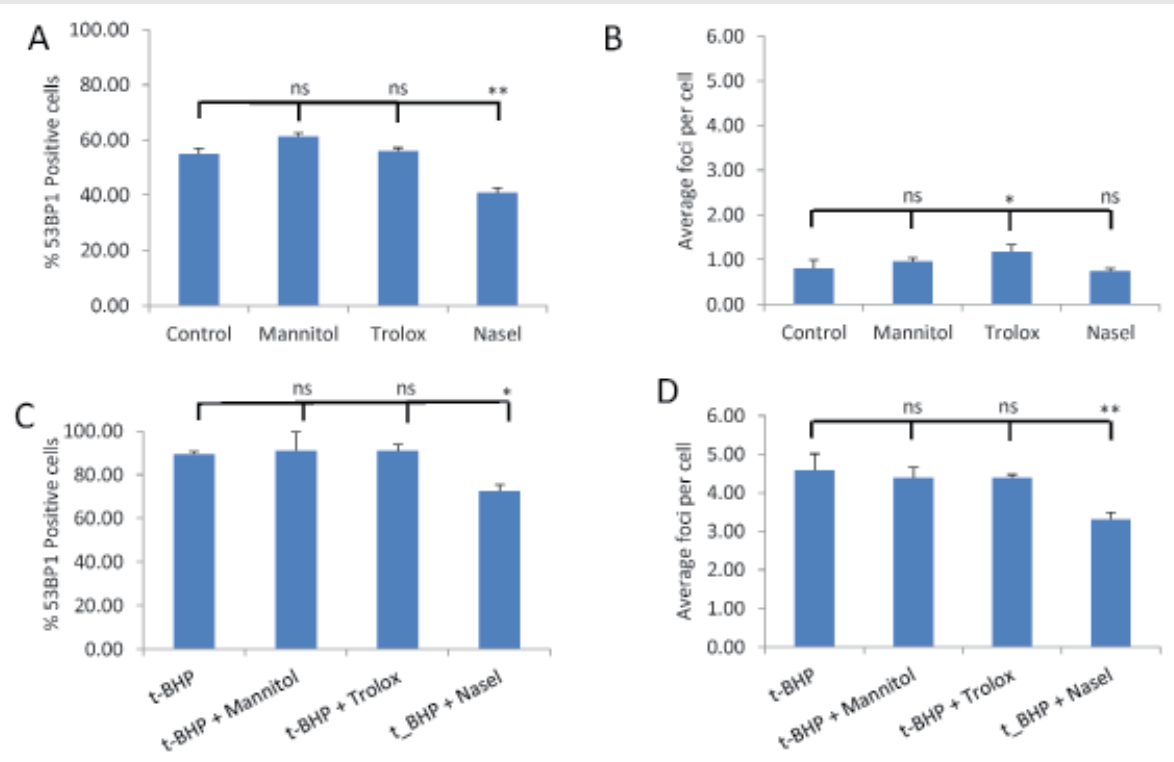

Fig. 3. Effect of antioxidant supplementation on DNA damage accrual. Effect of antioxidants (D-Mannitol 5mM; Trolox $50 \mu \mathrm{M}$ and sodium selenite $100 \mathrm{nM}$ ) on DNA damage load $(\boldsymbol{A}, \boldsymbol{B})$. DNA damage load was assessed by quantifying the percentage of 53BP1 positive cells $(A, C)$ and the number of 53BP1 foci per cell $(B, D)$ either in the absence of oxidative damage inducer $(A, B)$ or in the presence of the oxidizing agent tert-Butyl Hydroperoxide (50 $\mu M)(C, D)$. Error bars represent standard deviation. Statistical analysis were performed using one-way ANOVA and Tukey post-test with a significance of 0.05. Asterisks represent * $p<0.05,{ }^{* *} p<0.01$. ns - not significant. Nasel - Sodium Selenite, Ns - Non significant. 


\section{Supplementation of antioxidants enhances the yield of hMSCs}

To investigate whether antioxidant supplementation reduces the oxidative damage load during in vitro culture, we exposed hMSCs to antioxidants from the moment that the bone marrow biopsy was placed in the tissue culture flasks.

In order to prove the efficacy of antioxidant supplementation, hMSCs, were minimally expanded (passage 1), either in the presence, or absence of antioxidants/scavengers and then several parameters were evaluated (Fig. 4). Because 8-oxoguanine is the most common DNA adduct during oxidative damage and its production is linked to an increased risk of mutation/mutagenesis, the 8-oxoG content was measured by flow cytometry. When the normal culture medium was supplemented with Trolox, we detected a significantly lower level of 8-oxoguanine adducts compared to hMSCs grown under normal conditions (from $100 \% \pm$ 5.94 in the control to $84.71 \% \pm 2.69$ ) (Fig. 4A). We also measured the intracellular ROS production because part of the oxidative DNA damage cells face is created by normal metabolic activity. As can be seen in figure $4 \mathrm{~B}$, both $\mathrm{D}$-mannitol and Trolox significantly reduced intracellular ROS formation (from control 100.10\% \pm 1.35 to $88.65 \% \pm 2.39$ and $87.53 \% \pm 5.19$, for D-mannitol and Trolox, respectively). Selenium was able to reduce intracellular levels to $90.23 \% \pm 5.75$, although the observed difference was not statistically significant.

We then tested whether the reduction in oxidative damage by the antioxidants/ scavengers was reflected in hMSC growth and differentiation parameters. The compounds were added when the fresh bone marrow aspirate was plated and cell numbers were determined when cells nearly reached confluence. In the donor tested (D 215), supplementation of all scavengers resulted in a significantly higher MSC yield (281,400 \pm 18560 cells; $268540 \pm 21024$ cells and $278720 \pm 7005$ cells, for hMSCs supplemented with D-mannitol, Trolox or Selenium, respectively) than control (154898 \pm 16220 cells) (Fig. 4C). When a mineralization experiment was performed with these cells (Fig. 4E), the hMSCs grown on the presence of Trolox displayed a small, but statistically significant enhancement of mineralization. In contrast, the antioxidants had no effect on dex-induced ALP expression (Fig. 4D). When the cells were expanded up to passage three in the three different anti-oxidants, we observed no beneficial effect in the differentiation assays (mineralization and adipogenesis) (Fig. 5). 


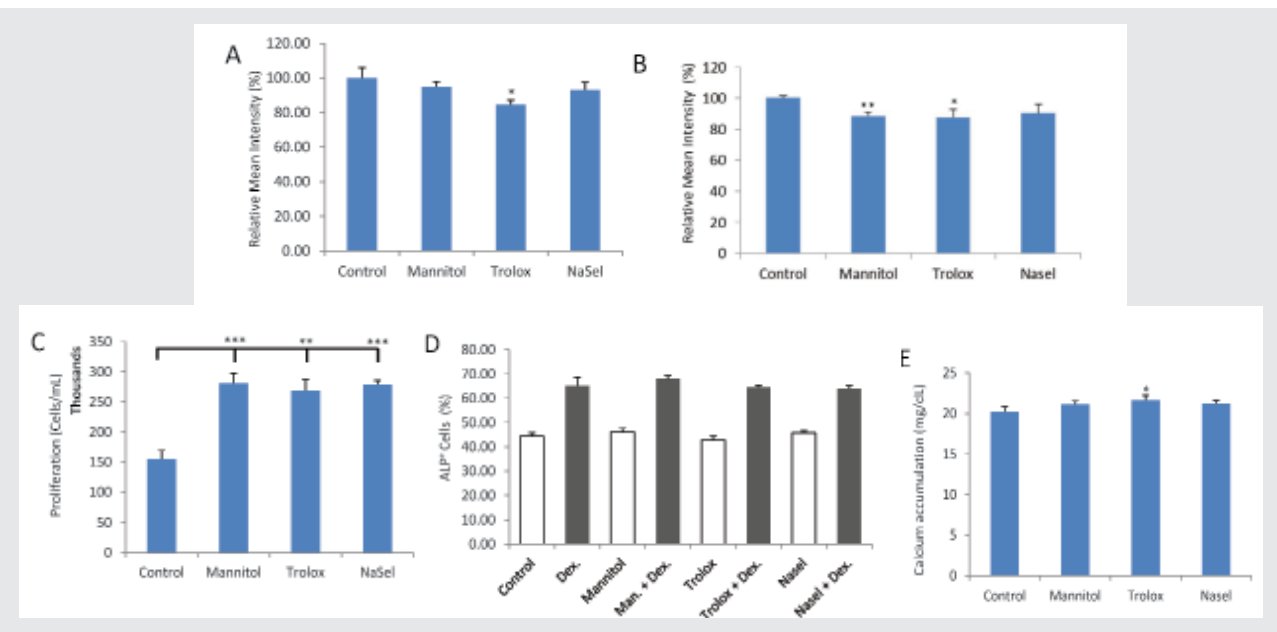

Fig. 4. Effect of antioxidant supplementation on cellular parameters of hMSCs (passage 1). The effect of antioxidant supplementation (D-Mannitol $5 \mathrm{mM}$; Trolox $50 \mu M$ and sodium selenite $100 \mathrm{nM})$ on the DNA damage load (A, B), on the proliferation in vitro (PO) (C) and differentiation potential $(P 1)(D, E)$ were evaluated. Oxidative damage accrual was assessed by quantifying 8-oxoguanine adducts (A) and intracellular ROS production (CM- $\left.\mathrm{H}_{2} D C F D A\right)(B)$ and expressed as percentage reduction of the mean intensity, relative to the control. Proliferation is expressed as thousands of cells/mL of culture medium (C). Percentage of ALP positive cells were analyzed by FACS after 6 days, both in the presence or absence of the osteogenic inducer (dexamethasone) (D). Mineralization capacity was also measured and calcium accumulation was quantified and expressed as $(\mathrm{mg} / \mathrm{dL})$. Error bars represent standard deviation. Statistical analysis were performed using Student $t$-test with a significance of 0.05. Asterisks represent ${ }^{*} p<0.05, * * 0<0.01,{ }^{* * * *} p<0.001$. Nasel-sodium selenite; Dex - dexamethasone.

A

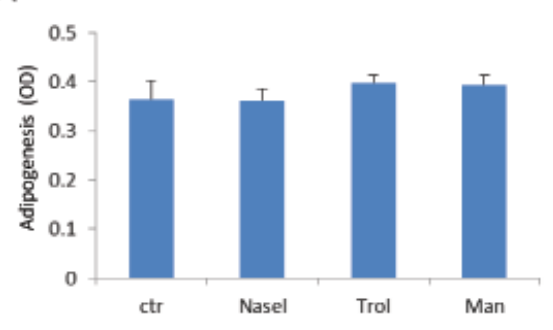

B

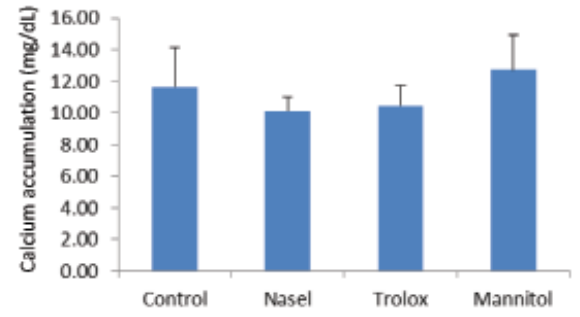

Fig. 5. Effect of continuous antioxidant supplementation on cellular parameters of expanded hMSCs (Passage 3). Effect of antioxidants (D-Mannitol 5mM; Trolox $50 \mu M$ and Sodium selenite $100 \mathrm{nM}$ ) on differentiation potential of in vitro expanded hMSCs in the presence of antioxidants. Adipogenic differentiation (A) and mineralization (B) were assessed in passage 3 cells. Error bars represent standard deviation. 


\section{Discussion and conclusions}

During normal culturing conditions, MSCs accumulate DNA damage and oxidative stress, and their antioxidant capacity is reduced [22]. The in vivo performance of hMSCs is also dependent on the extend of expansion. Supplementation of the antioxidant selenium was shown to reduce the oxidative stress levels in hMSC by restoring the antioxidant capacity of the cells [22]. However, several questions still remained, for example, whether antioxidant supplementation could delay the functional senescence of MSC after long term in vitro culture. In order to investigate the effect of antioxidant supplementation in reducing the early aging of human mesenchymal stromal cells in vitro, we tried to establish different model systems of induction of damage (oxidative stress) and therefore chemicallyinduced loss of differentiation potential and concomitantly tested whether this process could be reversed by the usage of antioxidants.

There is a wide variety of compounds with known antioxidant activity with a broad range of action. Therefore, our first step was to screen a set of antioxidants and inducers. After testing firstly their effect on proliferation and then on the ALP levels, we concluded that the best antioxidants to test further were D-mannitol and Trolox and decided to use as inducers peroxynitrite and tert-butyl hydroperoxide.

D-mannitol, is reported to be a potent hydroxyl free radicals scavenger $([25,26]$, while Trolox is a vitamin E hydro soluble analogue, which is known to bind the cell plasma membrane, where it exerts its main function of protecting cells from lipid peroxidation [27]. The oxidizing agent selected is tert-butyl hydroperoxide, a well-known compound and its toxicity is widely characterized $[28,29,30]$. Peroxynitrite $\left(\mathrm{ONOO}^{-}\right)$is formed when nitric oxide $(\mathrm{NO})$ reacts with the superoxide anion $\left(\mathrm{O}^{2-}\right)$ and its generation can lead to oxidation and nitration of lipids, DNA and amino acid residues on proteins [31,32]. It is also responsible for the formation of other dangerous reactive species. This compound has the capacity to act in a hydroxyl radical-like manner to induce lipid and protein oxidation, readily reacts with $\mathrm{CO}_{2}$ to form nitroso peroxocarboxylate $\left(\mathrm{ONOOCO}_{2}^{-}\right)$, can become protonated as peroxonitrous acid $(\mathrm{ONOOH})$ and can undergo homolysis to form either hydroxyl $(\cdot \mathrm{OH})$ radicals and nitrogen dioxide $\left({ }^{\circ} \mathrm{NO}_{2}\right)$ radicals, or be rearranged to nitrate $\left(\mathrm{NO}_{3}\right)$ [33].

After establishing a model system to mimic the oxidative stress that hMSCs face in culture, we then assessed, whether these antioxidants were able to reverse the chemically-induced loss of differentiation potential. Indeed, we show that both Trolox and D-mannitol were able to partially decrease the chemically-induced loss of differentiation potential, which lead us to test whether these antioxidants 
were also able to revert/prevent the loss of differentiation potential after in $v i$ tro expansion, since a similar process is believe to occur. For those experiments selenium was used as a positive control since it has previously demonstrated its efficacy on restoring the antioxidant capacity of hMSCs.

Although selenium was able to reduce the chemically-induced oxidative stress levels (the total number of percentage positive cells and average foci per cell), the effect seems to be on prevention of oxidative stress rather than actually a reversal of the damage already accumulated, since it failed to rescue cells that had already lost their differentiation potential after extensive in vitro expansion. Therefore, we investigated whether long term, continuous supplementation of different antioxidants was able to significantly prevent oxidative stress accumulation and enhance biological activity.

Interestingly, antioxidant supplementation had a beneficial reducing effect on the level ROS and 8-oxoG in the cells and a positive effect on the total yield of cells that could be obtained from the bone marrow biopsy. Supplementation of antioxidants during the early expansion phase can be an easy way to increase the total yield of low passage cells. We can only speculate on the precise mechanism responsible for this observed increase in cell numbers, but some possibilities could be the suppression of cell death and apoptosis by reducing the oxidative stress levels, by affecting the attachment during the initial phase or by actively inducing proliferation. Furthermore, we showed that antioxidant supplementation (especially Trolox) was able to significantly reduce the oxidative damage cells face during the initial phase of culture. This is in line with other reports where authors show that Trolox and other antioxidants were able to markedly inhibit the formation of 8-oxoguanine adducts in a concentration-dependent manner [34]. Intracellular vitamin $\mathrm{C}$ concentrations were shown to be negatively correlated with 8-oxo-deoxyguanosine concentrations in lymphocytes from 105 healthy volunteers [35]. Furthermore, vitamin $C$ has also been shown to act as an antioxidant in vivo [36] and from the 44 published in vivo studies examined, 38 demonstrated a decrease in the number of markers of oxidative damage to DNA, 14 showed no differences, while only 6 reported an increase in oxidative damage after supplementation with vitamin $\mathrm{C}$.

Addition of antioxidants revealed minor or no beneficial effects on the differentiation potential (ALP and mineralization) of early expanded hMSCs which could be due to the fact that cells had been only minimally expanded and still presented their maximum differentiation potential. To further confirm this, we assessed the effect of antioxidant supplementation on further expanded hMSCs, since after this expansion period, cells are known to accumulate significantly higher levels of 
DNA damage, as previously described [4].

Unfortunately, hMSCs still presented a decrease in differentiation potential and addition of antioxidants was not able to prevent the oxidative damage load cells face during in vitro culture. One of the reasons behind this could be the fact that hMSCs are accumulating high amounts of oxidative damage and that the observed preventive effect of antioxidant supplementation was unable to fully prevent the accumulation of oxidative damage during culture, ultimately leading to the loss of differentiation potential and render these cells less optimal for clinical usage. In addition, there is a huge variety of oxidizing radicals and these antioxidants only manage to scavenge a subset of them. Their half-life is also limited while oxidative damage is being constantly produced. Unfortunately, higher concentrations of antioxidants cannot be used since they produce cytotoxic effects. The discovery of novel and more potent antioxidants with lower side effects would be highly interesting, and a combination of several antioxidants might be worth testing.

Here we show, that continuous antioxidant supplementation during the early expansion phase of hMSCs, leads to enhanced yield of hMSC, which can be of high interest for clinical applications. We have also shown that Trolox supplementation can reduce the oxidative damage cells face during early culture periods. However, the beneficial effects shown by antioxidants were unable to rescue hMSC differentiation capacity after in vitro expansion, which could have been explained by several factors.

Oxidative damage to DNA, lipids and proteins is a reality during in vitro culturing since hMSCs are expanded out of their natural niche. Although there is a constant improvement of the culture conditions, they are still far from optimal, and may be the cause for the early loss of functionality. This might be a consequence of epigenetic events amongst other factors such as improper cell-cell contacts, improper surface area or protein modifications by oxidative damage, all of which might change the gene expression profile of hMSCs, and lead to the loss of expression of important proteins and ultimately to loss of multipotency.

Further work still needs to be performed in order to understand the basic phenomenon behind loss of multipotency after in vitro expansion in order to prevent it for occurring during normal culturing conditions. Other antioxidants can be further tested and might present higher preventive activity therefore, the results obtained here, leave a window for further experimentation. 


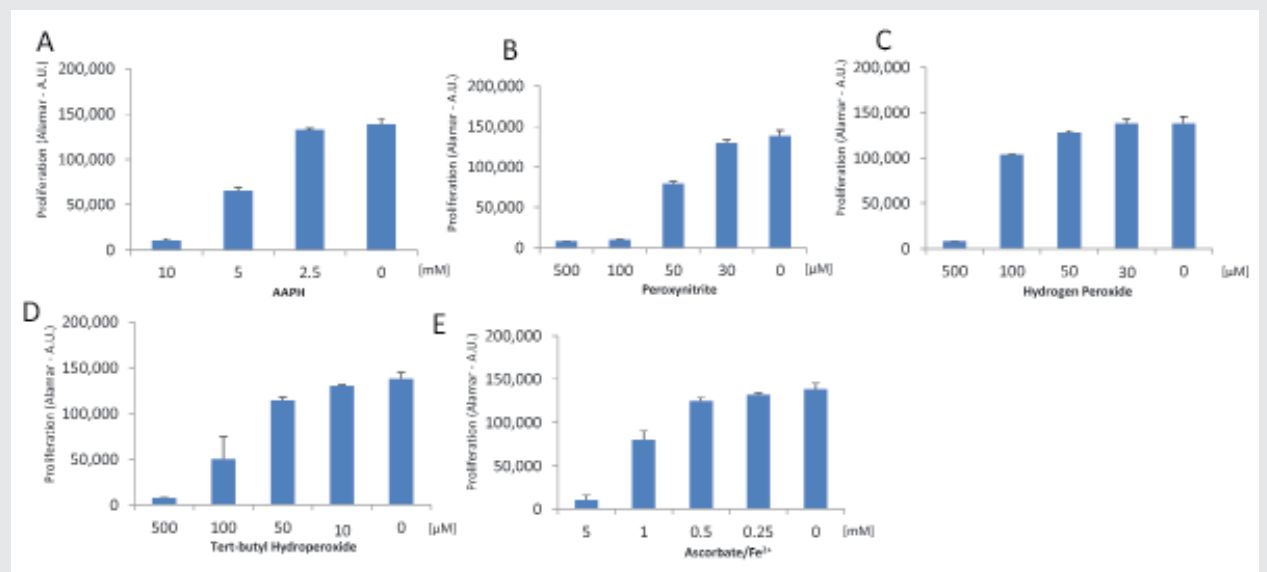

Fig. S1. Effect of oxidizing agents on hMSCs proliferation after 6 days. Effect of continuous exposure of AAPH (A), peroxynitrite (B), hydrogen peroxide (C), Tert-butyl Hydroperoxide (D) and the oxidizing system ascorbate/Fe ${ }^{2+}(E)$.

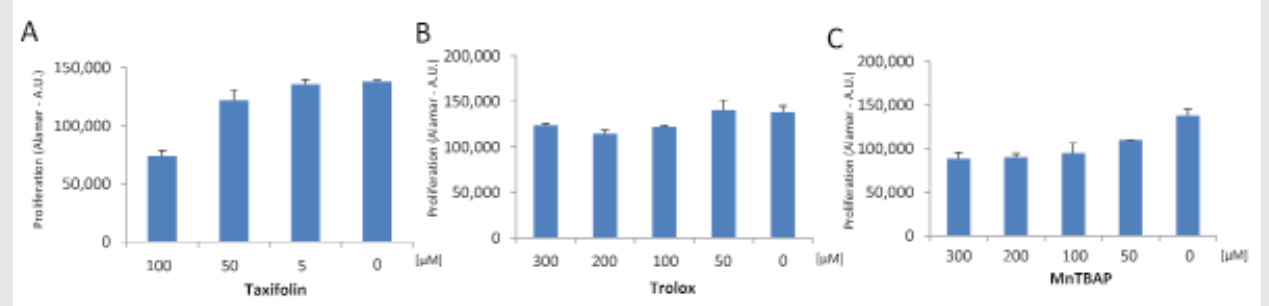

Fig. S2. Effect of antioxidants/scavenger agents on hMSCs proliferation after 6 days. Effect of continuous exposure of taxifolin (A), trolox (B), MnTBAP (C).

\section{Acknowledgments}

The Netherlands Technology Foundation (STW grant TGT.6745) is acknowledged for financial support. 


\section{References}

1. Pittenger MF, Mackay AM, Beck SC, Jaiswal RK, Douglas R, et al. (1999) Multilineage potential of adult human mesenchymal stem cells. Science 284: 143-147.

2. Petite H, Viateau V, Bensaid W, Meunier A, de Pollak C, et al. (2000) Tissue-engineered bone regeneration. Nat Biotechnol 18: 959-963.

3. Agata H, Asahina I, Watanabe N, Ishii Y, Kubo N, et al. (2010) Characteristic change and loss of in vivo osteogenic abilities of human bone marrow stromal cells during passage. Tissue Eng Part A 16: 663-673.

4. Alves H, Munoz-Najar U, De Wit J, Renard AJ, Hoeijmakers JH, et al. (2010) A link between the accumulation of DNA damage and loss of multi-potency of human mesenchymal stromal cells. J Cell Mol Med 14: 2729-2738.

5. Siddappa R, Licht R, van Blitterswijk C, de Boer J (2007) Donor variation and loss of multipotency during in vitro expansion of human mesenchymal stem cells for bone tissue engineering. J Orthop Res 25: 1029-1041.

6. Fagan JM, Sleczka BG, Sohar I (1999) Quantitation of oxidative damage to tissue proteins. Int J Biochem Cell Biol 31: 751-757.

7. Kohen R, Nyska A (2002) Oxidation of biological systems: oxidative stress phenomena, antioxidants, redox reactions, and methods for their quantification. Toxicol Pathol 30: 620650 .

8. Dalle-Donne I, Rossi R, Giustarini D, Milzani A, Colombo R (2003) Protein carbonyl groups as biomarkers of oxidative stress. Clin Chim Acta 329: 23-38.

9. Niki E, Yoshida Y, Saito Y, Noguchi N (2005) Lipid peroxidation: mechanisms, inhibition, and biological effects. Biochem Biophys Res Commun 338: 668-676.

10. Cadet J, Delatour T, Douki T, Gasparutto D, Pouget JP, et al. (1999) Hydroxyl radicals and DNA base damage. Mutat Res 424: 9-21.

11. Finkel T, Holbrook NJ (2000) Oxidants, oxidative stress and the biology of ageing. Nature 408: 239-247.

12. Valko M, Leibfritz D, Moncol J, Cronin MT, Mazur M, et al. (2007) Free radicals and antioxidants in normal physiological functions and human disease. Int J Biochem Cell Biol 39: 44-84.

13. Harshman LG, Haberer BA (2000) Oxidative stress resistance: a robust correlated response to selection in extended longevity lines of Drosophila melanogaster? J Gerontol A Biol Sci Med Sci 55: B415-417.

14. Dudas SP, Arking R (1995) A coordinate upregulation of antioxidant gene activities is associated with the delayed onset of senescence in a long-lived strain of Drosophila. J Gerontol A Biol Sci Med Sci 50: B117-127. 
15. Balaban RS, Nemoto S, Finkel $T$ (2005) Mitochondria, oxidants, and aging. Cell 120: 483-495.

16. Ku HH, Brunk UT, Sohal RS (1993) Relationship between mitochondrial superoxide and hydrogen peroxide production and longevity of mammalian species. Free Radic Biol Med 15: 621-627.

17. Maggio D, Barabani M, Pierandrei M, Polidori MC, Catani M, et al. (2003) Marked decrease in plasma antioxidants in aged osteoporotic women: results of a cross-sectional study. J Clin Endocrinol Metab 88: 1523-1527.

18. Basu S, Michaelsson K, Olofsson H, Johansson S, Melhus H (2001) Association between oxidative stress and bone mineral density. Biochem Biophys Res Commun 288: 275-279.

19. Tyner SD, Venkatachalam S, Choi J, Jones S, Ghebranious N, et al. (2002) p53 mutant mice that display early ageing-associated phenotypes. Nature 415: 45-53.

20. de Boer J, Andressoo JO, de Wit J, Huijmans J, Beems RB, et al. (2002) Premature aging in mice deficient in DNA repair and transcription. Science 296: 1276-1279.

21. Ito K, Hirao A, Arai F, Matsuoka S, Takubo K, et al. (2004) Regulation of oxidative stress by ATM is required for self-renewal of haematopoietic stem cells. Nature 431: 9971002.

22. Ebert R, Ulmer M, Zeck S, Meissner-Weigl J, Schneider D, et al. (2006) Selenium supplementation restores the antioxidative capacity and prevents cell damage in bone marrow stromal cells in vitro. Stem Cells 24: 1226-1235.

23. Hockenbery DM, Oltvai ZN, Yin XM, Milliman CL, Korsmeyer SJ (1993) Bcl-2 functions in an antioxidant pathway to prevent apoptosis. Cell 75: 241-251.

24. Jakubowski W, Bartosz G (2000) 2,7-dichlorofluorescin oxidation and reactive oxygen species: what does it measure? Cell Biol Int 24: 757-760.

25. Bors W, Saran M, Michel C (1979) Pulse-radiolytic investigations of catechols and catecholamines. II. Reactions of Tiron with oxygen radical species. Biochim Biophys Acta 582: 537-542.

26. Ching TL, Haenen GR, Bast A (1993) Cimetidine and other H2 receptor antagonists as powerful hydroxyl radical scavengers. Chem Biol Interact 86: 119-127.

27. Valko M, Rhodes CJ, Moncol J, Izakovic M, Mazur M (2006) Free radicals, metals and antioxidants in oxidative stress-induced cancer. Chem Biol Interact 160: 1-40.

28. Fernandes ER, Carvalho FD, Remiao FG, Bastos ML, Pinto MM, et al. (1995) Hepatoprotective activity of xanthones and xanthonolignoids against tert-butylhydroperoxideinduced toxicity in isolated rat hepatocytes--comparison with silybin. Pharm Res 12: 17561760. 
29. Joyeux M, Rolland A, Fleurentin J, Mortier F, Dorfman P (1990) tert-Butyl hydroperoxide-induced injury in isolated rat hepatocytes: a model for studying anti-hepatotoxic crude drugs. Planta Med 56: 171-174.

30. Tseng TH, Kao ES, Chu CY, Chou FP, Lin Wu HW, et al. (1997) Protective effects of dried flower extracts of Hibiscus sabdariffa $L$. against oxidative stress in rat primary hepatocytes. Food Chem Toxicol 35: 1159-1164.

31. Nordberg J, Arner ES (2001) Reactive oxygen species, antioxidants, and the mammalian thioredoxin system. Free Radic Biol Med 31: 1287-1312.

32. Halliwell B (2001) Role of free radicals in the neurodegenerative diseases: therapeutic implications for antioxidant treatment. Drugs Aging 18: 685-716.

33. Radi R, Peluffo G, Alvarez MN, Naviliat M, Cayota A (2001) Unraveling peroxynitrite formation in biological systems. Free Radic Biol Med 30: 463-488.

34. Qi W, Reiter RJ, Tan DX, Garcia JJ, Manchester LC, et al. (2000) Chromium(III)induced 8-hydroxydeoxyguanosine in DNA and its reduction by antioxidants: comparative effects of melatonin, ascorbate, and vitamin E. Environ Health Perspect 108: 399-402.

35. Lenton KJ, Sane AT, Therriault H, Cantin AM, Payette H, et al. (2003) Vitamin C augments lymphocyte glutathione in subjects with ascorbate deficiency. Am J Clin Nutr 77: 189-195.

36. Carr A, Frei B (1999) Does vitamin C act as a pro-oxidant under physiological conditions? FASEB J 13: 1007-1024. 


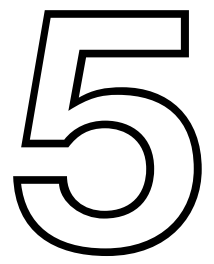




\title{
Chapter 5
}

\section{High-Throughput Assay for the Identification of Coumpounds Regulating Osteogenic differentiation of Human Mesenchymal Stomal Cells}

\author{
Hugo Alves ${ }^{1}$, Koen Dechering ${ }^{2}$, Clemens van Blitterswijk ${ }^{1}$, Jan de Boer ${ }^{1}$ \\ ${ }^{1}$ Department of Tissue Regeneration, MIRA Institute for Biomedical Technology and \\ Technical Medicine, University of Twente, Enschede, The Netherlands. ${ }^{2}$ Department of \\ Molecular Pharmacology, Merck Research Laboratories, Oss, The Netherlands.
}

\begin{abstract}
Human mesenchymal stromal cells are regarded as the golden standard for cellbased therapies. They present multilineage differentiation potential and trophic and immunosuppressive abilities, making them the best candidate for clinical applications. Several molecules have been described to increase bone formation and were mainly discovered by candidate approaches towards known signaling pathways controlling osteogenesis. However, their bone forming potential is still limited, making the search for novel molecules a necessity. High-throughput screening (HTS) not only allows the screening of a large number of diverse chemical compounds, but also allows the discovery of unexpected signaling pathways and molecular mechanisms for a certain application, even without the prior knowledge of the full molecular pathway. Typically HTS is performed in cell lines, however, in this manuscript we have performed a phenotypical screen on more clinically relevant human mesenchymal stromal cells, as a proof of principle that HTS can be performed in those cells and can be used to find small molecules that impact stem cell fate. From a library of pharmacologically active small molecules, we were able to identify novel compounds with increased osteogenic activity. These compounds allowed achieving levels of bone-specific alkaline phosphatase higher than any other combination previously known. By combining biochemical techniques, we were able to demonstrate that a medium to high-throughput phenotypic assay can be performed in academic research laboratories allowing the discovery of novel molecules able to enhance stem cell differentiation.
\end{abstract}

Adapted from Alves $\mathrm{H}$, et al. Submitted for publication. 


\section{Introduction}

Osteoporosis and other bone-related disorders represent a major public health threat. One out of every two women and one in four men, aged 50 or older, is expected to develop an osteoporosis-related fracture in their lifetime [1]. There is a huge demand for products enhancing bone regeneration. Therefore, the last decade was denominated the bone and joint decade by the World Health Authority. Over the last years, hMSCs have become the golden standard for cell therapy applications, mainly due to their multilineage potential, but also due to their secretion of trophic and immunomodulatory factors [2,3].

However, bone tissue engineering using hMSCs is being hindered by the lack of markers predicative of bone formation and due to the relatively poor performance of hMSCs, and there is therefore an urgent need for new molecules able to induce their differentiation potential with higher efficiency. In the past we and others have tried different candidate approaches in order to enhance the performance of hMSCs for bone tissue engineering applications, including the effect of Wnt signaling on the proliferation and differentiation of hMSCs [4], the effect of the inhibition of histone deacetylases on mineralization [5], and the activation of the cAMP/PKA pathway [6]. New technology is currently available in research laboratories, allowing the discovery of unexpected signaling pathways and molecular mechanisms for a certain application by screening libraries of reagents such as small molecules, siRNA or peptides.

High-throughput screening (HTS) is a process that allows the screen of thousands of chemicals in order to identify potential interesting compounds for a specific application. HTS techniques have been used for some years, but the technical settings and especially the costs involved in its implementation have restricted their application to large pharmaceutical companies. More recently, this method has become more accessible and, therefore, it is currently a technique that can be performed in an academic setting. In pharmacology, HTS assays are usually developed based on a certain target molecule in a cell line which is easy to culture. However, for bone tissue engineering, the usage of this technology for phenotypical screens in clinically relevant cells would be more appropriate since it would allow the discovery of new compounds and possible new target molecules for a cell-based bone tissue engineering. Using phenotypical assays, entire pathways of interest can be discovered, providing the opportunity for multiple intervention points, as opposed to a single direct molecular target commonly used in biochemical approaches. Cell-based assays can therefore be used to identify modulators of differentiation pathways (for example osteogenesis) in the physiological environment of the cell with all the intact regulatory networks and feedback control 
mechanisms present. The possibility to combine compounds is almost unlimited and several libraries should be explored. For bone tissue engineering, several approaches can be undertaken including the screening of libraries of small compounds (as described in this manuscript), the possibility to screen libraries of biomaterials generated by combinatorial chemistry [7] and libraries of surface topographies [8].

Although the design of the screens can vary, compound screens are usually performed at single dosage and a single measurement for each compound in the initial screen. This is frequently the only option available to economically screen a large library of compounds. Compounds identified are then re-tested and then further evaluated at different dosages. After a compound is validated by several techniques, it is usually considered as a lead and then can be further tested as a potential drug candidate for future clinical trials. Several aspects have to be taken into consideration while designing a screen, and both false negatives and false positives should be minimized by avoiding or correcting systematic errors $[9,10,11]$. Frequently a cutoff is established based on statistics to affirm positive compounds.

Alkaline phosphatase (ALP) is currently the most frequently used marker for osteogenic differentiation and it has been previously used as a readout in the search for novel osteogenic suppressors in hMSCs [12], novel promoters and inhibitors of osteogenic differentiation [13], and in the assessment of the osteogenic capacity of several compounds $[6,14,15]$.

Based on our experience in bone tissue engineering, we sought to find novel osteogenic molecules by performing a phenotypical screening of a library of pharmaceutically active compounds and, therefore, we describe a simple, yet effective way of screening for compounds in a common research laboratory without the need of expensive robotic techniques.

\section{Materials and Methods}

\section{Isolation, culture and characterization of hMSCs}

Bone marrow aspirates were obtained from donors with written informed consent and were approved by the medical ethical committee of the University medical Centre Utrecht. Briefly, aspirates were resuspended using $20 \mathrm{G}$ needles, plated at a density of $5 \times 10^{5}$ cells $/ \mathrm{cm}^{2}$ and cultured in hMSC proliferation medium (PM) containing $\alpha$-minimal essential medium ( $\alpha$-MEM, Life Technologies), $10 \%$ fetal bovine serum (FBS, Cambrex), $0.2 \mathrm{mM}$ ascorbic acid (Asap, Life Technologies), 
2 mM L-glutamine (Life Technologies), $100 \mathrm{U} / \mathrm{mL}$ penicillin (Life Technologies), $100 \mathrm{mg} / \mathrm{ml}$ streptomycin (Life Technologies) and $1 \mathrm{ng} / \mathrm{ml}$ basic fibroblast growth factor (bFGF, Instruchemie). Cells were grown at $37^{\circ} \mathrm{C}$ in a humid atmosphere with $5 \% \mathrm{CO}_{2}$. Medium was refreshed twice a week and cells were used for further subculturing or cryopreservation when reaching $80-90 \%$ confluence. After expansion, cells were characterized for surface marker expression (CD73, CD90, CD 105, CD11b, CD19, CD34, CD45 and HLA-DR) as previously described[16]. Furthermore, their multilineage potential was confirmed by performing several differentiation experiments[16]. hMSC basic medium/control medium (BM) was composed of hMSC PM without bFGF. hMSC osteogenic medium (OM) was composed of hMSC basic medium supplemented with $10^{-8} \mathrm{M}$ dexamethasone (dex, Sigma).

\section{LOPAC library for the phenotypical screen}

The Lopac library (Sigma-Aldrich) was purchased to screen for osteogenic compounds. It is composed of 1280 pharmacologically active compounds, with all multiple targets represented including GPCRs, kinases and ion channels (see figure $1 \mathrm{~B}$ for a representative diagram of the classes of action of the compounds used on the screen). Many molecules are marketed drugs and have pharmaceutically relevant structures, with predictable activity and directed against a wide range of drug targets. The compounds are highly purified, and the stock is pre-solubilized in DMSO. The final compound concentration used in the screen was $4.5 \mu \mathrm{M}$ in a volume of $200 \mu \mathrm{L}$ per well of osteogenic medium (OM), containing 0.25\% DMSO $(\mathrm{v} / \mathrm{v})$. In each test plate columns were reserved for positive $(\mathrm{OM}+0.25 \% \mathrm{DMSO})$ and negative $(\mathrm{BM}+0.25 \% \mathrm{DMSO})$ controls.

\section{High-throughput assay (HTA)}

To assess the osteogenic potential of the compounds present in the HTA library, hMSCs were seeded at 2000 cells $/ \mathrm{cm}^{2}$ in BM and allowed to attach overnight. The next day, medium was changed to $\mathrm{OM}$ and test compounds and controls were added to the plates. This initial screen was performed in HMSCs from two different donors (D36 and D41) to cover possible donor variation in the osteogenic response. After 4 days of incubation in OM, relative cell number was determined by measuring acidic phosphatase (ACP) activity $[17,18]$. First, cells were washed twice with PBS (Life technologies) and lysed using $30 \mu \mathrm{L}$ of $0.2 \%$ Triton X-100 solution in $100 \mathrm{mM}$ PBS pH7.8, supplemented with a protease inhibitor cocktail (Roche Applied Science). For the measurement of cell numbers, $5 \mu \mathrm{L}$ of the lysate 
was incubated with $100 \mu \mathrm{L}$ of $5 \mathrm{mM}$ 4-nitrophenyl phosphate disodium salt, dissolved in $0.1 \mathrm{M}$ sodium acetate, $0.1 \%$ Triton-X, pH 5.5 for 1.5 hours at $37^{\circ} \mathrm{C}$. After the incubation period, the reaction was stopped by adding $10 \mu \mathrm{L}$ of $0.5 \mathrm{~N}$ sodium hydroxide and allowed to equilibrate for $10 \mathrm{~min}$. The absorbance was then measured at $405 \mathrm{~nm}$.

Alkaline phosphatase activity was measured using a biochemical ALP assay. For this assay, part of the previously described lysate was incubated in the dark at $25^{\circ} \mathrm{C}$ with CDP-Star substrate (Roche) and allowed to react for $30 \mathrm{~min}$. Luminescence was then measured using a VICTOR ${ }^{3}$ luminometer (Perkin Elmer) at $25^{\circ} \mathrm{C}$. The total ALP luminescence was normalized for cell number using the ACP activity as readout.

\section{Primary Screen validation and Statistic analysis}

In order to measure the assay quality we used the most widely accepted method, the Z'factor [19]. This metric quantifies the separation of a positive activity (positive control - OM) from the background (negative control - BM) in the absence of test compounds. To determine this factor the following formula was used:

$$
Z^{\prime}=\mathbf{1}-\mathbf{3} \times \frac{\sigma \mathbf{p}-\sigma n}{|\mu p-\mu n|}
$$

where $\sigma \mathrm{p}$ and $\sigma \mathrm{n}$ are the standard deviations of the positive and negative control, respectively, and $\mu \mathrm{p}$ and $\mu \mathrm{n}$ are their means. A score of $Z^{\prime} \geq 0.5$ indicates and excellent assay, which is able to discriminate positive hits from background noise.

The next step involved the selection of a meaningful cutoff on the calculated statistics to declare positive compounds. Since it was only possible to test $80 \mathrm{com}$ pounds per plate and since positive and negative hits could easily influence the plate sample mean and standard deviation, to establish the cutoff we calculated the standard deviations from the trimmed mean of the tested compounds. The top and bottom $10 \%$ of the tested compounds were not taken into account for the calculation of the mean and standard deviation and hits were selected if they were higher than $3 \mathrm{SD}$-away from the trimmed mean and were present in at least 2 independent screens. 


\section{Hit validation}

The hit compounds obtained from the primary screen were then re-evaluated at 10 different concentrations in order to obtain the optimal concentration that induced the highest osteogenic activity. All the compounds were serially diluted in half-logarithmic steps, ranging from $3.16 \mathrm{e}^{-9} \mathrm{M}$ to $1 \mathrm{e}^{-4} \mathrm{M}$. hMSCs were seeded at 2000 cells $/ \mathrm{cm}^{2}$ in triplicate in both basic and osteogenic medium for 4 days. After this period, cells were lysed and both cell number and ALP activity were calculated as previously described. The optimal concentration was then selected for further studies.

Next, we confirmed enhanced ALP expression as a secondary screen by flow cytometry. Cells were seeded at 5000 cells $/ \mathrm{cm}^{2}$ in basic medium (BM), allowed to attach for 10-15 hrs and then cultured for 4 days in both BM and OM. Each experiment consisted of a negative control (cells grown in BM), a positive control (cells grown in OM), and one or more experimental conditions. Experiments were performed in triplicate and at least 10000 cells were measured. After 4 days of treatment, cells were trypsinized and incubated for $30 \mathrm{~min}$. in phosphate-buffered saline solution (PBS) containing $5 \%$ bovine serum albumin (BSA), after which cells were further incubated in PBS-1\% BSA containing primary antibody (anti-ALP B4-78; Developmental Studies Hybridoma Bank, University of Iowa, Iowa City, IA) for $1 \mathrm{hr}$. Cells were then washed and incubated with secondary antibody (goat anti-mouse IgG conjugated with phycoerythrin [PE]) for $30 \mathrm{~min}$. After incubation, cells were washed three times and resuspended in PBS-1\% BSA. Viaprobe (BD Biosciences) was added for live/dead staining and allowed to incubate for $10 \mathrm{~min}$. Cells were then analyzed using a BD FACScan (BD Biosciences) and ALP levels were determined on live cells only.

\section{Results}

\section{Assay Development:}

When developing an hMSC-based assay there are several critical steps, being reproducibility and assay validation the most important ones. A high-throughput assay was established as shown in figure 1. On day 0, hMSCs were dissociated using trypsin and a single cell suspension was obtained. hMSCs were then seeded in 96-well plates at 1000 cells/well in basic medium (BM) for one day, which allowed them to attach and recover better from the trypsinisation process. Medium was then changed to osteogenic medium (OM) and a library of 1280 active compounds 
were tested for 4 days. This period of time was considered optimal since it did not require re-addition of compounds and change of medium. For the selection of positive compounds, we used a luminescence-based ALP activity assay, and ACP activity to correct for cell number. This combination of assays works well and was compared with others such as CellQuant and para-nitrophenyl phosphate (pNPP) based-ALP measurement, yielding similar results, but reducing significantly the timeframe and workload (data not shown). In order to validate the assay, the $\mathrm{Z}$ score was calculated for each plate individually and for a control plate. The values ranged from 0.6 to 0.7 , meaning that the HTA is able to discriminate possible hits from statistical noise on a given plate. With this methodology we achieved a reliable and relatively fast method to screen libraries of compounds with osteogenic potential.

A

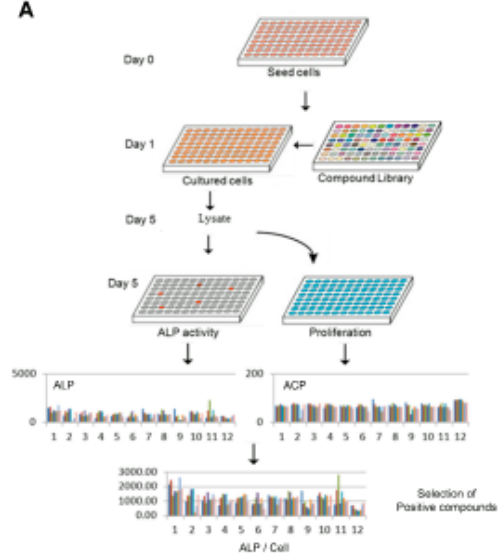

B

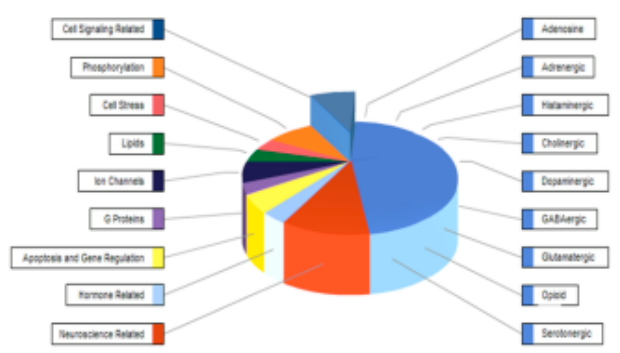

Fig. 1 High-throughput Assay. A) Schematic representation of HTA: hMSCs were grown on proliferation medium, dissociated using trypsin and plated into 96 well plates at a density of 2000 cells per well in osteogenic medium. Cells were allowed to attach for 24 hrs, after which medium was refreshed and compounds and controls were added to each plate. After 4 days, both ALP activity and proliferation was measured in a fluorescence plate reader. The compounds activity was evaluated in relation to the controls used. Positive compounds were then further confirmed by FACS and taken for further analysis. B) Representative diagram of the classes of action of the compounds used for the screen (Lopac library, Sigma-Aldrich). 


\section{Screening of the LOPAC library}

In order to investigate new molecules with osteogenic potential, high-throughput assays of a library of 1280 pharmacologically active compounds were performed in hMSCs from 2 donors (D36 and D41). The compounds were screened at a single dosage of $4.5 \mu \mathrm{M}$ in a volume of $200 \mu \mathrm{L}$ per well of osteogenic medium $(\mathrm{OM})$, containing $0.25 \% \mathrm{DMSO}(\mathrm{v} / \mathrm{v})$. ALP levels were normalized for cell number, and profound cytotoxicity was taken as an exclusion criterion, since for bone tissue engineering, proliferation is crucial in order to achieve proper differentiation. Only the compounds that were able to induce ALP above $3 \mathrm{SD}$-away from the trimmed mean of its plate and did not present a significant reduction of proliferation were taken into account. These hits were then compiled and only the ones appearing in more than one screen (on both donors tested) were taken for further studies. In the initial screens, 29 and 32 hits were obtained, from which 14 were present in both screens.

With ACP as readout, we have assessed whether any compounds exerted a mitogenic effect, and although some compounds did enhance significantly the proliferation of certain donor cells, there were no compounds that were able to significantly enhance proliferation in both donors tested, possible due to the fact that the mitogenic effect of the compounds was donor-specific.

\section{Selection of the optimal concentration}

After the compounds were selected from the primary screen, a subsequent dose-response curve was established in both basic and osteogenic medium. From the 14 compounds obtained in the initial screen, 2 were not available for retesting. An example of this assay for one compound ( $\mathrm{H}-8)$ can be seen in figure $2 \mathrm{~A}$. When $\mathrm{H}-8$ is added to basic medium, at a concentration of $1 \mu \mathrm{M}$, an induction of ALP activity $(\approx 2 x)$ can be seen (Fig. 2A1), lower concentrations do not produce any effect and higher ones present a decrease in total ALP activity. This decrease in ALP activity can be explained by a profound decrease in cell proliferation at concentrations higher than $3.16 \mu \mathrm{M}$ (Fig. 2A2). The same phenomenon occurs in osteogenic medium where dexamethasone is present, however a synergistic effect can already be seen for concentrations as low as $1 \mu \mathrm{M}$. Although adding $3.16 \mu \mathrm{M}$ of $\mathrm{H}-8$ to the medium induces a higher ALP activity per cell than $1 \mu \mathrm{M}$ (Fig. 2A3), the latter was chosen for further studies, since the former presents significant cytotoxicity (Fig. 2A 2). The same concentration range was used for all the different compounds and the optimal concentration obtained for each compound was then used for further studies. From the 12 compounds tested, we confirmed 5 (see Table 1). The induction ratios (ALP activity, proliferation and ALP per cell) of the compounds validated at the optimal concentration were compared to the control 
situation (basic medium) and are represented in Figure 2B. The compounds that induced higher ALP activity were $\mathrm{H} 8$ and Pinacidil when used in combination with dexamethasone.

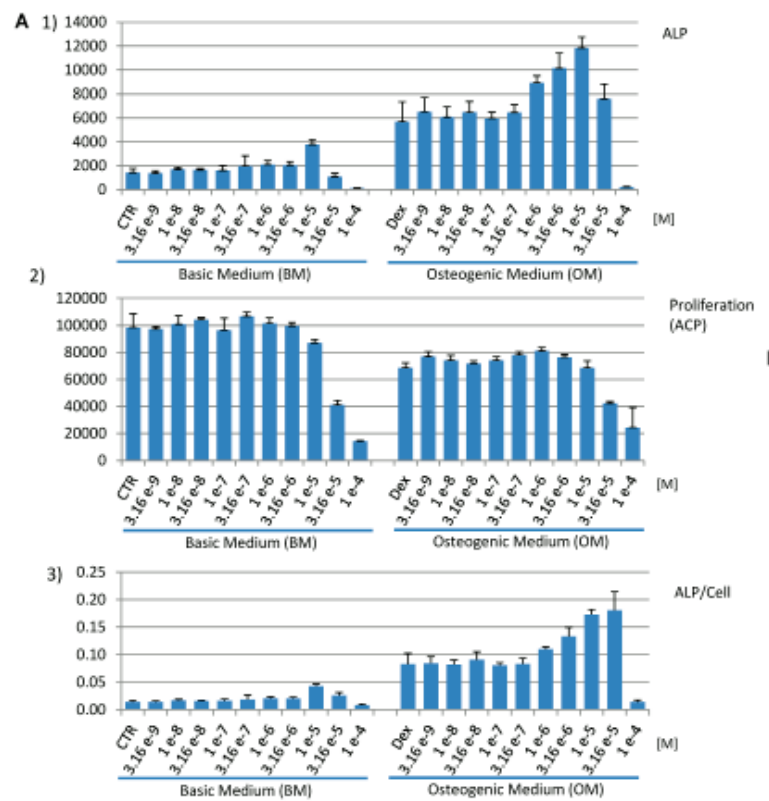

\begin{tabular}{|l|c|c|c|}
\hline & ALP & PROLIF (ACP) & ALP/CELL \\
\hline CTR (BM) & 1 & 1 & 1 \\
\hline H-8 & 2.64 & 0.885 & 2.98 \\
\hline GW 5070 & 1.07 & 0.86 & 1.24 \\
\hline PINACIDIL & 1.46 & 0.97 & 1.54 \\
\hline SQ 22,536 & 1.66 & 1.06 & 1.57 \\
\hline PROPENT & 1.84 & 0.78 & 2.32 \\
\hline & & & \\
\hline DEX (OM) & 3.52 & 0.72 & 4.86 \\
\hline OM + H-8 & 8.3 & 0.69 & 11.96 \\
\hline OM + GW 5070 & 5.69 & 0.8 & 7.06 \\
\hline OM + PINACIDIL & 7.94 & 0.75 & 11.45 \\
\hline OM + SQ 22,536 & 6.57 & 0.82 & 7.86 \\
\hline OM + PROPENT & 6.25 & 0.84 & 7.4 \\
\hline
\end{tabular}

Fig. 2. Hit validation. After being selected from the primary screen, the identified compounds (hits) were subjected to half-logarithmic dilutions in order to assess the optimal concentration of each compound that would induce the highest alkaline phosphatase (ALP) activity. The graphs represent: A1) ALP activity; A2) ACP activity A3) ALP activity/cell, in both basic and osteogenic medium when supplemented with different concentrations of the compound H-8 (as example, since the same was performed for all the hits obtained); B) The table represents the ALP-induction ratio when compared to the control situation (basic medium).

\section{Hits Validation by flow cytometry}

After the compounds were assessed for the optimal dosage to induce the highest ALP activity (marker for bone formation) without interfering significantly with proliferation, they were further validated in hMSCs derived from 4 donors (D26, D38, D41 and D42) by flow cytometry, using an antibody against bone/liver/ kidney-specific ALP. The percentage of cells expressing the ALP marker was evaluated and all the conditions were compared to either basic or osteogenic medium. Figure 3 represents the data from D41 (one of the donors used in the initial screen (Fig. 3A), and since some donor variation was present, we also include a table that summarizes the number of donors where each compound was effective (Fig. 3B). 
In the cells from D41 (A), we can observe that in control medium, the maximum effect of a compound in basic medium (BM) was an increase from $29.37 \% \pm 1.44$ of ALP positive cells (BM) to $38.12 \% \pm 1.20$ (when $\mathrm{H}-8$ was added to BM). However, it is clear that the best effect obtained by any compound is achieved when osteogenic medium (OM) is used. While the compound with less effect in this donor (Pinacidil) is able to synergistically increase the \% ALP positive cells from $44.19 \%$ $\pm 4.44(\mathrm{OM})$ to $50.62 \% \pm 1.63$, others $(\mathrm{H}-8$ and Propentofylline) can significantly increase it up to $69.76 \% \pm 0.68$ and $69.46 \% \pm 1.30$, respectively, representing a $57 \%$ increase over dexamethasone (the reference osteogenic molecule). However, not all the compounds exhibited a consistent effect on the four donors tested (Fig. $3 \mathrm{~B})$. Only one compound (H-8) was able to induce ALP in both BM and OM in the four donors tested, while 2 compounds (H-8 and GW 5074) were able to induce it in OM medium. The compound with the mildest effect was Propentofylline, since it only increased ALP in one donor (D41), although in that particular donor, was able to induce it significantly (from $44.19 \pm 4.44 \%$ of positive cells to 69.46 $\% \pm 1.30$, representing $\mathrm{a} \approx 57 \%$ increase over dex. alone) (Fig. $4 \mathrm{~A}$ ). In this donor, except for Pinacidil, all the other compounds that were used in OM, were able to significantly enhance ALP levels when compared to Dexamethasone alone (OM), showing that they were able to synergistically enhance ALP expression. When used alone (BM) only $\mathrm{H}-8$ and Propentofiline were able to significantly induce ALP (Figure 3A).

A

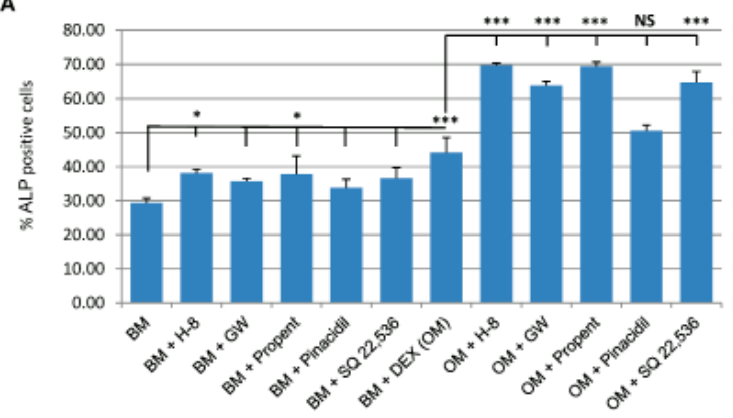

B

\begin{tabular}{|c|c|c|}
\hline Compounds & BM & OM \\
\hline H-8 & $4 / 4$ & $4 / 4$ \\
\hline GW 5074 & $2 / 4$ & $4 / 4$ \\
\hline Propentofylline & $1 / 4$ & $1 / 4$ \\
\hline Pinacidil & $2 / 4$ & $3 / 4$ \\
\hline SQ 22,536 & $3 / 4$ & $2 / 4$ \\
\hline
\end{tabular}

Fig. 3 Confirmation of the Hits by flow cytometry on ALP. A) Evaluation of the osteogenic potential of several treatment conditions by flow cytometry on hMSCS after 4 days treatment. Data is expressed as percentage of ALP positive cells. At least 10,000 cells were measured for each condition and experiments were performed in triplicate for each donor. B) Number of donors where each compound was effective. Error bars represent standard deviation. Statistical analysis was performed using (one-way ANOVA and Tukey post-test with a significance level of 0.05. Asterisks represent $* P<0.05,{ }^{* *} P<0.01$ and ${ }^{* * *} P<0.001$. BM (basic medium); OM (Osteogenic Medium); 
DEX (Dexamethasone). B) Number of donors in which the respective compound had a positive effect on ALP induction both in basic or osteogenic medium.

An overview of the average induction level (for 3 extra donors D26, D38 and D42) of each compound tested compared to the control can be seen in figure 4 . For each condition, data represents the average of the percentage of ALP positive cells for the 3 donors tested and was divided by the average of the controls to achieve the induction ratio. As can be seen from figure 4A, the compound that induces most ALP, in basic medium, is dexamethasone (positive control) with an average of 2.42 times more ALP-positive cells than the control. However the induction ratio varied largely between donors (1.50 to 3.69) as seen by the standard deviation (Figure 4A) and the data present in Figure 4C. From the compounds obtained in the screen, only H-8 and SQ 22,536 induced significantly more ALP positive cells than the control. However, when the compounds were added to OM (Figure 4B), all compounds induce an average ALP expression higher than the control (OM), showing that they synergistically act with dexamethasone to enhance ALP. The donor variation observed is depicted in figure $4 \mathrm{C}(\mathrm{BM})$ and $4 \mathrm{D}(\mathrm{OM})$.
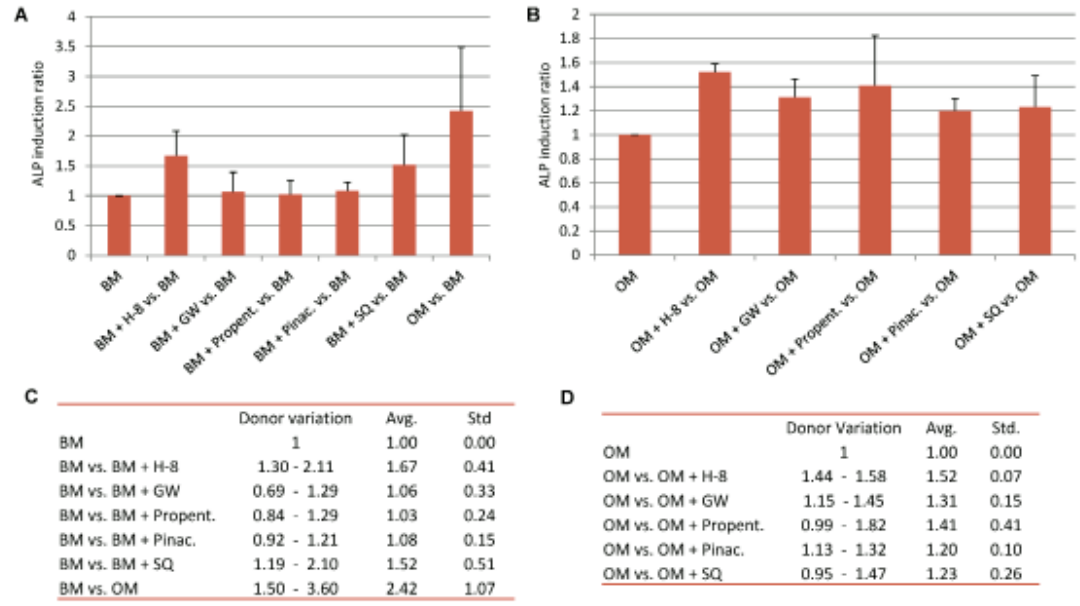

Fig. 4. Confirmation of the hits by flow cytometry in 3 extra donors A,B) Evaluation of the osteogenic potential of several treatment conditions on hMSCS after 4 days. Data is expressed as ALP induction ratio. Data reflects the average of induction of the percentage of ALP-positive cells of each condition divided by the average of induction of the percentage of ALP-positive cells of the respective control ( $\boldsymbol{A}$ - basic medium and $\boldsymbol{B}$ - osteogenic medium). Each experimental condition was performed in triplicate and data reflects the results of 3 independent donors). C,D) Table depicting the donor variation on the induction of the percentage of ALP positive cells after each experimental condition when compared to the respective control. 


\section{Comparison of the validated hits with the reference osteogenic molecules}

After performing the validation of the hits, we tested their activity in the context of other known compounds with known osteogenic activity (Fig. 5). The highest percentage of ALP positive cells was obtained when reference molecules vitamin D3 and dexamethasone $(41.67 \% \pm 0.22)$ were combined $(\mathrm{OM}+\mathrm{VitD} 3)$ (Figure $5 \mathrm{~A})$. This combination yielded a significantly higher percentage of ALP-positive cells than the combination of cAMP and dexamethasone $(\mathrm{p}<0.01)$, or dexamethasone alone $(\mathrm{p}<0.001)$. Supplementing this combination $(\mathrm{OM}+\mathrm{VitD} 3)$ with H-8 increased the percentage of ALP positive cells even further to $55.16 \% \pm 0.77$, representing an approx. $13 \%$ increase (Figure $5 \mathrm{C}$ ). However, the addition of $\mathrm{H}-8$ alone to OM already induced $50.13 \% \pm 0.46$ of cell to express ALP (Figure 5C). Even in the basic medium, the addition of $\mathrm{H}-8$ was able to increase the percentage of ALP-positive cells by $50 \%$, from $11.15 \% \pm 0.85$ (BM) to $22.56 \% \pm 1.06(\mathrm{BM}+$ $\mathrm{H}-8$ ) (Figure $5 \mathrm{~B}$ ). The addition of $\mathrm{H}-8$ to known osteogenic compounds (Dexamethasone, VitD3) increased ALP levels in a synergistic way (Fig. 5C), except with cAMP where the changes induced by the addition of $\mathrm{H}-8$ were not significant. Since lithium is known to inhibit the osteogenesis via Wnt signaling in hMSCs, we also tested the effect of lithium to $\mathrm{H}$-8-induced ALP expression. The addition of lithium did not have any effect on $\mathrm{H}$-8-induced ALP (Figure 5B), suggesting that the ALP induction by H-8 was not inhibited by the Wnt signaling pathway.
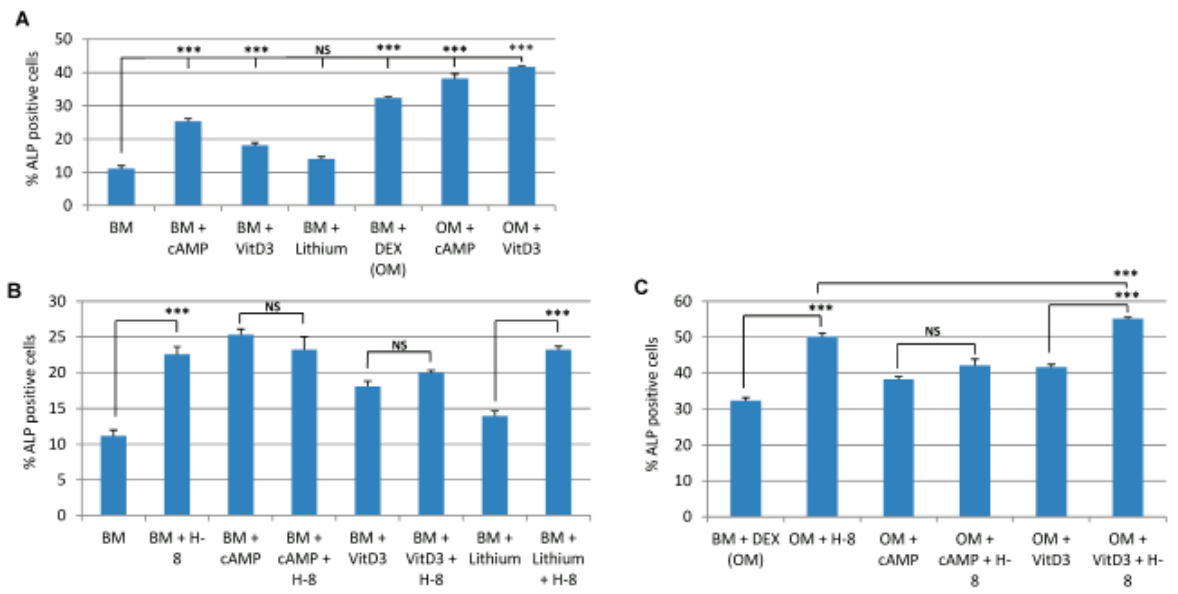

Fig. 5 Hit compound activity in the context of reference osteogenic compounds. The current graphs represents only one of the compounds validated $(H-8)$ and all the possible combinations with the reference osteogenic molecules. Graphs represent the \% ALP-positive cells of: the controls $(A)$, the different combinations possible in $B M(B)$ and the different combinations in OM (C). The osteogenic potential of each treatment was assessed by FACS 
after 4 days, in at least 10,000 cells, in triplicate. Error bars represent standard deviation. Statistical analysis was performed using one-way ANOVA and Tukey post-test with a significance level of 0.05. Asterisks represent $* P<0.05, * * P<0.01$ and $* * P<0.001$. OM - basic medium supplemented with dexamethasone; cAMP - di-buteryl cyclic AMP, DEX dexamethasone, NS - non significant.

\section{General Overview}

A general overview of the results is described in Figure 6. From the total 1280 compounds, 14 were selected for subsequent dose-response assays, in order to find the optimal dose to induce ALP. From the 14 selected compounds, 2 were not possible to be tested, and from the 12 that were assayed, 5 exhibited dose-depend effects on ALP induction. The list of the 5 compounds can be found in Table 1. The hits were then tested further by flow cytometry on three other donors, which resulted in 4 compounds with consistent ALP induction above the controls (Dexamethasone) and one (Propentofylline) that presented a non-significant increase in ALP expression in most donors. Based on this, $\mathrm{H}-8$ is the most promising compound for future in vivo studies.

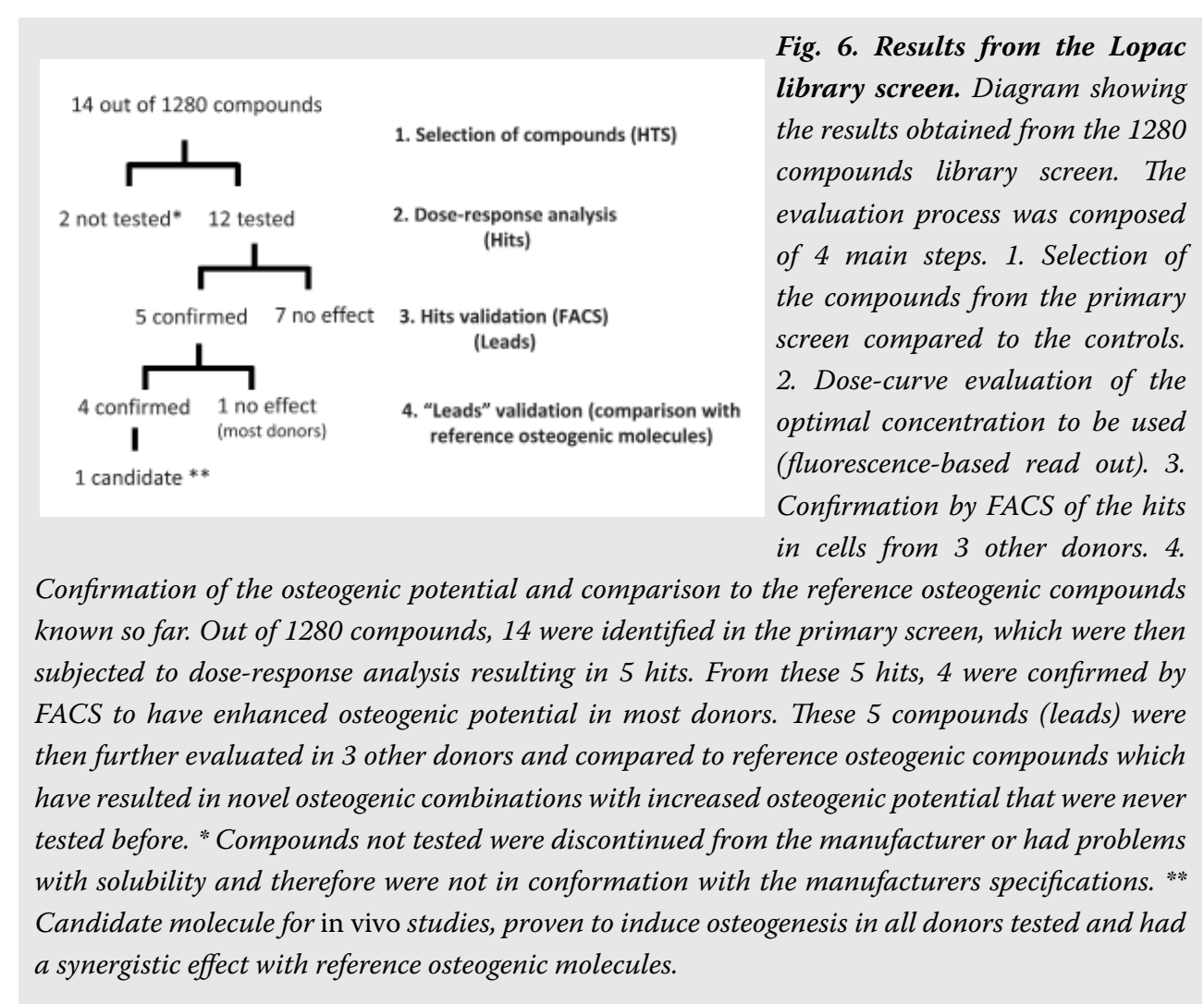




\section{Discussion}

\section{Design of the High-throughput assay}

When designing an HTA/ HTS the first consideration should be the goal of the screen and then the type of assays that would allow achieving that goal with the highest efficiency. Since our primary goal was to search for novel molecules with high osteogenic activity, the type of cells and readout marker to be used was our first consideration. Concerning cells, there were two immediate possible choices available, each one with their advantages and drawbacks. We had to choose whether we would use a highly homogeneous and abundant cell line with osteogenic potential (such as $\mathrm{C} 2 \mathrm{C} 12$ or MC3T3) or use human primary cells derived from bone marrow biopsies. While the first ones provide a more homogeneous cell source which will possibly result in an increased reproducibility between assays, they are isolated from mouse and are immortalized cell lines. Therefore, the results obtained could not directly been extrapolated to the human situation, without previously take in consideration, the species difference and even the differentiation state of the cells. An example is the usage of cAMP as an osteogenic inducer, where we have shown that the same compound results in an opposite effect when used in human cells as opposed to rodent models [20]. This study stresses the need that research experiments should be performed in more clinically relevant models.

Human mesenchymal stromal cells do not present the problem of species variation, however they are more heterogeneous, less abundant and present donor variation [21]. Nevertheless, when care is taken in the isolation of the cells and in the design of the experiment, most of these factors can be overcome. We therefore fell that the use of human primary cells is more clinically relevant and although more cumbersome since cells from different donors have to be used, it also contributes for the strengthening and validation of the results for possible future clinical applications. Furthermore, since HMSCs are multipotent, they could be a useful tool to unveil compounds that influence cell fate decisions. In this manuscript, we show that some compounds that induce osteogenesis are donor-specific, while others are able to robustly induce in all donors tested, making them better suited for in vivo studies.

For a fast and efficient high-throughput screening several factors are needed, one of them being the choice of the assays used as readout. They should be fast, economic, efficient, reproducible and, in the case of HTS, they should be simple enough to allow automation. The first step was the choice of assay to be used to determine cell numbers. Several methods exist, either by the direct or indirect determination of cell number, including cell counting using a microscope or a par- 
ticle counter [22], determination of cellular protein or DNA [23,24,25], measurement of 3H-thymidine incorporation [24], measurement of the uptake and conversion of tetrazolium dyes such XTT, MTS, and MTT $[26,27,28,29]$, or by measuring cellular enzymes such as lactic dehydrogenase [30]. However, most of them fail to obey to the desired characteristics mentioned above especially because most of them are time-consuming, therefore offering limited use in large-scale screening experiments. Another major limitation is that most of these methods are not sensitive enough to determine very low numbers of cells (less than 1000) and simple enough to be automated. When analyzing the effect of drugs on cell proliferation, one has to realize that these compounds can often be cytotoxic and therefore, it may be that in some wells the amount of cells is limited, therefore high-sensitivity is a prerequisite. Although, the assays based on cellular uptake and reduction of tetrazolium dyes are considered by some authors as the quickest, simplest, and most sensitive of the methods mentioned above, they offer several limitations [26]. These limitations include the fact that dye-based assays frequently suffer from high background signals, lack of reproducibility and limited linear response, in addition to the fact that some human cells metabolize tetrazolium dyes very inefficiently, not to mention that in some cases such dyes are even toxic to cells. In our screen we choose to use a well-established method to detect the activity of acidic phosphatase, due to the several advantages that this method offers on comparison to others. It is a simple method, it allows automation, can be performed in frozen lysates, it is inexpensive, reproducible and sensitive enough to detect low cell numbers. Acidic phosphatase activity assays can be performed since the endogenous levels of this enzyme is relatively constant in many cell types under different culture conditions and these methods have been proven to be the most sensitive and reproducible for counting different cell sources [17].

For the ALP activity quantification there was the possibility of quantifying it by using PNPP as substrate (colorimetric) or a luminescence method based on the conversion of the substrate CDP-Star (Roche). CDP-Star is a chemiluminescent substrate for alkaline phosphatase that enables an extremely sensitive and fast detection of biomolecules. It generates a luminescence signal which is approximately 10 times stronger than comparable chemiluminescent substrates and the signal is stable for long time. This method is fast, sensitive, presents very high signal to noise ratio and it is easily automated. After careful optimization and validation we decided to use this method for the detection of ALP activity.

Since the compounds were dissolved in DMSO the initial concern was to assess the potential toxicity of the dosage to be used. By reducing the amount of DMSO used in relation to the total volume of medium we achieved a very low final DMSO concentration (0.25\%) reducing significantly DMSO cytotoxicity (data 
not shown). Controls were used in each plate to assess for DMSO effects and also to provide a reference for the compounds being tested. We also opted to change medium in the plates only before the addition of the compounds present in the library. Thus, we used the compounds of the library only once, reducing the costs in both compounds and materials, in addition to the labour needed to replace the old medium and add new compounds. It also decreased the potential effect of adding DMSO for a second time, and since we previously knew that ALP was expressed at higher levels already after 4 days, we opted for the convenience of the screen, to use this time frame for the assay.

\section{Hit Rate on HTS screens and advantages of phenotypical screens}

One of the biggest problems in high-throughput screening experiments is the amount of false positive hits (inactive compounds misidentified as active by the primary screen). The concept of hit-rate designates the ratio of the number of actives to the number of compounds screened. Hit rates vary largely amongst screens and depend on several factors for instance whether the screen uses unknown synthetic compounds or "known bioactives". Despite known bioactive libraries are typically much smaller than commercial libraries of unknown synthetic compounds, they typically have a significantly higher hit rates than the libraries of synthetic compounds [31]. In our screen of bioactive compounds, 14 hits from a total of 1280 compounds tested were obtained, which corresponded to $1,09 \%$ of all compounds tested. Then on the counter screen (the dose-curve experiment) only 5 of the initial hits were confirmed and therefore, effectively, only $0,39 \%$ of the total screened compounds went for further validation. These hit rates are in line with other high-throughput screens (HTS), and as an example, in the siRNA library screen for osteogenic suppressors the hit rate was around 1,06\% [12], while in another HTS based on ALP as readout the hit rate for promoters of osteogenesis was around 3,46\% [13]. The percentage varies largely among bioactive screens, and in some cases the hit rates can be as high as 53,8 \%, as was the case of a screen for activators of deacetylase activity of purified Sirt1, where 1,151 initial hits were obtained out of 2,139 molecules screened (ChemBank). Without prior consideration of the true number of active compounds present in a library for the application in study, one cannot foresee the number of hits expected to be obtained in the first screen. 


\section{Validated hits and their mechanism of action}

The compounds selected as hits do not induce osteogenesis via the same signaling pathways, however, most of them are somehow involved in either the RafMEK-ERK or the cAMP signaling pathway. This discovery is in line with our previous findings that CAMP can mediate osteogenesis [6].

The most promising compound from the screen that was proven to enhance ALP formation in all the donors tested is $\mathrm{H}-8$, which has been described as a potent, cell-permeable, reversible and ATP-competitive inhibitor of cyclic-nucleotide protein kinases. It is known to inhibit protein kinase $\mathrm{A}(\mathrm{PKA})$, myosin light chain kinase (MLCK), protein kinase C (PKC) and protein kinase G (PKG) [32]. We previously reported, and show in Figure 5, that cAMP induces ALP expression, which is mediated via the activation of protein Kinase A (PKA). Yet, H-8 is still able to enhance significantly the ALP levels, apparently independent of PKA activity. The mechanism by which this occurs is still unknown. As mentioned, the mechanism of action of H-8 is broader than PKA alone. Similarly, a number of studies have identified that the action of 2 other PKA inhibitors (H89 and KT 5720) are independent of their effects on PKA. Low specificity of small molecules is a widespread phenomenon and include actions on other protein kinases and signaling molecules and also on basic cellular functions, such as transcription [33]. Interestingly, the other compound that was also able to increase the dex-induced ALP in all the tested donors was GW 5074, which is a Raf 1 kinase inhibitor, immediately downstream of Ras in the MAPK signaling pathway [34]. Amongst other effects, it stimulates Raf-MEK-ERK pathway and enhances the effects of most HDAC inhibitors [35].

The third compound more effective in OM was Pinacidil, which is a KATP channel opener, known to hyperpolarize various cell types. Both Pinacidil and other KATP channel openers like Diazoxide, are known to elevate bone marker expression, namely BSP and ALP, and it was shown that endogenous hyperpolarization is a functional determinant of hMSC differentiation and a possible control point for modulating stem cell function [36,37].

The other compounds selected as hits are both involved in the cAMP signaling however their effect seems to be somehow antagonist, which might lead to the speculation that their effects could be broader than the cAMP pathway itself. One of these compounds is SQ 22,536. It is a cell-permeable adenylate cyclase (AC) inhibitor [38] and since AC is the main responsible for the transformation of ATP to cyclic AMP (cAMP), the addition of SQ 22,536 should result in a decrease in cAMP levels, which is in contradiction with our previously published data [6] but in line with the results obtain with the compound $\mathrm{H}-8$ and with the report on 
the siRNA library screen for osteogenic suppressors [12]. However as a note, this compound was only effective in half of the donors tested and when all the donors are taken into account the addition of SQ 22,536 presented an average higher ALP than OM, but this increase was not significantly different. It could be that the increase on ALP observed could be via other pathway than the cAMP one, since it was recently proven that many compounds involved in cAMP pathway have a broader action than what was previously known.

The last compound is Propentofylline. It is a cAMP phosphodiesterase inhibitor, an adenosine transport inhibitor and a non-selective adenosine receptor antagonist. It has been proven to decrease free radical formation and lipid peroxidation [39], to reinforce the cAMP signaling and enhance the cAMP levels in plasma of mice [40]. Its predominant mechanism of action appears to be causally related to an increase of tissue cAMP/cGMP mainly by a) an indirect reinforcement of A2 receptor mediated cAMP formation (via adenosine transport blockade) and b) hindrance of intracellular cAMP breakdown (via inhibition of cAMP- and cGMPPDEs). As a note, this compound was only active in one of the donors used to validate the screen results, but in this particular donor, the increase in ALP expression was approx. $57 \%$ more than dexamethasone alone, which was highly significant. However this effect appeared to be donor specific.

Despite some of these compounds interact in pathways that are known to control osteogenesis, the full mechanism of action of some is still unknown. In phenotypical screens, however, the effect of a compound on the phenotype of choice, in this case osteogenic differentiation, is the relevant read-out. Even without detailed molecular knowledge on the mechanism of action of compounds, the positive effect of them can be exploited. Nevertheless, further work needs to be performed to deepen the knowledge of the signaling pathways investigated and should be regarded as an extra tool to reveal potential drug targets for future manipulation.

\section{Conclusions:}

In this manuscript we show that by performing an HTA we were able to obtain compounds that are able to enhance ALP expression (the best known indicator of osteogenic differentiation) even when compared to the reference osteogenic molecules (Dexamethasone, Vitamin D3, cAMP). The results obtained by this HTA show that many more compounds have the potential to induce ALP, and prove that this methodology can be very effective in discovering novel compounds with osteogenic potential or novel functions to currently known compounds. Furthermore, this type of HTA can be easily extrapolated to other differentiation experi- 
ments, once the methodology is changed.

In this screen only a relatively small library of compounds was tested (1280 compounds) and therefore many other libraries can reveal compounds that are still not known to induce osteogenesis. What would be equally interesting and highly valuable for the research in bone formation, would be the discovery of bone formation markers that are able to predict bone formation more efficiently, making the HTS with those markers even a more valuable tool towards improved bone formation and hopefully making the transition from bench to bedside quicker.

\section{Acknowledgements:}

We wish to thank Ruud Licht for the assistance with the implementation of the technical settings involved in this work and L. Creemers and W. Dhert (University Medical Center Utrecht) for kindly providing us with the bone marrow aspirates. 


\section{References:}

1. http://www.niams.nih.gov/Health_Info/Bone/Osteoporosis/default.asp.

2. Pittenger MF, Mackay AM, Beck SC, Jaiswal RK, Douglas R, et al. (1999) Multilineage potential of adult human mesenchymal stem cells. Science 284: 143-147.

3. Caplan AI (2009) Why are MSCs therapeutic? New data: new insight. J Pathol 217: 318-324.

4. De Boer J, Wang HJ, Van Blitterswijk C (2004) Effects of Wnt signaling on proliferation and differentiation of human mesenchymal stem cells. Tissue Eng 10: 393-401.

5. de Boer J, Licht R, Bongers M, van der Klundert T, Arends R, et al. (2006) Inhibition of histone acetylation as a tool in bone tissue engineering. Tissue Eng 12: 2927-2937.

6. Siddappa R, Martens A, Doorn J, Leusink A, Olivo C, et al. (2008) cAMP/PKA pathway activation in human mesenchymal stem cells in vitro results in robust bone formation in vivo. Proc Natl Acad Sci U S A 105: 7281-7286.

7. Anderson DG, Levenberg S, Langer R (2004) Nanoliter-scale synthesis of arrayed biomaterials and application to human embryonic stem cells. Nat Biotechnol 22: 863-866.

8. Lovmand J, Justesen J, Foss M, Lauridsen RH, Lovmand M, et al. (2009) The use of combinatorial topographical libraries for the screening of enhanced osteogenic expression and mineralization. Biomaterials 30: 2015-2022.

9. Malo N, Hanley JA, Cerquozzi S, Pelletier J, Nadon R (2006) Statistical practice in highthroughput screening data analysis. Nat Biotechnol 24: 167-175.

10. Wu Z, Liu D, Sui Y (2008) Quantitative assessment of hit detection and confirmation in single and duplicate high-throughput screenings. J Biomol Screen 13: 159-167.

11. Brideau C, Gunter B, Pikounis B, Liaw A (2003) Improved statistical methods for hit selection in high-throughput screening. J Biomol Screen 8: 634-647.

12. Zhao Y, Ding S (2007) A high-throughput siRNA library screen identifies osteogenic suppressors in human mesenchymal stem cells. Proc Natl Acad Sci U S A 104: 9673-9678.

13. Brey DM, Motlekar NA, Diamond SL, Mauck RL, Garino JP, et al. (2011) Highthroughput screening of a small molecule library for promoters and inhibitors of mesenchymal stem cell osteogenic differentiation. Biotechnol Bioeng 108: 163-174.

14. Heo JS, Lee SY, Lee JC (2010) Wnt/beta-catenin signaling enhances osteoblastogenic differentiation from human periodontal ligament fibroblasts. Mol Cells 30: 449-454.

15. Fickert S, Schroter-Bobsin U, Gross AF, Hempel U, Wojciechowski C, et al. (2011) Human mesenchymal stem cell proliferation and osteogenic differentiation during long-term $e x$ vivo cultivation is not age dependent. J Bone Miner Metab 29: 224-235. 
16. Alves H, Munoz-Najar U, de Wit J, Renard AJ, Hoeijmakers JH, et al. (2010) A link between the accumulation of DNA damage and loss of multipotency of human mesenchymal stromal cells. J Cell Mol Med 14: 2729-2738.

17. Connolly DT, Knight MB, Harakas NK, Wittwer AJ, Feder J (1986) Determination of the number of endothelial cells in culture using an acid phosphatase assay. Anal Biochem 152: 136-140.

18. (1995). CLONTECHniques. pp. 20-21.

19. Zhang JH, Chung TD, Oldenburg KR (1999) A simple statistical parameter for use in evaluation and validation of high throughput screening assays. J Biomol Screen 4: 67-73.

20. Siddappa R, Mulder W, Steeghs I, van de Klundert C, Fernandes H, et al. (2009) cAMP/ PKA signaling inhibits osteogenic differentiation and bone formation in rodent models. Tissue Eng Part A 15: 2135-2143.

21. Siddappa R, Licht R, van Blitterswijk C, de Boer J (2007) Donor variation and loss of multipotency during in vitro expansion of human mesenchymal stem cells for bone tissue engineering. J Orthop Res 25: 1029-1041.

22. Blaheta RA, Franz M, Auth MK, Wenisch HJ, Markus BH (1991) A rapid non-radioactive fluorescence assay for the measurement of both cell number and proliferation. J Immunol Methods 142: 199-206.

23. Becker B, Clapper J, Harkins KR, Olson JA (1994) In situ screening assay for cell viability using a dimeric cyanine nucleic acid stain. Anal Biochem 221: 78-84.

24. Olander JV, Marasa JC, Kimes RC, Johnston GM, Feder J (1982) An assay measuring the stimulation of several types of bovine endothelial cells by growth factor(s) derived from cultured human tumor cells. In Vitro 18: 99-107.

25. Rago R, Mitchen J, Wilding G (1990) DNA fluorometric assay in 96-well tissue culture plates using Hoechst 33258 after cell lysis by freezing in distilled water. Anal Biochem 191: 31-34.

26. Buttke TM, McCubrey JA, Owen TC (1993) Use of an aqueous soluble tetrazolium/ formazan assay to measure viability and proliferation of lymphokine-dependent cell lines. $J$ Immunol Methods 157: 233-240.

27. Cory AH, Owen TC, Barltrop JA, Cory JG (1991) Use of an aqueous soluble tetrazolium/formazan assay for cell growth assays in culture. Cancer Commun 3: 207-212.

28. Mosmann T (1983) Rapid colorimetric assay for cellular growth and survival: application to proliferation and cytotoxicity assays. J Immunol Methods 65: 55-63.

29. Roehm NW, Rodgers GH, Hatfield SM, Glasebrook AL (1991) An improved colorimetric assay for cell proliferation and viability utilizing the tetrazolium salt XTT. J Immunol Methods 142: 257-265. 
30. Jauregui HO, Hayner NT, Driscoll JL, Williams-Holland R, Lipsky MH, et al. (1981) Trypan blue dye uptake and lactate dehydrogenase in adult rat hepatocytes--freshly isolated cells, cell suspensions, and primary monolayer cultures. In Vitro 17: 1100-1110.

31. An WF, Tolliday N (2010) Cell-based assays for high-throughput screening. Mol Biotechnol 45: 180-186.

32. Hidaka H, Inagaki M, Kawamoto S, Sasaki Y (1984) Isoquinolinesulfonamides, novel and potent inhibitors of cyclic nucleotide dependent protein kinase and protein kinase $\mathrm{C}$. Biochemistry 23: 5036-5041.

33. Murray AJ (2008) Pharmacological PKA inhibition: all may not be what it seems. Sci Signal 1: re4.

34. Lackey K, Cory M, Davis R, Frye SV, Harris PA, et al. (2000) The discovery of potent cRaf1 kinase inhibitors. Bioorg Med Chem Lett 10: 223-226.

35. Lea MA, Ibeh C, Shah N, Moyer MP (2007) Induction of differentiation of colon cancer cells by combined inhibition of kinases and histone deacetylase. Anticancer Res 27: 741-748.

36. McBurney A, Henry JA, Ward JW (1988) Accumulation of pinacidil N-oxide during chronic treatment with pinacidil. Eur J Clin Pharmacol 35: 93-95.

37. Sundelacruz S, Levin M, Kaplan DL (2008) Membrane potential controls adipogenic and osteogenic differentiation of mesenchymal stem cells. PLoS One 3: e3737.

38. Fabbri E, Brighenti L, Ottolenghi C (1991) Inhibition of adenylate cyclase of catfish and rat hepatocyte membranes by 9-(tetrahydro-2-furyl)adenine (SQ 22536). J Enzyme Inhib 5: 87-98.

39. Wirtz-Brugger F, Giovanni A (2000) Guanosine 3,5'-cyclic monophosphate mediated inhibition of cell death induced by nerve growth factor withdrawal and beta-amyloid: protective effects of propentofylline. Neuroscience 99: 737-750.

40. Si Q, Nakamura Y, Ogata T, Kataoka K, Schubert P (1998) Differential regulation of microglial activation by propentofylline via cAMP signaling. Brain Res 812: 97-104. 
(ธ) 


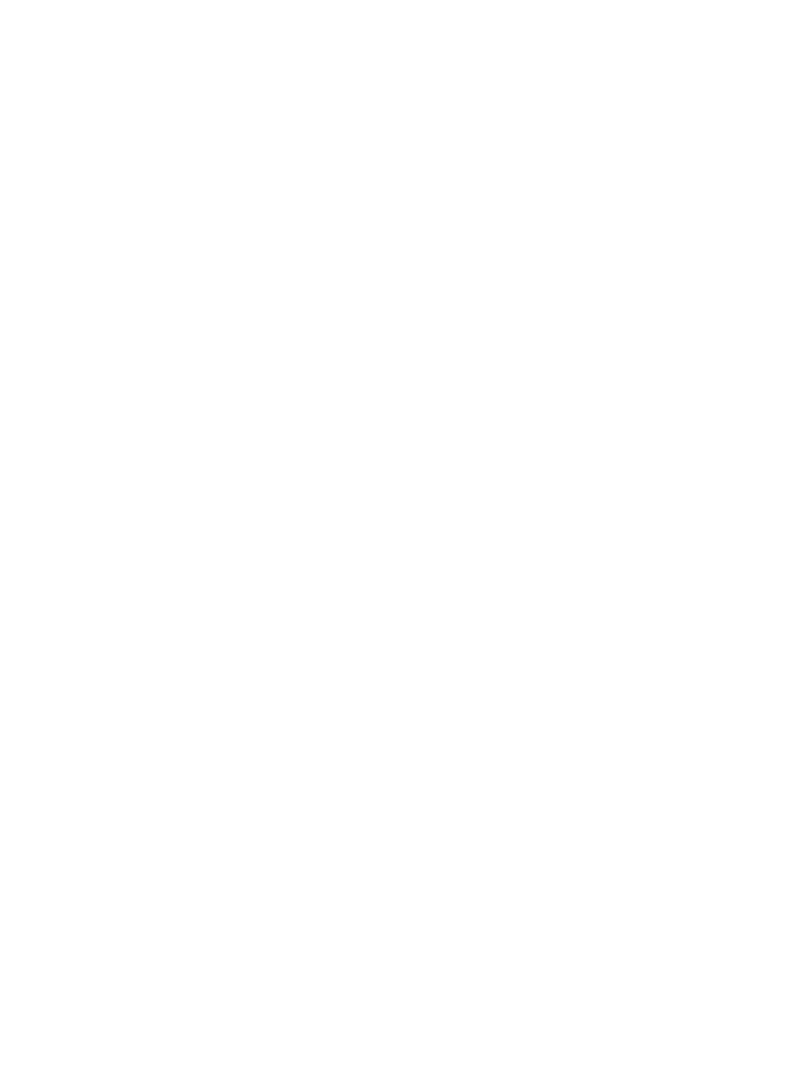




\title{
Chapter 6
}

\section{A Mesenchymal Stromal Cell Gene Signature for Therapeutic Efficacy of Bone Tissue Engineering}

Anouk Mentink*, Marc Hulsman†, Ruud Licht*, Koen Dechering‡, Hugo Alves*, Wouter Dhert $\$$, Eugene van Someren†, Marcel Reinders $\dagger$, Clemens van Blitterswijk* and Jan de Boer*

* Department of Tissue Regeneration, MIRA Institute for Biomedical Technology and Technical Medicine, University of Twente, Enschede, The Netherlands; †Delft Bioinformatics Lab, Faculty of Electrical Engineering, Mathematics and Computer Science, Delft University of Technology, Delft, The Netherlands; ‡ Department of Molecular Pharmacology, Merck Research Laboratories, Oss, The Netherlands; $\mathbb{\text { Translational Musculoskeletal }}$ Research, University Medical Center Utrecht, Division of Surgical Specialties, Dept. Orthopaedics, Utrecht, The Netherlands

\begin{abstract}
Cell-based regenerative therapies using mesenchymal stem or stromal cells (hMSCs) are advancing into the clinic but the use of autologous hMSCs presents the problem of donor variability in their therapeutic efficacy. For instance, in bone tissue engineering, cells from different individuals display large variation in their ability to deposit bone. To date no markers have been identified which can predict the bone forming capacity of hMSCs. To this end, we isolated hMSCs from 61 donors undergoing orthopedic surgery and systematically assessed their in vitro lineage differentiation capacity, gene expression signature and in vivo capacity for ectopic bone formation on porous calcium phosphate scaffolds in mice. Our data demonstrate that in vitro differentiation varies largely between donors, and does not correlate with ectopic bone formation in vivo. Using microarray analysis of early passage hMSCs we identified a diagnostic bone forming classifier that predicted the bone forming capacity of hMSCs following expansion and implantation. A single gene, CADM1, strongly correlated with the bone forming capacity of hMSCs and could be used as a reliable diagnostic maker. Furthermore, data mining of genes correlating with in vivo bone formation indicated a correlation with neurogenic processes and Wnt signaling in bone formation by hMSCs. We will apply our data set to predict therapeutic activity of hMSCs and to gain novel insight in the process of bone regeneration.
\end{abstract}




\section{Introduction}

Many human diseases are caused by failure of tissue function, with well-known examples such as diabetes, damage inflicted by myocardial infarcts and degeneration of the hip joint. The disciplines of tissue engineering and cell therapy aim at restoring worn-out or diseased tissues for which the patient's own body represents a source of autologous cells [1]. For instance, a much used source of autologous cells in the field of bone tissue engineering are human multipotent mesenchymal stromal cells (hMSCs), also referred to as mesenchymal stem cells [2]. Because hMSCs can be easily isolated from bone marrow aspirates and expanded in vitro, they are used for various cell-based therapeutic applications [3]. hMSCs are multipotent cells which are able to differentiate, depending on the stimulus, into several lineages including the osteogenic, chondrogenic and adipogenic lineage in vitro [4]. Osteogenic differentiation of hMSCs is characterized by expression of alkaline phosphatase (ALP) and the formation of a mineralized extracellular matrix (ECM) containing hydroxyapatite. Molecules such as dexamethasone (dex), 3'-5'-cyclic adenosine monophosphate (cAMP), 1,25-dihydroxy-vitaminD (vitD3) and bone morphogenetic protein 2 (BMP-2) are used to drive osteogenic differentiation of hMSCs in vitro [5-7]. For bone tissue engineering, we and others have demonstrated ectopic bone formation by seeding hMSCs onto porous calcium phosphate scaffolds and subsequent subcutaneous implantation into immune-deficient mice [8-9]. Although proof of principle exists for bone tissue engineering in animal models [10], clinical application is hampered by large donor variation in the ability of hMSCs to deposit bone tissue in vivo [11-12]. Unfortunately, bone tissue engineering efficacy is not correlated to known clinical or molecular labels. This is partly due to the fact that the field of hMSC biology lacks an elaborate classification system of CD markers to define stem cells, progenitor cells and differentiated cells as it is known for the hematopoietic stem cell system. Cell surface markers such as Stro-1 and the nerve growth factor receptor have been used to prospectively isolate clonogenic hMSCs from a crude bone marrow aspirate [13-14], but the resultant population of cells is still heterogenic in its biological performance. CD146 defines an hMSC subpopulation with the ability to organize a hematopoietic niche in vivo but its expression on hMSCs does not correlate to bone formation per se [15]. Therefore, it would be beneficial to define diagnostic markers in culture expanded hMSCs which can predict their in vivo performance. The markers can be used to select patients eligible for clinical trials but also provide biological tools to interfere with the osteogenic potential of hMSCs.

The use of diagnostic markers for tissue engineering outcome is successfully used in the field of cartilage regeneration, where Dell'Accio et al. identified a set of molecular markers predictive for in vivo cartilage formation of adult human ar- 
ticular chondrocytes. It was positively associated with the expression of fibroblast growth factor receptor $3, \mathrm{BMP}-2$ and $\alpha 1$ (II) collagen, and its loss was marked by the upregulation of activin receptor-like kinase 1 messenger RNA [16]. The genes were identified based on their known involvement in the chondrogenic process and similarly, we and others have tried to correlate the expression of genes involved in the osteogenic process in hMSC to their potency to form bone in vivo. Although correlations were found between collagen type I and osteoprotegerin [17] or ALP expression [18] and bone formation, the data sets used were too small to firmly establish a link between gene expression and bone formation and no new insight in the process was obtained. To this end, larger data sets are required for which genome wide gene expression profiling can be applied. We have previously reported on a micro-array based approach to distinguish metastasizing from nonmetastasizing breast tumors starting from RNA isolated from a breast tumor biopsy [19]. In this study, we have used a similar strategy to find in vitro diagnostic markers which are able to predict the in vivo bone forming capacity of hMSCs. We developed a bank of hMSCs from 61 different donors, performed various in vitro differentiation assays and analyzed the in vivo bone formation. In addition, we determined the gene expression profile of the hMSCs from the different donors to correlate it with the in vivo bone forming capacity (outlined in Figure 1). In this manuscript, we present a molecular signature of bone forming hMSCs.

\section{Materials and Methods}

\section{Isolation and culture of hMSCs}

Bone marrow aspirates $(5-20 \mathrm{~mL})$ were obtained from donors with written informed consent, and hMSCs were isolated and proliferated as described previously [19]. Briefly, aspirates were resuspended using a 20-Gauge needle, plated at a density of 500,000 cells $/ \mathrm{cm}^{2}$ and cultured in hMSC proliferation medium containing $\alpha$-MEM (Gibco), 10\% heat-inactivated fetal bovine serum (Biowhittaker), $0.2 \mathrm{mM}$ ascorbic acid (Sigma), $2 \mathrm{mM} \mathrm{L-glutamine} \mathrm{(Gibco),} 100 \mathrm{U} / \mathrm{mL}$ penicillin with $100 \mathrm{mg} / \mathrm{mL}$ streptomycin (Gibco) and $1 \mathrm{ng} / \mathrm{mL}$ basic fibroblast growth factor (Instruchemie, Delfzijl, The Netherlands). The serum batch was selected based on proliferation rate and osteogenic differentiation potential and used for all experiments in this paper. Cells were grown in a humid atmosphere with $5 \% \mathrm{CO}_{2}$. Basic medium was composed of proliferation medium without basic fibroblast growth factor, osteogenic medium was composed of basic medium supplemented with $10^{-8} \mathrm{M}$ dex (Sigma) and mineralization medium was composed of basic medium supplemented with $10^{-8} \mathrm{M}$ dex and $0.01 \mathrm{M} \beta$-glycerophosphate (Sigma). 


\section{In vivo bone formation}

To evaluate the bone forming capacity of hMSCs, cells were seeded onto porous biphasic calcium phosphate (BCP) ceramic granules of approximately 2-3 $\mathrm{mm}$, prepared and sintered at $1150^{\circ} \mathrm{C}$ as described previously [20]. In total, 200,000 cells per three particles were seeded, in osteogenic medium. After one week of culturing, tissue-engineered constructs were implanted subcutaneously in immune-deficient mice (Hsd-cbp:NMRI-nu, Harlan, $n=6$ ). The mice were anesthetized by intramuscular injection of $0.05 \mathrm{~mL}$ of $0.5 \mathrm{mg} / \mathrm{mL}$ of anesthetic $(1.75 \mathrm{~mL}$ of $100 \mu \mathrm{g} / \mathrm{mL}$ ketamine, $1.5 \mathrm{~mL}$ of $20 \mathrm{mg} / \mathrm{mL}$ xylazine and $0.5 \mathrm{~mL}$ of $0.5 \mathrm{mg} / \mathrm{mL}$ atropine). Four subcutaneous pockets were made dorsally and each pocket was implanted with three particles. Animals were housed at the Central Laboratory Animal Institute (Utrecht University, Utrecht, The Netherlands), and experiments were approved by the local animal care and use committee. After six weeks, the mice were sacrificed using $\mathrm{CO}_{2}$ and samples were explanted, fixed in $1.5 \%$ glutaraldehyde (Merck) in 0.14 M cacodylic acid (Fluka) buffer ( $\mathrm{pH} 7.3$ ), dehydrated and embedded in methyl methacrylate (LTI) for sectioning. Sections were processed on a histological diamond saw (Leica SP1600). Sections were etched with an $\mathrm{HCl} /$ ethanol mixture and sequentially stained to visualize bone, with $1 \%$ methylene blue (Sigma) and $0.03 \%$ basic fuchsin (Sigma), which stained cells blue and bone pink. Histomorphometry was performed by making low-magnification images from three sections per sample. Scaffold and bone were pseudo colored, and image analysis was performed with KS400 software (Zeiss Vision). A custom-made program (University of Utrecht) was used to measure percentage of bone area compared to scaffold area.

\section{Flow cytometry}

To analyze ALP expression and expression of CD markers, we used flow cytometry as described previously [21]. For measuring ALP expression, a 1:50 dilution of primary antibody was used (anti-ALP, B4-78, Developmental Studies Hybridoma Bank, University of Iowa) and a 1:100 dilution of secondary antibody (goat-antimouse IgG PE, DAKO). For cell surface markers, the same procedure was performed using antibodies for CD105, CD11b, CD19, CD45, HLA-DR, CD90 (R\&D Systems), CD73 and CD34 (AbCam).

\section{Mineralization}

To determine the mineralization capacity and calcium deposition, hMSCs were seeded in T25 flasks at 5000 cells $/ \mathrm{cm}^{2}$. Cells were cultured in mineralization medium for three weeks, in triplicate. The total calcium deposition was analyzed by using a Calcium Assay Kit (Quantichrom, BioAssay Systems) according to manu- 
facturer's protocol. Briefly, $0.5 \mathrm{~N} \mathrm{HCl}$ was used to release calcium and the calcium content was measured at $620 \mathrm{~nm}$ and expressed as $\mathrm{mg} / \mathrm{dL}$.

\section{Adipogenesis}

Adipogenic differentiation capacity of hMSCs was determined as described previously [21]. In short, after three weeks of culture in adipogenic medium, lipid formation was visualized by staining with Oil red $\mathrm{O}$ and staining was quantified by extraction of color and measuring absorbance at $540 \mathrm{~nm}$.

\section{Chondrogenesis}

Cells were grown in pellet culture for 21 days with 250,000 cells/pellet in serum-free chondrogenic medium containing TGF 33 [22]. Chondrogenic medium was supplemented with $250 \mathrm{ng} / \mathrm{mL}$ human BMP6 (Biovision) [23]. Pellets were fixed and stained with Alcian Blue (Sigma).

\section{Microarray analysis and quantitative polymerase chain reaction}

To analyze the gene expression profile of hMSCs, cells were seeded at 1000 cells $/ \mathrm{cm}^{2}$ and upon reaching near confluence RNA was isolated using an RNeasy mini kit (Qiagen) and DNase treated on column with $10 \mathrm{U}$ RNase free DNase I (Gibco) at $37^{\circ} \mathrm{C}$ for $30 \mathrm{~min}$. DNase was inactivated at $72^{\circ} \mathrm{C}$ for $15 \mathrm{~min}$. The quality and quantity of RNA was analyzed by gel electrophoresis and spectrophotometrically. For qPCR, we performed cDNA synthesis using the iScript cDNA synthesis kit (Bio-rad) and qPCR was carried out using iQ SYBR Green Supermix (Bio-rad). Primer (Sigma) sequences and PCR conditions are depicted in Table S2, as a reference gene we used GAPDH. For microarray analysis, the RNA was hybridized to the Human Genome U133A 2.0 Array (Affymetrix) and scanned with a GeneChip G3000 scanner (Affymetrix). The microarray experiments were performed in three batches. To normalize the measurements, we used a normalization method which removes hybridization, amplification and array location based technical effects [24]. To determine the most significant genes with respect to a label-set, we determined a (two-sided) p-value for each gene using a permutation test. As test statistic we used the significant analysis of microarrays [25] test statistic [26] for class labels and the F-test for continuous labels. In total, for each label-set, we performed 10,000 permutations. Genes were sorted on their estimated p-value. For further analysis, we also calculated gene set enrichments using gene sets from the database of molecular signatures (MsigDB) [27]. In addition to this, we trained a classifier for the binary bone label (bone or no bone), predicting if bone formation would occur for a certain donor or not. We applied a Nearest-Mean classifier (available as part of PRTools, [28]), and performance was estimated using leaveone-out cross-validation. The probesets to be used as features were selected by 
taking those with the highest SAM test statistic value on the training set. To determine the optimal number of probesets an inner leave-one-out cross-validation loop was performed. An area under curve (AUC) score of the Receiver Operating Characteristic (ROC), a widely used standard for describing and comparing the accuracy of diagnostic tests, was constructed by combining results for the different validation sets using the classifier class probability (determined using maximum likelihood posterior probabilities [28]). ROC represents the tradeoff between the false negative and false positive rates for every possible cut-off. AUC is a measure of the probability that a classifier based on this label would rank a randomly chosen positive donor higher than a randomly chosen negative donor, where $A U C=1$ is a perfect ranking classifier and $\mathrm{AUC}=0.5$ depicts complete randomness.

\section{Results}

\section{Study Outline}

In order to contextualize the reader, an outline of this study is presented on Fig. 1.

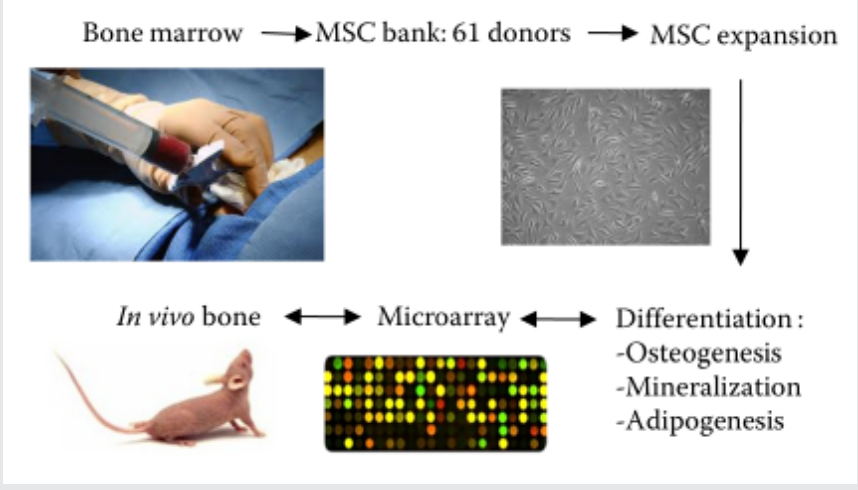

Fig. 1. Study outline. Bone marrow aspirates were obtained from 61 donors, hMSCs were isolated and expanded, subsequently the in vivo bone formation, microarray profile and differentiation capacity of the cells were determined.

\section{Large inter-donor variability in biological characteristics of hMSCs}

To find a predictive marker for bone formation by hMSCs in vivo we aspirated bone marrow from either the acetabulum or the iliac crest of 61 donors undergoing orthopedic surgery, 48 of which were female and 15 were male. The age of the 
donor varied from 17 to 84 years of age with an average of 56 years. Aspirates were put into culture and we confirmed the identity of the proliferating cells as hMSCs according to the set of standards proposed by the Mesenchymal and Tissue Stem Cell Committee of the International Society for Cellular Therapy [29]. The cells were adherent to plastic (Fig. S1a) and more than 94\% expressed CD73 and CD90, 60\% expressed CD105, and less than 2\% expressed CD45, CD34, CD11b, CD19 and HLA-DR, as measured by flow cytometry in hMSCs isolated from three donors (Fig. S1c). Moreover, we were able to differentiate the cells into the osteogenic, adipogenic and chondrogenic lineage under standard in vitro differentiation conditions, as demonstrated by histological staining (Fig. S1b).

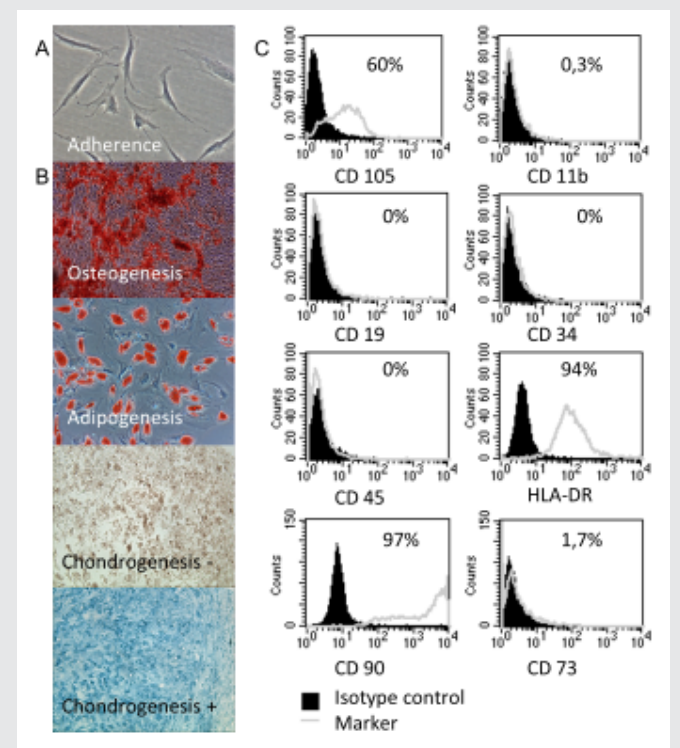

Fig. S1. Identification of hMSCs. We confirmed the identity of our hMSCs according to the set of standards proposed by the Mesenchymal and Tissue Stem Cell Committee of the International Society for Cellular Therapy [19]. A) hMSCs were adherent to tissue culture plastic. B) The cells were able to differentiate into the adipogenic (staining with Oil red O), osteogenic (staining with Alizarin Red) and chondrogenic (staining with Alcian Blue) lineage in vitro. C) Histograms showing flow cytometric analyses of our hMSCs, demonstrating expression of cell surface markers, representative for three different donors. Percentages of positive cells are indicated.

To confirm that donor variability in the bone forming capacity exists within this set of hMSCs, we used the ectopic bone formation model in immune-deficient mice $[6,14,30,31,32]$ to quantify ectopic bone formation in vivo. To this end, we seeded hMSCs of all donors onto porous calcium phosphate ceramic scaffolds and cultured them for one week in osteogenic medium, prior to implantation. After six weeks, scaffolds were explanted and bone formation was quantified (Fig. S2). Out of 61 donors, 35 did show bone formation ranging from 0.01 to $4.6 \%$ of bone area/ scaffold area demonstrating a large inter-donor variability (Fig. 2e).

To further investigate donor variability, we characterized the hMSCs for a number of cellular parameters, such as proliferation and in vitro differentiation. Indeed, we observed large differences in the rate of hMSC proliferation (Fig. 2a) 


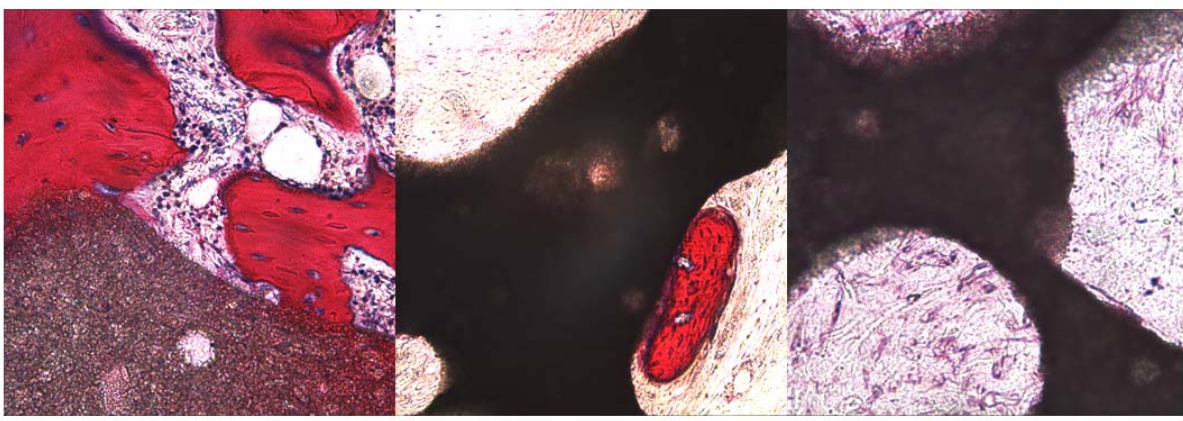

Fig. S2. In vivo bone formation of hMSCs. hMSCs were cultured on BCP particles (200,000 cells/3 particles) in osteogenic medium for seven days and implanted subcutaneously in nude mice for six weeks. Newly formed bone is stained pink and scaffold appears black. From left to right pictures show a lot of bone formation, average bone formation and no bone formation.

and osteogenic differentiation, indicated by the potency of dex to enhance the expression of the early osteogenic marker ALP. As reported by us previously, both basic and dex-induced expression of ALP shows large donor variation [5]. ALP expression in the control group ranged from $0.2-39 \%$ of ALP positive cells and in the dex-induced group from $0.3-47 \%$, with an average of $12 \%$ (Fig. 2b, Table S1). Next, we evaluated the mineralization capacity of hMSCs as a late marker for in vitro osteogenesis. Again, we found large donor variation in the ability of the cells to deposit a mineralized matrix, ranging from $0-20.3 \mathrm{mg} / \mathrm{dL}$ of calcium, with an average of 8.3 (Fig. 2c). Similarly, to determine the adipogenic differentiation capacity of hMSCs, we cultured cells in adipogenic medium for three weeks and lipid formation was quantified. The optical density (OD) ranged between 1-6.7 with an average of 3.3 in 18 different donors (Fig. 2d). In conclusion, the biological performance of hMSCs varies strong between donors, both in vitro and in vivo.

\section{Correlation between cell biological data labels, donor features and bone for- mation}

Differential bone apposition of hMSCs could be correlated to some of the cellular or physiological parameters associated with the hMSCs, as described above, or to the donors from which they were isolated, e.g. gender, age or site of aspiration. To this end, we correlated all available parameters to bone formation in vivo. As an example, ALP activity is commonly used to describe osteogenic differentiation in vitro. We investigated the correlation between ALP expression and the in vivo 


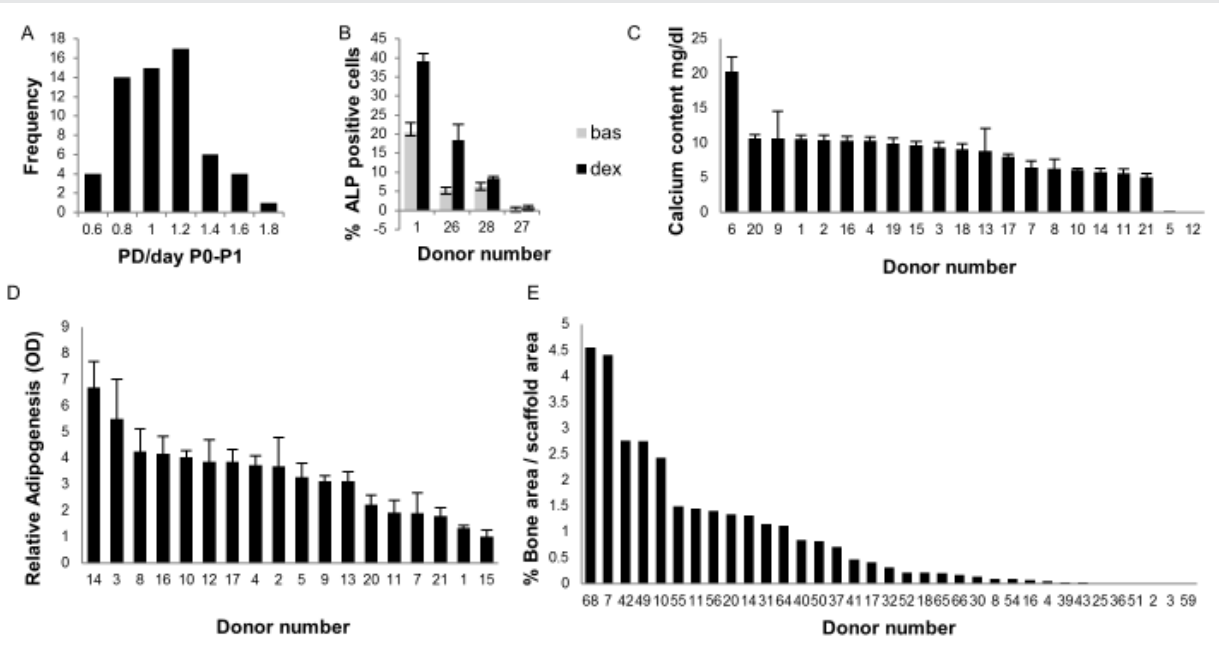

Fig. 2. Characterization of hMSCs. A) Proliferation; hMSCs were cultured and counted when reaching 70-80\% confluence. Frequency of population doublings (PD) per day was calculated, passage 0-1, for 61 donors in total. B) ALP expression; hMSCs were cultured in basic (bas) or osteogenic (dex) medium during seven days. The percentage of ALP positive cells was determined using flow cytometry. Error bars represent the standard deviation. Here we show an example for four donors, in Table S1 all values are depicted. C) Mineralization; hMSCs were seeded at $5000 / \mathrm{cm}^{2}$ and cultured in mineralization medium for three weeks. $\mathrm{HCl}$ was used to release calcium and calcium deposition was measured and expressed as $m g / d l$ sample. Error bars represent the standard deviation. D) Adipogenesis; hMSCs were cultured in adipogenic medium for three weeks. Adipogenic differentiation was visualized by staining with Oil red $O$; the color was extracted and measured spectrophotometrically. Error bars represent the standard deviation. E) In vivo bone formation of hMSCs; hMSCs were cultured on BCP particles (200,000 cells/3 particles) in osteogenic medium for seven days and implanted subcutaneously in nude mice for six weeks. Out of 61 donors, 35 showed bone formation. Histomorphometric analysis demonstrated the large variation between donors.

bone forming capacity of hMSCs. Similarly, we addressed the correlation between the cellular proliferation rate and the bone forming capacity because it has been shown previously that hMSCs undergo rapid senescence during in vitro culture and lose their ability to differentiate [5]. We created a correlation curve in which we plotted ALP expression and the proliferation rate against in vivo bone formation (Fig. 3a and 3b) but no significant correlation between either parameter or bone formation was found. Because we wanted to identify a marker which is able to classify bone forming versus non-bone forming donors, we visualized the probability of using ALP and proliferation rate versus bone formation in a Receiver Operating Characteristic (ROC) curve (Fig. 3c). The data indicate that neither 
ALP activity nor proliferation rate correlate with bone forming capacity in vivo.
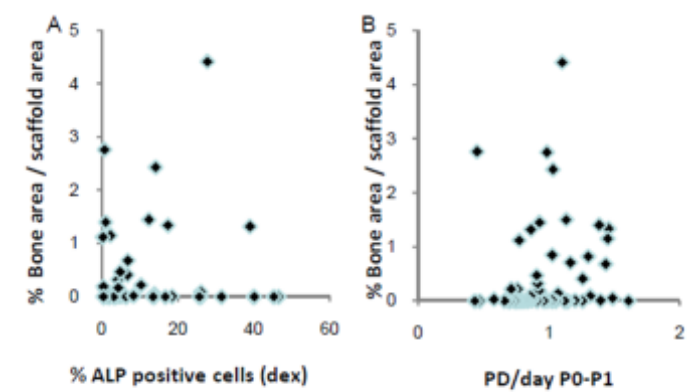

PD/day P0-P1

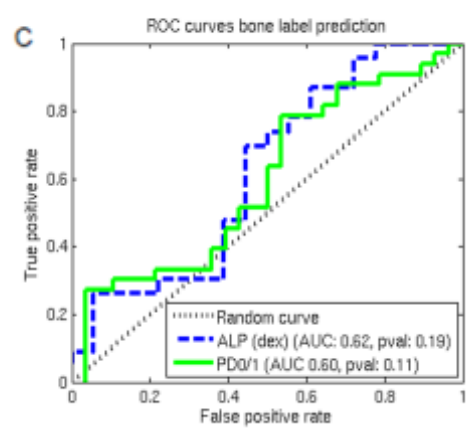

tion rate correlate with bone forming capacity in vivo.
Fig. 3 Correlation between cell biological data labels, donor features and in vivo bone formation. A correlation curve was created by plotting the different parameters against the in vivo bone formation. An example is shown of percentage of ALP positive cells (dex) (A) or proliferation doublings per day (B). No correlation was found with all data labels. C) Receiver Operating Characteristic (ROC) curves to represent the tradeoff between the false negative and false positive rates for every possible cut-off. The AUC (area under curve) was calculated for all labels, which is a measure of the probability that a classifier based on this label would rank a randomly chosen positive donor higher than a randomly chosen negative donor. The data indicate that neither ALP activity nor prolifera-

Next, we investigated whether other cell biological features such as the number of mononuclear cells per $\mathrm{mL}$ of bone marrow, amount of mineralization or rate of adipogenic differentiation or donor features such as surgery type, site of aspiration, gender and age correlate with the bone forming capacity. To this end, we generated ROC curves for all these parameters and from the ROC curves we calculated the area under curve (AUC) for all labels (Fig. S3a). In addition, for all labels the p-value was calculated, describing the significance of the AUC-score based on permutation tests (10,000 permutations, Fig. S3b). Significance was not found for any single parameter after multiple testing, neither when we used the presence or absence of bone as a cut off, nor when the threshold was based on percentage of bone apposition. Next, we tried to build a classifier using the clinical and biological data, because we anticipated that multiple labels combined may provide a higher predictive value (see Materials and Methods section). We calculated the AUC for all labels and the best AUC we obtained for imputation based strategies (i.e. classifier on all donors) was 0.59 , which is slightly above random. 

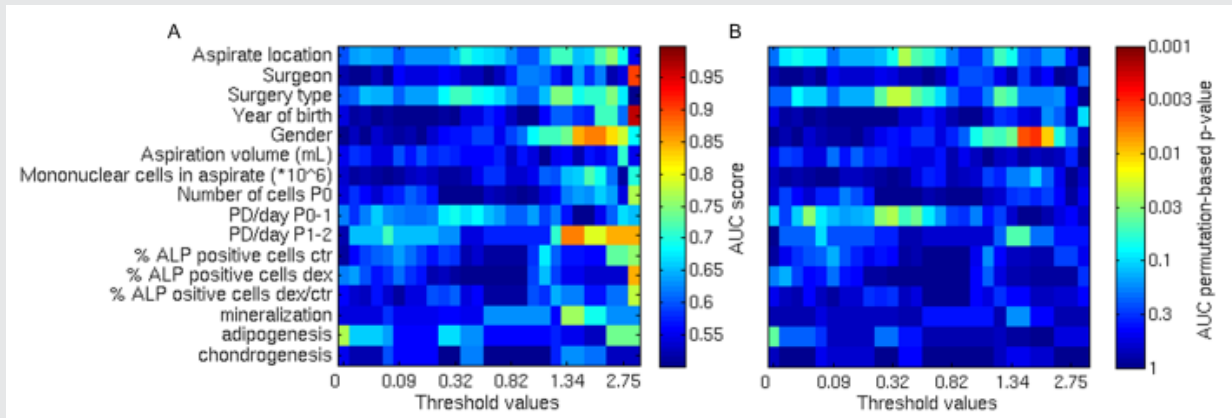

Fig. S3. Classification analyses of clinical features using AUC scores. For each clinical label the performance of the classifier for different bone area/scaffold area thresholds is depicted. A) AUC score, giving the probability that a classifier based on this label would rank a randomly chosen positive donor higher than a randomly chosen negative donor. B) P-value, describing the significance of the AUC-score, based on permutation tests (10,000 permutations).

\section{A single gene bone classifier based on whole genome gene expression profil- ing}

Since we were unable to identify a cellular or physiological marker for in vivo bone formation by hMSCs, we determined their genome-wide gene expression profile to find genes which expression could be correlated with in vivo bone formation. Therefore, we isolated RNA from undifferentiated hMSCs during the expansion phase in passage 2 and hybridized it to Human Genome U133A 2.0 Arrays (Affymetrix). We determined if we could predict bone forming capacity using the microarray measurements by making a diagnostic bone forming classifier. For this purpose, we trained a nearest-mean classifier, using the SAM test statistic to select features (see Materials and Methods section). Since we wanted to identify diagnostic markers which can be used to distinguish bone forming from non-bone forming donors, we decided to focus only on genes which display a relatively large difference between different arrays (standard deviation $>0.4$ ), which was observed in 1653 out of 22,277 genes. We produced a list of genes correlating with the in vivo bone formation of hMSCs. Interestingly, in the top 50 of probes (Table 1) we found 7 in genes which have been implicated in bone formation before such as IGF1 [33], WISP1 [34] and DKK1 [35] and 8 genes which are implicated in neural adhesion and neuronal functioning such as CADM1 [36], the neurotransmitter receptor GABBR2 [37] and carboxypeptidase E [38]. To calculate the predictive value of the probes, ROC curves were created (Fig. 4a), giving the result for different threshold values of the classifier. The best performing classifier had an AUC score of 0.76 , compared to 0.59 for the best clinical classifier. Interestingly, this 
performance could already be reached using only one probeset (Fig. 4b). We found that in all folds of the cross-validation, the top probeset was the same, which detects the CADM1 gene. We checked the performance of all CADM1 probes on
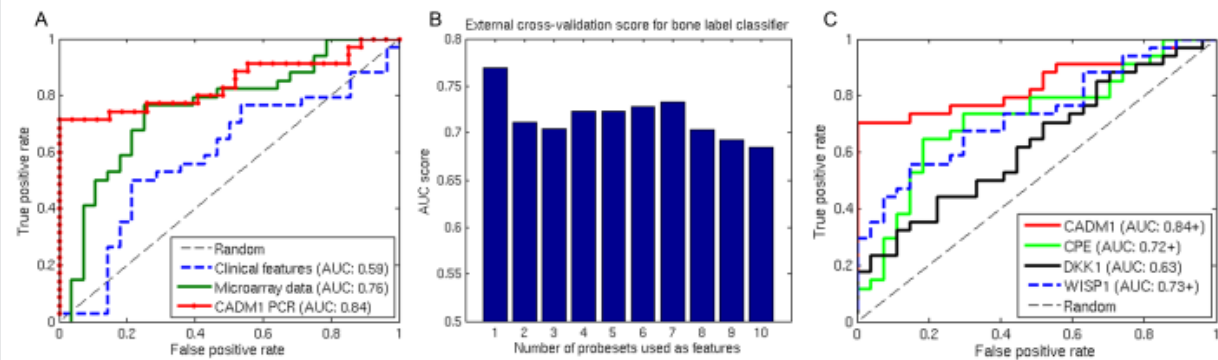

Fig. 4 Classifier performance on the bone labels. Classifier performance on the separation of bone forming donors from non-bone forming donors. The performance is presented using ROC curves (which represent the tradeoff between false negative and false positive rates for every possible classifier threshold) and the AUC (Area Under ROC curve) score (which represents the probability that the classifier would rank a randomly chosen positive donor higher than a randomly chosen negative donor). A) ROC performance curves of classifiers using either clinical features, microarray probesets or CADM1 qPCR data. ROC curves were obtained by using the posterior probabilities of the validation samples of the leaveone-out cross-validation procedure. Features (probesets) were ranked by using the SAM test statistic within the cross-validation loop. The optimal number of features to select from the top of the ranked list was determined using an inner cross-validation loop. Interestingly, the optimal microarray performance was reached using only one probeset, measuring CADM1. No feature selection (and thus cross-validation) was necessary for CADM1 qPCR. B) AUC (area under ROC curve) score for the microarray dataset, using a fixed number of features (probesets) from the top of the ranked list. The top probeset in every cross-validation fold was CADM1. C) qPCR validation of the microarray results. Some of the genes were not predictive for bone formation in vivo (data not shown), others did show a good correlation with $A U C$ in the range of the CADM1 micro-array data.

the micro-array by calculating the AUC score for each probe (Fig. S4a). Most of the probes show similar AUC scores, however, some of them show lower values, which does not seem to correlate to the existence of splice-variants (data not shown). The p-values were calculated (Fig. S4b), showing near significance between the different probes.

To validate the results obtained by microarray analysis, gene expression data of a number of genes in the top of the gene list was reproduced using quantitative polymerase chain reaction and with these data, ROC curves were created (Fig. 
4c). Some of the genes did show a good correlation with AUCs in the range of the CADM1 microarray data such as the Wnt target gene WISP1, with a positive correlation to bone formation (AUC 0.73), CPE (AUC 0.72) or the Wnt antagonist DKK1 with a negative correlation to bone formation (AUC 0.63). The positive correlation between bone formation and CADM1 expression was confirmed by qPCR with an AUC score of 0.84 .
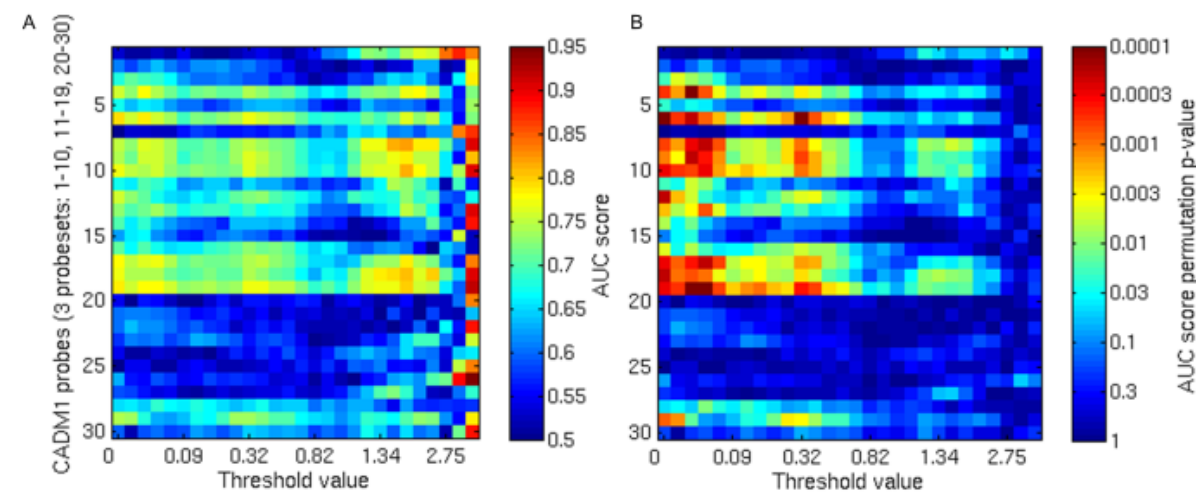

Fig. S4. Classification analyses of CADM1 probes using AUC scores. For each CADM1 probe the performance of the classifier for different bone area/scaffold area thresholds is depicted. A) AUC score, giving the probability that a classifier based on this label would rank a randomly chosen positive donor higher than a randomly chosen negative donor. B) P-value, describing the significance of the AUC-score, based on permutation tests (10,000 permutations).

\section{Discussion}

We have correlated the bone forming capacity of hMSCs in an immune-deficient mouse model to the expression of genes during the expansion phase of hMSC culture. We have identified the CADM1 gene as a marker which is able to predict bone formation with an AUC of more than 0.84. Furthermore, we have disclosed a novel link between the expression of neurogenic genes and bone forming capacity of hMSCs.

hMSCs have been targeted as potential source for autologous bone tissue engineering almost two decades ago and have been tested in phase 1 clinical trials [39]. Further evaluation is severely hampered by the large donor to donor variation in bone apposition. So far, no reliable markers exist that could help sort out the "good" from the "bad" donors. In our set, we were not able to link bone formation to any of the donor or cellular labels that were analyzed. Noticeable, also 
some labels for which we anticipated a link, such as donor age, dex-induced ALP expression or proliferation rate did not yield a level of predictiveness much above random. Using CADM1 expression profiling, we are able to obtain an AUC score of 0.84 for the whole donor set. In practical terms, this means for instance that using CADM1 expression, we have a tool to include patients into future clinical trials with a high probability of bone apposition. To put this score into perspective, in our experience this is a better performance than what can be obtained with diagnostic marker sets used to distinguish metastatic behavior of breast tumors [40]. It shows that in vitro gene expression profiling is an efficient strategy to find novel diagnostic markers predicting therapeutic efficacy of stem cell therapy. Using a combination of histology and gene expression profiling we have been able to bridge the gap between the expansion of hMSCs in culture and bone apposition in vivo. It is important to realize that this approach can be applied in any strategy where the therapeutic efficacy of a stem cell has to be assessed in vitro.

Another potential application of CADM1 lies in the area of drug discovery. The field of bone tissue engineering puts a lot of effort into optimizing the isolation procedures and culture conditions favoring the bone forming capacity of hMSCs $[6,30]$. So far, ectopic bone formation in vivo is the golden standard to verify the efficacy of a modification to the bone tissue engineering protocol. With CADM1 as a predictor of bone formation in vivo, we can embark on high throughput screening strategies to identify small molecules that improve the bone forming capacity of hMSCs. Moreover, we can screen libraries of scaffold materials which favor bone formation by hMSCs. We now have preliminary data showing that CADM1 expression in hMSCs growing on a family of porous ceramic materials correlates to bone formation in vivo. Besides screening, the link between CADM1 and bone formation may shed light on the bone formation process. CADM1 protein is involved in a broad, seemingly pleiotropic range of diseases and functions, such as neuronal synapse formation [36], as a tumor suppressor [41], in the communication between mast cells and smooth muscle cells [42] and in venous thrombosis [43]. For example, overexpression of CADM1 in HEK293 cells resulted in synapse formation in co-cultures with neuronal cells [36]. A common signature may be heterotypic cellular interaction, and the concurrent role of hMSCs as trophic mediators in tissue formation is in line with this. With respect to its neuronal role, it is interesting to note that in the top 20 of genes associated to bone formation, eight have a neuronal signature. GABBR2 is a neurotransmitter receptor, SEMA5A is a neuronal adhesion molecule, GPM6B is known to play a role in neurotransmitter release and carboxypeptidase E controls neurotransmitter activity.

Beyond CADM1, we identified a number of other genes with a correlation to bone formation and some of them have a known role in the osteogenic process. 
For instance, IGF1 is known to play a role in the mineralization phase of osteogenesis and controlled release of IGF1 in a bone defect is beneficial to the healing process [44]. We have previously identified IGF1 as a cytokine which is strongly upregulated in hMSCs treated with CAMP [6], which is associated with enhanced bone formation as well.

Another group of interesting genes are those involved in Wnt signaling. In the top 100 of genes associated to bone formation, we can find Wnt target genes WISP1, WISP2 [45], HoxB7 and S100A4 [46]. DKK1, a negative regulator of Wnt signaling [47] on the other hand is negatively associated to bone formation, suggesting a positive correlation between the level of Wnt signaling and their bone forming capacity, which is in line with a positive role of Wnt signaling in bone formation. Ironically, we have previously shown that increased Wnt signaling in hMSCs is negatively correlated to osteogenic differentiation of hMSCs in vitro but positively correlated to the rate of hMSC proliferation. In that respect, the relatively low $\mathrm{P}$-values correlating proliferation rate and bone formation (Fig. S3b) may be due to high Wnt signaling. We are now investigating the effect of Wnt signaling on bone formation in vivo.

Finally, we may isolate the CADM1 positive fraction, either from culture expanded hMSCs or directly from bone marrow and analyze whether the enrichment in percentage of CADM1 positive cells has a beneficial effect on bone formation. Furthermore, the analysis of the CADM1 positive fraction of hMSCs may teach us more about the nature of the bone forming hMSC. Considering the fact that the ceramics implanted in this study were fully covered by hMSCs, the amount of bone observed was rather low, suggesting that only a small subset of the implanted cells is actually able to enter the osteogenic process. Looking at the many steps and the long time that separates the moment of gene expression profiling in the expanding hMSCs and histomorphometric assessment of bone formation in nude mice, it is encouraging to see that CADM1 expression is able to predict it. Even though very little to nothing is known about the nature of the bone forming fraction of hMSCs, we have good hopes that the CADM1 positive fraction will shed a light on the process.

\section{Acknowledgements:}

We thank the Central Laboratory Animal Institute in Utrecht for taking good care of our animals. The authors gratefully acknowledge the support of the Smart Mix Program of the Netherlands Ministry of Economic Affairs and the Netherlands Ministry of Education, Culture and Science (AM, JdB), SenterNovem (JdB, MR, RL, AM, CvB), DPTE (HA, RL) and VIDI (JdB). 


\section{References:}

1. Arrington ED, Smith WJ, Chambers HG, Bucknell AL, Davino NA (1996) Complications of iliac crest bone graft harvesting. Clin Orthop Relat Res: 300-309.

2. Bianco P, Robey PG, Simmons PJ (2008) Mesenchymal stem cells: revisiting history, concepts, and assays. Cell stem cell 2: 313-319.

3. Caplan AI (2005) Review: mesenchymal stem cells: cell-based reconstructive therapy in orthopedics. Tissue Eng 11: 1198-1211.

4. Pittenger MF, Mackay AM, Beck SC, Jaiswal RK, Douglas R, et al. (1999) Multilineage potential of adult human mesenchymal stem cells. Science 284: 143-147.

5. Siddappa R, Licht R, van Blitterswijk C, de Boer J (2007) Donor variation and loss of multipotency during in vitro expansion of human mesenchymal stem cells for bone tissue engineering. J Orthop Res 25: 1029-1041.

6. Siddappa R, Martens A, Doorn J, Leusink A, Olivo C, et al. (2008) cAMP/PKA pathway activation in human mesenchymal stem cells in vitro results in robust bone formation in vivo. Proc Natl Acad Sci U S A 105: 7281-7286.

7. de Boer J, Licht R, Bongers M, van der Klundert T, Arends R, et al. (2006) Inhibition of histone acetylation as a tool in bone tissue engineering. Tissue Eng 12: 2927-2937.

8. Haynesworth SE, Goshima J, Goldberg VM, Caplan AI (1992) Characterization of cells with osteogenic potential from human marrow. Bone 13: 81-88.

9. de Bruijn JD, van den Brink I, Mendes S, Dekker R, Bovell YP, et al. (1999) Bone induction by implants coated with cultured osteogenic bone marrow cells. Adv Dent Res 13: 74-81.

10. Petite H, Viateau V, Bensaid W, Meunier A, de Pollak C, et al. (2000) Tissue-engineered bone regeneration. Nat Biotechnol 18: 959-963.

11. Phinney DG, Kopen G, Righter W, Webster S, Tremain N, et al. (1999) Donor variation in the growth properties and osteogenic potential of human marrow stromal cells. J Cell Biochem 75: 424-436.

12. Oyajobi BO, Lomri A, Hott M, Marie PJ (1999) Isolation and characterization of human clonogenic osteoblast progenitors immunoselected from fetal bone marrow stroma using STRO-1 monoclonal antibody. Journal of bone and mineral research: the official journal of the American Society for Bone and Mineral Research 14: 351-361.

13. Quirici N, Soligo D, Bossolasco P, Servida F, Lumini C, et al. (2002) Isolation of bone marrow mesenchymal stem cells by anti-nerve growth factor receptor antibodies. Experimental hematology 30: 783-791.

14. Sacchetti B, Funari A, Michienzi S, Di Cesare S, Piersanti S, et al. (2007) Self-renewing osteoprogenitors in bone marrow sinusoids can organize a hematopoietic microenvironment. Cell 131: 324-336. 
15. Dell'Accio F, De Bari C, Luyten FP (2001) Molecular markers predictive of the capacity of expanded human articular chondrocytes to form stable cartilage in vivo. Arthritis Rheum 44: $1608-1619$.

16. De Bari C, Dell'Accio F, Karystinou A, Guillot PV, Fisk NM, et al. (2008) A biomarkerbased mathematical model to predict bone-forming potency of human synovial and periosteal mesenchymal stem cells. Arthritis Rheum 58: 240-250.

17. Mendes SC, Tibbe JM, Veenhof M, Both S, Oner FC, et al. (2004) Relation between in vitro and in vivo osteogenic potential of cultured human bone marrow stromal cells. J Mater Sci Mater Med 15: 1123-1128.

18. Sontrop HMJ, Moerland PD, van den Ham R, Reinders MJT, Verhaegh WFJ (2009) A comprehensive sensitivity analysis of microarray breast cancer classification under feature variability. BMC bioinformatics 10: 389.

19. Both SK, van der Muijsenberg AJC, van Blitterswijk CA, de Boer J, de Bruijn JD (2007) A rapid and efficient method for expansion of human mesenchymal stem cells. Tissue Eng 13: 3-9.

20. Yuan H, Van Den Doel M, Li S, Van Blitterswijk CA, De Groot K, et al. (2002) A comparison of the osteoinductive potential of two calcium phosphate ceramics implanted intramuscularly in goats. Journal of materials science Materials in medicine 13: 1271-1275.

21. Fernandes H, Mentink A, Bank RA, Stoop R, van Blitterswijk C, et al. (2010) Endogenous collagen influences differentiation of human multipotent mesenchymal stromal cells. Tissue Eng Part A 16: 1693-1702.

22. Mackay AM, Beck SC, Murphy JM, Barry FP, Chichester CO, et al. (1998) Chondrogenic differentiation of cultured human mesenchymal stem cells from marrow. Tissue Eng 4: 415-428.

23. Sekiya I, Colter DC, Prockop DJ (2001) BMP-6 enhances chondrogenesis in a subpopulation of human marrow stromal cells. Biochemical and biophysical research communications 284: 411-418.

24. Hulsman M, Mentink A, van Someren EP, Dechering KJ, de Boer J, et al. (2010) Delineation of amplification, hybridization and location effects in microarray data yields betterquality normalization. BMC Bioinformatics 11: 156.

25. Dellavalle A, Sampaolesi M, Tonlorenzi R, Tagliafico E, Sacchetti B, et al. (2007) Pericytes of human skeletal muscle are myogenic precursors distinct from satellite cells. Nature cell biology 9: 255-267.

26. Tusher VG, Tibshirani R, Chu G (2001) Significance analysis of microarrays applied to the ionizing radiation response. Proc Natl Acad Sci U S A 98: 5116-5121.

27. Subramanian A, Tamayo P, Mootha VK, Mukherjee S, Ebert BL, et al. (2005) Gene set enrichment analysis: a knowledge-based approach for interpreting genome-wide expression 
profiles. Proc Natl Acad Sci U S A 102: 15545-15550.

28. Van der Heijden F, Duin, RPW, De Ridder, D, Tax,DMJ, Wiley J (2006) PRTools version 4.0: A matlab toolbox for pattern recognition.

29. Dominici M, Le Blanc K, Mueller I, Slaper-Cortenbach I, Marini F, et al. (2006) Minimal criteria for defining multipotent mesenchymal stromal cells. The International Society for Cellular Therapy position statement. Cytotherapy 8: 315-317.

30. Kratchmarova I, Blagoev B, Haack-Sorensen M, Kassem M, Mann M (2005) Mechanism of divergent growth factor effects in mesenchymal stem cell differentiation. Science 308: $1472-1477$.

31. Simonsen JL, Rosada C, Serakinci N, Justesen J, Stenderup K, et al. (2002) Telomerase expression extends the proliferative life-span and maintains the osteogenic potential of human bone marrow stromal cells. Nat Biotechnol 20: 592-596.

32. Meijer GJ, Mel P, Koole R, Cune MS (2007) Fixed partial dentures on two implants: raising comfort in irradiated edentulous patients. Int J Oral Maxillofac Surg 36: 646-648.

33. Zhang M, Xuan S, Bouxsein ML, von Stechow D, Akeno N, et al. (2002) Osteoblastspecific knockout of the insulin-like growth factor (IGF) receptor gene reveals an essential role of IGF signaling in bone matrix mineralization. J Biol Chem 277: 44005-44012.

34. French DM, Kaul RJ, D'Souza AL, Crowley CW, Bao M, et al. (2004) WISP-1 is an osteoblastic regulator expressed during skeletal development and fracture repair. The American journal of pathology 165: 855-867.

35. Li J, Sarosi I, Cattley RC, Pretorius J, Asuncion F, et al. (2006) Dkk1-mediated inhibition of Wnt signaling in bone results in osteopenia. Bone 39: 754-766.

36. Biederer T, Sara Y, Mozhayeva M, Atasoy D, Liu X, et al. (2002) SynCAM, a synaptic adhesion molecule that drives synapse assembly. Science (New York, N Y ) 297: 1525-1531.

37. Lopez-Bendito G, Shigemoto R, Kulik A, Paulsen O, Fairen A, et al. (2002) Expression and distribution of metabotropic GABA receptor subtypes GABABR1 and GABABR2 during rat neocortical development. Eur J Neurosci 15: 1766-1778.

38. Woronowicz A, Koshimizu H, Chang SY, Cawley NX, Hill JM, et al. (2008) Absence of carboxypeptidase $\mathrm{E}$ leads to adult hippocampal neuronal degeneration and memory deficits. Hippocampus 18: 1051-1063.

39. Meijer GJ, de Bruijn JD, Koole R, van Blitterswijk CA (2007) Cell-based bone tissue engineering. PLoS medicine 4: e9.

40. van Vliet MH, Klijn CN, Wessels LF, Reinders MJ (2007) Module-based outcome prediction using breast cancer compendia. PLoS One 2: e1047.

41. Kuramochi M, Fukuhara H, Nobukuni T, Kanbe T, Maruyama T, et al. (2001) TSLC1 is a tumor-suppressor gene in human non-small-cell lung cancer. Nature genetics 27: 427-430. 
42. Ito A, Hagiyama M, Oonuma J (2008) Nerve-mast cell and smooth muscle-mast cell interaction mediated by cell adhesion molecule-1, CADM1. Journal of smooth muscle research = Nihon Heikatsukin Gakkai kikanshi 44: 83-93.

43. Hasstedt SJ, Bezemer ID, Callas PW, Vossen CY, Trotman W, et al. (2009) Cell adhesion molecule 1: a novel risk factor for venous thrombosis. Blood 114: 3084-3091.

44. Schmidmaier G, Wildemann B, Bail H, Lucke M, Fuchs T, et al. (2001) Local application of growth factors (insulin-like growth factor- 1 and transforming growth factor-beta1) from a biodegradable poly(D,L-lactide) coating of osteosynthetic implants accelerates fracture healing in rats. Bone 28: 341-350.

45. Pennica D, Swanson TA, Welsh JW, Roy MA, Lawrence DA, et al. (1998) WISP genes are members of the connective tissue growth factor family that are up-regulated in wnt1-transformed cells and aberrantly expressed in human colon tumors. Proc Natl Acad Sci U $S$ A 95: 14717-14722.

46. de Boer J, Siddappa R, Gaspar C, van Apeldoorn A, Fodde R, et al. (2004) Wnt signaling inhibits osteogenic differentiation of human mesenchymal stem cells. Bone 34: 818-826.

47. Chamorro MN, Schwartz DR, Vonica A, Brivanlou AH, Cho KR, et al. (2005) FGF-20 and DKK1 are transcriptional targets of beta-catenin and FGF-20 is implicated in cancer and development. The EMBO journal 24: 73-84. 


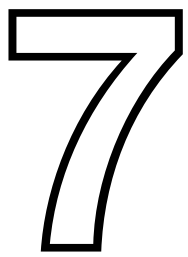




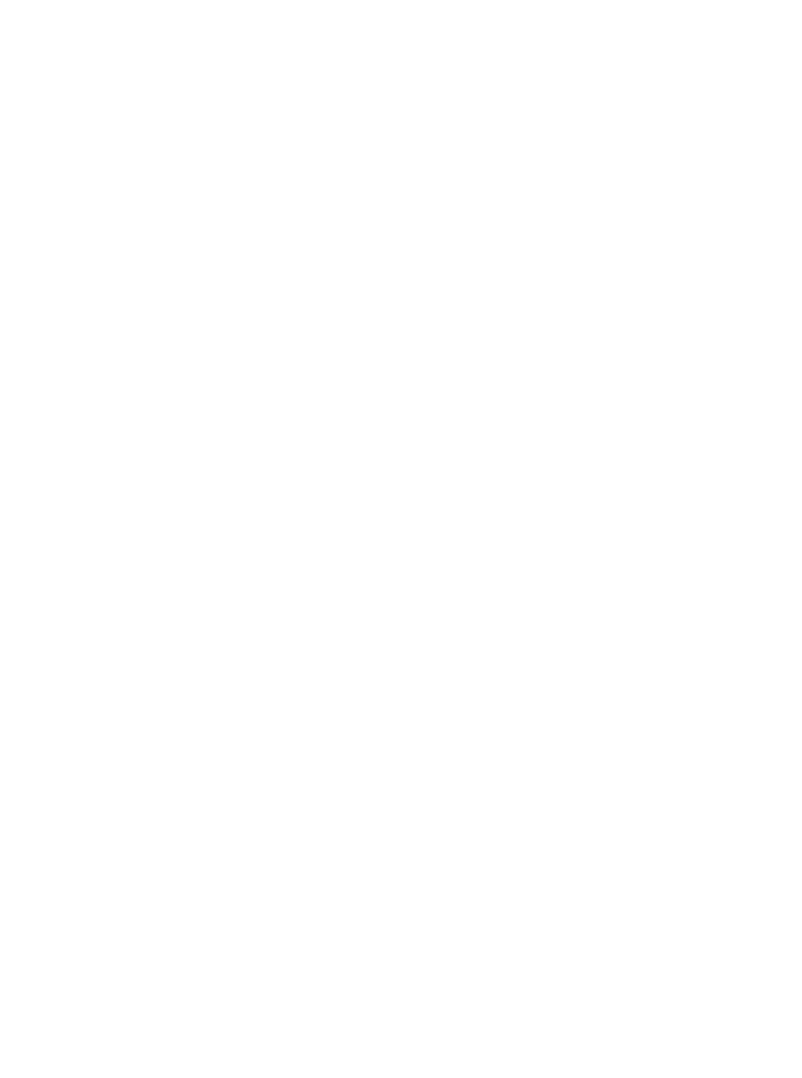




\title{
Chapter 7
}

\section{A Mesenchymal Stromal Cell Gene Signature for Donor Age}

Hugo Alves * ens van Blitterswijk *, Jan de Boer*

* Department of Tissue Regeneration, MIRA Institute for Biomedical Technology and Technical Medicine, University of Twente, Enschede, The Netherlands; †Delft Bioinformatics Lab, Faculty of Electrical Engineering, Mathematics and Computer Science, Delft University of Technology, Delft, The Netherlands.

‡ These authors contributed equally to this work

\begin{abstract}
Human aging is associated with loss of function and regenerative capacity. $\mathrm{Hu}$ man bone marrow derived mesenchymal stromal cells (hMSCs) are involved in tissue regeneration, evidenced by their capacity to differentiate into several lineages and therefore are considered the golden standard for cell-based regeneration therapy. Aging is thought to influence therapeutic efficacy, therefore, more insight in the process of aging of hMSCs is of high interest. In addition, tissue maintenance and regeneration is dependent on stem cells and declines with age. We, therefore, hypothesized that hMSCs might reflect signs of aging. In order to find markers for donor age, early passage hMSCs were isolated from bone marrow of 61 donors, with ages varying from 17-84, and clinical parameters, in vitro characteristics and microarray analysis were assessed. Although clinical parameters and in vitro performance did not yield reliable markers for aging since large donor variations were present, genome-wide microarray analysis resulted in a considerable list of genes correlating with human age. By comparing the transcriptional profile of aging in human with the one from rat, we discovered FST as a common marker for aging in both species. The gene signature presented here could be a useful tool for drug testing to rejuvenate hMSCs or for the selection of younger, more potent, hMSCs for cell-based therapy.
\end{abstract}

Adapted from Alves H, et al. Submitted for publication. 


\section{Introduction}

The average human life span has been increasing over the last decades, mainly due to the continuous advances in medical research but also due to the improvements of general life conditions. Unfortunately, human aging is associated with disease, loss of regenerative capacity and loss of function and, therefore, there has been an increasing crisis in organ transplantation but also in elderly-related diseases like Parkinson and Alzheimer. Also concomitant with an increasing aging of the population, elderly-related bone fractures increased significantly and since there is an evident loss of bone regenerative capacity with age, the amount of patients which will potentially benefit from stem cell based therapies keeps on increasing, which strengthens the need for further investigation on age-related differences in stem cell capacity. Focus has therefore, been placed in cell-based regenerative therapies, with stem cells as potential sources, with the hope to repair, restore or reduce these pathologies. Among stem cells, human mesenchymal stromal cells have been considered as the golden standard for cellular therapy. Not only because they are multipotent [1], easy to isolate and can be expanded in vitro, but also because they secrete trophic and immunomodulatory factors, giving them therapeutic qualities and making them more appropriate for allogeneic transplantation [2]. Furthermore, hMSCs have established their value in clinical trials $[3,4]$ and several others are currently being undertaken. Tissue maintenance and regeneration is dependent on stem cells and therefore, any loss in number or functionality due to aging will likely have a profound effect on our regenerative capacity [5].

Recently, Zhuo et al. found an equal contribution of donor age and recipient age to the efficacy of rat MSC-based therapy, with an overall decline in efficacy with age of the donor and the recipient, suggesting stem cells are indeed influenced by the process of aging [6,7]. For muscle, on the other hand, the age of the microenvironment and niche, in which progenitor cells reside, has a far greater influence than the intrinsic proliferative potential of the progenitor cells. Loss of regeneration in muscle is, at least partly, due to loss of Notch signaling, which could be restored by exposure of progenitor cells to a young microenvironment [8]. For MSCs the niche they reside in, the bone marrow, is less well-defined and little is known about the effect of aging on this microenvironment. The bone marrow is a complex three-dimensional structure comprising of hematopoietic cells, MSCs, adipocytes, endothelial cells and pericytes, all of which are influenced by aging [9]. Since MSCs interact with a lot of cells including hematopoietic cells, which were reported to be required to stimulate MSCs colony formation[10], it is important to consider that age-related changes in HSC [11] might impact MSC function as well. 
An important aspect is then to determine whether MSC are aging themselves (intrinsic aging) or whether it is the environment that is causing them to senesce by not providing the right signals (extrinsic aging). Since MSC reside in a very complex environment and since most of the bone marrow niche components (matrix, HSC, and other cells) show age-related changes [9], all these factors can easily interfere with the biological properties of MSCs.

Understanding the molecular pathways involved in aging is crucial and will help in the development of cell-based regeneration strategies.

Since different species age at different rates and possess distinct maximum lifespan, at least part of the process of aging is suggested to be controlled by gene expression. Human lifespan, determined by genetics and external factors such as injuries and lifestyle, is thought to be inheritable for up to 25\% [12]. Lifespan in centenarians has an even larger genetic component $[13,14]$. With microarray techniques improving in specificity and accuracy, extensive gene studies become of high interest in the search for markers for aging and the understanding of the genetics behind the process. The accumulation of DNA damages has been introduced as a cause of loss of multipotency of hMSCs in vitro [15]. Moreover, we and others reported on defects in DNA repair pathways which have been associated with premature aging and reduced longevity in mice with a genetic mutation similar to the human disorder trichothiodystrophy (TTD) [16]. However, the link between in vitro senescence and in vivo aging remains unclear.

While some authors have already correlated various tissue-specific gene expression profiles with aging, such as: human brain [17], human muscle [18] or human kidney [19] and some aging patterns are similar between human tissues, much of it is tissue specific [18]. Therefore, in this study we searched for general markers of aging. Here, we present a molecular signature of human aging by performing a genome-wide gene expression analysis in human MSCs as a function of the age of the donors. Moreover, we compared the performance of these aging markers in both aging human and rat MSCs. We also evaluated if these markers obtained also reflected the process of in vitro aging.

\section{Materials and Methods}

\section{Isolation and culture of human mesenchymal stromal cells}

Bone marrow aspirates $(5-20 \mathrm{~mL})$ were obtained from donors with written informed consent, and hMSCs were isolated and proliferated as described previously [37]. Briefly, aspirates were resuspended using a 20-G needle, plated at a den- 
sity of 500,000 nucleated cells $/ \mathrm{cm}^{2}$ and cultured in hMSC proliferation medium containing $\alpha$-minimal essential medium ( $\alpha$-MEM; Gibco), 10\% fetal bovine serum (FBS; Biowhittaker, Australia), $0.2 \mathrm{mM}$ ascorbic acid (Sigma), $2 \mathrm{mM}$ L-glutamine (Gibco), $100 \mathrm{U} / \mathrm{mL}$ penicillin with $100 \mu \mathrm{g} / \mathrm{mL}$ streptomycin (Gibco) and $1 \mathrm{ng} / \mathrm{mL}$ basic fibroblast growth factor (bFGF; Instruchemie, Delfzijl, The Netherlands). The serum batch was selected on proliferation rate and osteogenic differentiation potential and used for all experiments in this paper. Cells were grown at $37^{\circ} \mathrm{C}$ in a humid atmosphere with $5 \% \mathrm{CO}_{2}$. Medium was first changed after 5 days to remove non-adherent cells and was further refreshed twice a week. Cells were used for further subculturing or cryopreservation upon reaching near confluence. hMSC basic/control medium (BM) was composed of hMSC proliferation medium without bFGF, hMSC osteogenic medium was composed of hMSC basic medium supplemented with $10^{-8} \mathrm{M}$ dexamethasone (dex, Sigma). Basic medium was used as a control. ALP expression was measure by qPCR.

\section{Isolation and culture of rat mesenchymal stem cells}

Rat MSCs were obtained as described previously [38]. Femora of 1, 12 and 24 months old male rats (Male Crl:WI(Han), Charles River, $n=3$ ) were removed, thoroughly cleaned and submerged in PBS containing $250 \mu \mathrm{g} / \mathrm{mL}$ Fungizone (Invitrogen). After removal of the epiphyses, the bone marrow was flushed out with 10 $\mathrm{ml}$ of rat MSC proliferation medium containing $\alpha$-MEM (Gibco), 15\% FBS (Biowhittaker, Australia), $0.2 \mathrm{mM}$ ascorbic acid (Sigma), $2 \mathrm{mM} \mathrm{L-glutamine} \mathrm{(Gibco),}$ $100 \mathrm{U} / \mathrm{mL}$ penicillin with $100 \mathrm{mg} / \mathrm{mL}$ streptomycin (Gibco) and $1 \mathrm{ng} / \mathrm{mL} \mathrm{bFGF}$ (Instruchemie, Delfzijl, The Netherlands) and cultured in T75 flasks. Cells were grown at $37^{\circ} \mathrm{C}$ in a humid atmosphere with $5 \% \mathrm{CO}_{2}$. Medium was first changed after 3 days to remove non-adherent cells and was further refreshed three times a week. Animals were housed at the Central Laboratory for Animal Institute (Utrecht University, Utrecht, The Netherlands), and experiments were approved by the local animal care and use committee.

\section{Microarray analysis}

To analyze the gene expression profile of hMSCs, cells were seeded at 1000 cells $/ \mathrm{cm}^{2}$ and upon reaching near confluence RNA was isolated using an RNeasy mini kit (Qiagen) and DNase treated on column with $10 \mathrm{U}$ RNase free DNase I (Gibco) at $37{ }^{\circ} \mathrm{C}$ for $30 \mathrm{~min}$. DNase was inactivated at $72{ }^{\circ} \mathrm{C}$ for $15 \mathrm{~min}$. The quality and quantity of RNA was analyzed by gel electrophoresis and spectrophotometrically. The RNA was hybridized to the Human Genome U133A 2.0 Array (Affyme- 
trix) and scanned with a GeneChip G3000 scanner (Affymetrix). The microarray experiments were performed in three batches. Although this was done at the same microarray facility using arrays from the same production batch, there were still noticeable batch effects. To normalize the measurements, we used a normalization method which removes hybridization, amplification and array location effects [39]. Afterwards, probe sets which did not show significant differences in expression between arrays $($ std $<0.4)$ were removed. The remaining 1653 probe sets (out of 22,277 probe sets) were used for further analysis. To determine the most significant probe sets with respect to age, we determined a p-value for each gene by permuting F-test scores. In total, 105 permutations were performed for each gene. To adjust for multiple testing, we calculated a false discovery rate.

\section{Quantitative polymerase chain reaction (qPCR)}

To investigate gene expression, hMSCs were seeded at 1000 cells $/ \mathrm{cm}^{2}$ and freshly isolated rat MSCs were used, upon reaching near confluence RNA was isolated using an RNeasy mini kit (Qiagen) and DNase treated on column with $10 \mathrm{U}$ RNase free DNase I (Gibco) at $37^{\circ} \mathrm{C}$ for $30 \mathrm{~min}$. DNase was inactivated at $72^{\circ} \mathrm{C}$ for $15 \mathrm{~min}$. The quality and quantity of RNA was analyzed using gel electrophoresis and spectrophotometrically. The iScript cDNA synthesis kit (Bio-rad) was used according to the manufacturer's protocol to synthesize first strand complementary DNA (cDNA) from $1 \mu \mathrm{g}$ RNA. qPCR was carried out on a iQ ${ }^{\mathrm{m}} 5$ Real-Time PCR Detection System (Bio-Rad) using $1 \mu \mathrm{L}$ of $1 \mathrm{x}, 10 \mathrm{x}$ or $100 \mathrm{x}$ diluted cDNA, $500 \mathrm{nM}$ forward primers, $500 \mathrm{nM}$ reverse primers, 2x iQ SYBR Green Supermix (Bio-rad). For the gene expression analysis of AUTS2, DLK1 and JAG2, the forward and reverse primers were substituted for $1 \mu \mathrm{L}$ gene-specific $\mathrm{RT}^{2}$ qPCR Primers (SABiosciences). As a reference gene, GAPDH was used for hMSCs and $\beta$-actin for rat MSCs. Primer efficiencies were determined and gene expression was calculated and normalized to the average gene expression according to the method of Pfaffl et al. [40].

\section{Statistics}

Regression analysis and Pearson correlations were used to analyze correlations between donor age and biological parameters and gene expression. Multiple regressions were used to exclude gender and location of aspiration as confounding factors (Eq. 1) and to analyze if the combinations of multiple genes gave a more accurate description of the age of the donor (Eq. 2). One-way ANOVA was used to determine significant differences in ALP expression after treatment with dexa- 
methasone, follistatin or activinA, Tukey was used for post-hoc testing. A value of $\mathrm{p}<0.05$ was considered significant.

\section{Results}

\section{Correlation of biological characteristics and donor age}

In order to identify molecular markers of the aging process which hopefully, could provide insights into the molecular mechanism that ultimately limit human lifespan, we have isolated hMSCs from bone marrow of 61 healthy donors undergoing corrective orthopedic surgeries. Bone marrow aspirates were collected from either the acetabulum or the iliac crest and the entire donor population was comprised of 46 females and 15 males in the age between 17 to 84 years, with an average of 55 years. The distribution of age, gender and locations of aspiration can be found in Figure 1.

A

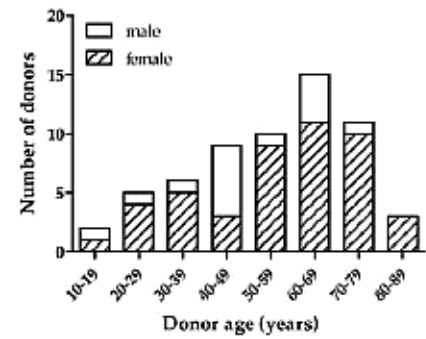

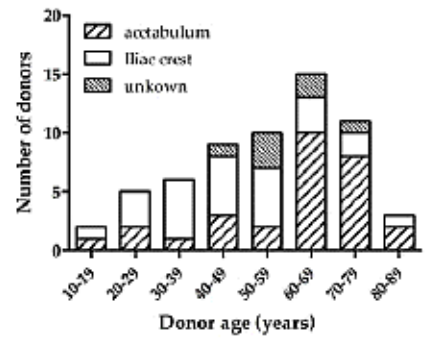

Figure 1. Distribution of the donor population. A) The distribution of gender with age and B) the distribution of site of aspiration with age.

The aspirates were put in culture and the cells were identified according to the set of standards proposed by the Mesenchymal and Tissue Stem Cell Committee of the ISCT [20]. Cells were adherent and over 94\% expressed CD73 and CD90, 60\% expressed CD105, and less than 2\% were CD45, CD34, CD11b, CD19 and HLA-DR positive, as determined by flow cytometry in cells from 3 different donors (data not shown).

We started by examining whether several biological characteristics, such as population doublings, total yield and differentiation capacity of the hMSCs correlated to donor age. The relation between these parameters and donor age were evaluated with Pearson correlations (strength is given by $\mathrm{R}$ ). The results for all correlations with age are shown in Table 1. The data indicates that no strong correlations were identified among the biological characteristics and donor age. 
Table 1. Pearson correlation of biological characteristics with donor age. * represents $p<0.05$.

\begin{tabular}{lll}
\hline Characteristic & R & Sig. \\
\hline Yield (mL) & 0.167 & 0.198 \\
Number of nucleated cells per ml & $-0,178$ & 0,170 \\
Population doublings, day 0-1 & -0.193 & 0.135 \\
Population doublings, day 1-2 & -0.621 & 0.074 \\
Bone formation & 0.033 & 0.799 \\
Percentage of bone compared to scaffold & 0.105 & 0.420 \\
Percentage of bone contact & 0.097 & 0.458 \\
• Mean ALP expression (control) & -0.315 & 0.045 \\
Mean ALP expression (dex) & -0.299 & 0.057 \\
Mean ALP expression (index) & -0.167 & 0.297 \\
"Percentage ALP positive cells (control) & -0.353 & 0.023 \\
Percentage ALP positive cells (dex) & -0.217 & 0.174 \\
Percentage ALP positive cells (index) & -0.143 & 0.372 \\
Mineralization & -0.129 & 0.587 \\
Adipogenesis & -0.131 & 0.570 \\
Cartilage formation (GAG/DNA ) & 0.423 & 0.063 \\
\hline
\end{tabular}

Most parameters, such as the number of population doublings between day 0 and day 1 (Figure 2A), did not correlate with donor age. While only the expression of the early osteogenic marker, Alkaline Phosphatase (ALP), did show a slight correlation $(\mathrm{P}<0.05)$ with donor age, for both the mean expression (Figure $2 \mathrm{~B}$ ) and the percentage of positive cells (Figure $2 \mathrm{C}$ ), this was mainly due to high expression of ALP in a number of young donors. However, when the osteogenic differentiation capacity was assessed by determining the potency of dexamethasone to induce ALP expression, no correlation was found.

\section{Genetic markers for donor age}

Since gene expression is altered with cellular senescence and since it is currently unknown the extent to which age regulation of gene expression is specific to a particular tissue or common across many, we ought to find whether the gene expression profiles of 61 human bone-marrow-derived hMSCs correlated with the age of their donors. Since stem cells are involved in the regenerative process which is lost during age, it is likely that hMSC will also reflect changes during the aging process as well. To perform this genome-wide gene expression analysis, RNA was isolated from undifferentiated hMSCs (passage 2) and hybridized to Human Genome U133A 2.0 Arrays (Affymetrix) comprising of 22,277 probe sets representing 18,400 transcripts and variants. After statistical processing, probe sets with sufficient difference in expression (standard deviation $>0.4$ ) remained. P-values 
A)

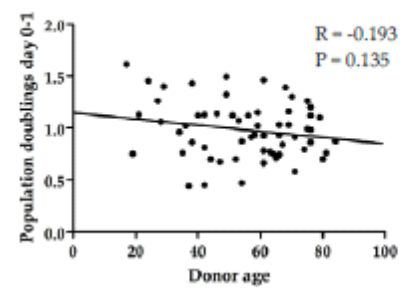

C)

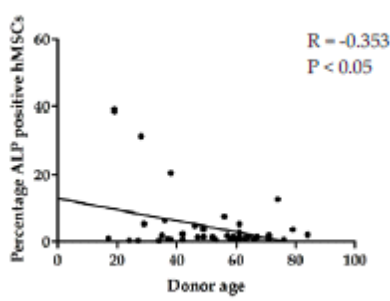

B)

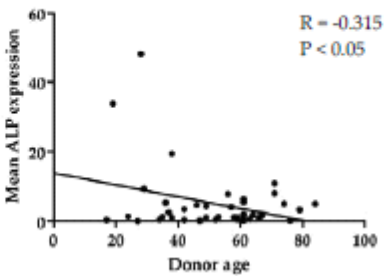

Figure 2. Correlation between biological parameters and donor age. $A$ correlation between age and clinical and biological labels could not be determined for labels such as A) population doublings per day between day 0-1 and bone formation. Correlation with donor age could solely be determined for B) the mean ALP expression and $\mathrm{C})$ the percentage ALP positive cells in basic medium.

were determined for these 1653 probe sets by permuting F-test scores and false positive rates were calculated. The probe sets were ranked by significance and $8.07 \%$ showed correlations with a significance of $\mathrm{p}<0.05$. The top 50 probe set list is represented in Table 2. In addition to the list based on Pearson correlations, a top 50 list based on non-parametric Spearman rho correlations was also calculated (data not shown). This list was $75 \%$ similar to the list in Table 2, indicating the majority of the correlations were linear. Therefore, Pearson correlations were used for further data analysis.

To further verify our findings, quantitative polymerase chain reaction (qPCR) was used to validate the gene expression of 12 genes in a selection of 20 donors from the total donor bank. We used 10 male and 10 female donors, with 5 young and 5 old donors for each gender that were selected randomly. Correlations were calculated and 5 genes showed a significant linear trend with donor age, all except one, zinc finger protein 395 (ZNF395), appeared in the top 50 (Table 3). ZNF395, however, did show a correlation based on the microarray results, but did not meet the requirement of a standard deviation of at least 0.4. Homeobox B7 (HOXB7) 
Table 2. The top 50 of genes correlating in hMSCs with donor age based on $f$ test statistics. The p-value indicates the significance of the Pearson correlation, fdr stands for false discovery rate. Gene number 50 in this list (LIF) has an fdr of 0.1055 meaning a little over 5 genes in this list are false positive. $\uparrow$ Indicates upregulation and $\downarrow$ indicates downregulation of gene expression with donor age.

\begin{tabular}{|c|c|c|c|c|c|c|c|c|c|}
\hline & Official symbol & p-value & fdr & & & Official symbol & p-value & fdr & \\
\hline 1 & SI.JT3 & 0.0000 & 0.0000 & $\downarrow$ & 26 & $\mathrm{CDH} 13$ & 0.0009 & 0.0555 & $\uparrow$ \\
\hline 2 & FST & 0.0000 & 0.0055 & $t$ & 27 & TFPI & 0.0009 & 0.0555 & $\uparrow$ \\
\hline 3 & ZNF365 & 0.0000 & 0.0055 & $\uparrow$ & 28 & HOXB7 & 0.0009 & 0.0555 & $\downarrow$ \\
\hline 4 & FGFR2 & 0.0000 & 0.0083 & $\downarrow$ & 29 & TFPI & 0.0011 & 0.0616 & $\uparrow$ \\
\hline 5 & FGFR2 & 0.0000 & 0.0099 & I & 30 & FOSL2 & 0.0012 & 0.0683 & $\downarrow$ \\
\hline 6 & $\mathrm{FMO}_{3}$ & 0.0000 & 0,0138 & $\uparrow$ & 31 & $\mathrm{NR}_{2} \mathrm{~F}_{2}$ & 0.0013 & 0.0683 & $\uparrow$ \\
\hline 7 & FMO3 & 0.0001 & 0.0165 & $\uparrow$ & 32 & PCDH9 & 0.0015 & 0.0770 & $\uparrow$ \\
\hline 8 & COLEC12 & 0.0001 & 0.0165 & $\downarrow$ & 33 & S1IOX2 & 0.0017 & 0.0807 & $\uparrow$ \\
\hline 9 & SHOX2 & 0.0001 & 0.0248 & $\uparrow$ & 34 & FBN2 & 0.0017 & 0.0807 & $\dagger$ \\
\hline 10 & ANK 3 & 0.0001 & 0.0248 & $\uparrow$ & 35 & JAG1 & 0.0017 & 0.0812 & $\uparrow$ \\
\hline 11 & COI.13A1 & 0.0002 & 0.0346 & $\uparrow$ & 36 & TIMP3 & 0.0018 & 0.0831 & $\uparrow$ \\
\hline 12 & TNFAIP6 & 0.0003 & 0.0358 & $\uparrow$ & 37 & MAFF & 0.0019 & 0.0831 & $\uparrow$ \\
\hline 13 & FST & 0.0003 & 0,0381 & $\uparrow$ & 38 & PLN & 0.0019 & 0.0831 & $\uparrow$ \\
\hline 14 & C4orf31 & 0.0003 & 0.0408 & 1 & 39 & $\mathrm{CH} 25 \mathrm{H}$ & 0.0021 & 0.0897 & $\uparrow$ \\
\hline 15 & TFPI & 0.0004 & 0.0408 & $\uparrow$ & 40 & HEPH & 0.0022 & 0.0897 & $\uparrow$ \\
\hline 16 & PTX3 & 0.0004 & 0.0447 & $\uparrow$ & 41 & MYO1D & 0.0023 & 0.0927 & $\uparrow$ \\
\hline 17 & ANKRD1 & 0.0005 & 0.0447 & $\uparrow$ & 42 & HOXB7 & 0.0025 & 0.0961 & $\downarrow$ \\
\hline 18 & JAG1 & 0.0006 & 0.0503 & $\uparrow$ & 43 & DCBLD2 & 0.0025 & 0.0961 & $\uparrow$ \\
\hline 19 & C21orf7 & 0.0006 & 0.0503 & $\uparrow$ & 44 & S100A4 & 0.0026 & 0.0961 & $\uparrow$ \\
\hline 20 & NR2F2 & 0.0006 & 0.0503 & $\uparrow$ & 45 & cDNA DKF $\angle p 564$ N1116 & 0.0027 & 0.0961 & $\uparrow$ \\
\hline 21 & OSR2 & 0.0007 & 0.0503 & $\uparrow$ & 46 & MOXD1 & 0.0028 & 0.0961 & $\uparrow$ \\
\hline 22 & EMX2 & 0.0007 & 0.0503 & $\downarrow$ & 47 & MCAM & 0.0028 & 0.0961 & $\downarrow$ \\
\hline 2.3 & JAG1 & 0.0007 & 0.0503 & $\uparrow$ & 48 & FZD1 & 0.0028 & 0.0961 & $\downarrow$ \\
\hline 24 & NR2F2 & 0.0009 & 0.0555 & $\uparrow$ & 49 & MCAM & 0.0030 & 0.1009 & $\downarrow$ \\
\hline 25 & C4orf31 & 0.0009 & 0.0555 & $\downarrow$ & 50 & I.IF & 0.0032 & 0.1055 & $\uparrow$ \\
\hline
\end{tabular}

was on the list, but did not correlate with donor age based on the qPCR results, which could mean that HOXB7 is a false positive.

Table 3. Gene expression validated with qPCR in 20 donors. Except HOXB7, all genes that are depicted in the top 50 (0) gave significant, or near significant, correlations with qPCR as well. Therefore, HOXB7 might be a false positive. ZNF395 on the other hand, has a significant trend while it was not on the list. * represents $p<0.05$.

\begin{tabular}{llll}
\hline \multicolumn{4}{c}{ Position (Pearson qPCR-validation } \\
Official symbol correlation) & P-value & R \\
\hline AUTS2 & - & 0.194 & -0.303 \\
"COL13A1 & 11 & 0.006 & 0.595 \\
"COLEC12 & 8 & 0.044 & -0.454 \\
CCNG2 & - & 0.214 & -0.291 \\
DLK1 & - & 0.219 & 0.288 \\
FGFR2 & 4 & 0.055 & -0.435 \\
"FST & 2 & 0.006 & 0.593 \\
HOXB7 & 28 & 0.942 & 0.017 \\
"JAG1 & 18 & 0.006 & 0.593 \\
JAG2 & - & 0.507 & 0.158 \\
SLIT3 & 1 & 0.088 & -0.392 \\
"ZNF395 & - & 0.004 & -0.617 \\
\hline
\end{tabular}


Since these genes that had a significant, or near significant, correlation with age were only validated in a small part of the full bank, we further confirmed by qPCR these data in all 61 donors (Figure 3). As expected from the microarray data, ZNF395 presented a nearly flat correlation curve, especially when compared to collectin sub-family member 12 (COLEC12), which showed a 5-fold decrease in expression with age. The genes that were near significant in 20 donors, Fibroblast growth factor receptor 2 (FGFR2) and Slit homolog 3 (SLIT3), proved to have a valid correlation when all 61 donors were taken in account.

A)

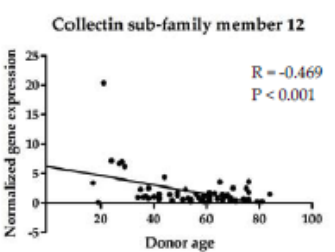

C)

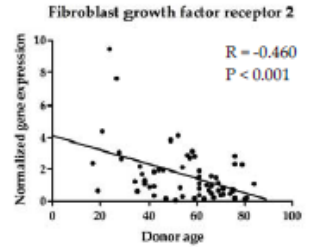

E)

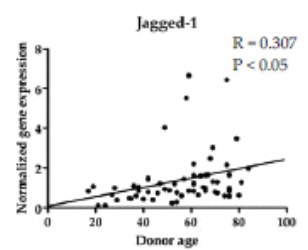

G)

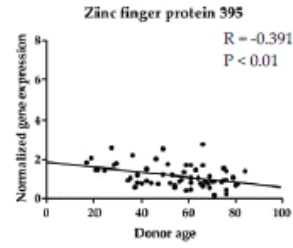

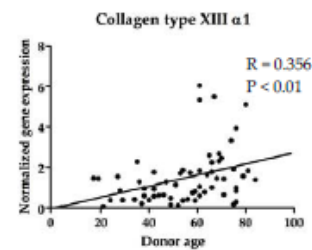

D)

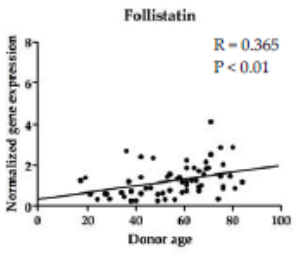

Figure 3. qPCR validation on the whole donor population. Correlation curves were produced for the expression of A) COLEC12, B) COL13A1, C) FGFR2, D) FST, E) JAG1, F) SLIT3 and G) ZNF395 in the entire donor population and significant correlations could be confirmed.
F)

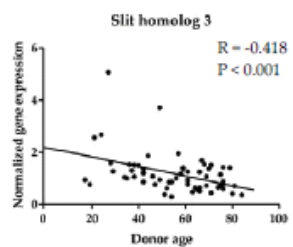


Multiple regression analysis has been used to exclude gender and location of aspiration, as depicted in (Figure 1), as confounding factors. For this, the following equation (Eq. 1) was used as described previously [19]:

$$
Y_{i j}=\beta_{0 j}+\beta_{1 j} \text { Age }_{i}+\beta_{2 j} \text { Gender }_{i}+\beta_{3 j} \text { Location }_{i}+\varepsilon_{i j}
$$

Although slightly different trends were observed in hMSCs obtained from male and female, gene expression of COLEC12, Collagen type XIII $\alpha 1$ (COL13A1), FGFR2, Follistatin (FST), SLIT3 and ZNF395, solely, correlated with donor age. The expression of jagged-1 (JAG1), on the other hand, had a better correlation with location. JAG1 expression was significantly higher in hMSCs obtained from the acetabulum compared to hMSCs from the iliac crest. Multiple regression analysis was used to combine these 7 genes in a general model for donor age according to the following equation (Eq. 2):

$$
\begin{aligned}
Y_{i j}= & \beta_{0 j}+\beta_{1 j} J A G 1_{i}+\beta_{2 j} C O L 13 A 1_{i}+\beta_{3 j} S L I T 3_{i}+\beta_{4 j} Z N F 395_{i}+\beta_{5 j} C O L E C 12_{i}+ \\
& \beta_{6 j} F S T_{i}+\beta_{7 j} F G F R 2_{i}+\varepsilon_{i j}
\end{aligned}
$$

and an $\mathrm{R}$ was reached of 0.673 . When a small data set is used, the $\mathrm{R} 2$ has to be corrected, resulting in an adjusted $\mathrm{R} 2$. In this case the adjusted $\mathrm{R} 2$ is 0.381 , in other words, $38.1 \%$ of the variance of donor age is explained by the combination of these 7 genetic markers.

\section{Correlation of gene expression with in vitro senescence}

An important question remaining is whether in vitro senescence of hMSCs reflects in vivo aging. It has been shown that long term in vitro expansion of hMSCs leads to senescence and that this process was associated with the accumulation of DNA damage [15], which is also associated to premature aging in vivo [16]. Since it is fundamental for the clinical application of hMSCs to have cells with high differentiation potential and with the least signs of aging, we investigated whether the genetic markers we discovered for in vivo aging, simultaneously were relevant for in vitro aging. Therefore, we performed qPCR on RNA isolated from hMSCs that have been serially expanded in vitro (3 donors, passage $0-7$ ). Unfortunately, for the four genes we examined, consistent trends could not be determined (Figure 4). For FST, for example, its expression in D.024 shows a clear negative relation to passage number, however, this could not be confirmed in the other two donors. 


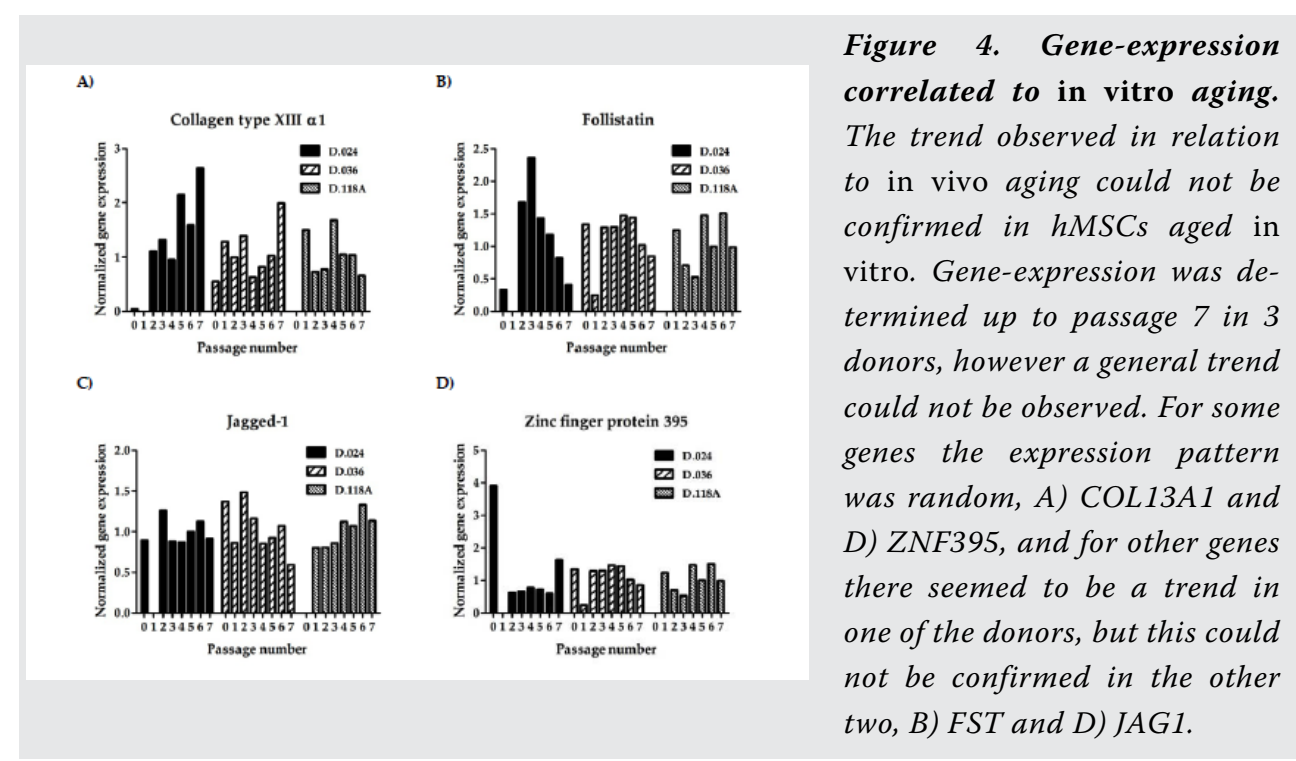

\section{Correlation of gene expression and age in rat MSCs}

To validate if the genes we found are correlated to the mechanisms of aging in different species, we investigated their expression also in rat bone marrow stromal cells. To determine if these genetic markers could be used as markers of aging inter-species, we isolated MSCs from femora of young (1 month), adult (12 months) and old (24 months) Wistar rats. We have performed qPCR on four genes that were confirmed by qPCR to be significantly correlated with age. The agerelated expression of COL13A1, JAG1 and ZNF395 could not be verified in rat MSCs. However, the expression of FST was significantly higher in MSCs from young rats than in old rats (Figure 5), consistent with our finding in human MSCs.

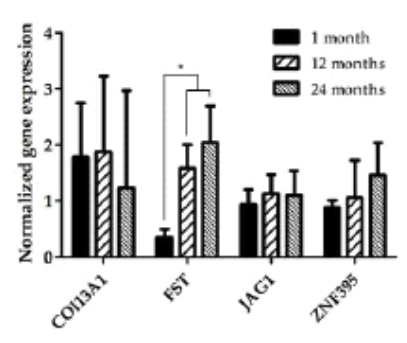

Figure 5. Validation of gene-expression in rat MSCs. To assess if age-related gene-expression was similar inter-species, MSCs were isolated from 1, 12 and 24 month old rats. The correlation between the expression of follistatin and age could be verified in rat MSCs, suggesting this is possibly a marker for several species. For the other three genes no correlation was found. 


\section{Discussion}

Aging is characterized by a series of progressive changes often associated with increased loss of tissue function and leading to increased risk of mortality. Many age-related changes are already described such as hair loss, decreased respiratory and kidney function, and decreased tissue regeneration which leads, for example, to an increased wrinkling of the skin. A single overall mechanism that gradually reduces functional capacity has not yet been identified even though the process of aging is likely to be genetically controlled by a small set of genetic mechanisms [21]. But if it is true that aging has a strong genetic component, it is also true that individual aging is subject to external influences as well. Stem cells are thought to be in the base of tissue regeneration by giving rise to progenitor cells that can differentiate and replace damaged cells and therefore delaying the onset of aging.

In this study, the first step taken in the search of a marker for aging was to evaluate whether chronological age had an effect on stem cells differentiation potential and proliferation capacity. For this, several biological parameters were then analyzed (table 1) and correlated to age, ex: (population doublings per day in different passages, bone formation, ALP expression, adipogenesis, etc.). Most of these parameters did not correlate with age, and only the expression of bonespecific ALP (basic medium) did present a correlation with donor age $(\mathrm{P}<0.05)$. This was mainly due to high expression of ALP in a number of young donors and therefore, a significant general trend was obtained. However, the osteogenic differentiation capacity determined by dexamethasone-induced ALP expression, mineralization and in vivo bone formation did not correlate in any way.

Since the correlation obtained was only mildly significant, in order to find a better marker for aging, we have generated a high-resolution transcriptional profile of aging in human mesenchymal stromal cells, by using a large sample size of 61 donors, with ages ranging from 17-84 years. A gene expression profile on hMSC has been previously performed, however, on a limited donor population (young, median aged and elderly donors, $n=4$ per group) [22]. Their analysis revealed 184 genes correlating with age, of which, only HOXB7, S100A4 and SHOX2 are present in our list. Although HOXB7 was present in our list as well, we could not verify it by PCR, suggesting it was a false positive. Our work provides, however, a significantly larger sample size which enables a higher statistical resolution and further evaluates the relation between donor age and MSC differentiation capacity, compares the expression of the markers obtained by the gene expression profiles with in vitro replicative senescence and assesses whether the same markers can predict the chronological age also in animal models (Whistar rats).

Other studies have focused on the characterization of tissue-specific gene ex- 
pression profiles such as: human brain [17], human muscle [18] or human kidney [19]. Similar studies have also been done in a large Epstein-barr virus-immortalized lymphoblastoid cell lines bank (46 three-generation families) [23] and in multiple mouse strains [24].

The main advantage of our work is that a whole genome-wide profiling was performed in a large sample size of untransformed hMSCs (61 donors) and since it was performed on human MSCs, it allowed us to obtain general markers for aging rather than tissue-specific ones, which are more prone to present higher donor variation due to external factors since in our study the co-founder effects can be more easily evaluated. While some patterns of aging are similar between human tissues, much of it is tissue specific [18].

Interestingly, our top 50 (probe-sets) contains 10 genes that have never been correlated to age or aging in any species. Examination of the gene ontology (GO) terms revealed SLIT3, COL13A1, JAG1, empty spiracles homeobox 2 (EMX2), HOXB7 and frizzled homolog 1 (FZD1) as being involved in multi-cellular organismal development, which is the most occurring biological process in our list. Other, frequently occurring, $\mathrm{GO}$ terms are of a more general nature, such as protein binding, and located to the nucleus.

A number of genes could be linked to hMSC function or aging. FGFR2 is targeted by bFGF and positively regulates osteogenic differentiation [25], as expected, FGFR2 expression declines with donor age. Additionally, FST has been identified as a stimulator of bone mineralization [26], however gene expression increases with donor age.

Ankyrin 3 (ANK3) is overexpressed in cells with the progeroid syndrome Hutchinson-Gilford [27], which is supported by the increase of gene expression with donor age in our research. The expression of JAG1, part of the Notch signaling pathway and essential for the regeneration of muscle, is impaired in aged human muscle tissue [28]. In addition, JAG1 enhances the potential of MSC to differentiate into cardiomyocytes [29]. We expected JAG1 expression to decrease with donor age, however, our results prove the contrary, suggesting a different function for Notch signaling in MSCs compared to muscle. Notch receptors are however, known to regulate cell fate determination, stem cell self-renewal, proliferation and apoptosis and JAG1 was previously associated with a poor prognosis for breast cancer patients [30] and therefore, it could be associated with the increased chance of cancer occurrence in elderly patients.

Some genes occur more often in the top 50 probe-set list, making them more powerful indicators for donor age. Moreover, false positive rates were calculated, 
showing our top 50 list contains less than 5 false positive probes. qPCR validation confirmed our microarray analysis as a reliable method for gene expression studies. Moreover, we have shown that FST is also differently expressed during age in rat MSCs, indicating it as a possible inter-species marker for age.

Despite it was reported that several MSCs age-related gene expression changes (especially genes involved in genomic integrity and regulation of transcription that were age-repressed) were also differentially expressed during in vitro senescence [22], we haven't seen the same in our study. Our aging markers do not apply to in vitro senescence since no correlation was found amongst the three donors tested. Similar results were obtained previously where it has been shown that the expression signature of in vitro senescence resembled mouse but not human aging [31].

Our results showed a big donor variation in gene expression during in vitro replicative senescence and therefore, suggested that data obtain in vitro might not be entirely correlated with what happens in vivo. Although both intrinsic as extrinsic factors might contribute for in vitro senescence, it is likely that the adverse culture conditions influence more the in vitro senescence process, presumably making hMSCs to be more exposed to DNA damage than they would face in vivo. This is more likely to happen then the fact that in vivo and in vitro aging, occur through distinct mechanisms, still we were unable to rule out that possibility and further studies should include a higher number of replicates.

We did however found that FST was valid for both human and rat aging, showing that it could be used as a marker for aging in human and rats.

In this study we were able to identify genes that significantly correlated with donor age, suggesting that stem cells are also influenced by the aging process. Interestingly, we have observed a remarkably small effect of donor age on the biological characteristics tested (table 1), which shows that MSCs from the bone marrow seem to maintain their quality with aging. This is in agreement with the hypothesized fact that stem cells themselves seem to be protected from aging due to their mostly quiescence status, however, in contradiction with the studies on aging hematopoietic stem cells (HSCs) where it was demonstrated that although the repopulation ability of HSC from young versus old follow the same time frame, some months after transplantation the contributions from the old HSCs drop considerably, which suggests that aging HSCs lose their repopulating capacity [32]. If there are some disparities between HSC and MSC aging effect on their quality and performance, little disagreements exist about the fact that regenerative potential and body repair systems deteriorate with age. 
Another interesting aspect was the fact that there is a clear large inter-donor variability present on MSC from the same age, even though aging itself has no clear effect on performance.

In our top list we describe 10 genes that were not associated with aging before, providing a window of opportunity to acquire more insight into the molecular mechanisms behind human aging.

In conclusion, we have identified a set of genes which expression in human MSCs correlates to donor age but not in vitro senescence. The presence in the list, of genes known to be involved in aging demonstrates the biological relevance of the genes. The new genes correlated to age unveiled in this manuscript may lead the way to a better insight into the process of human MSC aging.

\section{Acknowledgements:}

We are grateful to L. Creemers (UMC), W. Dhert (UMC) for kindly providing us with bone marrow aspirates. This work was supported by The Netherlands Technology Foundation (STW grant TGT.6745) and Senter/Novem research grant (R.S., R.L.,JdeB.)

\section{References:}

1. Pittenger MF, Mackay AM, Beck SC, Jaiswal RK, Douglas R, et al. (1999) Multilineage potential of adult human mesenchymal stem cells. Science 284: 143-147.

2. Caplan AI (2009) Why are MSCs therapeutic? New data: new insight. J Pathol 217: 318-324.

3. Meijer GJ, de Bruijn JD, Koole R, van Blitterswijk CA (2007) Cell-based bone tissue engineering. PLoS Med 4: e9.

4. Koc ON, Peters C, Aubourg P, Raghavan S, Dyhouse S, et al. (1999) Bone marrow-derived mesenchymal stem cells remain host-derived despite successful hematopoietic engraftment after allogeneic transplantation in patients with lysosomal and peroxisomal storage diseases. Exp Hematol 27: 1675-1681.

5. Bellantuono I, Aldahmash A, Kassem M (2009) Aging of marrow stromal (skeletal) stem cells and their contribution to age-related bone loss. Biochim Biophys Acta 1792: 364-370.

6. Bellantuono I, Keith WN (2007) Stem cell ageing: does it happen and can we intervene? Expert Rev Mol Med 9: 1-20. 
7. Zhuo Y, Li SH, Chen MS, Wu J, Kinkaid HY, et al. (2010) Aging impairs the angiogenic response to ischemic injury and the activity of implanted cells: combined consequences for cell therapy in older recipients. J Thorac Cardiovasc Surg 139: 1286-1294, 1294 e1281-1282.

8. Conboy IM, Conboy MJ, Wagers AJ, Girma ER, Weissman IL, et al. (2005) Rejuvenation of aged progenitor cells by exposure to a young systemic environment. Nature 433: 760-764.

9. Sethe S, Scutt A, Stolzing A (2006) Aging of mesenchymal stem cells. Ageing Res Rev 5: 91-116.

10. Friedenstein AJ, Latzinik NV, Gorskaya Yu F, Luria EA, Moskvina IL (1992) Bone marrow stromal colony formation requires stimulation by haemopoietic cells. Bone Miner 18: 199-213.

11. Greenwood MJ, Lansdorp PM (2003) Telomeres, telomerase, and hematopoietic stem cell biology. Arch Med Res 34: 489-495.

12. Browner WS, Kahn AJ, Ziv E, Reiner AP, Oshima J, et al. (2004) The genetics of human longevity. Am J Med 117: 851-860.

13. Atzmon G, Cho M, Cawthon RM, Budagov T, Katz M, et al. (2010) Evolution in health and medicine Sackler colloquium: Genetic variation in human telomerase is associated with telomere length in Ashkenazi centenarians. Proc Natl Acad Sci U S A 107 Suppl 1: 1710-1717.

14. Perls TT, Wilmoth J, Levenson R, Drinkwater M, Cohen M, et al. (2002) Life-long sustained mortality advantage of siblings of centenarians. Proc Natl Acad Sci U S A 99: 84428447.

15. Alves H, Munoz-Najar U, de Wit J, Renard AJ, Hoeijmakers JH, et al. (2010) A link between the accumulation of DNA damage and loss of multipotency of human mesenchymal stromal cells. J Cell Mol Med 14: 2729-2738.

16. de Boer J, Andressoo JO, de Wit J, Huijmans J, Beems RB, et al. (2002) Premature aging in mice deficient in DNA repair and transcription. Science 296: 1276-1279.

17. Lu T, Pan Y, Kao SY, Li C, Kohane I, et al. (2004) Gene regulation and DNA damage in the ageing human brain. Nature 429: 883-891.

18. Zahn JM, Sonu R, Vogel H, Crane E, Mazan-Mamczarz K, et al. (2006) Transcriptional profiling of aging in human muscle reveals a common aging signature. PLoS Genet 2: e115.

19. Rodwell GE, Sonu R, Zahn JM, Lund J, Wilhelmy J, et al. (2004) A transcriptional profile of aging in the human kidney. PLoS Biol 2: e427.

20. Dominici M, Le Blanc K, Mueller I, Slaper-Cortenbach I, Marini F, et al. (2006) Minimal criteria for defining multipotent mesenchymal stromal cells. The International Society for Cellular Therapy position statement. Cytotherapy 8: 315-317.

21. de Magalhães J (2003) Is mammalian aging genetically controlled? Biogerontology 4 119-120. 
22. Wagner W, Bork S, Horn P, Krunic D, Walenda T, et al. (2009) Aging and replicative senescence have related effects on human stem and progenitor cells. PLOS ONE 4: e5846.

23. Kerber RA, O'Brien E, Cawthon RM (2009) Gene expression profiles associated with aging and mortality in humans. Aging Cell 8: 239-250.

24. Park SK, Kim K, Page GP, Allison DB, Weindruch R, et al. (2009) Gene expression profiling of aging in multiple mouse strains: identification of aging biomarkers and impact of dietary antioxidants. Aging Cell 8: 484-495.

25. Kodama N, Nagata M, Tabata Y, Ozeki M, Ninomiya T, et al. (2009) A local bone anabolic effect of rhFGF2-impregnated gelatin hydrogel by promoting cell proliferation and coordinating osteoblastic differentiation. Bone 44: 699-707.

26. Eijken M, Swagemakers S, Koedam M, Steenbergen C, Derkx P, et al. (2007) The activin A-follistatin system: potent regulator of human extracellular matrix mineralization. FASEB J 21: 2949-2960.

27. Wang J, Robinson J, O'Neil C, Edwards J, Williams C, et al. (2006) Ankyrin G overexpression in Hutchinson-Gilford progeria syndrome fibroblasts identified through biological filtering of expression profiles. Journal of Human Genetics 51: 934-942.

28. Carey KA, Farnfield MM, Tarquinio SD, Cameron-Smith D (2007) Impaired expression of Notch signaling genes in aged human skeletal muscle. J Gerontol A Biol Sci Med Sci 62: 9-17.

29. Li H, Yu B, Zhang Y, Pan Z, Xu W (2006) Jagged1 protein enhances the differentiation of mesenchymal stem cells into cardiomyocytes. Biochem Biophys Res Commun 341: 320-325.

30. Dickson BC, Mulligan AM, Zhang H, Lockwood G, O'Malley FP, et al. (2007) Highlevel JAG1 mRNA and protein predict poor outcome in breast cancer. Mod Pathol 20: 685693.

31. Wennmalm K, Wahlestedt C, Larsson O (2005) The expression signature of in vitro senescence resembles mouse but not human aging. Genome Biol 6: R109.

32. Chambers SM, Shaw CA, Gatza C, Fisk CJ, Donehower LA, et al. (2007) Aging hematopoietic stem cells decline in function and exhibit epigenetic dysregulation. PLoS Biol 5: e201. 
(8) 


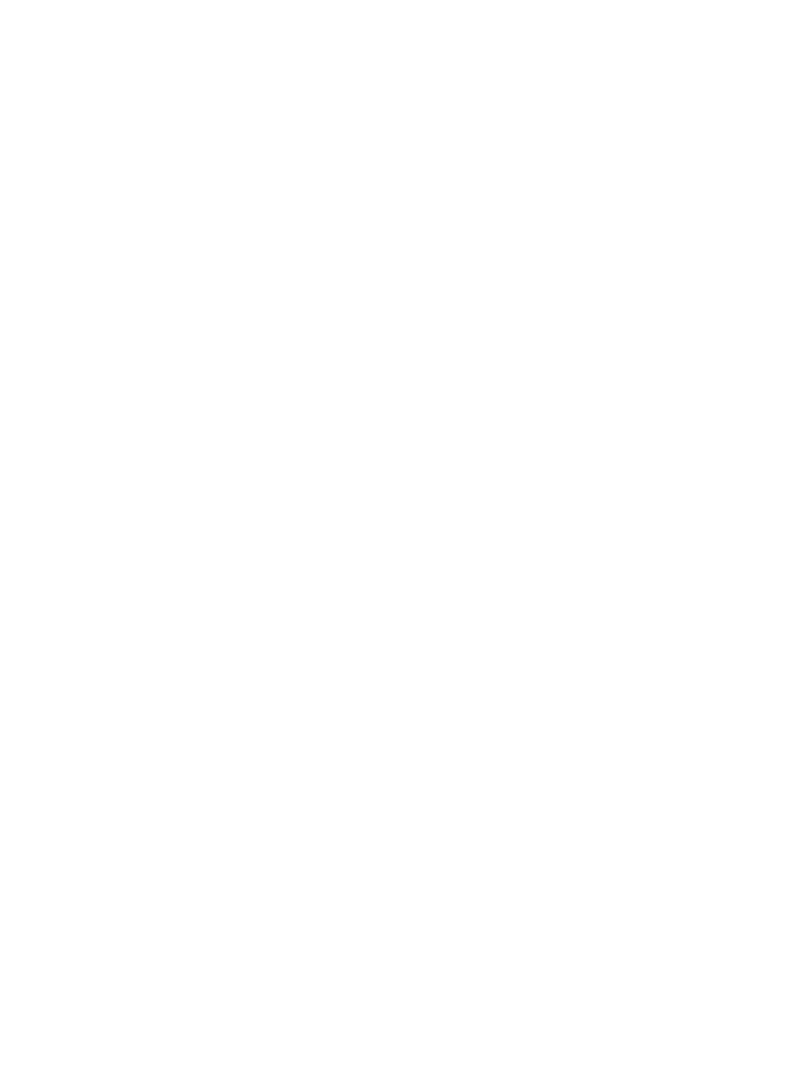




\section{Chapter 8}

\section{Overview, Discussion and General Conclusions}

\section{Tissue Engineering and Regenerative Medicine}

Tissue engineering is a multidisciplinary discipline that merges biology, engineering and medical concepts, whose aim is the repair and regeneration of damaged tissues. Several technologies are constantly being developed to help guide the growth of new functional tissue, by providing biological cues and materials, to mimic the natural in vivo environment, in order to restore, maintain or improve tissue function.

The basic concept of the field started to develop since the first successful kidney transplantation, back in 1954. Since then, the concept of artificial organs has emerged and the possibility of tissue repair has gained increased importance amongst the scientific community. But it was not until the early nineties that the field has really blossomed, in great part by new technological developments and increased availability of funds towards regenerative research that ultimately allowed early clinical trials to be conducted. Although some were only marginally successful, the cross-talk between biology and medicine has shed some light to the phenomenon of tissue repair, bringing hope that tissue engineering could be the solution for some medical conditions and therefore, the future of regenerative medicine.

Along with technological development an improvement in health care was observed, which allowed an increment in human lifespan. But "every rose has its torn", and concomitantly with the increment in human lifespan, an increase in elderly-related diseases was also observed. With advancing age, somatic changes occur, originating a time-related progressive loss in cellular capacity to maintain homeostasis. Cellular repair functions are unable to cope with persistent action of stress conditions, leading to organ/system function changes.

Human mesenchymal stromal cells are thought to be in the base of tissue regeneration by giving rise to progenitor cells that can differentiate and replace damaged cells, and therefore, are considered the golden standard for possible therapeutic 
applications. They are multipotent, present trophic and immune-modulatory action and are relatively easy to isolate and expand making then one of the best cellular models for cell-based therapies. However, they also suffer from the stresses faced during in vitro culture and still present limited regenerative potential.

Amongst the elderly-related diseases besides Alzheimer and Parkinson, those of the skeletal system are among the most frequent ones, being bone, the second most implanted material in the body, just behind blood transfusions. As referred to in more detail in the introductory chapter, the market for bone grafts is increasing every year and cell therapy is expected not only to increase current available therapies but also to allow the treatment of clinical pathologies that have currently limited or no cure.

Currently, several aspects are hampering the broader usage of cell-based therapies for bone regeneration, which includes the loss of multipotency hMSCs face after in vitro culture, the limited amount of bone formed in vivo, the lack of correlation between in vitro differentiation techniques and in vivo performance, the lack of proper MSC markers, and the lack of adequate biomarkers capable of quantifying the degree of aging at both cellular and molecular level.

Now, more than ever, it is crucial to unveil the fundamental basis behind tissue regeneration and, therefore, the focus of this thesis was to study the in vitro culture of hMSCs and the phenomenon behind loss of multipotency, as well as, ways to improve the performance of human mesenchymal stromal cells, specifically for bone-related applications. This thesis also focussed on the improvement of current markers for bone formation and in the improvement of in vitro models used during research, by showing the feasibility of using a more clinical relevant cellular model system. Strong efforts were also employed in the search for novel osteogenic compounds, by performing high-throughput assays on pharmacologically active small molecules and, on the improvement of current in vitro culture techniques aiming to achieve higher in vivo performance.

\section{Factors influencing hMSCs quality for therapeutic application}

In vivo, human mesenchymal stromal cells reside in a complex microenvironment (niche) and are influenced by both chemical cues and by the mechanical composition of the matrix they reside in. Furthermore, there seems to be a close cross-talk between several cells within the bone marrow environment (hMSCs, hematopoietic stem cells, endothelial cells, macrophages, etc.) and it could happen that more than one niche exists within the bone marrow, which makes it very complex to grasp. This intricate environment is very difficult to mimic and, 
therefore, currently in vitro media and expansion methods are far from optimal. Although some efforts for medium improvement have been made [1], in vitro expansion, in my opinion, has not yet received a thorough investigation and needs to be extensively studied. In chapter 2 , a review is presented where several parameters are evaluated regarding their contribution to hMSCs quality upon culture expansion. While some parameters, like the method of isolation, the fact whether aspirates are drawn once or twice or even donor age, do not seem to affect hMSCs performance, other factors including oxygen levels and choice of serum, seem to have a profound effect on their performance. Other studies have focused on the fact that even the treatment that culture flasks receive or the methods used during cultivation seem to play a role on hMSCs performance [1]. The lack of proper MSC markers makes the improvement of in vitro culture techniques more difficult and raises the question whether in vitro expansion is really MSC expansion or rather expansion of progenitor cells, with less differentiation potential. This is a very pertinent question which still elicits high effusive debates but whose proper resolution is pending the discovery of specific markers for MSCs.

The focus of chapter 2 was then to provide an overview of factors that might influence the performance of hMSCs for clinical applications.

\section{Part 1 - Aging of hMSCs}

\section{Effect of culture expansion of hMSCs multipotency}

Previously, it was described that hMSCs during in vitro culture not only lose the differentiation potential but are also less able to produce bone after being implanted ectopically in nude mice [2,3]. Furthermore, the extent the cells were expanded proved to be highly correlated with the observed loss of differentiation potential, rendering hMSCs unfit for bone-related clinical applications by passage 4, under the conditions tested [3]. The causes behind this loss of multipotency are still not fully understood and several different mechanisms are suggested [4]. The goal of chapter 3 was to further elucidate the molecular mechanism behind this phenomenon and assess whether DNA damage played a significant role or not. In chapter 3 we show that expansion of hMSCs in vitro leads to the accumulation of DNA damage and that it is a continuous process since the beginning of the culture period. Furthermore, we demonstrate that around passage 3 to 4 there is an increment in the DNA damage load and that this coincides with the biggest loss of differentiation potential cells face, suggesting a high correlation between both phenomena. This is further substantiated by the fact that when 
non-cytotoxic concentrations of oxidative stress inducers are used (e.g. hydrogen peroxide), there is a significant increase on the DNA damage accrual cells face and concomitantly a reduction in the differentiation potential. Moreover, looking at nucleotide excision repair (NER) capacity of hMSCs during in vitro culture, we have demonstrated that this type of DNA damage repair remains unchanged during the culturing period. This phenomenon is quite interesting showing that, even though the major DNA repair machinery (NER and base excision repair) remains unchanged, hMSCs still accumulate increasing levels of DNA damage, suggesting that the amount of damage cells face during culture is more than what they can efficiently repair. A parallel can be drawn with experiments where knockout mouse models where used to demonstrate accelerated aging symptoms when the DNA repair machinery is ineffective, proving a causal relationship between both phenomena and explain the basis of some progeria syndromes [5,6]. Also to further corroborate this link, it has been shown that also in hematopoietic stem cells (HSCs), deficiencies in DNA repair limit HSC function during aging [7,8,9]. These authors show evidence that point to age-dependent DNA damage accumulation as an important factor contributing to stem cell aging [10]. This hypothesis is in line with the results obtained in chapter 3, revealing that DNA damage accrual seem to contribute to stem cells aging and loss of multipotency both in vivo as in vitro. Further research should focus on the specific type of damage that is eliciting the loss of multipotency and whether other phenomena might be involved. There is increasing evidence suggesting the role of telomeres and, therefore, telomere damage/uncapping or reduced telomerase activity, as the cause of several diseases associated with age. An example of this, is the recent report that telomerase deficiency (knockout mice) impairs glucose metabolism and insulin secretion [11]. Another report also shows that telomerase deficiency impairs differentiation of mesenchymal stem cells [12]. Interestingly, a recent study performed in aged telomerase-deficient mice has shown that telomerase reactivation was able to reverse tissue degeneration [13]. These authors have shown that in mice with advanced degenerative phenotypes, short-term telomerase reactivation restored telomere reserves, quelled DNA damage signalling and alleviated cellular checkpoint responses in several high-turnover organ systems. The impact of telomere reactivation was significant in terms of organ system functionality leading even to increased fecundity without promoting carcinogenesis. Similarly, the same group has published another report where they show that telomere dysfunction induced metabolic and mitochondrial compromises, linking diminished organismal fitness to telomere dysfunction [14]. They further show that this process is induced by telomere dysfunction and is mediated by $\mathrm{P} 53$ which in turn binds and represses PGC- $1 \alpha$ and PGC- $1 \beta$ promoters, leading to an impairment of mitochondrial bio- 
genesis/function, gluconeogenesis and oxidative defence. PGC-1 $\alpha$ is known to increase the antioxidant defence through the upregulation of antioxidants [15] and therefore its inhibition underlies an escalating cycle of genotoxic damage leading to increased ROS concentrations and, consequently, further DNA damage. These recent breakthroughs have linked functional decline of telomeres, mitochondria and stem cells during aging, showing for the first time an integrative vision of the aging process. These new discoveries place the cause of aging in the genotoxic stress triggered by telomere dysfunction. Interestingly, in chapter 3 we also observe that the onset of telomere damage in hMSCs culture (shown by increased telomere-dysfunction induced foci) coincides with the accelerated decrease in differentiation potential, further strengthening this novel finding. The work presented in this thesis seems to suggest that like in mice, in human mesenchymal stromal cell aging (in vitro) the same process might occur and shows that stem cells are much more prone to DNA damage than anticipated.

To further substantiate the role of telomerase in the differentiation potential, it has been shown that telomerase expression extended the life-span and maintained the osteogenic potential of human bone marrow stromal cells [16]. Other authors even have shown that bone formation is enhanced by telomerase expression in human postnatal bone marrow stromal cells [17] and that the differentiation potential of hMSCs immortalized by human telomerase reverse transcriptase gene is maintained despite extensive proliferation [18].

Further research should therefore focus on the better understanding of factors that influence telomere erosion and genes that protect cells against ROS-induced damage. It however, still needs to be proven that the loss of multipotency observed in vitro is regulated under the same mechanism now disclosed in mice models.

From this chapter it can thus be concluded that hMSCs accumulate DNA damage during in vitro expansion and that there is a highly suggestive link between that phenomenon and the loss of multipotency observed after protracted culture. It further shows that hMSC damage accumulates from the beginning of culture and that, desirably, low passage hMSCs should be used for therapeutic applications. Significant loss of differentiation potential is seen as early as passage 3 (RPD 13). 


\section{Is antioxidant supplementation able to prevent or rescue the DNA damage ac- cumulation that hMSCs face during in vitro culturing?}

DNA damage accumulation seems to be one of the major factors contributing to loss of multipotency. hMSCs during in vitro culture can face damage via both intrinsic (telomere uncapping, ROS production) or extrinsic factors (high oxygen levels, improper cell-cell contacts and culturing matrix, among others). Reactive Oxygen Species, including superoxide anions, hydroxyl radicals and hydrogen peroxide, are produced on a continuous basis and are generated in multiple compartments, and by multiple enzymes, within the cell, but are mainly produced in the mitochondria as a consequence of oxidative phosphorylation [19]. They are known to induce damage to DNA, lipids and proteins and, therefore, could be directly involved with the loss of multipotency.

In chapter 3 we have shown that loss of multipotency may be linked to DNA damage and, more specifically, now hypothesized to be due to telomere dysfunction, which leads to a down regulation of antioxidants defences, to mitochondrial dysfunction and concomitantly, to a ROS outburst which will originate further damage. Therefore, in chapter 4 , we have tested whether antioxidant supplementation was able to rescue or to prevent hMSCs from accumulating DNA damage during culturing, and assess whether this had an impact in their biological functions, including multipotency. Antioxidant defences, as the name implies, refers to compounds or scavenging enzymes that are capable of inhibiting the oxidation of other molecules whose function is largely to counteract the burden of ROS production. The degree of oxidative stress is determined by the balance between ROS production and antioxidants defences. Since it was previously shown that selenium supplementations restored the antioxidant capacity and prevented cell damage in hMSCs in vitro [20], we tested the effect of a range of antioxidants by supplementing them to the culture medium. For that, we developed a model system of induction of DNA damage to mimic what happens during normal in vitro culture and to obtain a system that allowed us to test rather quickly the effect of several compounds in counteracting the oxidative stress imposed by those oxidants. From all the compounds tested, D-mannitol and Trolox, were the ones that were able to recover the loss of differentiation potential observed after the oxidative treatment. This recovery was mainly partial and showed that they exerted a preventive/protective action rather than a recovery/reduction of the DNA damage accrual that cells already had. These free radical scavengers were then used to determine their protective effects in terms of DNA damage prevention and maintenance of differentiation potential. Interestingly, all the antioxidants were able to enhance the total yield of hMSCs that could be obtained from a bone marrow biopsy making them promising compounds to include during standard 
culture procedures. A remark must be added that, due to time constrains, this experiment was only performed in hMSCs from one donor, and therefore, their general effects must be confirmed in a variety of other donors. Furthermore, we show that despite the fact that some compounds were able to reduce oxidative damage hMSCs face while in culture, this beneficial effect is unable to rescue the loss of differentiation potential which occurs during in vitro culture. This could be potentially explained by the fact that the amount of DNA damage cells are facing in culture is higher than what they can repair and, that antioxidants are only able to block some of the oxidative damage hMSCs face in culture. It could also be explained by the fact that DNA damage during in vitro culture, triggers early telomere dysfunction (as discussed previously), leading to the onset of aging and, therefore, antioxidant supplementation is unable to cope with the increase in ROS production due to mitochondrial dysfunction. The fact that $\mathrm{p} 53$ promotes the repression of PGC-1 $\alpha$ and, thus, decreased antioxidant defences might also explain why antioxidant supplementation alone is not able to counteract this cascade of events. Interestingly, in chapter 3 (figure 2), we can see that telomere damage increases early in culture following an increase in total DNA damage (53BP1). Remarkably, by the end of the culture, the telomeric probe is no longer able to bind to telomeres suggesting them to be significantly shortened, even though we have not performed telomere length assays to confirm this. P53 seems, therefore, to exert an antagonist pleiotropic function, since in early phases of life it suppresses cancer formation by blocking possible mutagenic events, but later in life by actively blocking the cell cycle, leads to the aging process. It was also shown that under conditions of low oxidative stress, p53 activation induces preferentially the expression of antioxidants genes, however, when ROS production is high, instead, it activates pro-oxidant genes [21].

Further work needs to be performed in order to understand the basic phenomenon behind the loss of multipotency after in vitro expansion so that proper measures can be undertaken to prevent it from occurring. A special focus should be placed in the damage towards telomeres and ways to overcome this damage from occuring. In hMSCs and HSC, damage acccumulation seems to be avoided by induction of quiescense, a function also atributed to p53 [22], where antioxidants defences might be induced and DNA repair machinery might be called to repair this damage. However, it is when these damaged stem cells are recruted in stress situations to renew tissues, when problems seem to arrise since they have impaired functional capacity. 
From this chapter it can thus be concluded that the antioxidants tested lead to a significant enhancement of hMSCs that could be obtained from a bone marrow biopsy even though they fail to rescue/prevent the loss of multipotency observed after hMSCs in vitro culture expansion.

\section{Part 2 - Improving hMSC osteogenic potential}

Another goal of the thesis was to give a contribution towards the improvement of in vitro osteogenic differentiation capacity by hMSCs. This task was subdivided in two other subgoals: the establishment of a high-throughput assay method to screen for novel compounds with osteogenic activity and the evaluation of current osteogenic markers and, concomitantly, to search for a new marker predicative of in vivo bone formation.

\section{Discovery of novel compounds with osteogenic activity}

As previously mentioned, there is an increasing demand for bone grafts and a continuous pressure for the development of novel graft materials able to produce new bone, therefore, restoring or improving diseased or damaged bone tissue. Several methods are currently applied but there is an urgent need for improvement of the current procedures since available technologies rely mainly in autografts and allograft, that despite successfully application, produce a series of disadvantages including donor site morbidity, require multiple surgeries and frequently provide insufficient materials (autografts) or poor performance and rejection by the host (allografts). Several pathways are known to be involved in osteogenic differentiation [23], and a number of clinical trials have been performed to validate its efficacy, however, the outcome of most of the studies was that the amount of bone formed by hMSCs was insufficient and frequently did not bridge the implant $[24,25,26]$. In this context, our research group have tried different candidate approaches in order to enhance the performance of hMSCs for bone tissue engineering applications. Examples of some of these studies are the effect of Wnt signaling on the proliferation and differentiation of hMSCs [27], the effect of the inhibition of histone deacetylases [28], and the activation of the cAMP/PKA pathway [29]. Although these manuscripts revealed novel ways of improving osteogenic differentiation, they all followed a candidate approach. In chapter 5, we report a highthroughput assay towards the identification of novel osteogenic molecules from a library of pharmacologically active molecules. One advantage of the phenotypical 
screen we have used lies in the fact that there is no need to target a specific pathway allowing, therefore, the discovery of compounds acting on other pathways not known to be involved in osteogenesis. In chapter 5 , we show that it is possible to perform osteogenic screens in an academic research laboratory and more importantly, that we were able to find novel osteogenic molecules that allowed achieving the highest ALP expression (early osteogenic marker) so far, even when compared with the best known osteogenic molecules. Furthermore, as reported in chapter 5 , it is feasible to perform these assays in human primary cells, making the screen more relevant to the clinical set-up avoiding inter-species variations. Apart from this huge benefit, it must be stated that several donors must be applied to overcome inter-donor variation. This work revealed novel compounds with potential application for bone research, however, they require to be tested further. Compounds with similar activity (same target) should be evaluated to further prove the osteogenic potential and to discover the best compounds for this purpose. As presented in chapter 6, CADM1 was shown to be the best marker predicative of osteogenic bone formation in vivo, therefore a similar experiment should be performed by using CADM1 as readout. Unfortunately, this marker was discovered after this work has been conducted and, therefore, CADM1 could not be taken as readout in these assays.

This type of work is important, not only towards the clinical application of stem cells for bone tissue engineering, but also because it provides an in vitro model to investigate further libraries, showing that high-throughput assays in primary cells are feasible and that similar experiments can be performed towards the identification of novel compounds in other differentiation lineages or towards other cellular parameters. Understanding what limits stem-cell osteogenic potential and the ways to improve the process is essential for the field of regenerative therapeutics.

From this chapter it can be concluded that high-throughput assays can be performed in a standard academic laboratory without the need of very expensive robotic equipment and that easy techniques can be established for the screening of new compounds for a certain application. We have unveiled H-8 as a promising new osteogenic compound and shown that screens on human cells are feasible and therefore research, whenever possible, should be performed in more clinically relevant hMSCs. 


\section{Discovery of novel osteogenic markers predicative of in vivo bone formation}

The discovery of potential osteogenic molecules has been relying on the use of suboptimal osteogenic markers that were shown to have limited predictability of the bone formation in vivo. In chapter 6, we present the combined efforts of several researchers for the discovery of a new marker predicative of bone formation in vivo. In this chapter, we have systematically assessed the biological properties (proliferation, ALP expression, in vitro differentiation capacity, among others) of human mesenchymal stromal cells from 61 donors and correlated these parameters to the in vivo bone forming capacity, in order to reveal the best marker predicative of bone formation in vivo. The results have shown the presence of large inter-donor variability in the biologic characteristics of hMSCs from different donors. In addition, none of the biological parameters tested was significantly predicative of bone formation in vivo, including the expression of ALP, which has been extensively used within the field as an osteogenic marker. We have also performed genome-wide gene expression profiles of hMSCs from all donors and correlated these data with all the biological parameters tested. Data-mining of gene expression profile data showed that a single gene, CADM1, highly correlated with ectopic bone formation (AUC score of 0.84). To our knowledge, this is the best osteogenic marker reported so far. The usage of this marker is of high relevance since it can be applied as an inclusion criterion for patients in clinical trials and, as a reporter gene, for optimization of none tissue engineering protocols. This work further contributes to the advance of osteogenic research since we have systematicaly assessed the correlation between several in vitro parameters and in vivo performance, which frequently is not evaluated. By comparing all available parameters we were able to estimate the best parameter that is able to predict in vivo performance and then, possibly, use it in future as a diagnostic marker.

From this chapter it can be concluded that none of the biological parameters tested which were frequently used as osteogenic markers, could significantly predict ectopic bone formation in vivo. We have unveiled a new marker, CADM1, which can highly predict ectopic bone formation in vivo (AUC 0.84) bridging a gap on osteogenic research. Additionally it brings high hopes for the future of bone-related research possibly contributing to foster clinical applications. 


\section{Part 3 - hMSC aging markers}

From chapter 6 we have demonstrated that donor age (post-puberty) does not correlate with hMSCs differentiation potential, however, its undeniable that in vivo, there is a clear loss of tissue function with age. The mechanism by which this happens is still unclear, but reasons could be the dysfunction of the environment (niche) or the signalling pathways, the accumulation of DNA damage or just by the intrinsic aging of the MSCs. In chapter 7 we have evaluated whether we could obtain a gene expression signature for MSC aging, hopping to further elucidate which genes are significantly affected by donor age.

\section{A mesenchymal stromal cell gene signature for donor age}

Loss of tissue function and regenerative capacity is associated with human age and tissue maintenance and regeneration is known to be dependent on stem cells. Therefore, in chapter 7 we have tried to investigate whether hMSCs do reflect signs of aging, and, whether an aging marker could be obtained.

By using the same 61 donors as in chapter 6 , we have correlated the biological parameters tested with the age of the donor from whom the cells were extracted. No strong correlations were observed. Then, we performed a genome wide gene expression profile and correlated the gene expression to donor age. We have found $8,07 \%$ (1798) probe sets by permuting F-test scores that did correlate with age, from which 1653 presented a standard deviation higher than 0.4. Gene expression data was validated by qPCR for 12 genes in the 61 donors and, with the primers tested, we were able to validate 7 as having a significant correlation with age $(\mathrm{p}<0.05)$.

An important aspect to test was whether the in vitro senescence resembled the gene expression profile of in vivo aging. For this purpose, we have tested gene expression of 4 validated genes by qPCR in 3 donors that have been expanded in vitro (passage 0-7). Consistent trends were not observed in the 3 donors tested and a big donor variation was present. We have also performed gene expression profiles in hMSCs from 2 donors during in vitro expansion (passage 0-7) but conclusions were hampered due to the big donor variation observed (data not shown). More donors had to be included to overcome the donor variation observed. It has been shown that the expression profile of several genes (mainly genes involved in genomic integrity and regulation of transcription) that change with age, are also differentially expressed during in vitro senescence [30], we have not observed the 
same in this study. Our data is in line with a study from Wennmalm et al., where it has been shown that the expression signature of in vitro senescence resembled mouse, but not human aging [31]. One of the reasons that could explain the difference between our study and the one from Wagner et al. is the sample size, since our data is based on gene expression profiles of 61 donors, while their study is based on 12 donors. Their analyses also revealed only 3 genes in common with our study, one of which we were unable to validate by qPCR. Our work however, provides a significantly larger sample size, allowing higher statistical resolution.

As discussed previously on chapter 7 , other studies have focussed on the characterization of tissue-specific gene expression profiles, such as human brain, human muscle and human kidney. There is also one report on transformed cell lines (lymphoblastoid cell line bank) and one in multiple mouse strains. The big advantage of our work is that besides using a large sample size, a whole genome-wide profiling was performed in untransformed, minimally expanded hMSCs, allowing us to obtain general markers for normal aging in hMSCs, rather than tissuespecific ones.

Another important aspect of our study is that our list of top 50 probe-sets contains 10 genes that, to best of our knowledge, have not yet been correlated with age in any species. An important fact is that several genes appear more than ones in the top-50 probe-set list, further validating the results, and suggesting them as powerful indicators of donor age. Furthermore, we have shown that FST was an inter-species marker for age since it was also validated in MSCs from aging rats.

This chapter shows that some genes are indeed significantly correlated with age, and that a gene expression profile for aging can be obtained. This is highly interesting, not only because it allows us to verify which specific genes do change with age, and how their function might interfere with aging of stem cells, but also, it might allow us to select, based on this signature, MSCs that resemble younger donors.

From this chapter it can thus be concluded that hMSCs seem to be influenced by the aging process and that, remarkably, a small effect of donor age was observed in the biological parameters tested, which shows that aging itself has no clear effect on hMSC performance. Moreover, this work showed that a clear large inter-donor variability is present in hMSCs, from donor of the same age. This stresses the need of new markers predicative of clinical output, as an exclusion criterion in cellular therapy to select the best performing hMSCs for a specific application. It further demonstrates that gene expression profiles of 
in vitro senescence differs from in vivo aging and that other genes, which have not been previously correlated with age, might play a relevant role in aging and, therefore, are worth of a thorough investigation. It also stresses the need for further investigation on hMSCs aging, that will, hopefully, contribute to unveil the molecular mechanism behind hMSCs aging and reveal why tissue regeneration decreases with increasing human age.

\section{References:}

1. Sotiropoulou PA, Perez SA, Salagianni M, Baxevanis CN, Papamichail M (2006) Characterization of the optimal culture conditions for clinical scale production of human mesenchymal stem cells. Stem Cells 24: 462-471.

2. Siddappa R, Licht R, van Blitterswijk C, de Boer J (2007) Donor variation and loss of multipotency during in vitro expansion of human mesenchymal stem cells for bone tissue engineering. J Orthop Res 25: 1029-1041.

3. Agata H, Watanabe N, Ishii Y, Kubo N, Ohshima S, et al. (2009) Feasibility and efficacy of bone tissue engineering using human bone marrow stromal cells cultivated in serum-free conditions. Biochem Biophys Res Commun 382: 353-358.

4. Itahana K, Campisi J, Dimri GP (2004) Mechanisms of cellular senescence in human and mouse cells. Biogerontology 5: 1-10.

5. Hasty P, Campisi J, Hoeijmakers J, van Steeg H, Vijg J (2003) Aging and genome maintenance: lessons from the mouse? Science 299: 1355-1359.

6. de Boer J, Hoeijmakers JH (2000) Nucleotide excision repair and human syndromes. Carcinogenesis 21: 453-460.

7. Rossi DJ, Bryder D, Seita J, Nussenzweig A, Hoeijmakers J, et al. (2007) Deficiencies in DNA damage repair limit the function of haematopoietic stem cells with age. Nature 447: 725-729.

8. Nijnik A, Woodbine L, Marchetti C, Dawson S, Lambe T, et al. (2007) DNA repair is limiting for haematopoietic stem cells during ageing. Nature 447: 686690.

9. Rube CE, Fricke A, Widmann TA, Furst T, Madry H, et al. (2011) Accumulation of DNA damage in hematopoietic stem and progenitor cells during human aging. PLoS ONE 6: e17487. 
10. Rossi DJ, Seita J, Czechowicz A, Bhattacharya D, Bryder D, et al. (2007) Hematopoietic stem cell quiescence attenuates DNA damage response and permits DNA damage accumulation during aging. Cell Cycle 6: 2371-2376.

11. Kuhlow D, Florian S, von Figura G, Weimer S, Schulz N, et al. (2010) Telomerase deficiency impairs glucose metabolism and insulin secretion. Aging (Albany NY) 2: 650-658.

12. Liu L, DiGirolamo CM, Navarro PA, Blasco MA, Keefe DL (2004) Telomerase deficiency impairs differentiation of mesenchymal stem cells. Exp Cell Res 294: 1-8.

13. Jaskelioff M, Muller FL, Paik JH, Thomas E, Jiang S, et al. (2011) Telomerase reactivation reverses tissue degeneration in aged telomerase-deficient mice. Nature 469: 102-106.

14. Sahin E, Colla S, Liesa M, Moslehi J, Muller FL, et al. (2011) Telomere dysfunction induces metabolic and mitochondrial compromise. Nature 470: 359-365.

15. St-Pierre J, Drori S, Uldry M, Silvaggi JM, Rhee J, et al. (2006) Suppression of reactive oxygen species and neurodegeneration by the $\mathrm{PGC}-1$ transcriptional coactivators. Cell 127: 397-408.

16. Simonsen JL, Rosada C, Serakinci N, Justesen J, Stenderup K, et al. (2002) Telomerase expression extends the proliferative life-span and maintains the osteogenic potential of human bone marrow stromal cells. Nat Biotechnol 20: 592-596.

17. Shi S, Gronthos S, Chen S, Reddi A, Counter CM, et al. (2002) Bone formation by human postnatal bone marrow stromal stem cells is enhanced by telomerase expression. Nat Biotechnol 20: 587-591.

18. Abdallah BM, Haack-Sorensen M, Burns JS, Elsnab B, Jakob F, et al. (2005) Maintenance of differentiation potential of human bone marrow mesenchymal stem cells immortalized by human telomerase reverse transcriptase gene despite [corrected] extensive proliferation. Biochem Biophys Res Commun 326: 527-538.

19. Balaban RS, Nemoto S, Finkel T (2005) Mitochondria, oxidants, and aging. Cell 120: 483-495.

20. Ebert R, Ulmer M, Zeck S, Meissner-Weigl J, Schneider D, et al. (2006) Selenium supplementation restores the antioxidative capacity and prevents cell damage in bone marrow stromal cells in vitro. Stem Cells 24: 1226-1235.

21. Sablina AA, Budanov AV, Ilyinskaya GV, Agapova LS, Kravchenko JE, et al. (2005) The antioxidant function of the p53 tumor suppressor. Nat Med 11: 13061313. 
22. van Os R, de Haan G, Dykstra BJ (2009) Hematopoietic stem cell quiescence: yet another role for p53. Cell Stem Cell 4: 7-8.

23. Siddappa R, Fernandes H, Liu J, van Blitterswijk C, de Boer J (2007) The response of human mesenchymal stem cells to osteogenic signals and its impact on bone tissue engineering. Curr Stem Cell Res Ther 2: 209-220.

24. Meijer GJ, de Bruijn JD, Koole R, van Blitterswijk CA (2007) Cell-based bone tissue engineering. PLoS Med 4: e9.

25. Derubeis AR, Cancedda R (2004) Bone marrow stromal cells (BMSCs) in bone engineering: limitations and recent advances. Ann Biomed Eng 32: 160-165.

26. Petite H, Viateau V, Bensaid W, Meunier A, de Pollak C, et al. (2000) Tissueengineered bone regeneration. Nat Biotechnol 18: 959-963.

27. De Boer J, Wang HJ, Van Blitterswijk C (2004) Effects of Wnt signaling on proliferation and differentiation of human mesenchymal stem cells. Tissue Eng 10: 393-401.

28. de Boer J, Licht R, Bongers M, van der Klundert T, Arends R, et al. (2006) Inhibition of histone acetylation as a tool in bone tissue engineering. Tissue Eng 12: 2927-2937.

29. Siddappa R, Martens A, Doorn J, Leusink A, Olivo C, et al. (2008) cAMP/ PKA pathway activation in human mesenchymal stem cells in vitro results in robust bone formation in vivo. Proc Natl Acad Sci U S A 105: 7281-7286.

30. Wagner W, Bork S, Horn P, Krunic D, Walenda T, et al. (2009) Aging and replicative senescence have related effects on human stem and progenitor cells. PLoS ONE 4: e5846.

31. Wennmalm K, Wahlestedt C, Larsson O (2005) The expression signature of in vitro senescence resembles mouse but not human aging. Genome Biol 6: R109. 


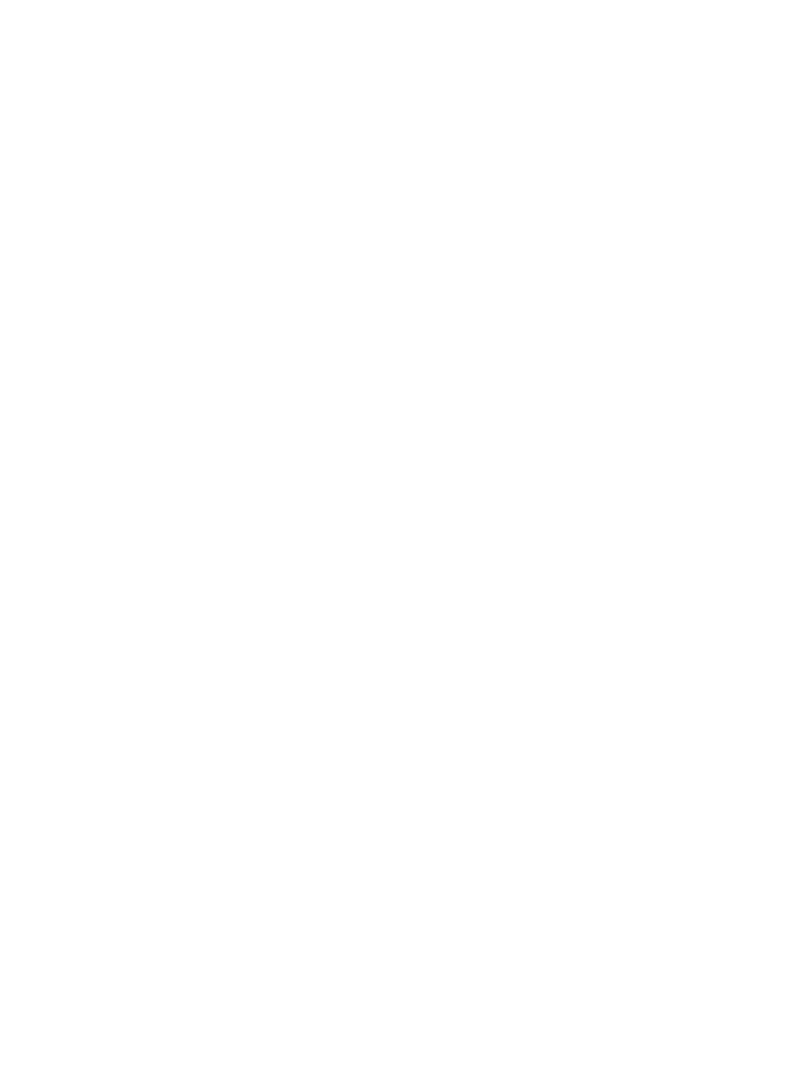




\section{Summary}

In the last decades, an improvement in general life conditions has led to an increase in human life span but, concomitantly, also led to an increasing incidence of bone related disorders. A substancial effort has been placed in the development of new technologies to overcome current limitations of regenerative medicine. Human mesenchymal stromal cells (hMSCs) emerge as the golden standard for cell-based applications and are expected not only to increase current available therapies, but also, to allow the treatment of pathologies that, currently, have few accepted treatments or no cure. While hopes are high that many age-related degenerative diseases will be cured by stem cell therapy, there are still some hurdles that need to be addressed. Therefore, this thesis aims at improving hMSCs performance by using a diversified approach.

In chapter 1, a general introduction is given with particular emphasis on tissue engineering and more specifically, the properties of hMSCs and their potential usage to treat bone-related clinical disorders. Chapter 2 reviews current literature on several factors, which might influence, the quality/properties of hMSCs, such as: donor variation, donor age, hypoxia, to name a few.

The first experimental chapter (chapter 3) consists of the evaluation of hMSC in vitro expansion, in order to elucidate the basic mechanism behind loss of multipotency that occurs during this process. Then, since DNA damage accumulation seems to play a pivotal role, we have tried to prevent/revert the harmful effects of culture expansion by supplementing antioxidants to the culture of hMSCs (chapter 4). Although an improvement in total yield during the prospective isolation of hMSCs was observed, antioxidant supplementation was unable to prevent loss of differentiation potential that follows expansion.

Then, in order to improve the current osteogenic protocols, a high-throughput assay system was established to screen for novel compounds with osteogenic activity (chapter 5). Although we were able to obtain new molecules with the highest osteogenic activity described so far, the available markers for bone formation were not predictive enough of the in vivo outcome. Therefore, we combined efforts to evaluate all the available parameters, and by performing a whole genome-wide gene expression profile in 61 donors, we unveiled a new marker for in vivo bone 
formation with high predictability (chapter 6). We then use the same data to correlate gene expression with donor age, but also correlated several in vitro parameters with age as well, in order to possibly identify a gene signature for donor age (Chapter 7). In chapter 8 , an overview, discussion and main conclusions of the thesis are presented.

Overall, this thesis presents a multifactorial approach to improve the use of hMSCs for cell-based clinical applications with special emphasis on bone regeneration/repair. The work presented here, shows that hMSCs accumulate DNA damage upon expansion, which seems to be correlated with the loss of multipotency. It also shows that antioxidant supplementation was unable to prevent the loss of multipotency after in vitro expansion. Furthermore, we have demonstrated that most of the current markers for bone formation are not predicative of in vivo performance and should be replaced by the new marker discovered (CADM1). We have also showed that, there is space for improvement of current osteogenic assays, therefore, screening for novel compounds with enhanced osteogenic activity should be actively implemented. By performing genome-wide microarrays in 61 donors, we have demonstrated that hMSC in vitro expansion does not share a similar expression profile as in vivo aging, that gene expression analysis resulted in a considerable list of genes correlating with human age, and that, by comparing the transcriptional profile of aging in human with the one from the rat, we discovered FST as a common marker for aging on both species. 


\section{Samenvatting}

Gedurende de afgelopen decennia heeft de verbetering in algemene levenscondities er toe geleid dat de levensverwachting is toegenomen, maar tegelijkertijd heeft dit ook geresulteerd in een toename van bot-gerelateerde ziektes. Er is veel geïnvesteerd in de ontwikkeling van nieuwe technologieën om de huidige limitaties van de regeneratieve geneeskunde te overwinnen. Humane mesenchymale stromale cellen (hMSCs) worden gezien als de gouden standaard voor cell-gebaseerde toepassingen en de verwachting is dat deze niet alleen het aantal beschikbare therapieën zullen doen toenemen, maar ook ziekten kunnen doen behandelen waarvoor momenteel enkel slecht geaccepteerde, of geen enkele behandeling voor handen is. Hoewel de toepassing van stamceltherapieën voor vele leeftijdgerelateerde degeneratieve ziekten in de nabije toekomst veelbelovend is, zijn er nog een aantal hordes die moeten worden genomen. Dit proefschrift heeft als doel om de potentie van hMSCs te bevorderen.

In hoofdstuk 1 wordt een algemene introductie gegeven met de nadruk op tissue engineering en specifiek de eigenschappen van hMSCs en hoe deze gebruikt zouden kunnen worden om bot-gerelateerde klinische ziektes te behandelen. Hoofdstuk 2 geeft een overzicht van de huidige literatuur over verschillende factoren welke de kwaliteit en de eigenschappen van hMSCs kunnen beïnvloeden; onder andere donor variatie, donor leeftijd en hypoxia.

Het eerste experimentele hoofdstuk (hoofdstuk 3) bestaat uit de evaluatie van de in vitro expansie van hMSCs, om het onderliggende mechanisme van het verlies van de multipotentie tijdens dit proces te ontrafelen. Vervolgens, aangezien DNA schade hierin een belangrijke rol lijkt te spelen, hebben we geprobeerd om de schadelijke effecten van kweek expansie te voorkomen / terug te draaien, door antioxidanten toe te voegen tijdens de kweek van hMSCs. Hoewel dit tijdens de isolatie van hMSCs tot een verbetering in de totale opbrengst leidde, heeft de toevoeging van antioxidanten niet geleidt tot de verminderde differentiatie na expansie.

Vervolgens, om het huidige osteogene kweekprotocol te verbeteren, is een high-throughput systeem opgezet om nieuwe stoffen met osteogene activiteit te kunnen screenen (hoofdstuk 5). Hoewel we in staat waren nieuwe moleculen te 
vinden, met de tot dusverre hoogst beschreven osteogene activiteit, waren de beschikbare markers voor botformatie niet voldoende voorspelbaar voor de in vivo uitkomst. Daarom hebben we de krachten verenigd, om alle beschikbare parameters te evalueren. Door het genoom brede genexpressie profiel van 61 donoren te bepalen, hebben we een nieuwe marker gevonden welke de in vivo botformatie goed voorspelt. Vervolgens is dezelfde data gebruikt om genexpressie, maar ook verschillende in vitro parameters, te correleren met donor leeftijd met als doel een gen karakteristiek te vinden voor donor leeftijd (hoofdstuk 7). De samenvatting, de discussie en de hoofdconclusies van dit proefschrift worden in hoofdstuk 8 gepresenteerd.

Dit proefschrift presenteert een multifactoriële aanpak om het gebruik van hMSCs voor cel-gebaseerde klinische toepassingen te verbeteren, met nadruk op botregeneratie. Het werk dat hier wordt gepresenteerd, laat zien dat hMSCs DNA schade oplopen tijdens de expansie en dat dit lijkt te correleren met het verlies van multipotentie. Het laat ook zien dat het toevoegen van antioxidanten niet leidt tot het verlies van multipotentie na in vitro expansie. Verder hebben we hier laten zien dat de meeste huidige markers voor botformatie het in vivo gedrag niet voorspellen en vervangen zouden moeten worden door de nieuw ontdekte marker (CADM1). We hebben ook laten zien dat er ruimte is voor verbetering van de huidige osteogene assays. De screening voor nieuwe stoffen met osteogene activiteit zou actief moeten worden geïmplementeerd. Door middel van genoom brede microarrays in 61 donoren hebben we laten zien dat hMSCs tijdens in vitro expansie niet hetzelfde expressie profiel vertonen als in vivo gedurende veroudering, dat gen expressie analyse heeft geresulteerd in een aanzienlijke lijst met genen welke correleren met leeftijd, en dat, door de transcriptie profielen van verouderde mensen en ratten te vergelijken, FST een gemeenschappelijke marker voor veroudering is. 


\section{Acknowledgements}

It is my great pleasure to express my gratitude towards many individuals who made the completion of this thesis a possibility. Moreover, my appreciation extends to those who were involved in my study but whose names might not have been mentioned here.

First and foremost, I have to thank my promoter Clemens van Blitterswijk and co-promoter Jan de Boer for giving me the opportunity to pursue a PhD in their group. Clemens your work is truly impressive, not only for creating a great group and founding many spin-off companies with extraordinary scientists, but also for promoting the integration of a multidisciplinary working team and actively contributing to a great working environment. Thank you for providing me all the necessary tools to perform the work present on this thesis. I will always remember the great fun it was to run along the beautiful surroundings of Bilthoven. Jan I cannot thank you enough for all the help provided during this PhD. You were a crucial part of the success and your guidance and advices were precious along the way. Your ability to conciliate work and family is very impressive and we certainly had a lot of fun. Thank you for making me part of your big family during all the time spent in NL.

I couldn't go on without express a word of appreciation towards my previous supervisors Dorit Schuller and Margarida Casal. Muito obrigado por me acolherem no departamento de Biologia e me darem a oportunidade de trabalhar no vosso excelente laboratório. Obrigado por me darem muitas das bases necessárias para o trabalho do doutoramento e por terem acreditado em mim durante a fase inicial da minha careira de investigação.

To Ruud for all the help provided in Bilthoven. You are a truly nice person and I will always be grateful for all the help and knowledge you have provided me during my early stay at Bilthoven. You showed me that research can be fun as well. I wish you a lot of success for the future.

To my paranymphs (Anand and Joyce), I can't describe all the gratitude I have for both. Anand thank you for all the great moments we had (from photo shots, to the animal course, thank you for the great Indian food and a great company after hours in the lab. You are, and for sure will be, a friend for life. Thank you for 
everything. Joyce, we had great times together, from the cycling trips with Bram and your friends, to the nice environment during office hours, to the great dinners, parties and TR football games. It was a great pleasure to meet you. Looking forward to welcome you and Bram in Portugal and show you the nice landscapes we have here.

To my students Anindita and Jetty. It was a pleasure to work with both of you. Thank you for the help provided in the optimization of some of the techniques and in some of the work presented here. I hope you enjoyed as much as I did and wish you both the best for the future. Thank you for all the help.

Then I would like to express my gratitude for all the secretaries (Janita, Viola, Annette, Audrey, Joyce and Miranda), you were always there to help in every single situation.

I would like to address my gratitude as well for all the friends I have met in Utrecht and you were so many... (hope I am not missing anyone here). Roka, Mireille, Gianluca, Eyk, Fernando, April, Jeroen, Aart, Germán, Elise, Jorg, Chantal and Maarten. Thank you for all the great times we had during my stay at Utrecht and for showing me all that Utrecht had to offer, we surely had great times. I would also like to thank all the people from Isotis, Cellcotech and Progentix (Riemke, Yuan, Jiaping, Linda, Florance, Klass, Jost, Davide, Vincent and many others...) for the great working environment. Yanling thank for sharing the same passion in research, wish you all the best at NKI. To Jerome, for the same passion for photography and for many funny moments we had together. Eyk, backgammon will never be the same.

To you Lorenzo for everything. You are a great friend that was always there for me from the moment I arrived, to the funny and relaxing moments spent in Aosta. Buying sofas in IKEA will never be the same. Thank you for everything.

Aos amigos Portugueses que encontrei na Holanda: Cristiana, Joana, Sónia, e os respectivos namorados/maridos. Obrigado a todos pelos bons momentos passados e pelos jantares, pela diversão e por me por me acolherem no vosso grupo. Nuno (Santarém) obrigado por tudo, grandes momentos que passamos em Leiden, obrigado pelas retiradas ao fim de semana e por me mostrares as bonitas esplanadas de Leiden.

I would like to thank all my office roommates I had during the thesis, and were many during these years (Pamela, Frank, Jeroen, Jun, Jeanine, Karolina, Hugo, Joyce and Ram). Jeroen thank you for sharing the Canon hype and for the great discussions we had about photography, it was certainly great fun. (Looking forward to see your upcoming pictures). Jun, you were like a sister to me, thank you 
for the fun in the lab, in the office and in your place (Wii rules). You were one of the nicest persons I meet in Enschede and I wish you all the best for the future. I would like to extend my compliments to Nan as well.

"Professor" Ramakrisha Siddappa, thank you for sharing the office, and for providing me one of the coolest office environment one could wish for. It was a pleasure to meet you and I am sure you will do great in life. We will keep in touch for sure and looking forward to your new sexy publications.

Hugo, sem dúvida que a vida nem sempre foi fácil pela Holanda, e que os tempos de Braga foram outros. No entanto, obrigado por tudo durante estes anos na Holanda. O meu reportório de massas jamais será o mesmo. Obrigado por toda a ajuda e por partilhares a casa desde o primeiro ao último dia. Pelas corridas, pelas viagens e pela animação constante. Abraço e boa sorte para o futuro.

Ana, ainda me lembro de ir de férias e sermos só dois lá em casa e quando voltei, tínhamos uma nova residente. Sem dúvida que o ambiente lá em casa jamais foi o mesmo. Obrigado por trazeres um toque feminino ao nosso lar e por animares aquela casa.

Anouk thank you for all the help you have provided me while I was not able to work in the lab anymore. You are a great friend and I wish you all the best for the future. Jeroen L, thank you for all the conversations on the lab. I was lucky to meet you. I am sure we will see each other many more times in the future. Liliana e Sandra, sinceramente não sei como vos agradecer por tudo que fizeram por mim. Dos maravilhosos jantares, aos bons momentos passados juntos, à preciosa ajuda durante as mudanças, vocês sem dúvida ajudaram a matar algumas saudades de casa. Muito obrigado por tudo.

Bernke, thank you for everything. Moving from Utrecht to Enschede was a big change and life in Enschede would never be the same without you. Thank you for all the fun we had and for showing me Friesland!! Your contagious happiness made the adaptation to Enschede so much easier.

Federica, you were always ready to go everywhere and to organize dinners. Thank you for all the delicious Italian dishes, for the parties, for joining the sports and for the great fun.

Dr. Hemant, you are a great friend. Thank you for the company during the late working hours in the lab, it was a pleasure to meet you. I enjoyed a lot all our dinners and get-togethers. I think most people will never understand you like I did, but I hope you realize life can't be so black and white and, definitely, there is more in life than work. Enjoy India and I am sure we will see each other somewhere in the future. 
And then to all the others that somehow have contributed to the great atmosphere during these years. Gus, you will always be our best sticker and goalkeeper. Nico, thanks for the French cuisine, but I must confess the Andouille was a bit too much :D How is the hasselblad performing? Aart, Janneke and Bram, I really enjoyed our racing bike trips, we should have done it more often. Karolina and Maciek thanks for the polish dinners and the nice time together. Juan, when are those home-made beers ready? Jojanneke, thank you for all the help you have provided me during this time. Sanne, thank you for the assistance in the lab, during the early days, and for the oportunity for the first tandem flight. It was really nice.

Ineke thank you for all the help with the burocracy during the PhD. I must confess the inventory of all the chemicals for the moving was quite exhausting, hope you will never have to deal with it again.

Paul, Ferry and Jetse. Thank you for inviting me for the runs, it was a great pleasure, I have tried... but it was very hard to keep up with your fitness levels.

And to all others: Prof. Marcel (thank you for the comments and suggestions during the group meetings), Emilie (Ainda por Utrecht?), Alice, Eelco, Doreen, Jacqueline, Andreia, Inês, Jorge, Filipe, Bin, Ling, Liang, Roman, Ellie, Chris, Nicole, Nathalie, Charlene, Bjorn, Tim, Liang, João, Florence, Veda, Vicky, Petra, Mijke, Anne and all the other students and many members from other groups that have contributed by providing a great atmosphere in the lab.

Renuka thank you for inviting me over to taste those delicious meals. I became a fan of the lemon rice and all the other plates. See you soon and good luck for the future as an independent lawyer.

And then to all my Portuguese friends: obrigado pelos inúmeros jantares e convívios ao longo destes últimos anos. Em especial ao Telmo e João por me receberem sempre que estava de volta a Portugal. Bruno, que é feito de ti? Vera, Patrícia, Stephanie, Cristiana, Fátima e todos os outros que tiveram a oportunidade de comparecer, os jantares em Vinhós jamais serão os mesmos sem a vossa presença.

A todos os meus amigos de Braga e são tantos que correria o risco de falhar alguns, obrigado pelos jantares de despedida, pelas idas ao cinema, pelas caminhadas no Gerês, pelas idas à praia e tantas outras atividades que me deram forças para voltar à Holanda novamente. Obrigado por estarem sempre presentes nos jantares de despedida.

Em especial ao JP e à $\mathrm{Su}$, por me terem ido visitar à Holanda, o meu mais sincero obrigado por tudo, adorei a vossa visita. Su obrigado pelos inúmeros telefonemas e conversas no gmail. Serás sempre uma grande amiga. Ainda estou à espera da sobremesa que me prometeste. 
À Mariana e ao Nuno obrigado por tudo... foram jantares, lanches, idas à praia, enfim, inúmeras horas de boa disposição.

Aos meus familiares, tios, padrinhos e primos, obrigado por me acolherem tão bem quando regressava nas mini-férias. Em especial ao Norberto e à Manuela por me terem ido visitar e aos meus padrinhos por me terem proporcionado excelentes férias passadas em Vila do Conde. Norberto, Manuela e Rui, o tempo não ajudou muito, mas já ficaram com uma ideia do que passei nos últimos anos.

Não podia deixar de agradecer também às pessoas que mais contribuíram para o meu bem-estar, a minha felicidade e por me darem tanto apoio durante a minha estadia na Holanda.

Andreia, jamais serei capaz de te agradecer por tudo que fizeste por mim. Foram centenas de horas ao telefone, inúmeras viagens e muita boa disposição. A tua ajuda foi preciosa e se há alguém a quem tenha de agradecer por tudo o que fizeste é a ti. A verdadeira estrela és tu, e quem tiver o prazer de te ter como amiga, não sabe a sorte que tem. Obrigado por tudo desde os remotos tempos da Micro IV, até agora, se tivesse de te agradecer eu é que não teria como...

A ti Rita, pela cumplicidade, pelo carinho, pela paciência, pela tua alegria contagiante, pela motivação, pelo apoio, pelas viagens maravilhosas, por todos os momentos juntos e pelas inúmeras horas ao telefone, apesar da distância, estávamos sempre juntos. Obrigado pela compreensão e por Acreditares que era possível. Adoro-te pequenina.

Aos meus pais e irmã pelo apoio incondicional durante estes anos todos, pelos mimos e pela motivação, se hoje sou o que sou, é graças a vocês. Obrigado por tudo e espero um dia poder retribuir o que me ofereceram.

Por último se tivesse de dedicar esta tese a alguém seria às minhas avós, tia Julia e avô. Vocês foram os verdadeiros segundos pais, que me criaram que me amaram incondicionalmente, que acreditaram em mim e fizeram tudo ao vosso alcance para me proporcionar sempre o melhor. Pouca gente gostará tanto de mim como vocês e espero que aonde quer que estejam, se orgulhem de mim. Se há coisa que mais me custou foi não ter tido a oportunidade de me despedir de vocês e de vos dizer, o quão grato estou por tudo que me fizeram.

Obrigado por tudo.<smiles>C=CC=CC</smiles> 


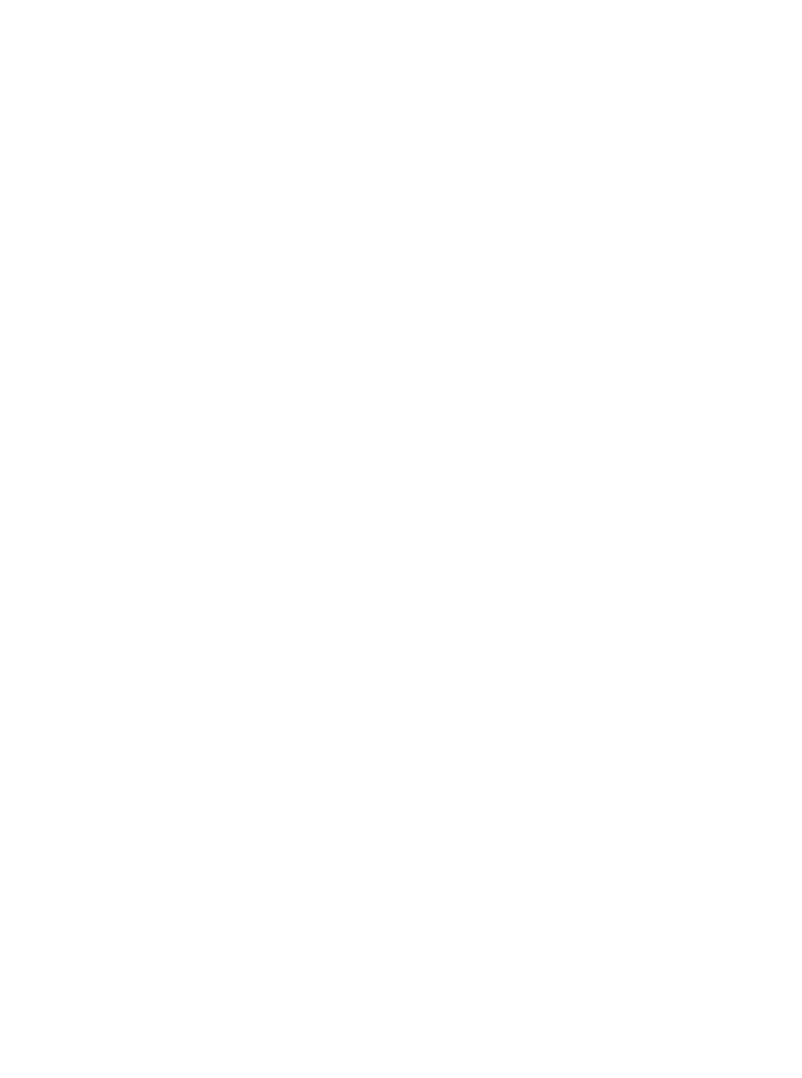




\section{Curriculum Vitae}

Hugo Alves was born on the $1^{\text {st }}$ November 1980 in Fafe, Portugal. After his graduation from Escola Secundária de Fafe, in 1999, he enrolled in Applied Biology at the University of Minho, where he graduated in December 2003. During his internship at the Department of Biology of the same university, he focussed on the physiological characterization and genotyping of yeasts with oenological interest (Dr. Dorit Schuller and Prof. Dr. Margarida Casal). Then, between 2004 and 2005, he was appointed as a research fellow in the ENOSAFE project whose focus was the implementation of fast techniques for the monitorization and microbial screening (Dr. Dorit Schuller and Prof. dr. Margarida Casal). During the same period under a Luso-french interchange project, he went to INRA, Montpellier, France to perform karyotyping and bioreactor cultures. In 2004 he was also invited to lecture the practical classes of genetics from the Applied Biology graduation at the University of Minho. In October 2005, he accepted a PhD position at the MIRA institute, University of Twente (Enschede, The Netherlands). The research performed during the $\mathrm{PhD}$ is presented in this thesis entitled "Improved performance of aging human mesenchymal stromal cells for bone tissue engineering" and was performed under the supervison of Dr. Jan de Boer and Prof. Dr. Clemens van Blitterswijk. In 2010 he has enrolled the Master degree in Medicine, at the University of Algarve, Portugal. In 2010, he was awarded the first prize at the XI JOCEM, Porto, PT. 
